\title{
Marriage in transition: Evidence on age, education, and assets from six developing countries [Arabic]
}

Agnes R. Quisumbing

Kelly Hallman

Population Council

Follow this and additional works at: https://knowledgecommons.popcouncil.org/departments_sbsr-pgy

Part of the Demography, Population, and Ecology Commons, Family, Life Course, and Society Commons, and the International Public Health Commons How does access to this work benefit you? Let us know!

\section{Recommended Citation}

Quisumbing, Agnes R. and Kelly Hallman. 2003. "Marriage in transition: Evidence on age, education, and assets from six developing countries," Policy Research Division Working Paper no. 183 [Arabic]. New York: Population Council. Version of record: https://doi.org/10.17226/11524 


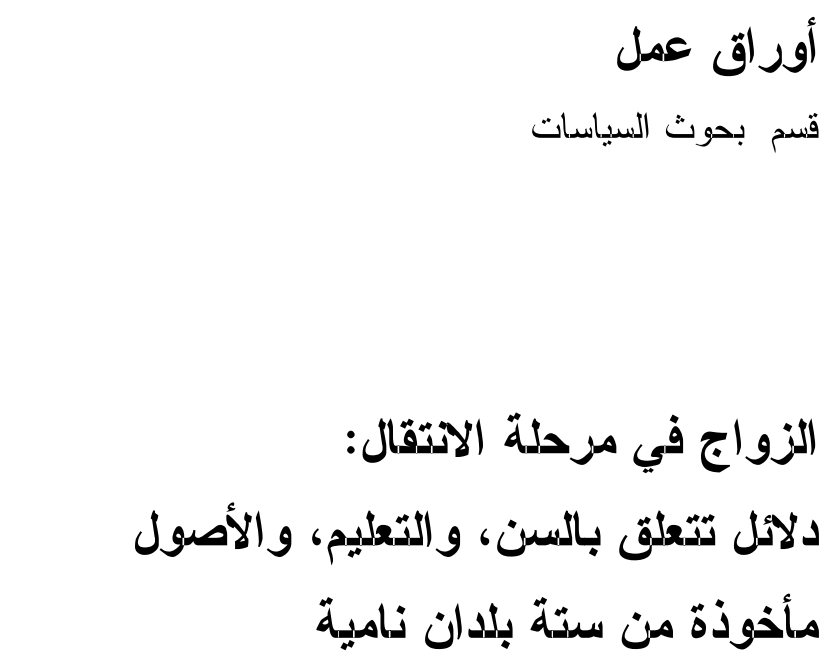

Agnes R. Quisumbing أجنس ر. كويسمبنج

كيللي هولمان Kelly Hallman

2003

Population Council مجلس السكان 


\section{الزواج في مرحلة الادتقال: \\ دلآل تتعلق بالسن، والتعليم، والأصول \\ مأذوذة من ستة بلدان نامية}

Agnes R. Quisumbing أجنس ر. كويسمبنج

كيلاي هولمان Selly Hallman

senior research fellow هي زميلة أولى فى مجال الأبحاث Agnes R. Quisumbing أجنس ر. كويسمبنج بالمعهد الدولي لبحوث سياسات الغذاء International Food Policy Research Institute، بواثنطن فئن العاصدة. أما كيلي هولمان Kelly Hallman، فهي باحثة مشاركة research associate في شعبة بحوث السياسات بمجلس السكان.

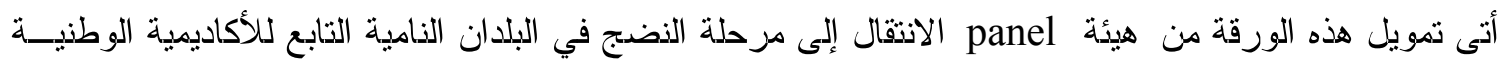

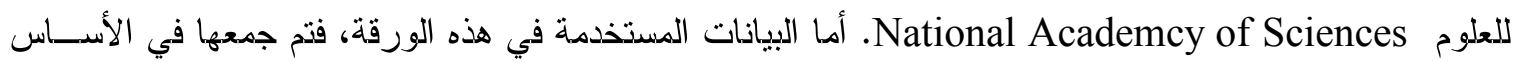
بموجب منح مولتها الوكالة الأمزيكية للتمية الدولية (USAID)، مكتب النساء في التتمية، منحـة رقهـم - FAO

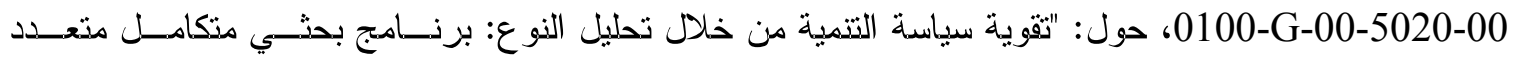

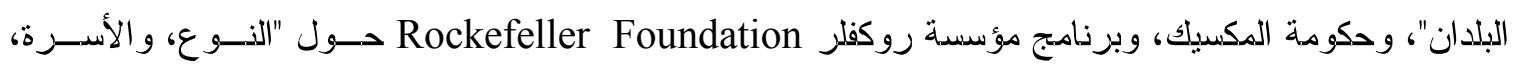
و التغيز الفني في البلدان منذفضة الدخل" بمزكز النمو الاقتصادي بجامعة ييل Yale University. ويستقي هــذا العمل مما قمنا به من عمل مع كل من بينيديكت دي لا بريـار Bénédicte de la Brière، ومارسـيل فافئشـام

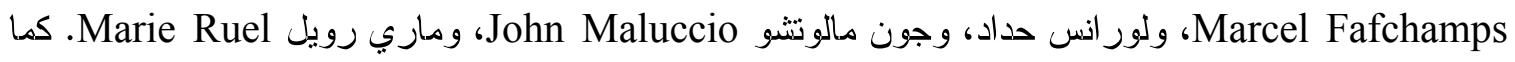

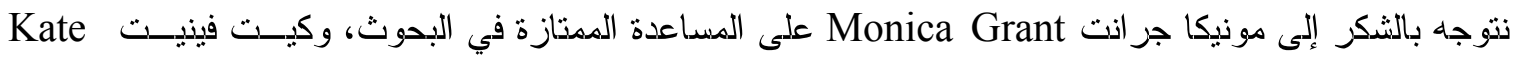

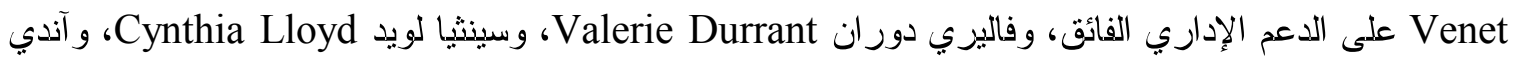
فوستر Andy Foster، علاوة على حكَمين مجهولَين، على التعليقات المفيدة. 
الزواج هو حدث له أهميته الاجتماعية و الاقتصادية الكبرى بالنسبة لأغلب المجتمعات. و وعلى الزغم من مركزيــة الزو اج في تاريخ حياة الفزد، فإن المز اجع المتوفرة حول أنماط الزو اج لا توجه سوى درجة بسيطة من الاهتمسام

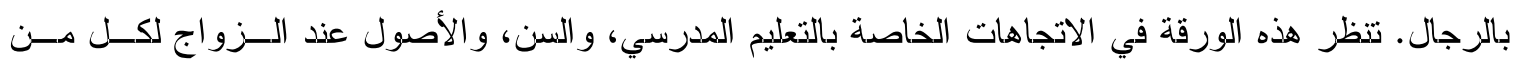
الرجال و النساء، و الفوارق بين الأزواج و الزوجات بالذسبة لكل من تلك المتغيزات في ستة بلدار --سي بنجالاديش

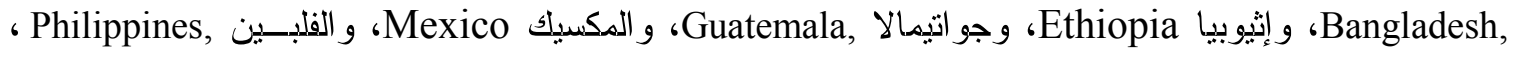
وجنوب إفريقيا South Africa باستخدام مجموعات من البيانات و المنهجيات المقارنة.

تبين الإحصائيات الوصفية أن العلاقة المتبادلة بين الخصائص الثخصية في ازدياد، مقارنةً بالعلاقة المتبادلة بين خصائص الو الدين، الأمر الذي يشير إلى وجود قدر أكبر من الحرية الشخصية في الاختيار عند الزواج. وتثير لئريز

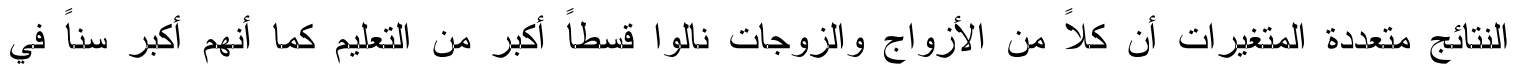

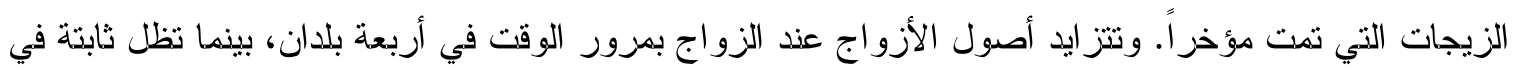
اثثين. أما أصول الزوجات عند الزواج، فتزداد في ثلاثة بلدان، وتظل ثابتة في اثثين، وتقل في بلد و واحد.

و انخفضت الميزة التعليمية للأزواج عند الزواج في ثلاثة بلدان، ولم تتغير في اثثين، وارتفعت في بلد واحد. كما

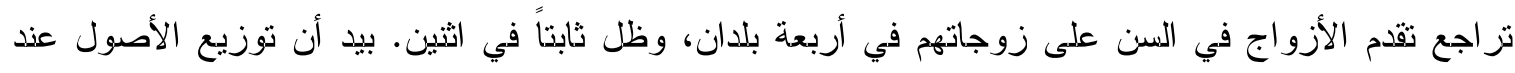
الزواج يستمز في تحبيذ الأزواج. ففي ثلاثة من بين ستة بلدان شملتها الدراسة، لم يتغيز الفارق بين الأزواج و الزوجات على مدار الوقد --التالي فإنه يستمر في تفضيل الأزواج وارتفع في البلدان الثلاثة الأخرى.

و على الرغم من أن ثراجع الفجوة التعليمية و العمرية بين الأزواج والزوجات قد يحسن من التوازن في القوى

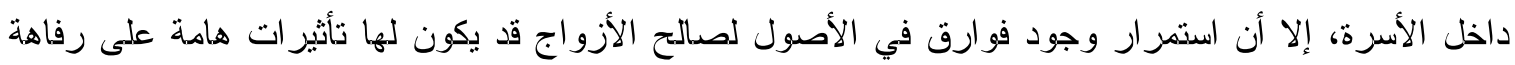

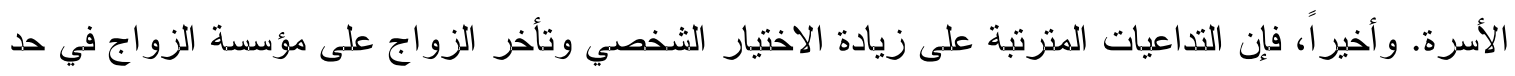

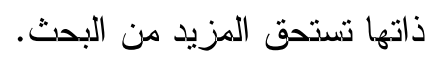

لا يجوز إعادة إنتاج هذه المادة العلمية دون المو افقة الخطية للمؤلفين. للحصول على قائمة بورقات العمل الصادرة عن شعبة بحوث السياسات، بما في ذلك الأوراق المتاحة للتحميل على هيئة ملفات PDF، يرجى زيارة الموقع الإكتروني Www.popcouncil.org/publications/wp/prd/rdwlist.html 
الزواج هو حدث له أهميته الاجتماعية والاقتصادية الكبرى بالنسبة لأغلب المجتمعات. فهو الطقس الذي يجزي فيه الانتقال من مرحلة إلى مرحلة، ويشهد بداية انفصال الفرد عن و الديه، حتى و إن استمرت الأجيال في الاعتماد

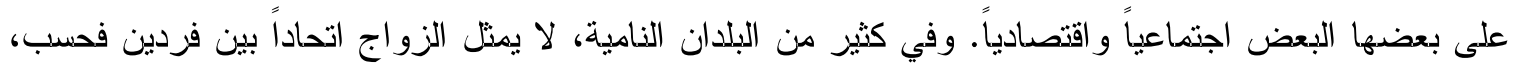

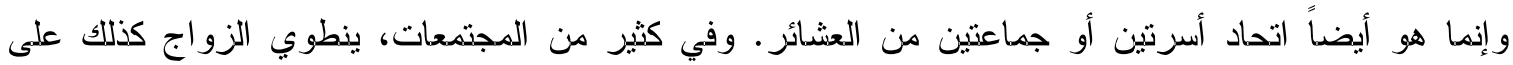
تحول بارز في الأصول من الو الدين إلى الأبناء.

فالأصول التي يتم جلبها إلى داخل الزيجة تكون أكثر من مجرد شكل من أثكال تحويل ممثلكات من جيل إلى جيا -فإنها قد تؤثر على توزيع السلطة التفاوضية و الموارد داخل الزيجة نفسها.

ويقترح العمل الذي تم مؤخر| --ني اختبر الذموذج الجماعي في مقابل النموذج القائم على الوحسدات بالنسـبة للسلوكيات داخل الأسر المعيشية أن الظروف القائمة في وقت الزواج قد تؤثر على توزيع الثروة داخل الزواج. و على وجه الخصوص، تبين أن توزيع الأصول بين الأزواج و الزوجات في وقت الزواج يكون مدهـداً محستملاً للقوة التفاوضية داخل الزواج (كويسـمبنج Quisumbing ودي لا بريسار de la Brière ، 2000؛ وكويسـمبذج

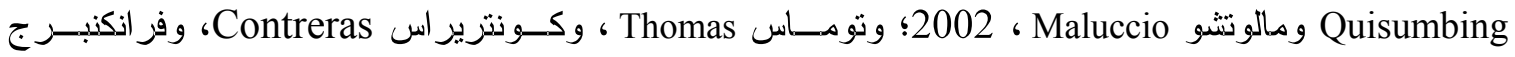
1997 Frankenberg الخروج المتاحة أمام الأزواج و الزوجات. وعلى الرغم من أنه من الجائز ألا تؤثر الأصول في وقــت الــزواج بالكامل على نوزيع الممتلكات عقب الطلاق (فافشام وكويسمبنج Fafchamps and Quisumbing) ، 2002)، فــإن هذه التدابير في حد ذاتها تستحق البحث، حيث أنها تلقي الضوء على مؤسسة الزو اج و الميراث

وبالنظر إلى مركزية الزواج في تاريخ حياة الفرد، فالمدهش أنه لم يكتب سوى القليل فيمـا يتعلـق بالاتجاهـات

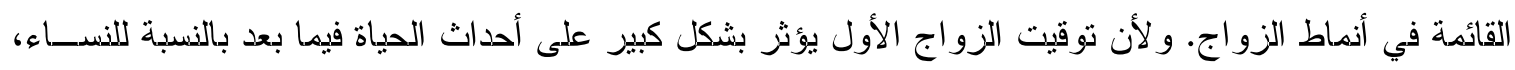

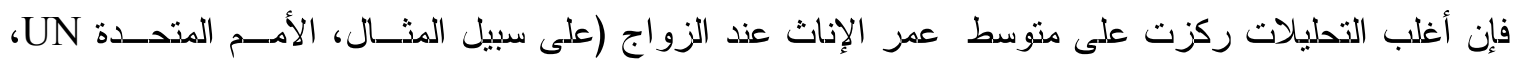

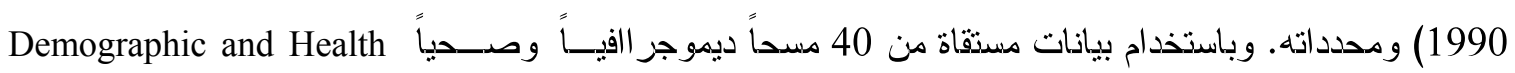
Surveys في البلدان النامية، وجد كل من سنِج Singh وسمار Samara (1996) أنه بينما يأخذ سن الزواج في الارتفاع، فإن نسبة لا يستهان بها من الذساء في البلدان النامية تستمر في الزواج خلال سن المز اهقـة. ويـرتبط

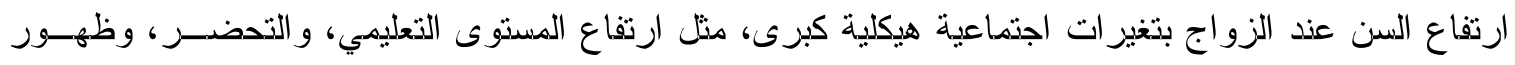
أدوار جديدة للنساء غير المتزوجات. قامت جيجيبهوي ل Jejeebhoy (1995) بتحليل 51 در اسة تقوم على عسدد

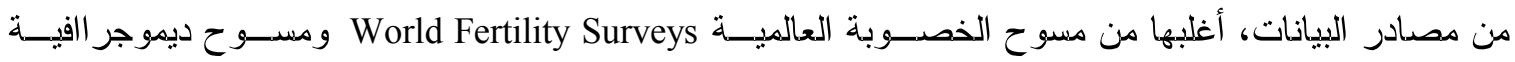

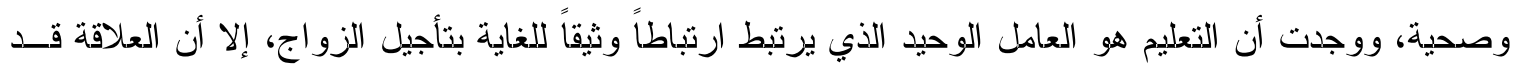

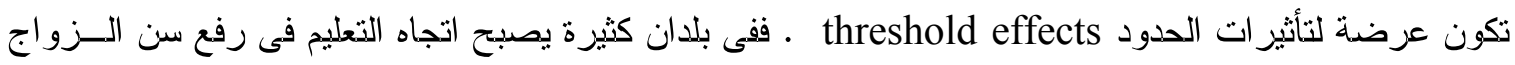

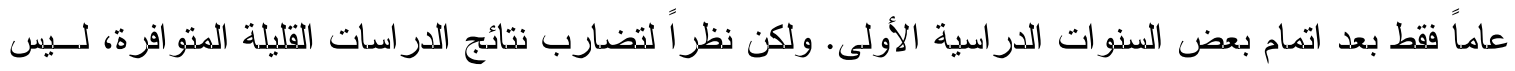


هiالك ما يمكن قوله عن اتجاهات العلاقة بين التعليم و السن عند الـزواج عبـر الـزمن , Jejeebhoy 1995, جيجيبهوى صفحة 66)

ونظراً لأن الدافع وراء الدراسات التى أجزيت عن نوقيت الزواج كان الاهتمام الـديموجر افى ببـدء الانجـاب

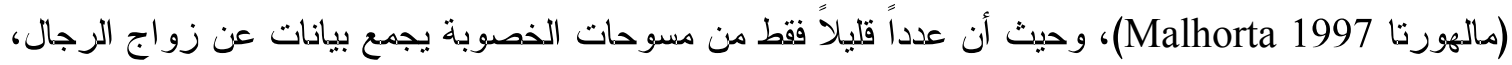

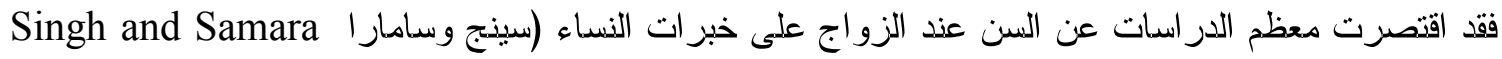
1996) • ويجادل مالهورتا (1997) Malhorta أن التزكيز الكبيز على النساء قد أهمل أن الدخول فى الـزئرواج

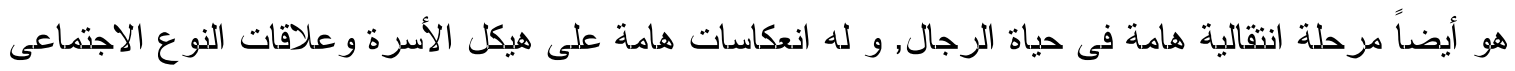

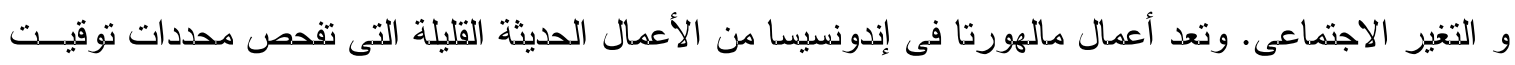

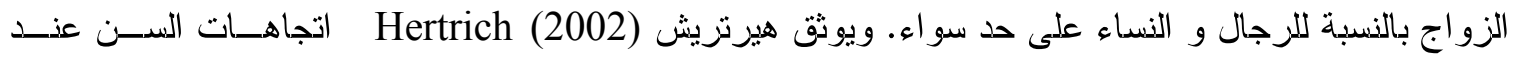

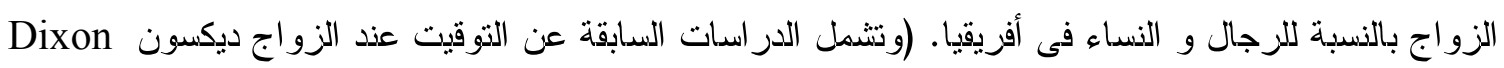
(. Smith 1971

بالاضافة الى ذلك، نادراً ما تولى الأدبيات عن الزواج اهتماماً بالموارد التى يجلبها الرجال و النساء الــى اتحـاد

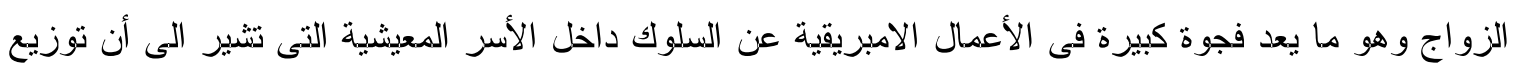

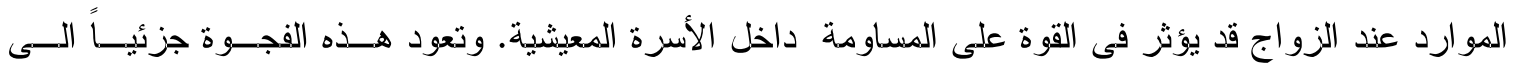
القصور فى البيانات.

أما الدراسات الأنثروبولجية فهى مفصلة ومفيدة ولكن فقط فيما يتعلق بمجموعة محدودة من الناس فى سياق محدد

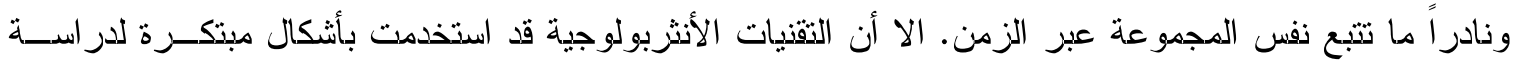
التغيرات فى أنساق الزواج. فعلى سبيل المثال مزج كالـدويل Caldwell و ريـدى عنى

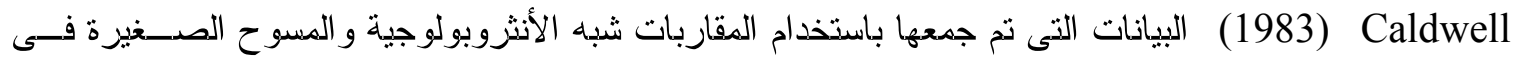

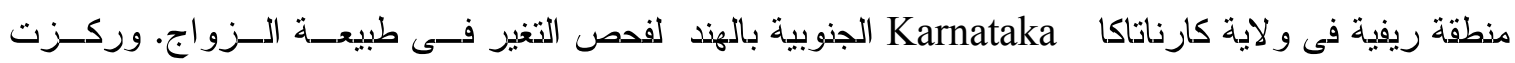

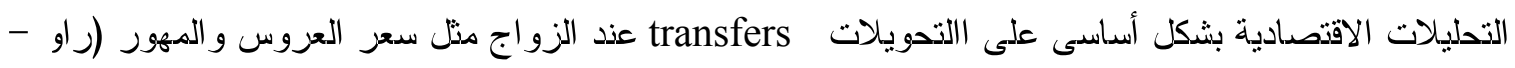

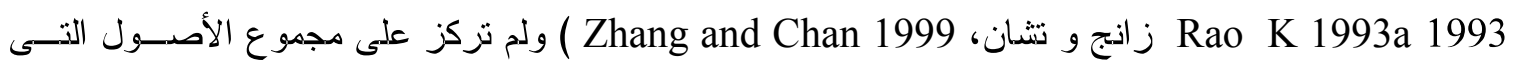
يجلبها المتزوجون الى الزواج. وحتى وان كان لسعر العزوس و المهور مغزى ثقافى و اجتماعى كبيز ، فهناك مـن

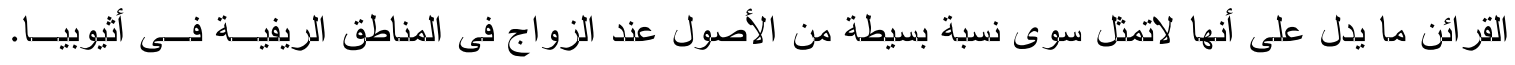

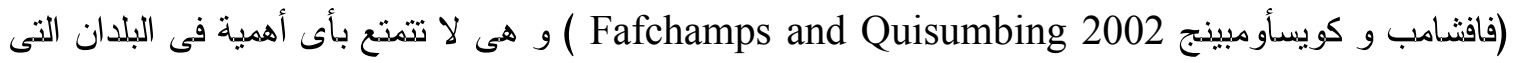
لا تمارس تلك العادات. 
وبشكل عام، تأسر البيانات الكمية الثحيحة المتوفرة التفاوتات المقطعية و الطولية ، بقدر كاف من التفصيل همــا

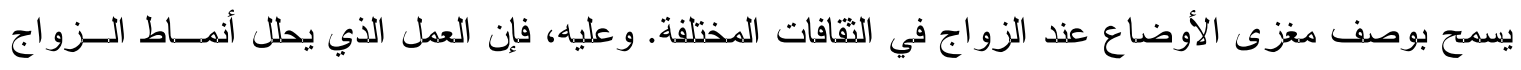
و الموارد عذد الزواج في عدد من البلدان، باستخدام مذهجيات جمع البيانات المقارنة و إجزاء التحليلات التجريبية، كان نادرًا.

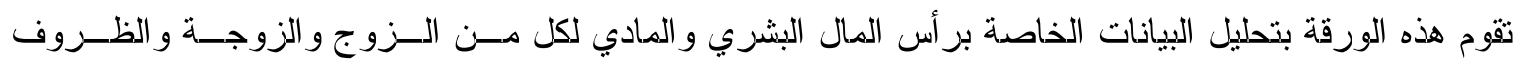

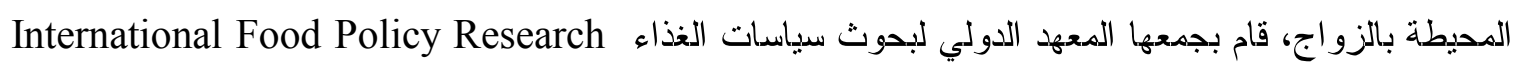

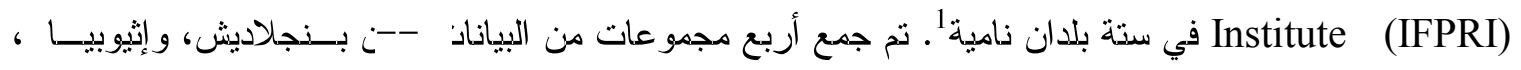

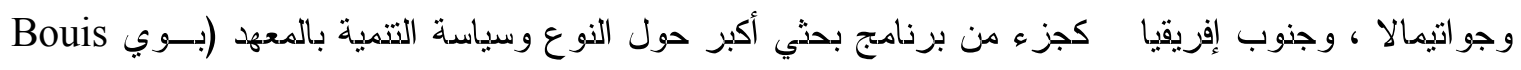

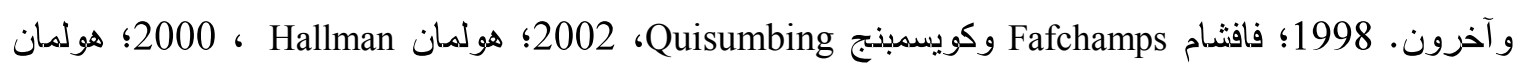

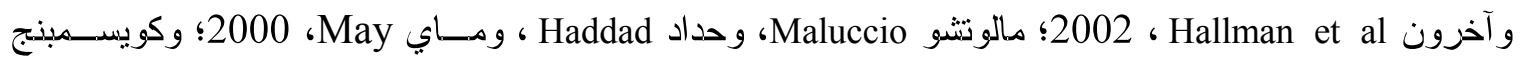

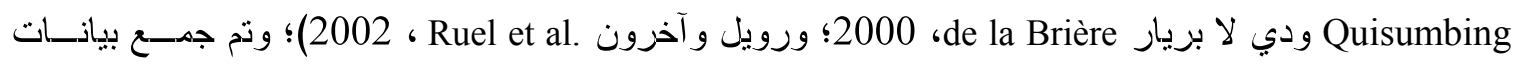

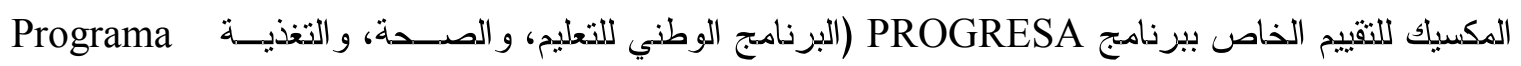
(Nacional de Educación, Salud y Alimentación

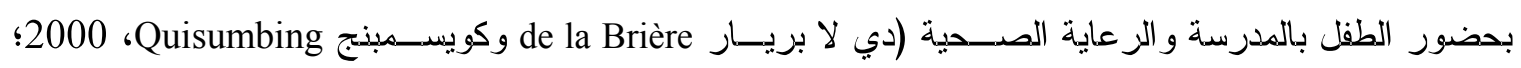

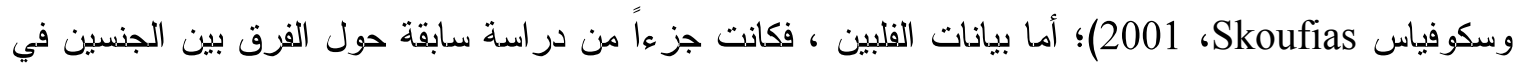
التحويلات بين الأجيال (كويسمبذج Quisumbing، 1994)². استخدمت مجموعات البيانات الخاصة بالبلدان الستة

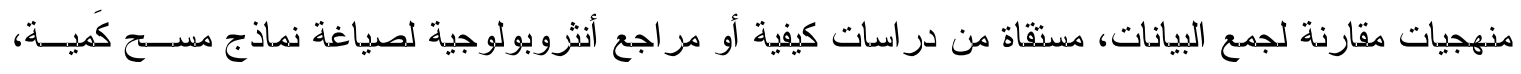
وتضدم بيانات حول خلفية الأسر ورأس المال المادي و البشري عند الزواج لكل من الأزواج و الزورجات. كذلك نم دئم

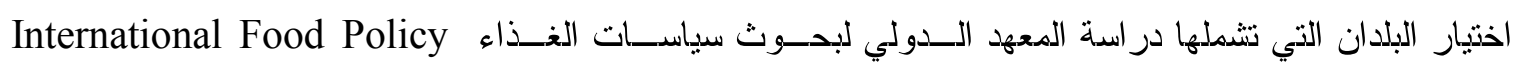
Research Institute (IFPRI) بما بحقق التنوع الجغر افي و التقافي، علاوة على التركيز على قضـايا محسددة خاصة بالسياسات تتعلق بالذوع. ونم تذفيض قيمة الأصول عند الزواج بسبب الانكماش، وذلك باسـتخدام بيسان

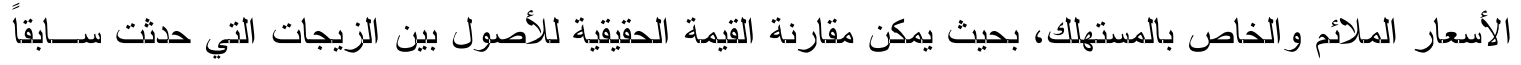

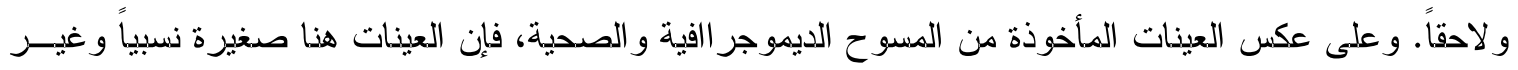

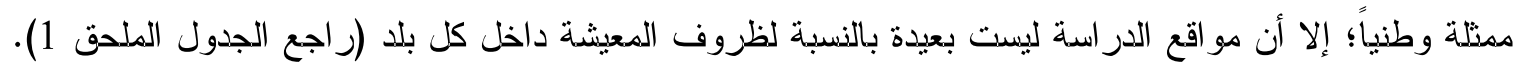

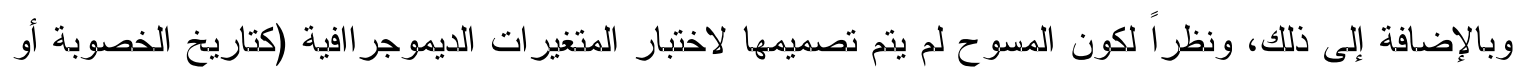
السن عند الزواج)، فإنه من الممكن ألا تكون هذه الجوانب من البيانات يعند بها بذفس القدر كالنماذج الاقتصادية.

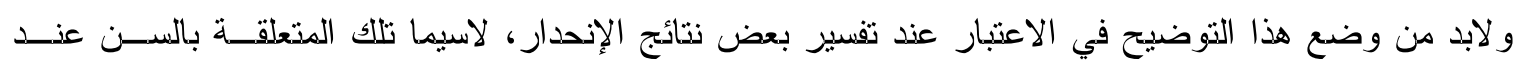
الزو اج.

إننا نستخدم هذه البيانات لتقدير أنثكال شبيرة من الإنحدار بالنسبة لجميع البلدان: (1) الإنحدار علـى مسـتويات رأس المال البشري (التعليم)، و السن عند الزواج، والأصول عند الزواج (و التي تم النظر فيها بصورة مذفصلة بين 
الزوج و الزوجة) كدليل على خلفية آباء و أمهات كلا الزوجين؛ ونسب كل جنس بين السكان (نسبة الإنساث إلـى

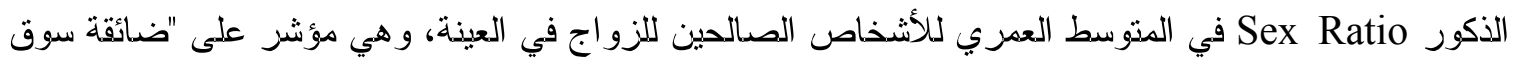

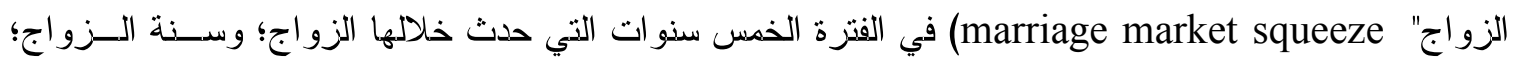

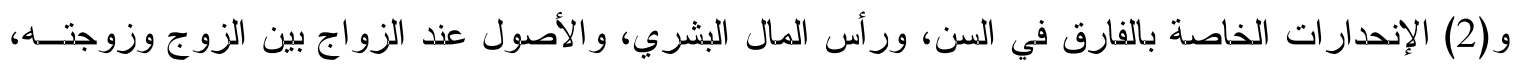

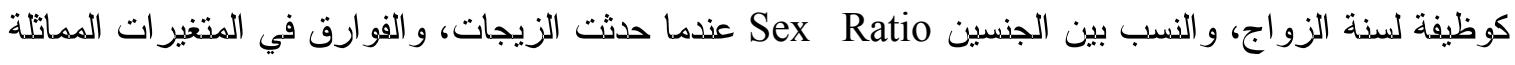

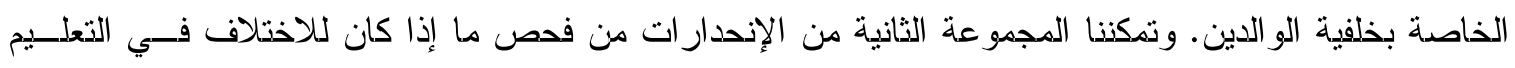

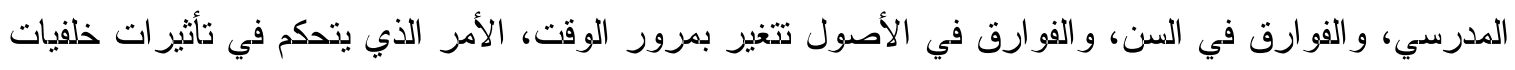

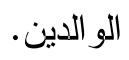

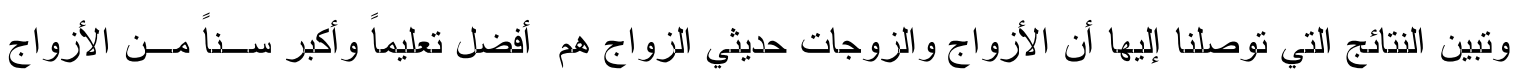

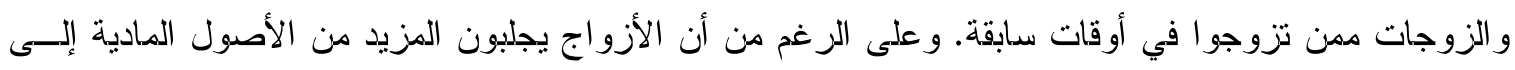

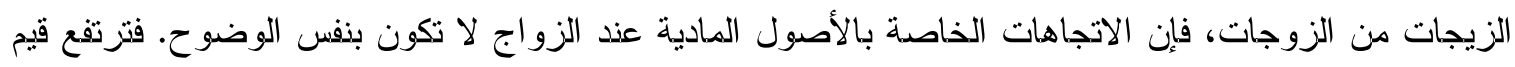

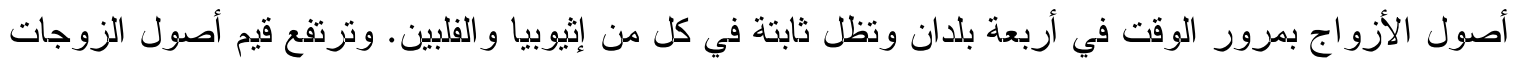

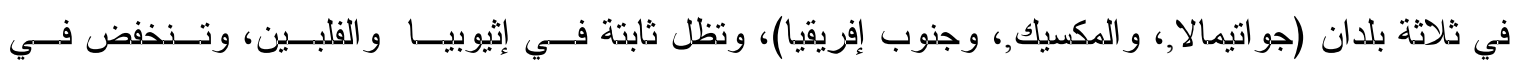

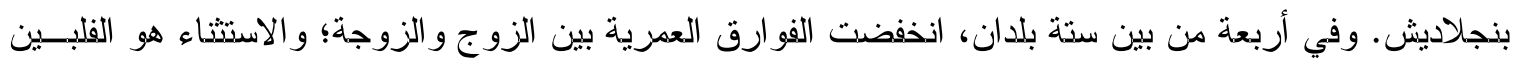

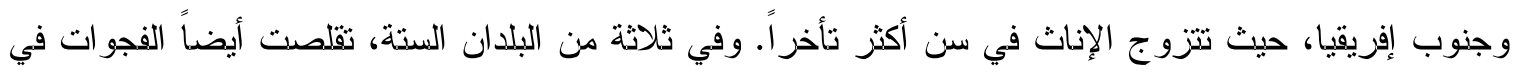

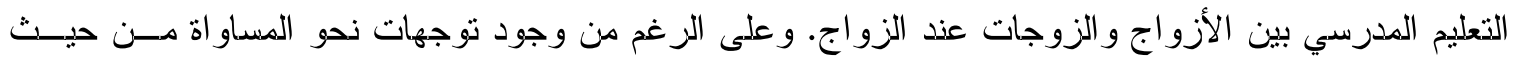

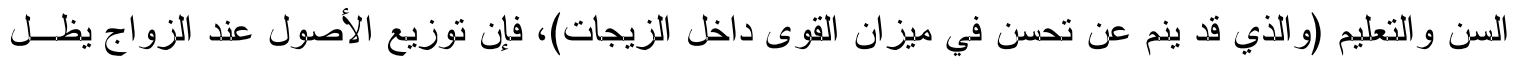

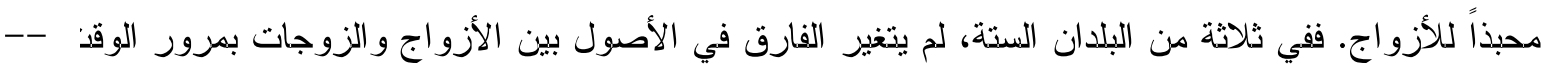

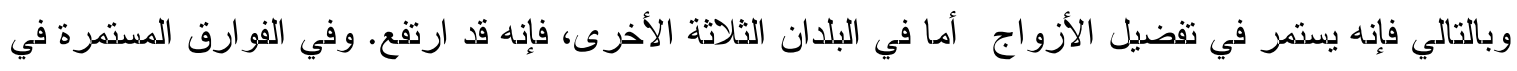

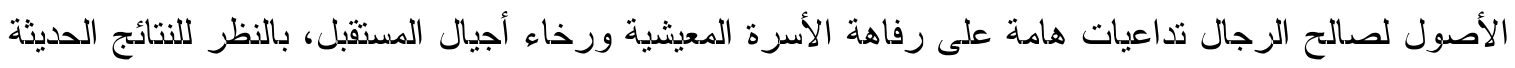

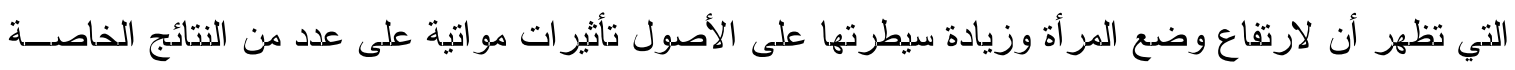
برأس المال البشري، لاسيما في الجيل القادم. 


\section{الخلفية و الوسائل}

\section{Assets at marriage and bargaining power الأصول عند الزواج وقوة المساومة}

قامت الدراسات التي أجراها المعهد الدولي لبحوث سياسات الغذاء International Food Policy Research Institute (IFPRI)

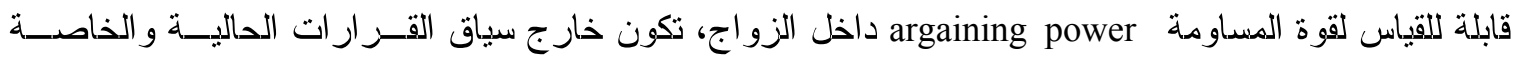

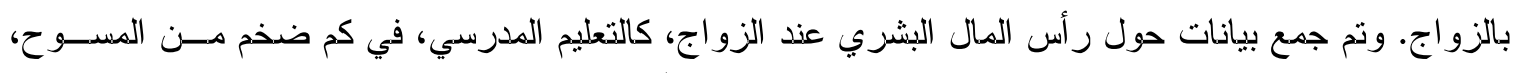

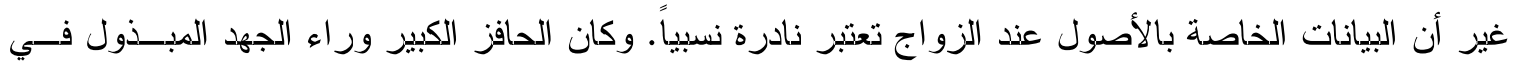

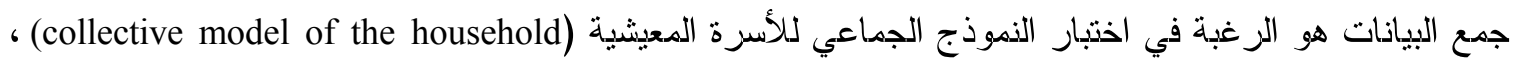

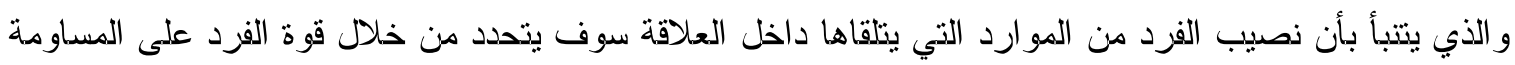

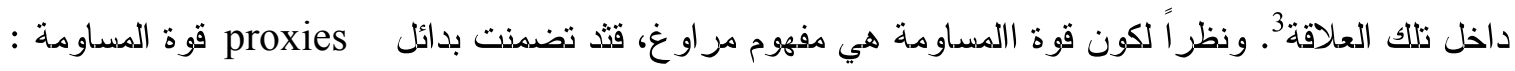

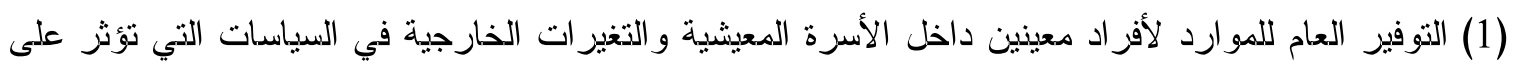

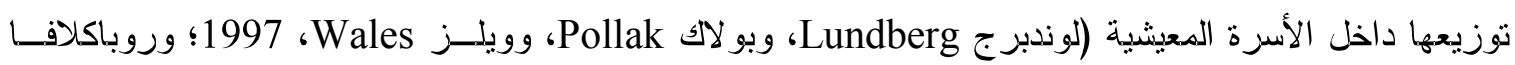
Rubaclava

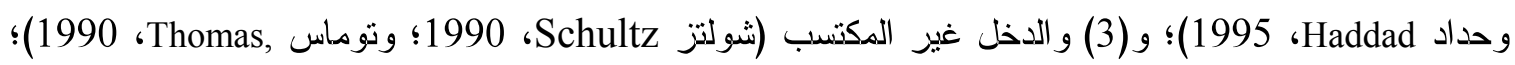

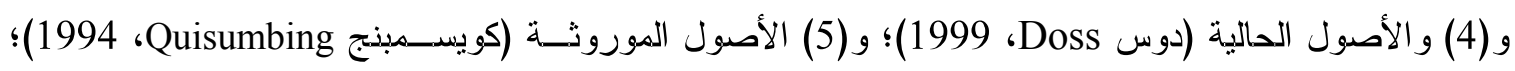

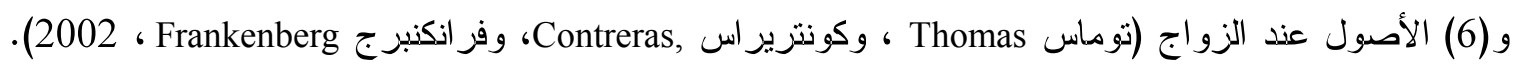

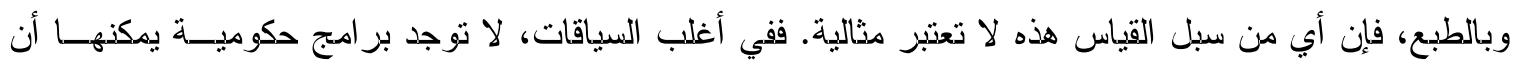

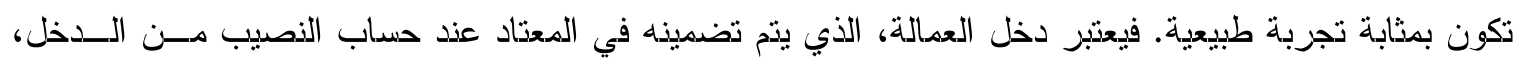

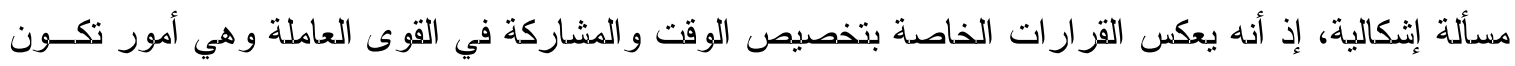

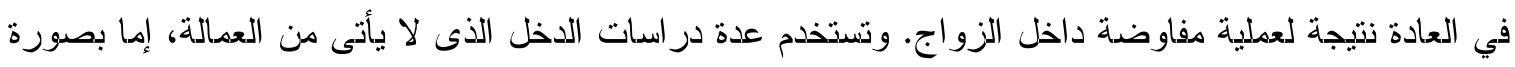

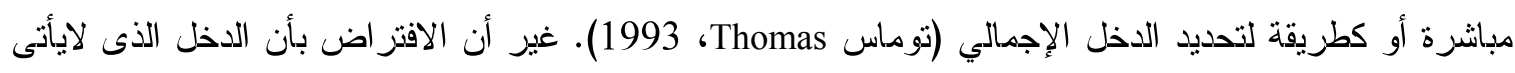

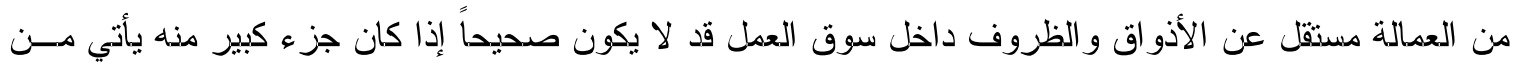
المعاثات، أو إعانات البطالة، أو المال المكتسب من الأصول التي تتجمع على مدار دورة الدياة.

كما أن المكتسبات الدالية للأصول، و التي استعانت بها دوس Doss (1999) في دراستها عن الأسر المعيشية في

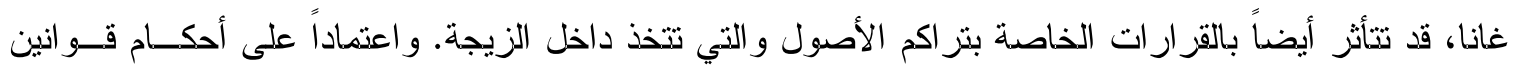

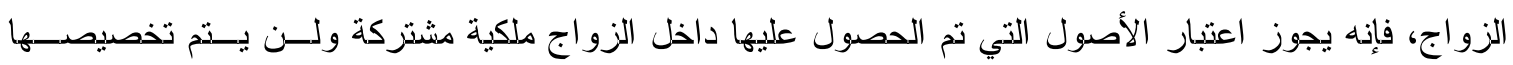

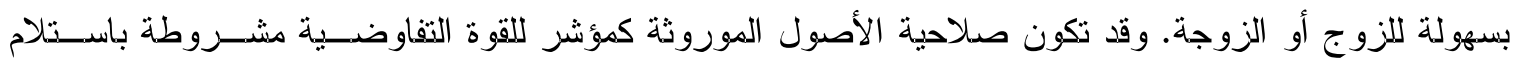

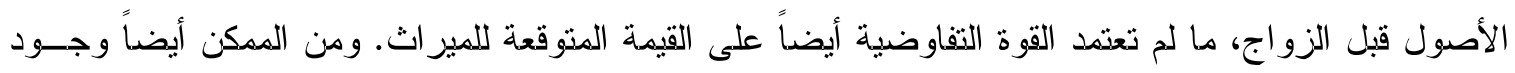

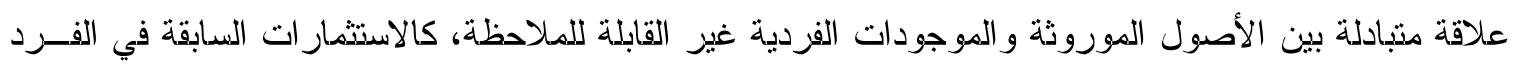

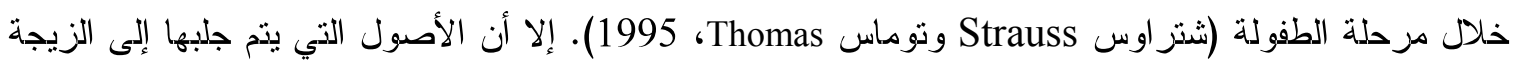


تكون مؤشرات مقبولة للقوة التفاوضية التي لا تتأثر بالقرارات المتخذة داخل الزواج (بمعنى أنها عناصر خارجة

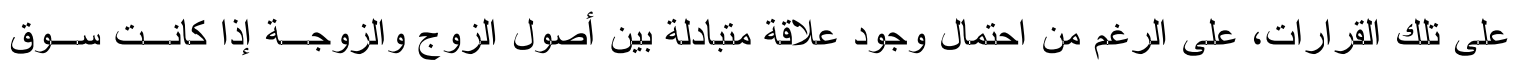

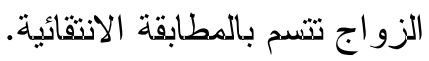

اختلافات في خصائص أخرى بين الزوج والزوجة الزية ودلالاتها

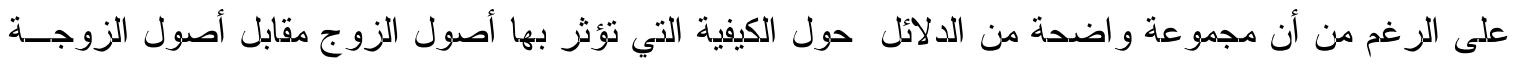

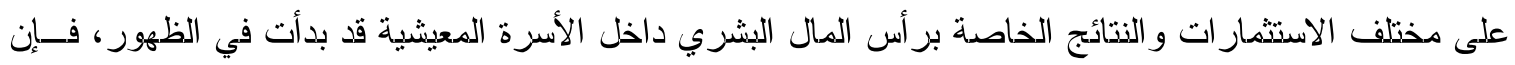

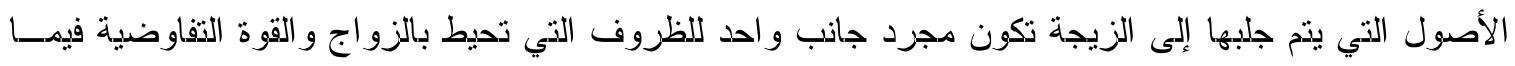

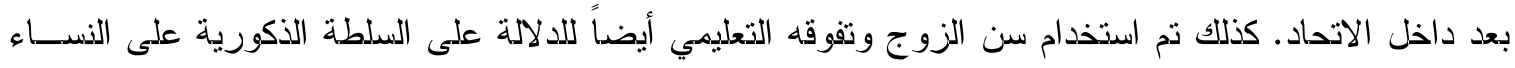

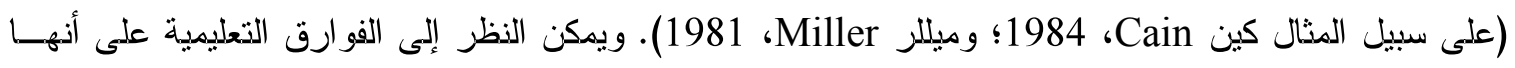

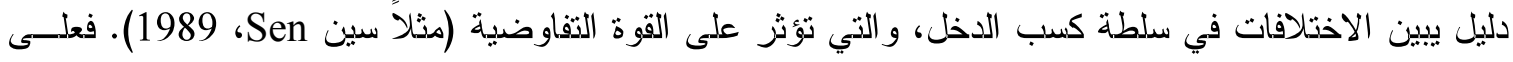
سبيل المثال، نجد أن سميث وآخرين Smith et al (تحت الطبع) يستندون في مقاييسهم إلى سلطة النساء في اتخاذ

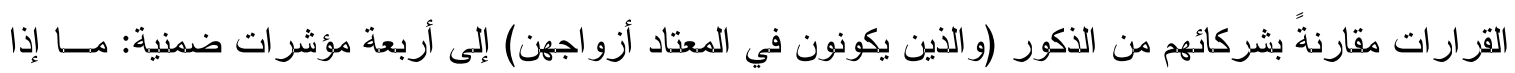

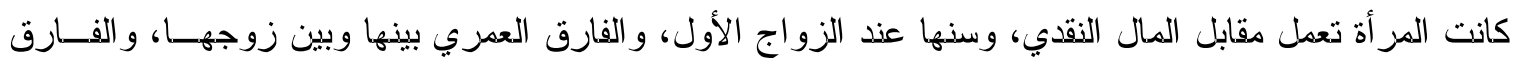

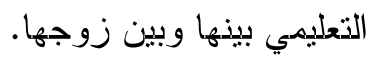

وبخلاف استخدام تأثيزات الفارق العمري بين الزوجين على إختلالات القوى كأدلة علـى الدــوارد الاقتصــادية

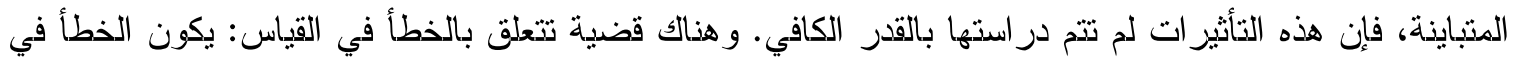

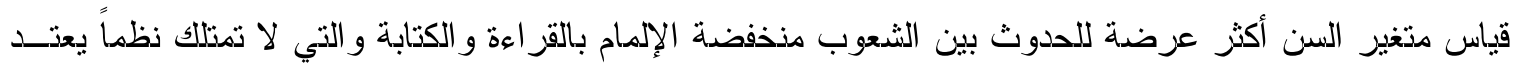

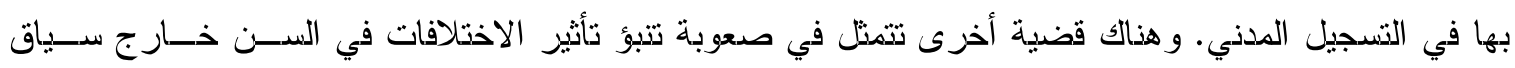
اجتماعي وتقافي محدد.

وتبين دراسات حديثة تأتي من منطقة جنوب الصدر اء الإفريقية sub-Saharan Africa ، على ســيل المثـال، أن

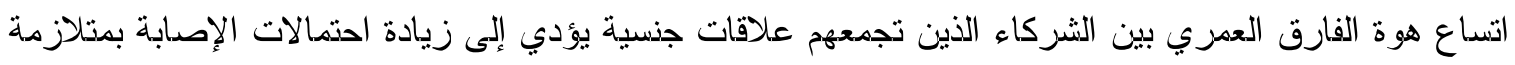

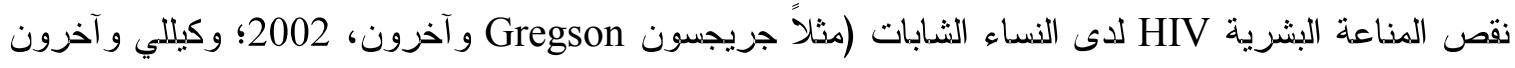

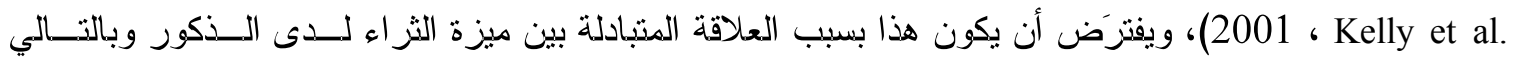

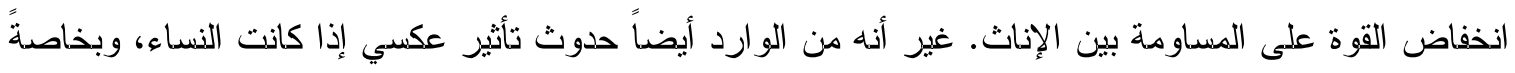

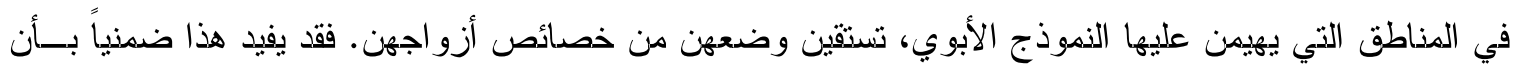

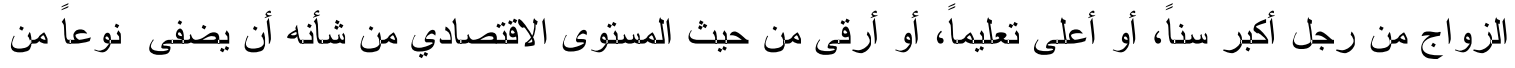

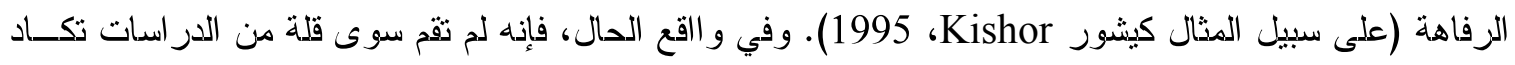

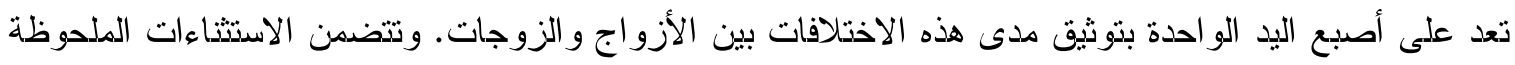

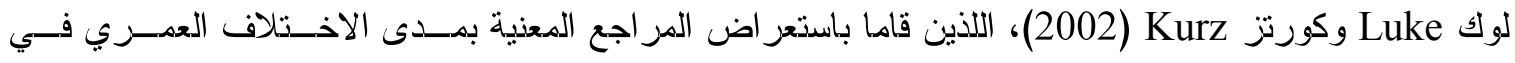
العلاقات الجنسية بمنطقة جنوب الصدر اء الإفريقية sub-Saharan Africa ووجدا أن نسبة ضخمة من الثــركاء 
الذين تجمعهم علاقة جنسية بفتيات ناثئيات يكونوا أكبر منهن بــ - -10 سنوات على الأقل. ويوثـق هرنــريش Hertrich

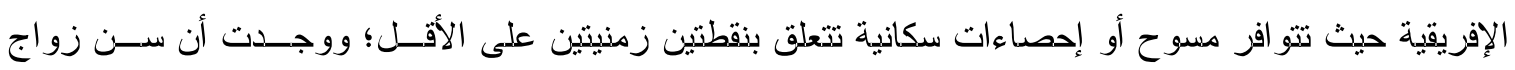

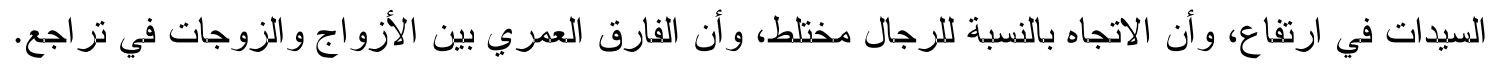

استخدم كل من منش Mensch وبروس Bruce وجـرين Greene (1998) بيانـات المسـوح الديموجر افيـة و الصدية من كل من كولومبيا ، ومصر، وتركيا لتوثيق الفارق في السن بين الأزواج و الزورجات عند سـن زين زواج

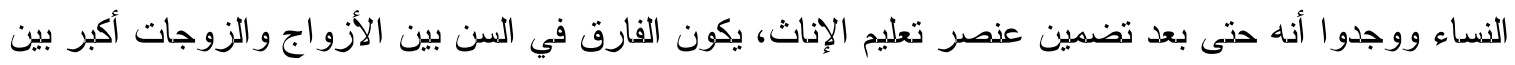

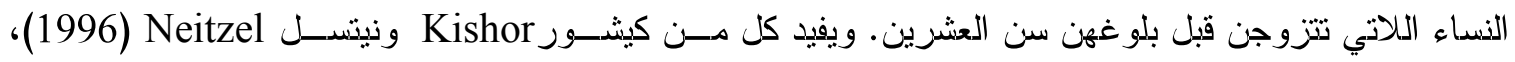

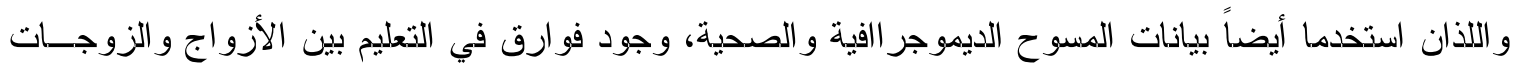

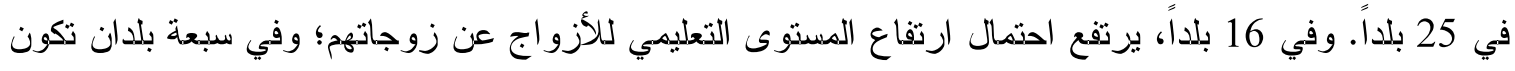

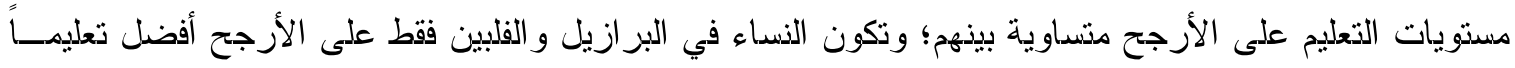

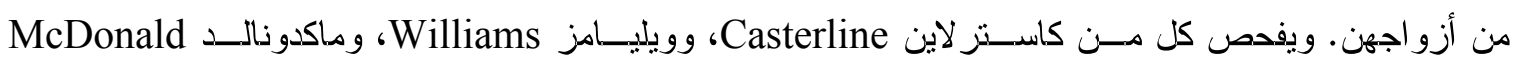

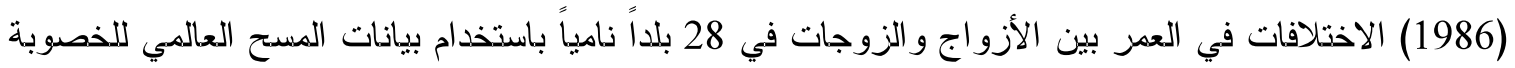
World Fertility Survey

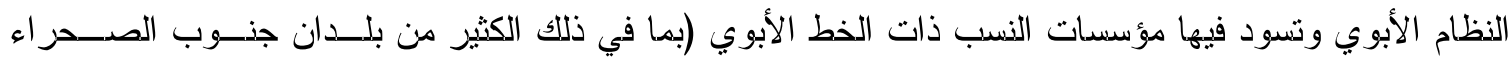

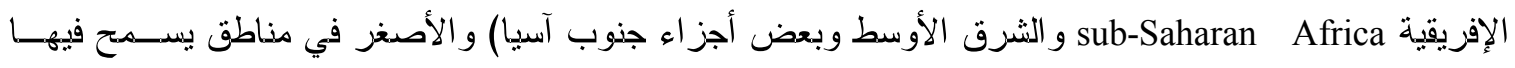

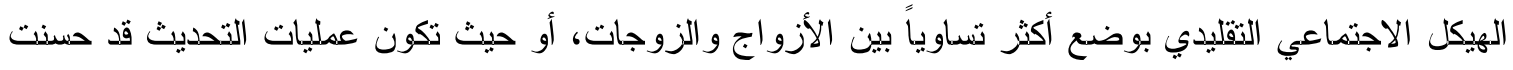

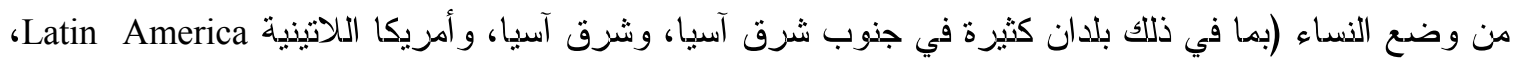
و البحر الكاريبي)، أو حيث يسود كلا النظامين.

\section{منهجية جمع البيانات}

زودت دراسات كيفية مذفصلة حول الجو انب المختلفة للنوع، مذها الطقوس الخاصة بالزواج، بالمعلومـات التسي أفادت في تصميم المسوح في كل من بنجلاديش، و إثيو بيا، وجو اتيمالا، وجنوب إفريقيا. أما في المكسيك و الفلبين،

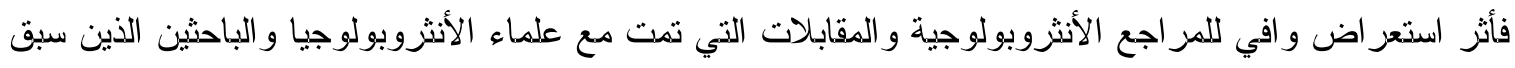

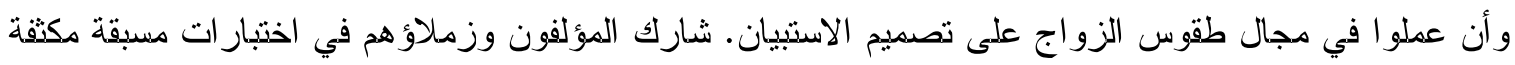
لوحدات المسح في جميع البلدان باستثناء المكسيك.

ونظراً لكون كل مجموعة من البيانات تتمتع بذصائص محددة تتعلق بالغرض من المسح، فإننا نكتفي بمناقثة

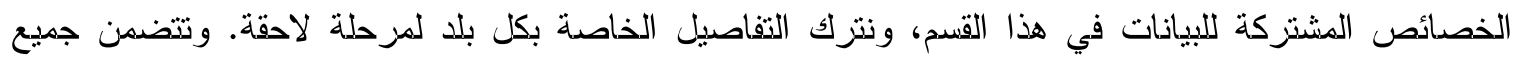

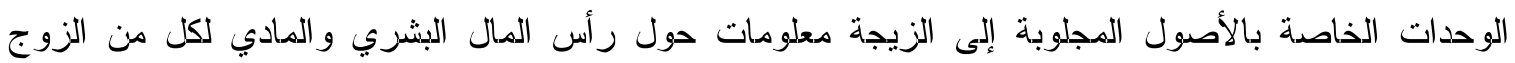
و الزوجة قبل الزواج (كالسن، و التعليم، وخبرة العمل، والأراضي، والدواب، وغير ذلك من الأصول)، وسنة 
الزواج، وخلفية الو الدين. وتم تسجيل مجموعة متنوعة من الأصول تم جلبها إلى الزيجة، بالإضافة إلى جميع

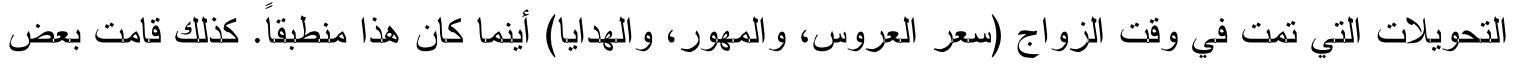

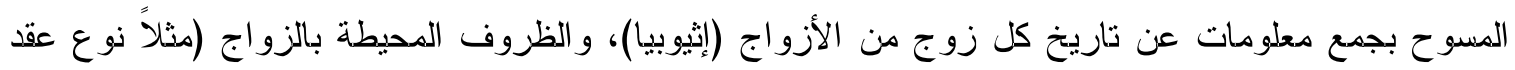

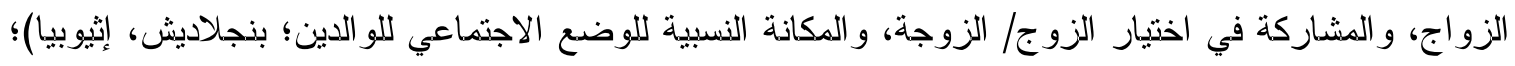

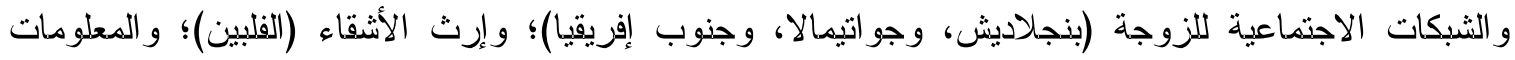

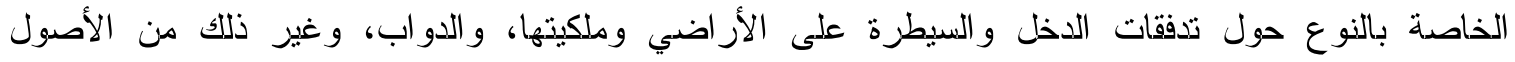

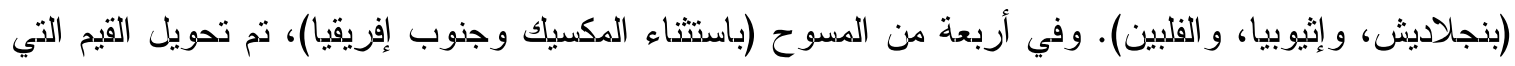

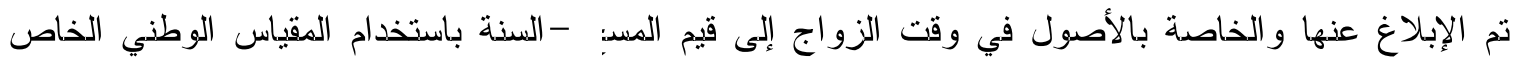

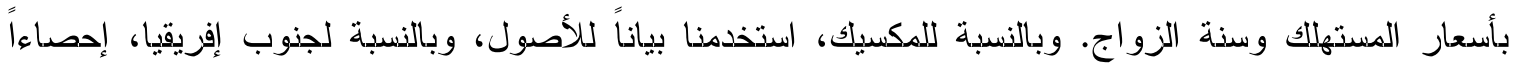
للأصول عند الزواج. ويمكن الاطلاع على تفاصيل حول هيكل قياسات الأصول في الأقسام الخاصة بكل بلد. لـالد.

\section{Empirical methodology المنهجية التجزيبية}

نقوم في البداية بتقدير سلسلة من انحدارات الدستويات بالنسبة لرأس المال البشري للزوج والزوجة (التعليم)، و السن عذد الزواج، والأصول التي نم جلبها إلى الزواج باستخدام المعادلة العامة:

$$
\begin{aligned}
& \text { + } \\
& \gamma_{2} \\
& \text { ס (غير ذلك من المتغيرات الذاصة بخلفية الأسرة) }
\end{aligned}
$$

حيثما تكون A هي متجه vector يتألف من نتائج مثل رأس المال البشري، والسن عند الزواج، والأصول،

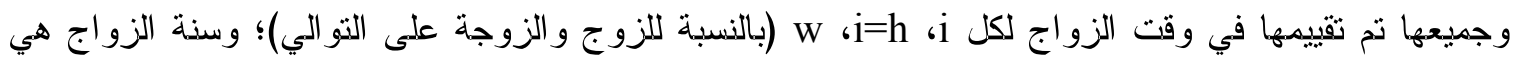

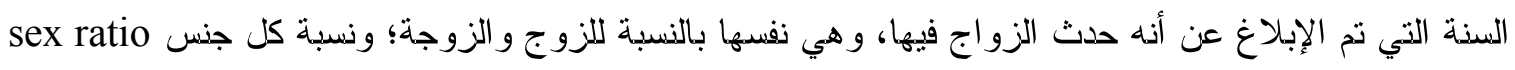

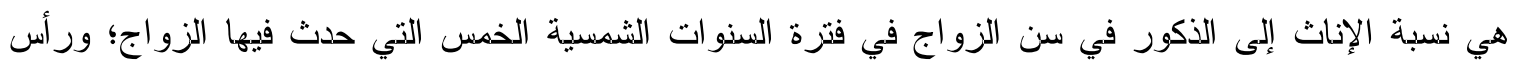

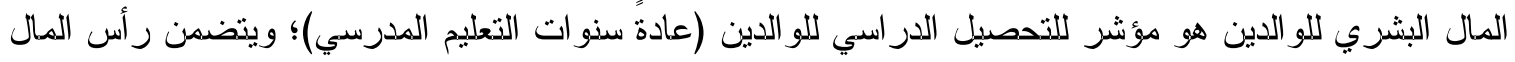
المادي للو الدين حيازة الو الدين للأراضي (و التي تكون في بعض الألئ الأحيان مذفصلة بالنسبة للآباء عن الأمهات)؛

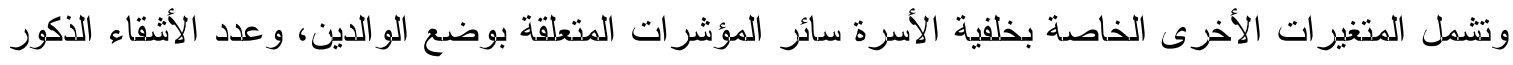

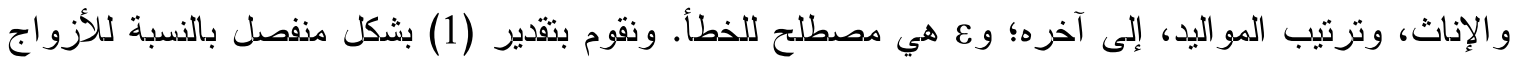

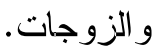

وباستثناء نسبة كل جنس sex ratio، فإنه تم الدصول على جميع المتغيرات التفسيرية هـن المسـوح الخاصــة بالأسر المعيشية. وتم الحصول على نسبة كل جنس sex ratio (وتعريفها أنها نسبة الإناث في الثريحة العمريـة 
التي تتماثشى مع المتوسط العمزي لزواج الإناث إلى ذفس النسبة مع الذكور في متوسط الفئة المقابلـة و الخاصــة

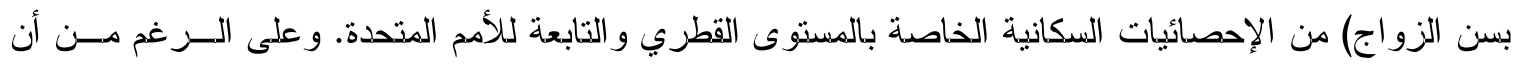
الاستعانة بنسب جنس sex ratio على مستوى الحي أو القرية تتماثىى مع سنة الزو اج كان سيكون أمزاً محموداً، فإن البيانات التاريخية على هذا المستوى من الفصل لم تكن منوفرة لكل موقع در اسة. لذا، فإننا استعضـنا عنهـا

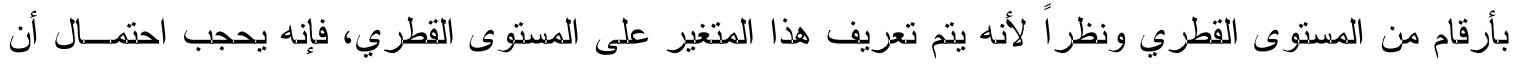
يكون لبعض المناطق داخل ذفس البلد (مثلاً المناطق الريفية التي ترتفع فيها نسب هجزة الذكور لذارجها) فائض

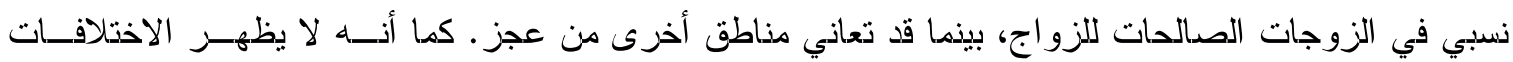

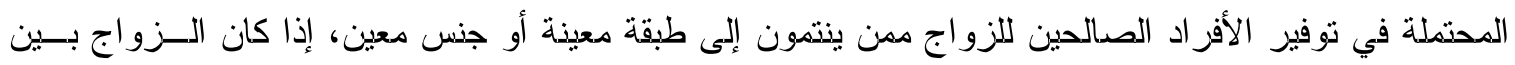

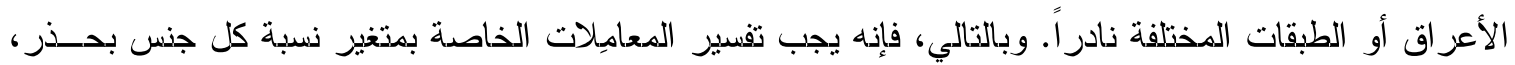
حيث أنه مقياس أبعد ما يكون عن الكمال لــ "ضائقة الزواج marriage squeeze". ويشار إلى أنذا نستخدم ســنة

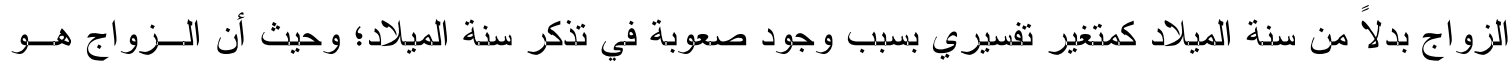

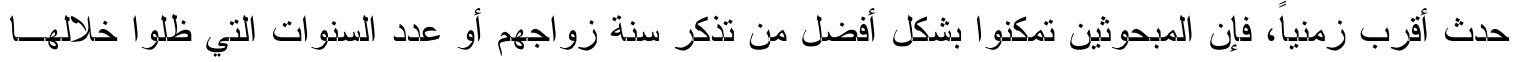

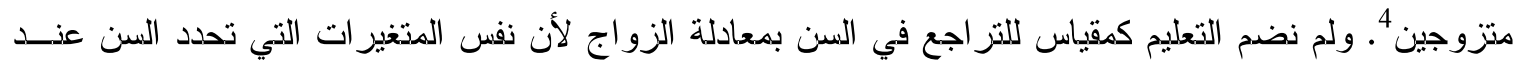

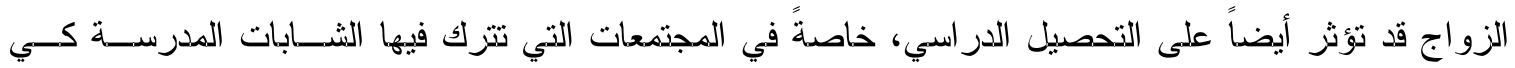
تنزوجن. وبيذما كان من الممكن إتباع أسلوب معين يمكن بمقتضاه تقدير معادلة السن عند الزواج بالتعليم ومعاملته

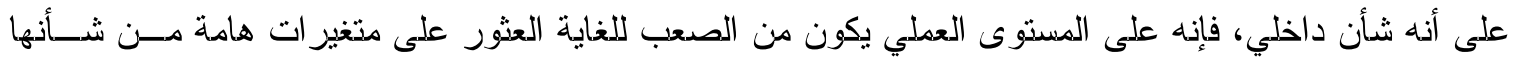
التأثير فقط على التعليم ولكن ليس على السن عذد الزو اج.

وللتأكد مما إذا كانت الفوارق بين الأزواج والزوجات تضيق بمزور الوقت، فإننا نقوم أيضاً بتقدير نسخة من (1)

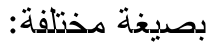

$$
\begin{aligned}
& + \text { + } \beta^{\prime}+\alpha^{\prime}=d \mathbf{A}
\end{aligned}
$$

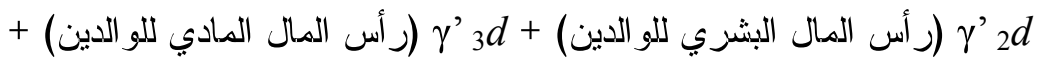

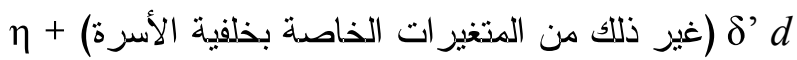

حيث تكون d هي الفارق بين متغيرات الزوج ومتغيرات الزوجة، فإن جميع المتغيرات في المعادلة (باستثناء سنة الزو اج ونسبة كل جنس) تكون في شكل الفارق، وتكون $\eta$ هي مصطلح الخطأ.

\section{أنماط الزواج في آسيا، وإفريقيا، وأمريكا اللادينية: لمحة عامة} في هذا الجزء، نقدم لمحة عامة وصفية عن اتجاهات الزواج في البلدان الستة التي شملتها الدراسة، فنقوم بتشخيص المجتمعات التي تم فيها جمع البيانات، وذقوم بوصف العينات، واختبار الاتجاهات في السمات الخاصة بالأزو اج و الزوجات و المطابقة الانتقائية بمرور الوقت. نتألف عينتنا من بلدين في كل من آسيا، وجنوب الديات الصحراء

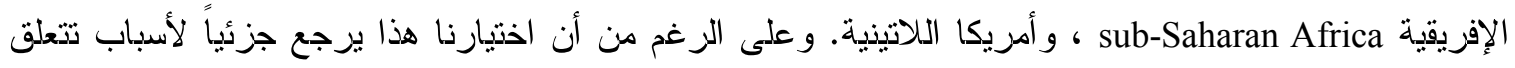


بتوفز البيانات، فإننا أيضاً اختزنا البلدان المختلفة وليست المتشابهة داخل كل منطقة جغرافية لتسليط الضوء على هلى ما تلعبه الاختلافات التقافية من دور ولتحديد ما إذا كانت هذالك، على الرغم من هذه الاختلافات، اتجاهات ناشئلة مشتركة

\section{لمحات عامة قطرية}

يتألف الجدول (1) من انحرافات متوسطة means ومعيارية standard deviations لخصائص الأزواج و الزوجات عند الزواج --ن، والتعليم المدرسي، والأصول بينما يقدم الجدول(2) الاتجاهات الخاصة بهذه المتغيرات على مدار الوقت بالنسبة لجميع البلدان الستّة التي شملتها الدراسة ولندات

بنجلادبث 6. بالتشابه مع غيره من مجتمعسات منطقـة جنـوب آســيا South Asia Region، فــإن المجتمـع

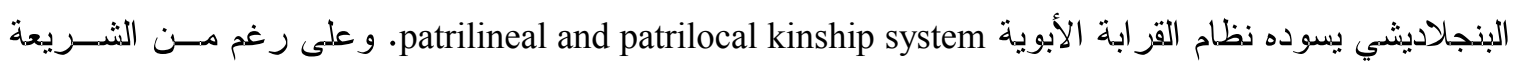

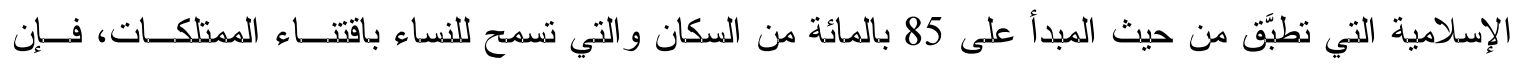

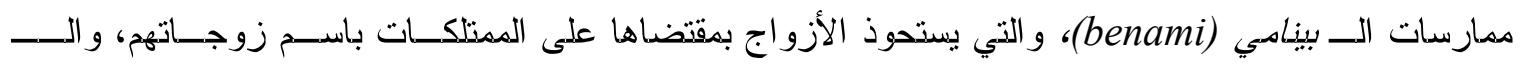

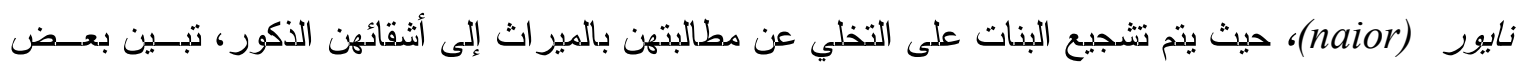

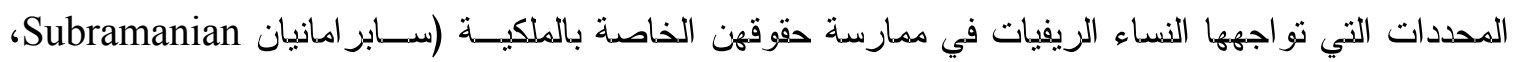
.$(1998$ 
جدول(1 ) الأصول عند الزواج ورأس المال البشري للزوج والزوجة

\begin{tabular}{|c|c|c|c|c|}
\hline \multicolumn{2}{|c|}{ الزوجة } & \multicolumn{2}{|c|}{ 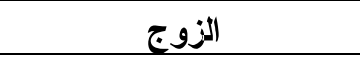 } & \\
\hline الآحزاف & المتوسط & الآحزاف & المتوسط & \\
\hline 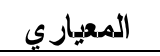 & & 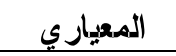 & & \\
\hline & & & & 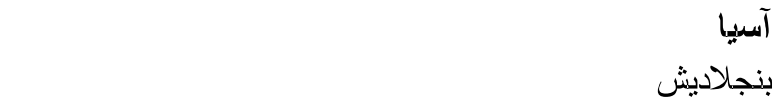 \\
\hline 3.8 & 15.0 & 5.7 & 23.8 & السن عند الزواج (سنوات) \\
\hline 2.8 & 1.7 & 4.0 & 3.2 & سذو ات التعليم المدرسي \\
\hline 20.139 .5 & 12.950 .0 & 150.560 .2 & 36.428 .5 & قيمة الأصول+ التحويلات عند الزواج (تاكا 1996 Taka) \\
\hline 10.477 .0 & 2.542 .9 & 148.767 .9 & 32.146 .0 & قيمة الأصول عند الزواج (تاكا 1996 Taka) \\
\hline 16.339 .0 & 10.333 .5 & 15.116 .7 & 4.258 .7 & قيمة التحويلات عند الزواج للأزواج/ الزوجات (تاكا \\
\hline & & & & 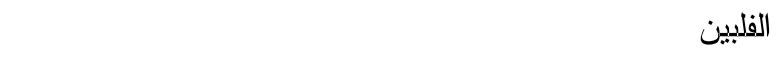 \\
\hline 5.1 & 22.2 & 5.7 & 25.1 & السن عند الزواج (سنوات) \\
\hline 3.0 & 6.3 & 3.1 & 6.3 & سذوات التعليم المدرسي \\
\hline 0.6 & 0.2 & 0.9 & 0.5 & مساحة الأراضي عند الزواج (بالهكتار) \\
\hline 473.2 & 463.3 & 769.3 & 761.8 & قيمة الأصول (بخلاف الأراضي) عند الزواج (بيزو Peso \\
\hline & & & & إفريقيا \\
\hline & & & & 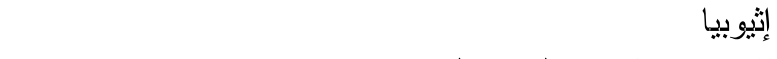 \\
\hline 6.0 & 17.9 & 7.6 & 26.3 & السن عند الزواج (سنوات) \\
\hline 1.6 & 0.7 & 2.3 & 1.7 & سذوات التعليم المدرسي \\
\hline 3.744 .4 & 1.918 .0 & 8.340 .3 & 4.584 .0 & قيمة الأصول عند الزواج (بيز" 1997 Birr) \\
\hline & & & & جنوب إفريقيا \\
\hline 7.1 & 23.2 & 8.4 & 28.5 & السن عند الزواج (سنوات) \\
\hline 3.6 & 5.1 & 3.8 & 5.2 & سذو ات التعليم المدرسي \\
\hline 1.0 & 0.7 & 1.6 & 2.1 & إحصاء الأصول عند الزواج \\
\hline 22.680 .6 & 6.435 .4 & 50.740 .4 & 36.272 .4 & قيمة التدويلات من أسرة الزوج/ الزوجة عند الزواج (راند Rand \\
\hline
\end{tabular}




$\begin{array}{cccc}4.0 & 18.4 & 6.3 & 23.3 \\ 2.8 & 3.0 & 2.9 & 3.2 \\ 0.06 & 0.00 & 0.34 & 0.13 \\ 0.06 & 0.01 & 0.08 & 0.02 \\ & & & \\ 3.7 & 19.9 & 5.1 & 22.6 \\ 3.7 & 6.0 & 3.5 & 7.2 \\ 1.684 .5 & 727.4 & 12.013 .8 & 5.226 .8\end{array}$

السن عذد الزواج (سنوات)

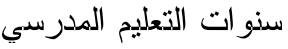
الأرض المملوكة عند الزواج (1 إذا كانت الإجابة بنعم) مجموع الأصول عند الزواج الزاج السن عند الزواج (سنوات)

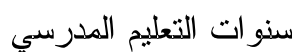
قيمة الأصول عند الزواج (كويتسال 1999 quetzal 


\begin{tabular}{|c|c|c|c|c|c|c|c|c|c|c|c|c|}
\hline \multirow{2}{*}{$\begin{array}{c}\text { نسبة } \\
\text { sex } \\
\text { satio } \\
\text { ration }\end{array}$} & \multicolumn{2}{|c|}{ التحويلات إلى } & \multicolumn{2}{|c|}{ الأصول عذد الزواج } & \multicolumn{2}{|c|}{ في الزأصول والتدويلات } & \multicolumn{2}{|c|}{ السن عذد الزواج } & \multicolumn{2}{|c|}{ سذوات الدراسة } & \multirow{2}{*}{\multicolumn{2}{|c|}{ الزيجات }} \\
\hline & الزوجة & الزوج & الزوجة & الزوج & الزوجة & الزوج & الزوجة & الزوج & الزوجة & الزوج & & \\
\hline & & & & & & & & & & & & بنجلاديش \\
\hline 1.02 & 0.00 & 0.00 & 0.00 & 0.00 & 0.00 & 0.00 & 9.00 & 27.00 & 0.00 & 0.00 & 1 & $34-930$ \\
\hline 1.02 & 0.00 & 0.00 & 0.00 & 0.00 & 0.00 & 0.00 & 12.50 & 28.19 & 0.00 & 0.00 & 2 & $39-935$ \\
\hline 1.02 & 0.00 & 0.00 & 0.00 & 0.00 & 0.00 & 0.00 & 11.33 & 19.42 & 1.67 & 5.00 & 3 & $44-940$ \\
\hline 1.02 & 0.00 & 0.00 & 0.00 & 0.00 & 0.00 & 0.00 & 11.32 & 20.84 & 0.88 & 2.31 & 16 & $49-945$ \\
\hline 1.02 & 19.021 .64 & 2.770 .26 & 5.335 .48 & 5.679 .54 & 21.507 .74 & 8.621 .90 & 13.05 & 22.93 & 0.82 & 2.82 & 34 & $54-950$ \\
\hline 1.06 & 15.727 .31 & 9.955 .70 & 19.257.46 & 28.739 .80 & 19.638 .39 & 40.355 .99 & 13.62 & 22.47 & 0.86 & 2.64 & 50 & $59-955$ \\
\hline 1.12 & 19.977.07 & 5.621 .68 & 11.918 .45 & 27.329 .91 & 23.142 .25 & 33.399 .62 & 12.70 & 22.40 & 0.97 & 2.44 & 62 & $64-960$ \\
\hline 1.11 & 18.009 .26 & 4.673 .96 & 7.388 .71 & 32.792 .70 & 20.959 .34 & 37.466 .66 & 14.45 & 24.39 & 1.77 & 3.86 & 94 & $69-965$ \\
\hline 1.31 & 15.576 .75 & 5.442 .83 & 5.800 .13 & 58.167 .31 & 18.201 .53 & 65.319 .44 & 14.16 & 22.92 & 1.42 & 3.54 & 120 & $74-970$ \\
\hline 1.10 & 7.400 .15 & 4.355 .09 & 16.617 .34 & 39.691 .58 & 11.703 .86 & 44.708 .19 & 14.98 & 23.22 & 2.15 & 4.38 & 121 & $79-975$ \\
\hline 1.11 & 4.995 .88 & 3.243 .71 & 3.468 .11 & 28.571 .70 & 6.524 .70 & 28.593 .82 & 16.01 & 24.09 & 1.46 & 2.76 & 141 & $84-980$ \\
\hline 1.08 & 4.085 .83 & 2.400 .25 & 13.602 .81 & 24.637 .40 & 6.919 .89 & 27.741 .57 & 16.28 & 24.64 & 1.44 & 2.42 & 108 & $89-985$ \\
\hline 1.07 & 4.703 .04 & 3.547 .63 & 1.885 .30 & 24.900 .69 & 5.679 .25 & 27.482 .85 & 17.45 & 26.26 & 3.39 & 3.13 & 83 & $94-990$ \\
\hline 1.06 & 2.548 .52 & 3.237 .43 & 1.334 .24 & 26.947 .19 & 3.228 .01 & 30.184 .62 & 16.00 & 26.54 & 5.17 & 3.33 & 6 & $99-995$ \\
\hline
\end{tabular}




\begin{tabular}{|c|c|c|c|c|c|c|c|c|c|c|}
\hline \multirow{2}{*}{$\begin{array}{c}\text { كلس } \text { كل } \\
\text { sex } \\
\text { ratio }\end{array}$} & \multicolumn{2}{|c|}{ الأصول عند الزواج } & \multicolumn{2}{|c|}{ مساحة الأراضي عند الزواج } & \multicolumn{2}{|c|}{ السن عذد الزواج } & \multicolumn{2}{|c|}{ سذوات الدراسة } & \multirow{2}{*}{ الزيجات } & \\
\hline & الزوجة & 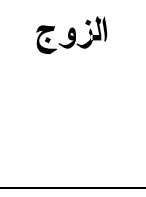 & الزوجة & 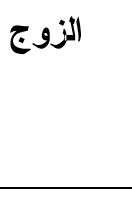 & الزوجة & 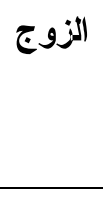 & الزوجة & 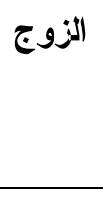 & & \\
\hline & & & & & & & & & & الفلبين \\
\hline 1.15 & 472.45 & 407.64 & 0.50 & 0.00 & 22.00 & 16.00 & 9.50 & 5.50 & 2 & $29-925$ \\
\hline 1.15 & 299.84 & 693.72 & 0.67 & 0.25 & 19.75 & 23.25 & 3.25 & 4.75 & 4 & $34-930$ \\
\hline 1.15 & 413.82 & 723.82 & 0.24 & 0.10 & 23.50 & 21.50 & 3.63 & 2.75 & 8 & $39-935$ \\
\hline 1.15 & 442.27 & 888.83 & 0.50 & 0.18 & 19.75 & 24.17 & 4.08 & 4.08 & 12 & $44-940$ \\
\hline 1.15 & 435.28 & 704.53 & 0.52 & 0.02 & 22.14 & 25.21 & 4.86 & 4.64 & 14 & $49-945$ \\
\hline 1.15 & 506.99 & 902.62 & 0.40 & 0.27 & 22.45 & 24.45 & 5.24 & 4.34 & 29 & $54-950$ \\
\hline 1.29 & 582.67 & 790.80 & 0.26 & 0.89 & 22.25 & 25.75 & 5.46 & 7.32 & 28 & $59-955$ \\
\hline 1.15 & 434.45 & 516.27 & 0.39 & 0.48 & 21.30 & 24.04 & 6.63 & 5.93 & 27 & $64-960$ \\
\hline 1.17 & 490.17 & 757.92 & 0.11 & 0.66 & 21.97 & 24.45 & 6.15 & 6.61 & 33 & $69-965$ \\
\hline 1.13 & 388.06 & 595.65 & 0.12 & 0.72 & 21.38 & 25.29 & 6.74 & 6.85 & 34 & $74-970$ \\
\hline 1.26 & 449.85 & 868.60 & 0.00 & 0.37 & 24.13 & 27.71 & 7.58 & 7.37 & 38 & $79-975$ \\
\hline 1.17 & 440.84 & 847.86 & 0.03 & 0.52 & 21.80 & 24.20 & 7.73 & 7.87 & 30 & $84-980$ \\
\hline 1.16 & 700.34 & 1.243 .85 & 0.64 & 0.00 & 31.00 & 34.00 & 10.00 & 10.00 & 3 & $89-985$ \\
\hline
\end{tabular}




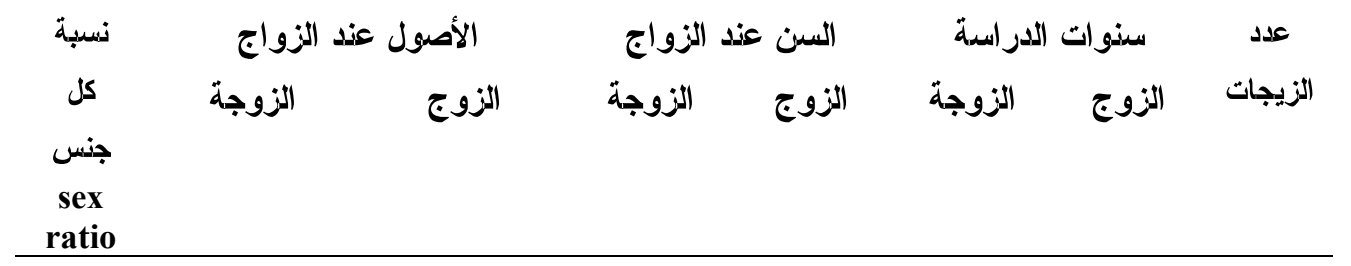

إفريقيا

$\begin{array}{lllllllll}\text { إثيوبيا } \\ 1.37 & 2.360 .70 & 6.664 .50 & 20.11 & 31.68 & 0.08 & 0.69 & 144 & 59-955 \\ 1.38 & 3.450 .78 & 6.661 .85 & 16.44 & 25.52 & 0.09 & 0.67 & 56 & 64-960 \\ 1.39 & 1.789 .68 & 4.964 .11 & 15.72 & 23.76 & 0.36 & 1.20 & 84 & 69-965 \\ 1.39 & 2.548 .83 & 3.818 .32 & 16.32 & 23.65 & 1.00 & 2.29 & 62 & 74-970 \\ 1.39 & 1.233 .61 & 2.925 .50 & 17.01 & 24.08 & 1.03 & 2.31 & 72 & 79-975 \\ 1.45 & 1.059 .34 & 2.873 .41 & 17.98 & 24.17 & 1.52 & 2.86 & 99 & 84-980 \\ 1.47 & 1.133 .21 & 2.565 .61 & 19.43 & 26.29 & 1.24 & 3.29 & 53 & 89-985 \\ 1.45 & 500.00 & 1.605 .21 & 46.25 & 50.25 & 0.00 & 5.00 & 1 & 94-990\end{array}$




\begin{tabular}{|c|c|c|c|c|c|c|c|c|c|c|}
\hline \multirow{4}{*}{$\begin{array}{c}\text { نسبة } \\
\text { Sنx } \\
\text { ratio } \\
\text { rax }\end{array}$} & \multicolumn{2}{|c|}{ التحويلات من } & \multicolumn{2}{|c|}{ الأصول عذد الزواج } & \multicolumn{2}{|c|}{ السن عند الزواج } & \multicolumn{2}{|c|}{ سذوات الدراسة } & \multirow{2}{*}{ الزيجات } & \multirow[b]{5}{*}{ جنوب إفزيقيا } \\
\hline & الزوجة & الزوج & الزوجة & الزوج & الزوجة & الزوج & الزوجة & الزوج & & \\
\hline & & & & & & & & & & \\
\hline & & & & & & & & & & \\
\hline & & & & & & & & & & \\
\hline 1.06 & 7.413 .69 & 17.477 .13 & 0.00 & 1.14 & 11.57 & 17.86 & 2.14 & 2.57 & 7 & $54-950$ \\
\hline 1.07 & 6.480 .63 & 44.270 .71 & 0.36 & 2.00 & 17.93 & 25.36 & 2.50 & 3.36 & 14 & $59-955$ \\
\hline 1.12 & 8.110 .00 & 51.014 .27 & 0.63 & 1.60 & 18.17 & 24.03 & 3.00 & 3.30 & 30 & $64-960$ \\
\hline 1.18 & 8.617 .73 & 46.676 .74 & 0.53 & 1.89 & 21.42 & 26.03 & 3.62 & 4.15 & 66 & $69-965$ \\
\hline 1.17 & 15.143 .04 & 46.719 .09 & 0.55 & 1.96 & 21.82 & 26.55 & 4.69 & 5.51 & 67 & $74-970$ \\
\hline 1.20 & 7.624 .90 & 55.176 .04 & 0.77 & 2.20 & 20.75 & 26.08 & 5.30 & 5.39 & 92 & $79-975$ \\
\hline 1.12 & 3.713 .56 & 29.727 .18 & 0.80 & 2.22 & 24.18 & 30.13 & 6.04 & 6.00 & 83 & $84-980$ \\
\hline 1.17 & 1.792 .36 & 16.419 .83 & 0.82 & 2.47 & 26.19 & 31.92 & 5.57 & 5.75 & 72 & $89-985$ \\
\hline 1.19 & 937.60 & 11.608 .50 & 1.04 & 2.40 & 28.87 & 34.04 & 6.38 & 5.68 & 47 & $94-990$ \\
\hline 1.11 & 1.007 .00 & 6.517 .53 & 1.57 & 1.93 & 35.93 & 39.00 & 7.43 & 6.29 & 14 & $99-995$ \\
\hline
\end{tabular}




\begin{tabular}{|c|c|c|c|c|c|c|c|c|c|c|}
\hline \multirow{2}{*}{$\begin{array}{c}\text { نسبة } \\
\text { دلس } \\
\text { sex } \\
\text { ratio }\end{array}$} & \multicolumn{2}{|c|}{ مجموع الأصول عند الزواج } & \multicolumn{2}{|c|}{ الأرض المملوكة عند الزواج } & \multicolumn{2}{|c|}{ السن عند الزواج } & \multicolumn{2}{|c|}{ سذوات الدراسة } & \multirow{2}{*}{ الزيجات } & \multirow[b]{3}{*}{ أمريكا اللاتيذية } \\
\hline & الزوجة & 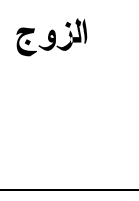 & الزوجة & 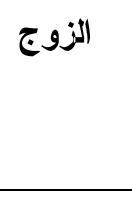 & الزوجة & 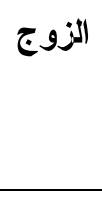 & الزوجة & 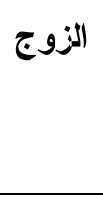 & & \\
\hline & & & & & & & & & & \\
\hline & & & & & & & & & & ال المكسيك \\
\hline 1.15 & 0.00 & 0.00 & 0.00 & 0.00 & 16.00 & 17.00 & 0.00 & 0.00 & 1 & $24-920$ \\
\hline 1.15 & 0.00 & 0.00 & 0.00 & 0.00 & 17.00 & 23.00 & 0.00 & 1.00 & 1 & $29-925$ \\
\hline 1.15 & 0.01 & 0.01 & 0.00 & 0.21 & 17.00 & 22.24 & 0.39 & 0.76 & 17 & $34-930$ \\
\hline 1.15 & 0.02 & 0.02 & 0.00 & 0.23 & 17.00 & 21.79 & 0.58 & 0.73 & 52 & $39-935$ \\
\hline 1.15 & 0.02 & 0.01 & 0.01 & 0.16 & 17.00 & 22.41 & 0.54 & 0.84 & 128 & $44-940$ \\
\hline 1.15 & 0.01 & 0.01 & 0.00 & 0.15 & 18.00 & 22.37 & 0.75 & 0.97 & 215 & $49-945$ \\
\hline 1.15 & 0.01 & 0.02 & 0.01 & 0.15 & 18.00 & 23.15 & 0.83 & 1.33 & 421 & $54-950$ \\
\hline 1.14 & 0.01 & 0.01 & 0.00 & 0.15 & 18.00 & 23.06 & 1.04 & 1.47 & 665 & $59-955$ \\
\hline 1.20 & 0.01 & 0.02 & 0.01 & 0.15 & 18.00 & 23.24 & 1.26 & 1.56 & 889 & $64-960$ \\
\hline 1.19 & 0.01 & 0.02 & 0.00 & 0.14 & 18.00 & 23.44 & 1.46 & 1.86 & 1.210 & $69-965$ \\
\hline 1.24 & 0.01 & 0.02 & 0.00 & 0.14 & 18.00 & 23.45 & 1.87 & 2.23 & 1.457 & $74-970$ \\
\hline 1.24 & 0.01 & 0.02 & 0.01 & 0.14 & 18.00 & 23.42 & 2.51 & 2.88 & 1.854 & $79-975$ \\
\hline 1.22 & 0.01 & 0.02 & 0.01 & 0.13 & 18.00 & 23.25 & 3.09 & 3.44 & 2.008 & $84-980$ \\
\hline 1.26 & 0.01 & 0.03 & 0.01 & 0.12 & 19.00 & 23.04 & 4.08 & 4.27 & 2.165 & $89-985$ \\
\hline 1.24 & 0.01 & 0.03 & 0.00 & 0.11 & 19.00 & 22.99 & 4.92 & 4.94 & 2.047 & $94-990$ \\
\hline 1.10 & 0.02 & 0.04 & 0.00 & 0.13 & 20.00 & 24.05 & 5.34 & 5.36 & 1.038 & $99-995$ \\
\hline
\end{tabular}




\begin{tabular}{|c|c|c|c|c|c|c|c|c|}
\hline نسبة & \multicolumn{2}{|c|}{ الأصول عذد الزواج } & \multicolumn{2}{|c|}{ السن عند الزواج } & \multicolumn{2}{|c|}{ سذوات الدراسة } & \multirow{2}{*}{ الزيجات } & \\
\hline $\begin{array}{c}\text { كنس } \\
\text { sex } \\
\text { ratio }\end{array}$ & الزوجة & الزوج الزوج & الزوجة & الزوج & الزوجة & الزوج ل & & \\
\hline & & & & & & & & جو اتيمالا \\
\hline 1.14 & 700.50 & 16.075 .40 & 20.00 & -- & 1.00 & -- & 2 & $49-945$ \\
\hline 1.14 & 773.91 & 167.79 & 22.00 & 18.00 & 0.00 & 4.00 & 3 & $54-950$ \\
\hline 1.07 & 0.00 & 0.00 & 16.00 & 24.00 & 7.00 & 3.00 & 1 & $59-955$ \\
\hline 1.13 & 375.75 & 374.50 & 17.75 & 21.33 & 7.00 & 5.33 & 4 & $64-960$ \\
\hline 1.20 & 932.53 & 306.25 & 18.00 & 20.50 & 2.00 & 1.50 & 7 & $69-965$ \\
\hline 1.25 & 141.61 & 900.50 & 19.83 & 26.33 & 3.00 & 5.53 & 18 & $74-970$ \\
\hline 1.17 & 204.96 & 1.818 .03 & 19.58 & 22.34 & 4.00 & 5.75 & 55 & $79-975$ \\
\hline 1.22 & 525.46 & 5.224 .25 & 19.73 & 22.90 & 4.00 & 6.09 & 117 & $84-980$ \\
\hline 1.21 & 469.78 & 3.876 .46 & 20.61 & 23.45 & 6.00 & 6.83 & 224 & $89-985$ \\
\hline 1.23 & 728.64 & 5.476 .17 & 20.53 & 23.24 & 6.00 & 7.13 & 424 & $94-990$ \\
\hline 1.21 & 1.236 .61 & 6.288 .56 & 21.10 & 23.35 & 6.00 & 7.60 & 435 & $99-995$ \\
\hline
\end{tabular}


أجري المسح في 47 قرية تنتمي إلى ثلاثة مو اقع في ريف بنجلاديش، ونم اختيار كل منها كجزء من تقيييم لتأثير

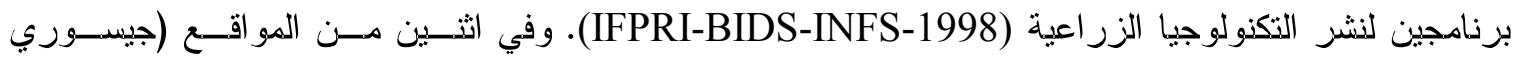
Jessore

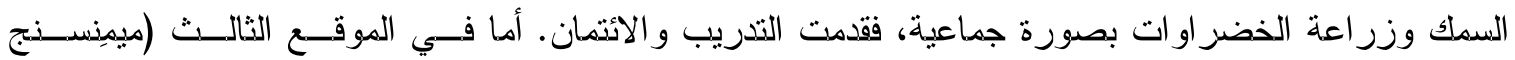

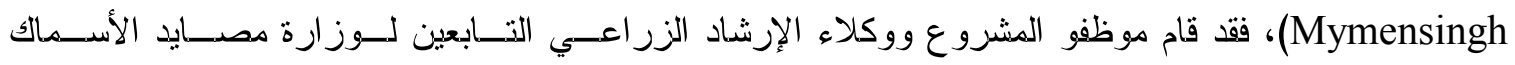
Department of Fisheries extension agents

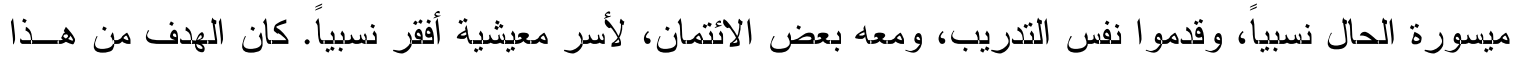

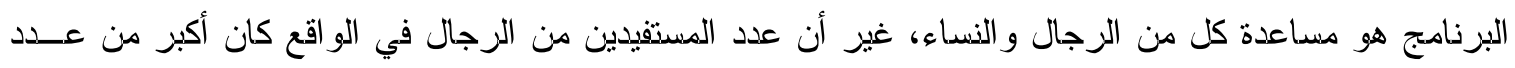

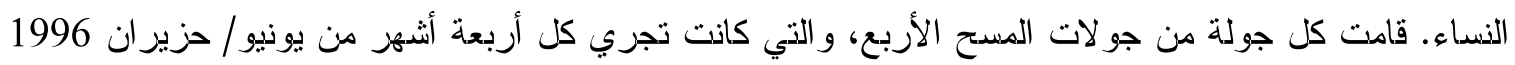

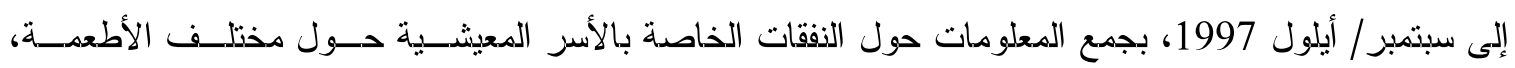

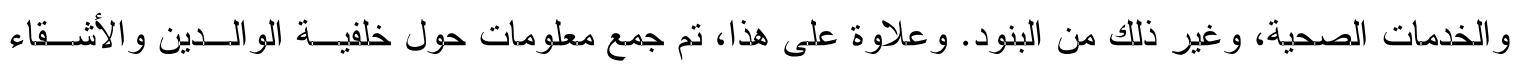

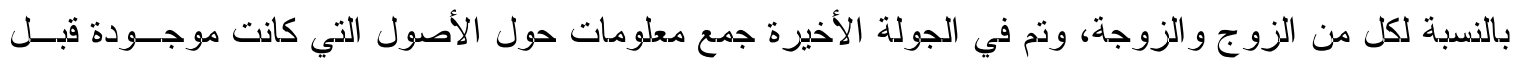

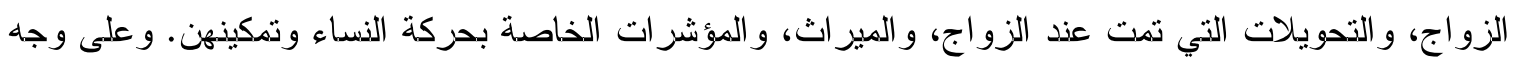

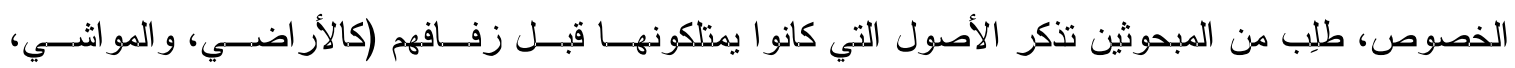

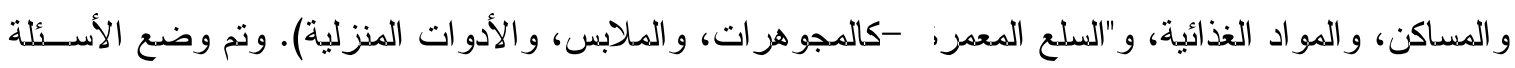

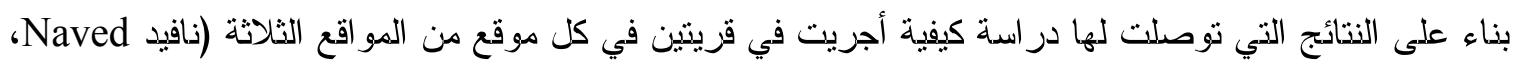

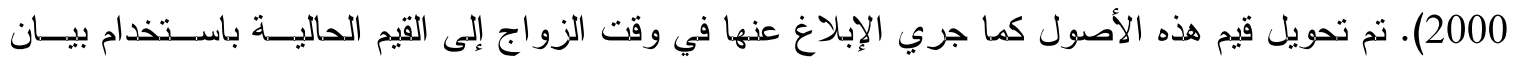
الأسعار الوطني الخاص بالمستهلك.

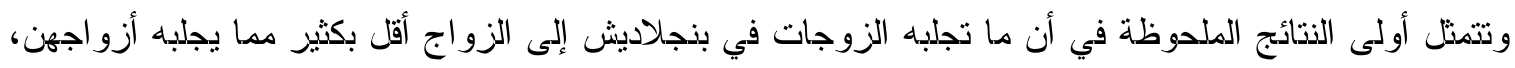

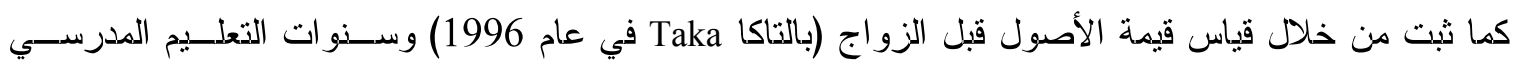

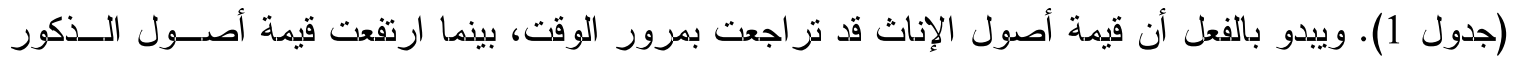

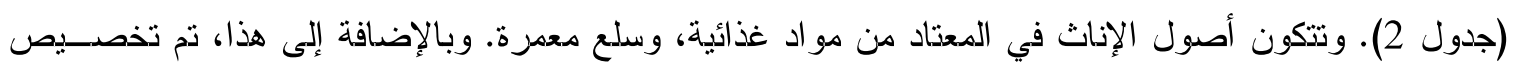

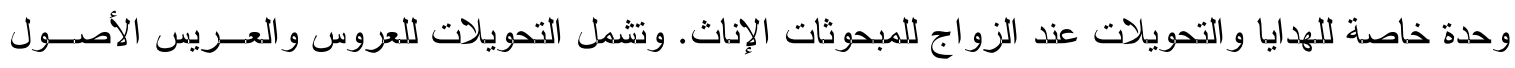

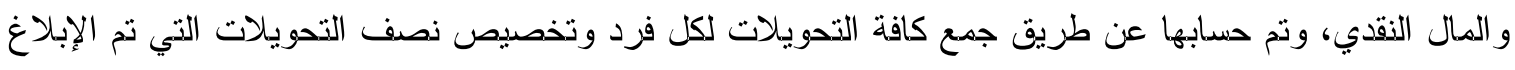

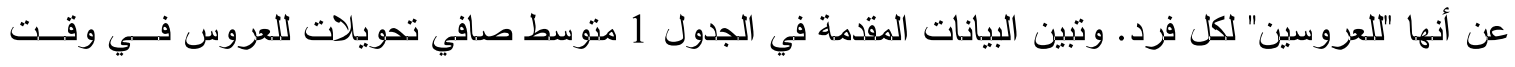

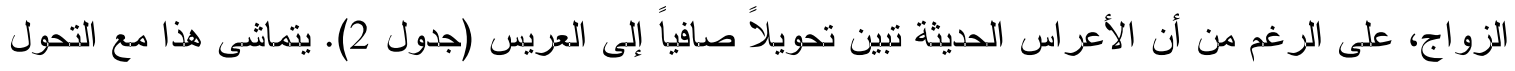

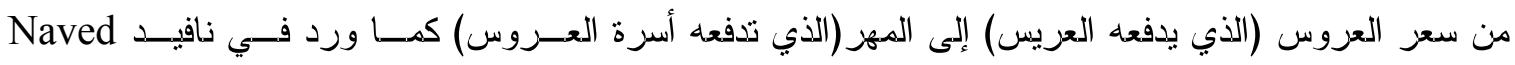

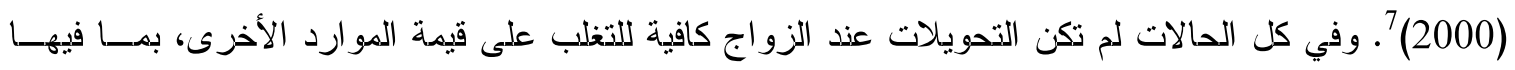

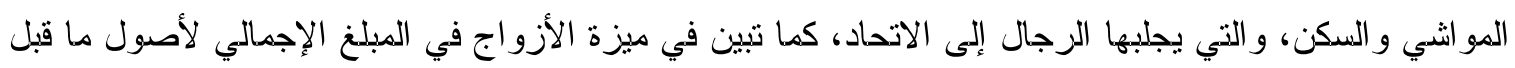

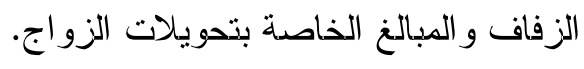


وتعد النساء البنجلاديشيات هي الأصغر سناً عذد الزواج بين الدراسات الست (جدول 1)، على الرغم من أن السن

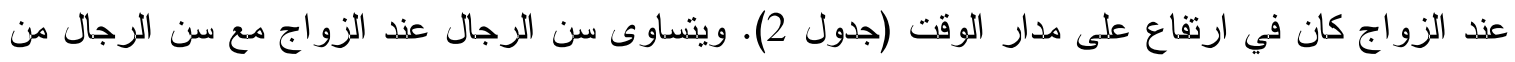

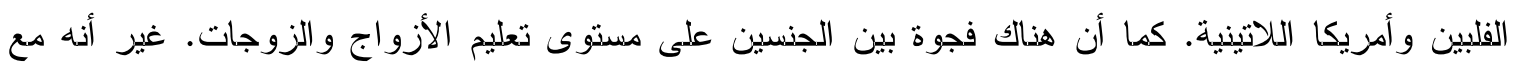
وضع برنامج "الطعام مقابل التعليم" أو "Food For Education" وغيره من البرامج التي توفر الدئين الدعم لتعليم

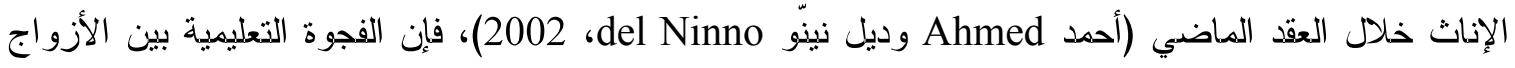

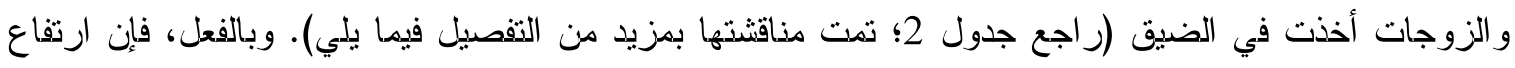

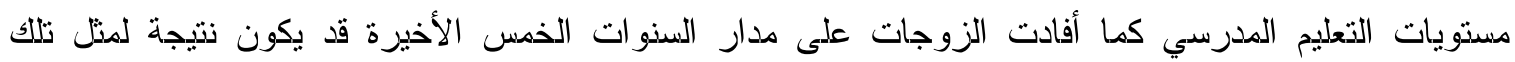
البرامج التي تزبط بين تلقي الطعام وغير ذلك من سبل المساعدة بحضور فصول المدرسة الثانوية.

الفلبين. على عكس بنجلاديش، البلد الأسيوي الآخر في عينتا، تتسم الفلبين بذظام القرابة الثنائي و أنمـاط الإرث

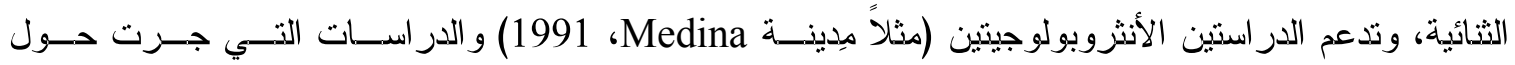

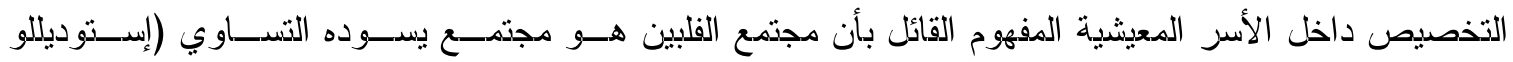

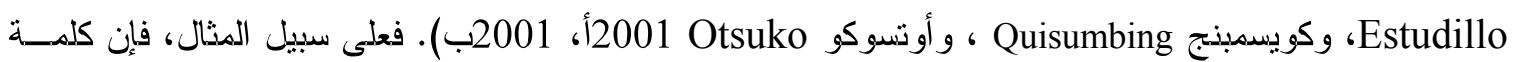

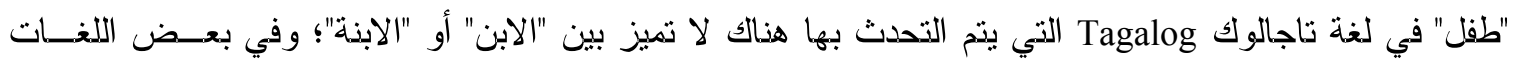

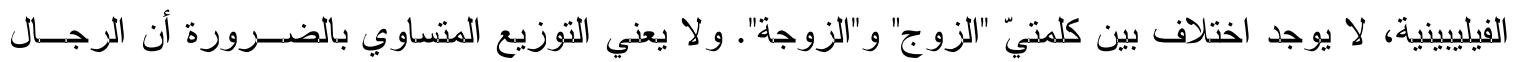

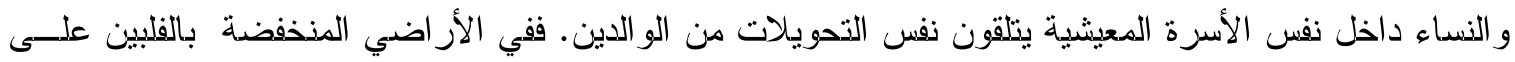

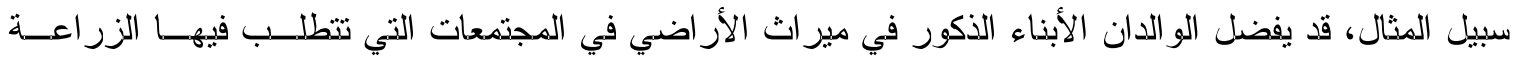

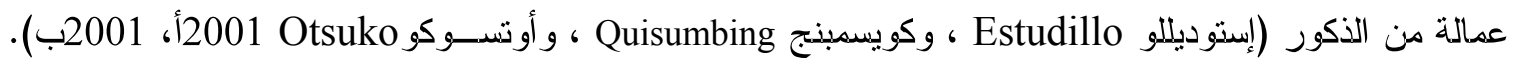

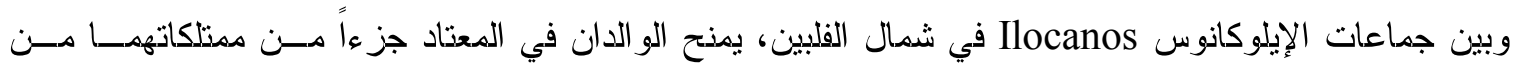

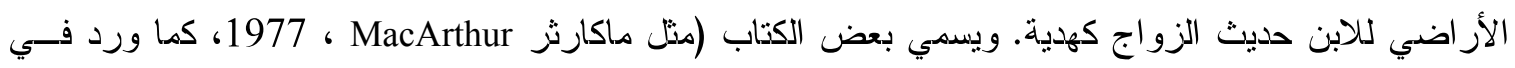

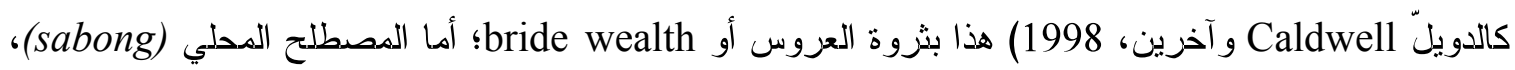

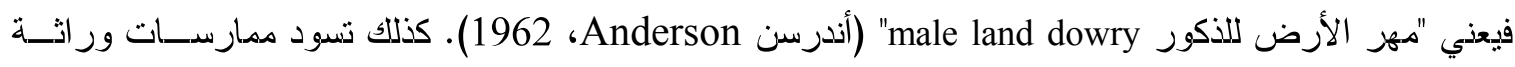

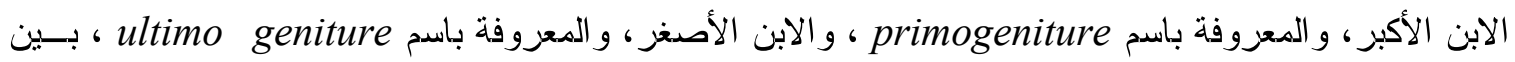
جماعات الإيلوكانوس Ilocanos ، اعتماداً على تو افر الأرض. و السائد بين قبائل الإيلونجوس Ilonggos الإند الإندمين

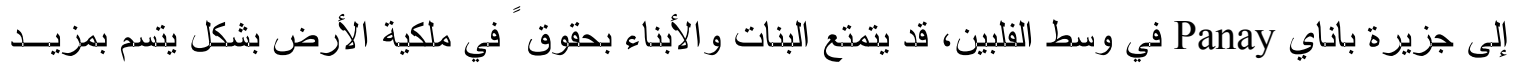

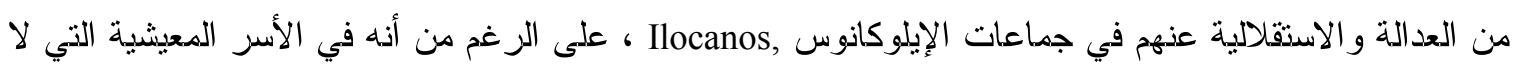

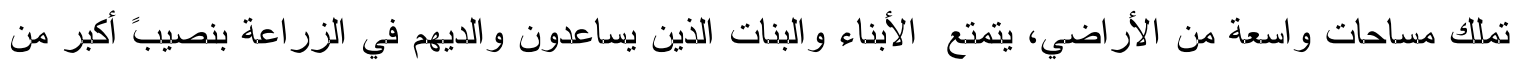

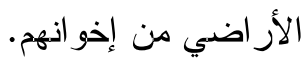

وتتم هو ازنة تفضيل الذكور على مستوى ميراث الأرض من خلال زيادة التحصيل الدراسي للإناث، على الأقــل

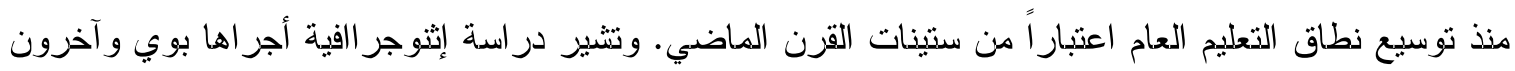
Bouis et al. 
للطفل. فو فقاً لهذه الدر اسة، يستثمز الآباء والأمهات الفلبينيون في تعليم الفتيات لأنهن "أكثز اجتهاداً في الدراسـة"،

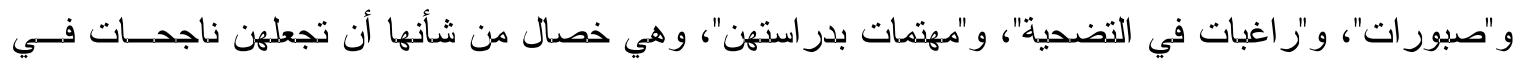

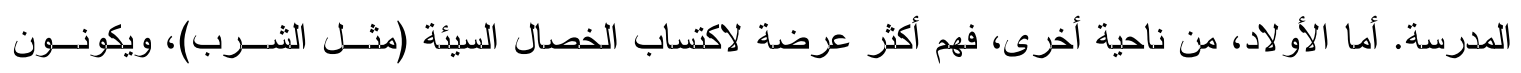

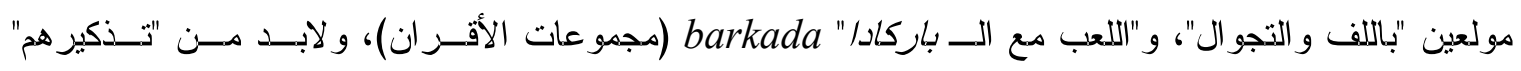
و "توبيخهم" للقيام بأعمالهم المدرسية.

وتأتي البيانات المستخدمة في تحليلنا من مسح استعادى retrospective survey لــ 344 أسرة معيشية في خمسس

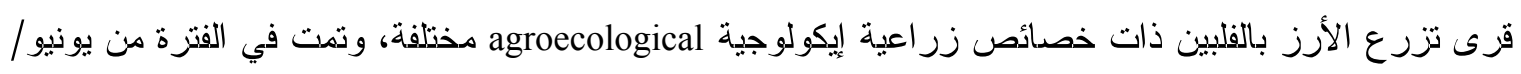

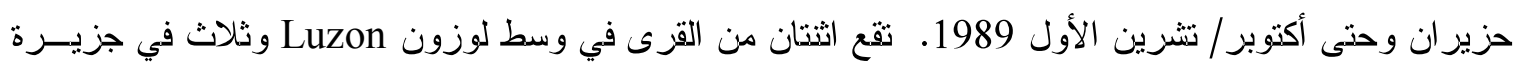

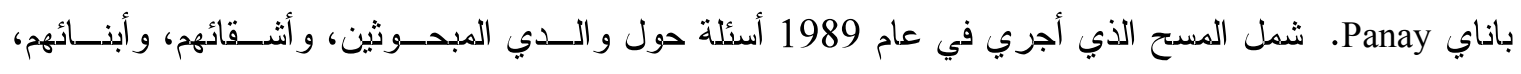
وحصلت على دعلومات حول ثلاثة أجيال، هي أجيال الأجداد، و الو الدين (المبحوثين و الأثقاء)، والأبناء/ الأحفاد.

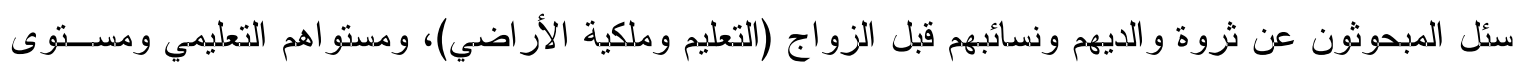

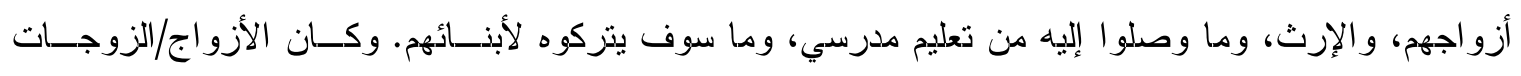

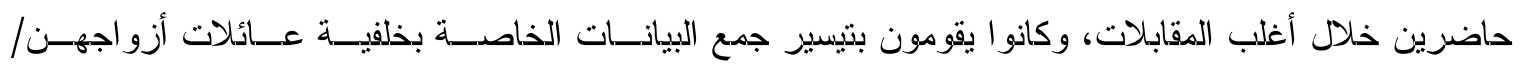

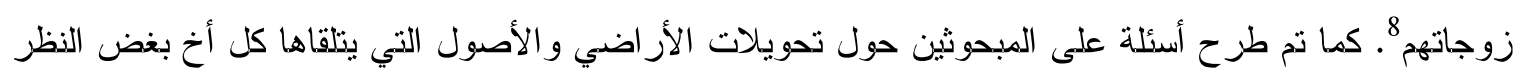

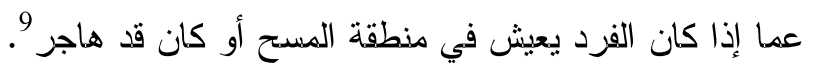

ودقارنةً ببذجلاديش، فإن النساء في الفلبين نتزوجن في سن أكثر تأخراً (جدول 1) على الرغم هن أذه في هذه

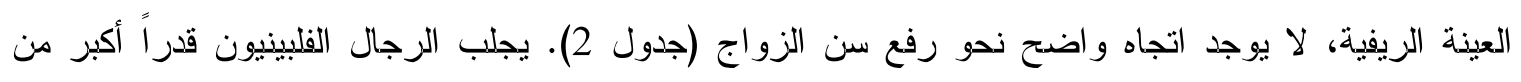
الأراضي و الأصول إلى الزيجات، غير أنه لا توجد فجوة تعليمية بين الجنسين بين هذه المجموعة من المبحوثين.

أثيوبيا. تتسم إثيوبيا بتتوع عزقى وديني ضخم؛ فتضدم البلاد أكثر من 85 جماعة عرقية تمثَّل فيها أغلب الأديسان

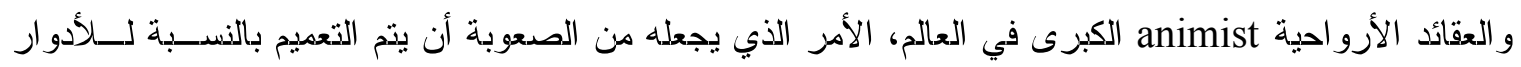

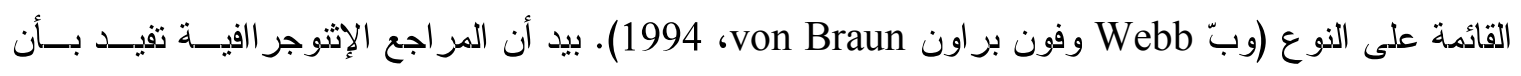

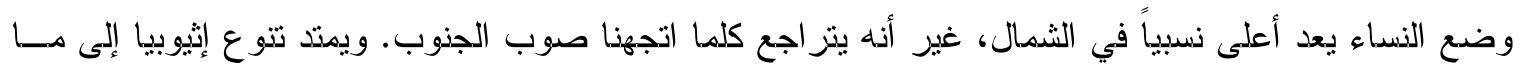

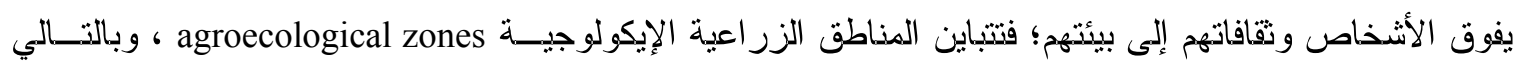

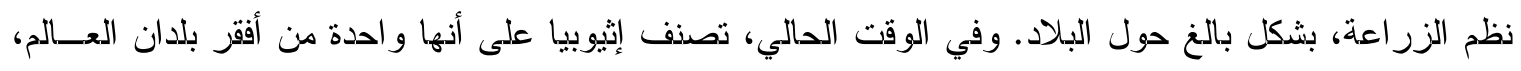

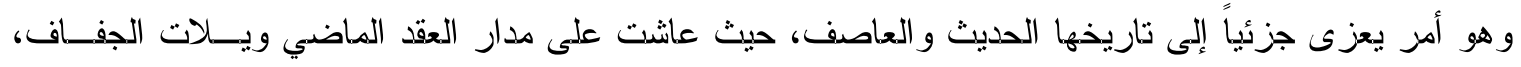
و المجاعات، و الحرب الأهلية، و انحسار الحكومة العسكرية.

لقد قام المسح الإثيوبي للأسر المعيشية الريفية (ERHS) بإجز اء مقابلات مع حو الي 1.500 أسرة معيشية في 15

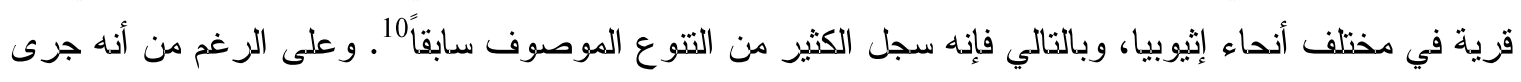


انتقاء الأسر المعيشية العينات داخل القرى بشكل عشو ائي، فإن اختيار القزى أنفسها كان يهدف لضمان أن يمذـلـل

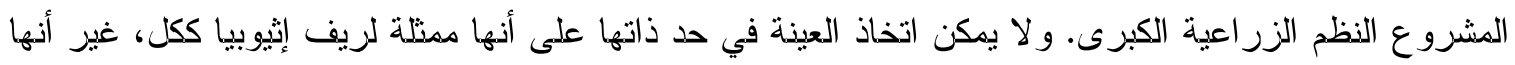

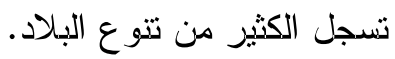

قام المسح بجمع عينات من الأفراد المتزوجين أو الذين سبق لهم الزواج، تتعلق بظروفهم في وقت الزواج

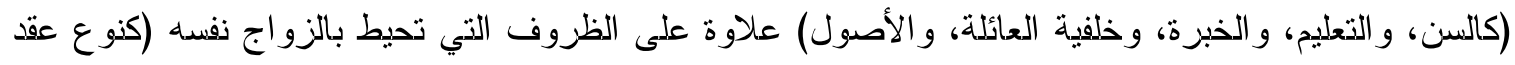

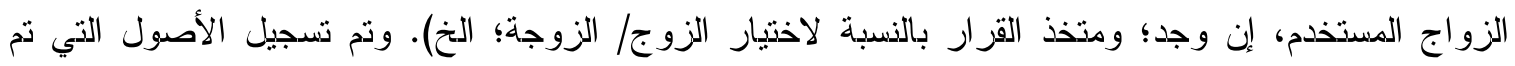

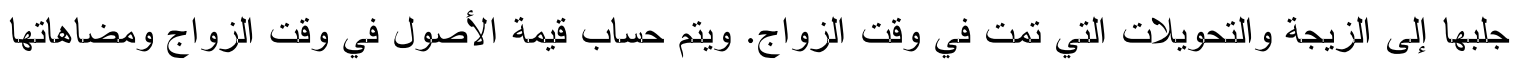

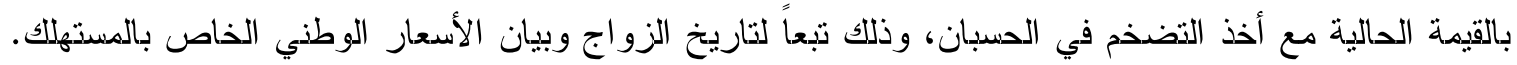

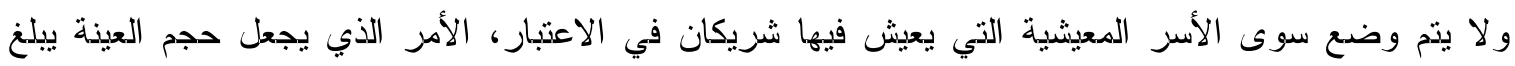

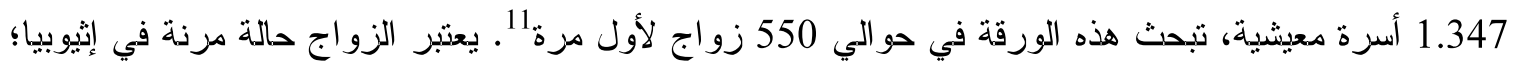
فينكرر الطلاق وينتشر الزواج المتكرر (بانكهورست Pankhurst، 1992). ويرجع تزكيزنا على الزواج الإن الأول

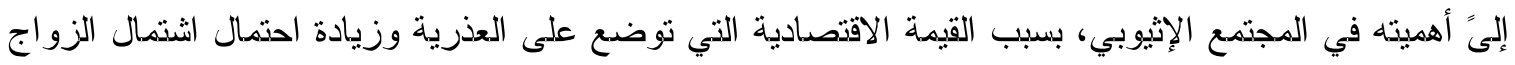

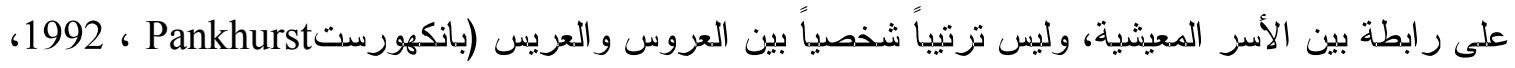

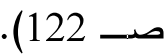

وبالنظر إلى التعقيدات الكامنة التي يشتمل عليها طول الفترة الو اجب تذكرها، واختيار عنصر التضذم بالنسبة لهذه

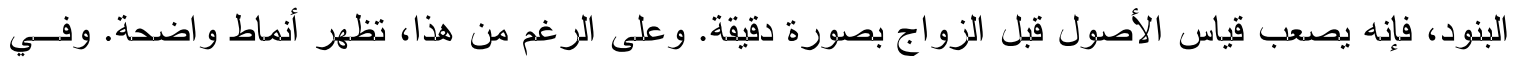

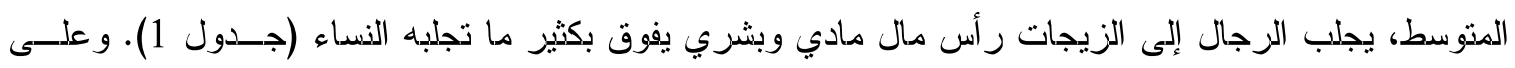

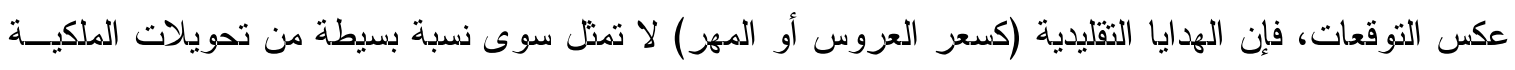

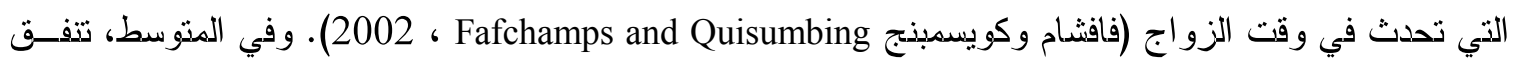

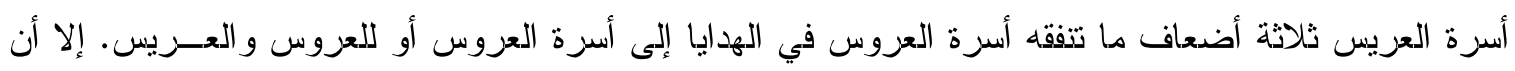

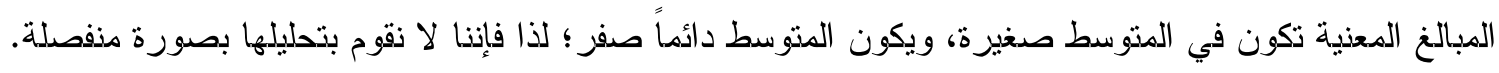

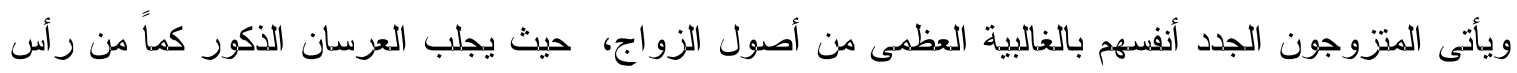

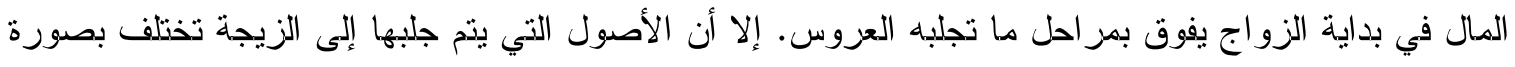

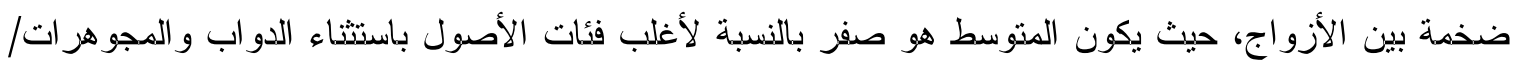

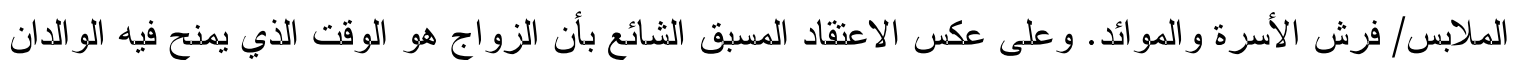

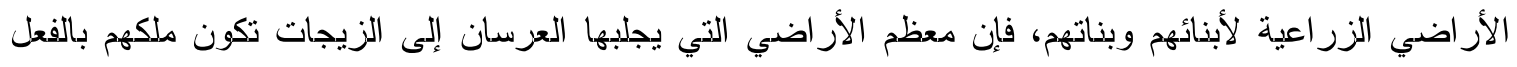

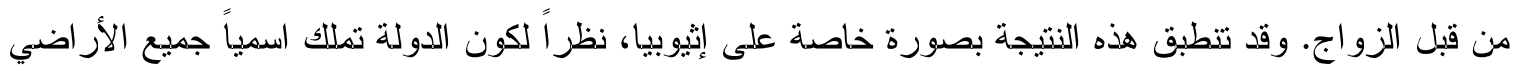

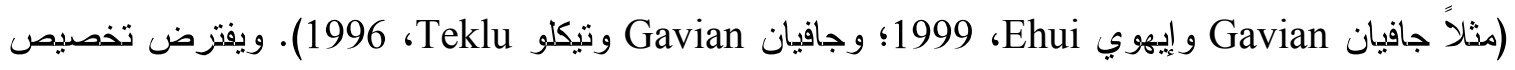
حقوق استخدام الأراضي عن طريق جمعيات المزارعين، والتي تعد الوحدات الإدارية المدلية في المناطق 
الريفية، على الرغم من أن أقاليم كثيرة بالبلاد لم تمارس نظام إعادة تخصيص الأراضي في السنوات الأخيرة.

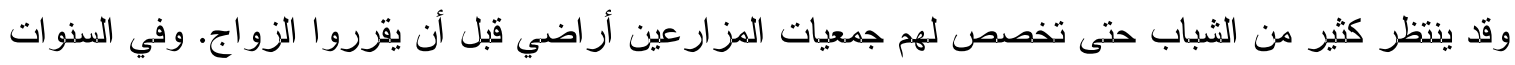

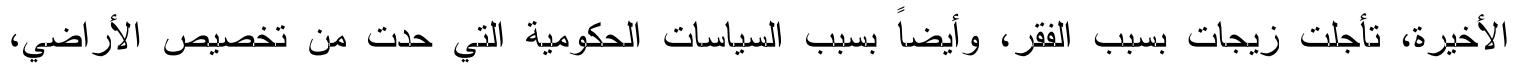

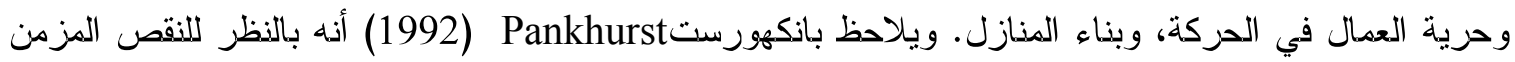

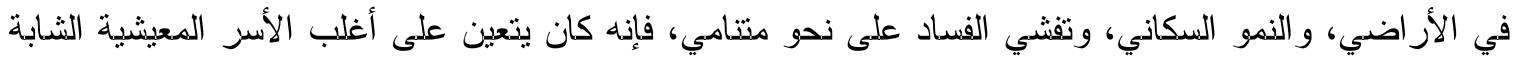

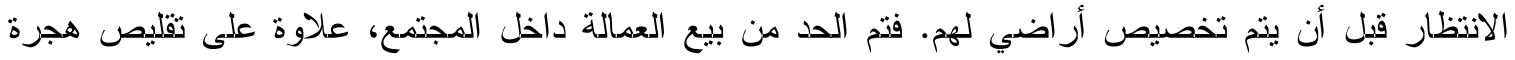

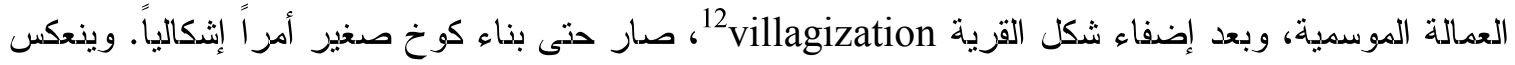

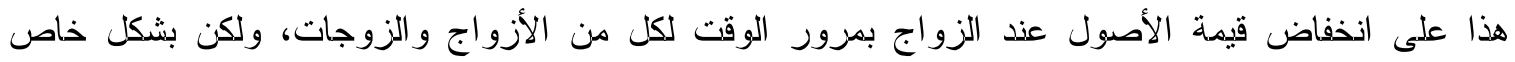

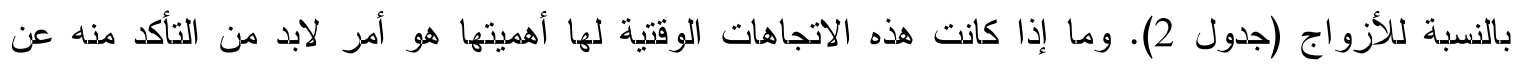

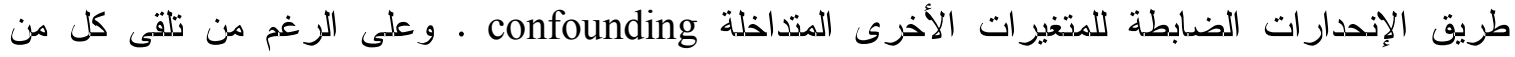

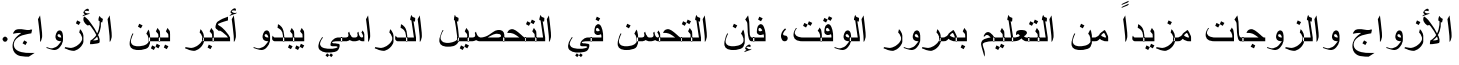

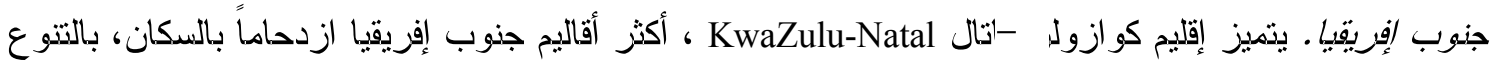

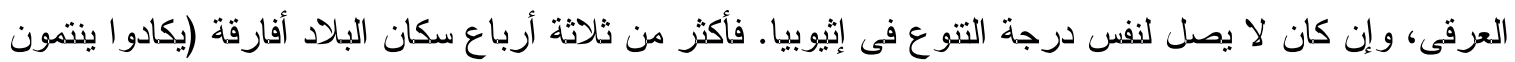

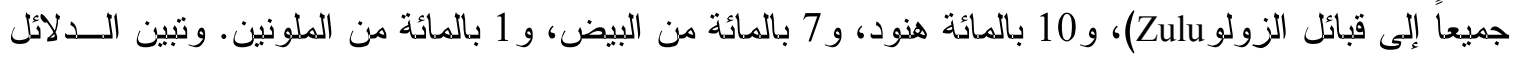

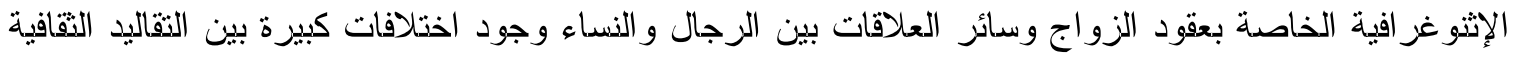

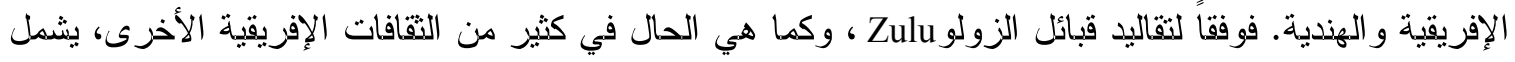

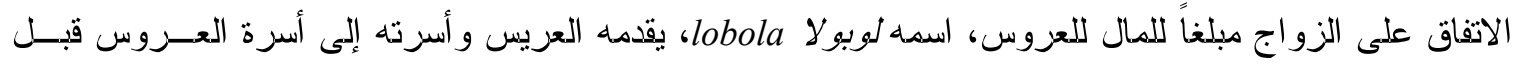

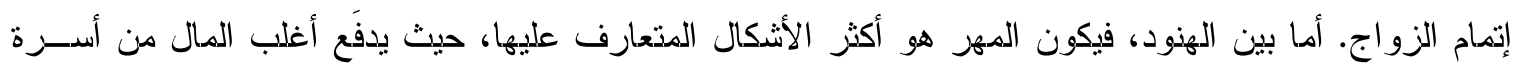

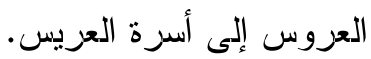

ويشمل مسح جنوب إفريقيا، و المعزوف باسم دراسة ديناميكيات الدخل في إقليم كو ازول --ل (KIDS) أفارقــة

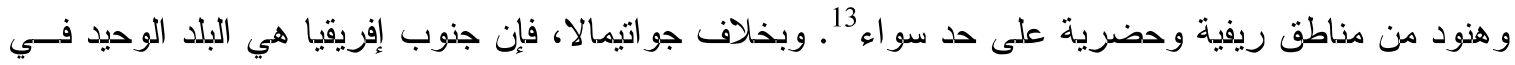

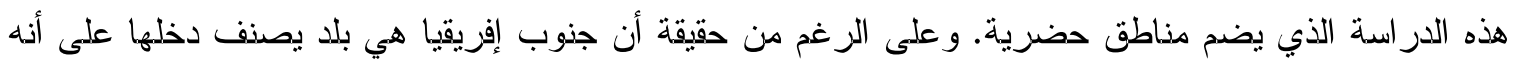

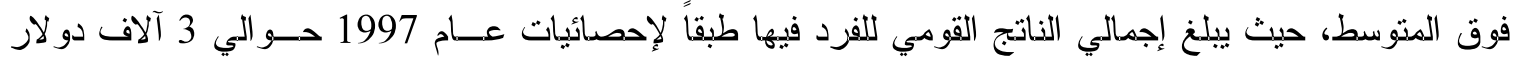
أمريكي، فإن ثروة البلاد تتوزع على ندو غير متساوٍ على الإطلاق، وتعيش غالبية السكان فـي فقــر (كسارتز

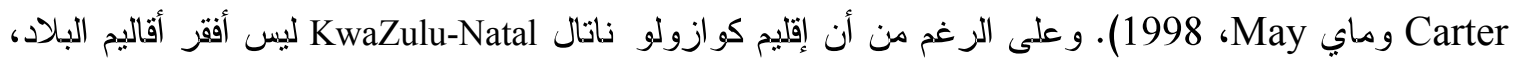

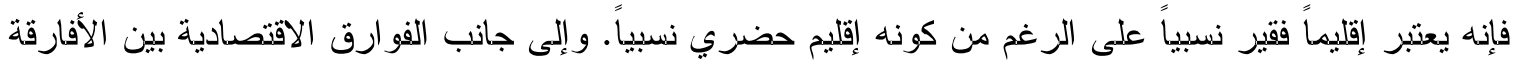

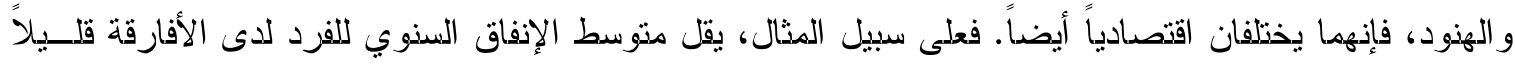

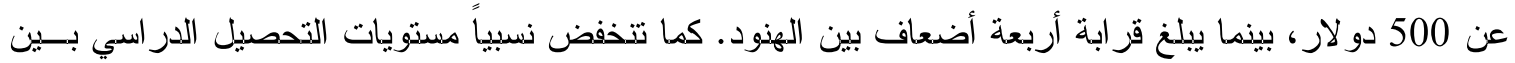
الأفارقة وسكان الريف، الأمز الذي يعكس الاختلافات التاريخية في الوصول إلى الى التعليم. 
وبالذسبة للأزو اج و الزوجات (75 بالمائة منهم كانوا من الأفارقة و 25 بالمائة من الهذود)، تم جمع معلومات حول ما إذا كان كل شريك حياة يملك مجموعة من الأصول قبل الزواج، بما فيها المو اشي، وغير ذلك مــن الــدواب، و الأر اضي، و البيوت، و المجوهرات. وتم استخدام إحصاء بسيط لعدد الأصدول التي بملكها كل شريك كبـديل

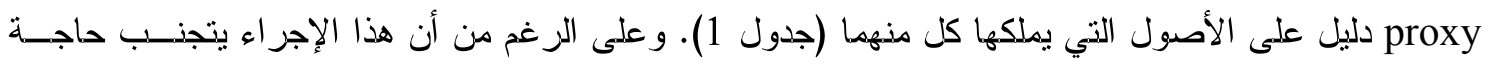

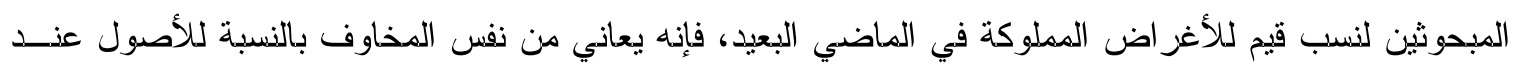
الزو اج و الموصوفة بالتفصيل فيما سبق، ألا و هي عدم دقتها. وبسبب الحساسية المرتبطة بالإفادة بملكية الأصــول بلئل

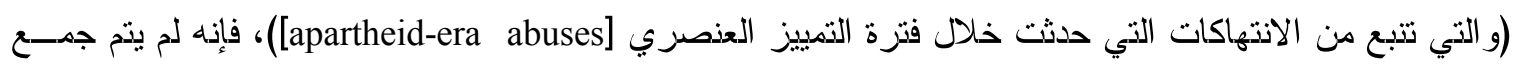

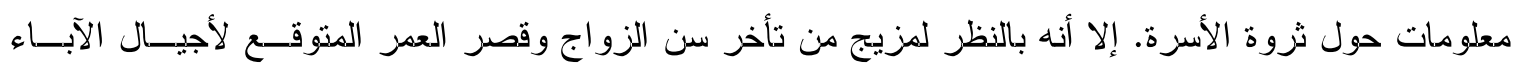

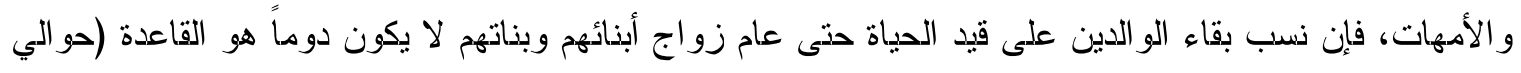
80 بالمائة من الأمهات و 65 بالمائة من الآباء يكونون على قيد الحياة في وقت زو اجن أبنائهم وبناتهم)، و عليه فإنه

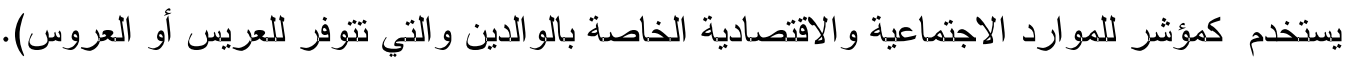

وفي جنوب إفريقيا، كما هي الحال في البلدان الأخرى الموصوفة في هذه الورقة، يجلب الرجال قدراً من الأصول

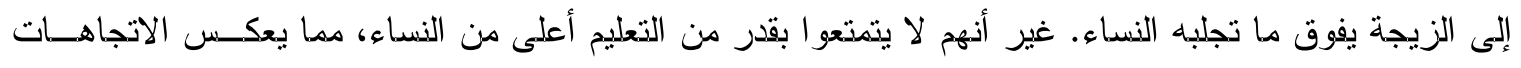
التاريخية و الحالية في المساو اة بين الجنسين في التحصيل الدراسي داخل الفئات العرقيـة التقليديـة (إحصــائيات جنوب إفريقيا، 2001؛ برنامج الأمم المتحدة الإنمائي UNDP، 2000). وقد ارتفعت مستويات التعليم لكل مـن الرجال و النساء بمزور الوقت (جدول 2). وبالمقارنة بإثيوبيا، فإن الرجال و النساء في جنوب إفريقيا يتزوجون في سن متأخرة (جدول 1)، مع ارتفاع السن عند الزواج كذلك خلال السذوات الأخيزة (جدول 2). وبسـبب هيمنـة ولية

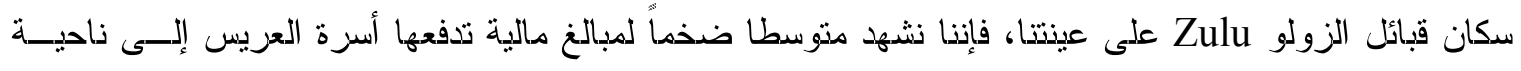
العزوس. إلا أن ما يدفع من مال عند الزواج قد انذفض بمزور الوقت من الناحيتين، مما يعكس الحداثــة التسي

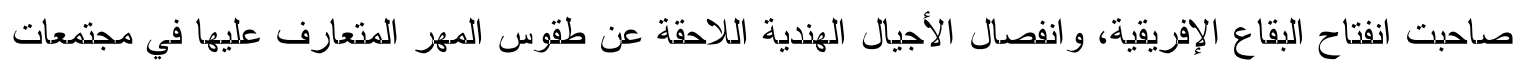
جنوب آسيا (جدول 2). و الملاحظ أن الأفارقة يقومون بتحويلات مالية عند الزواج تفوق ما يدفعه الهذود، كما أن

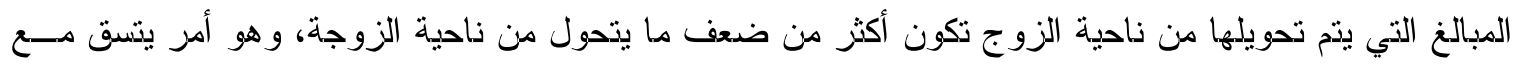

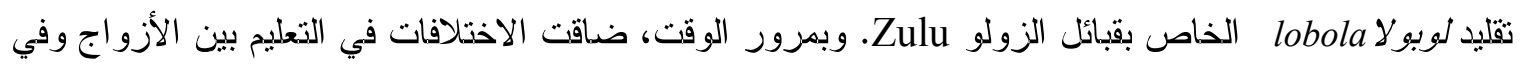

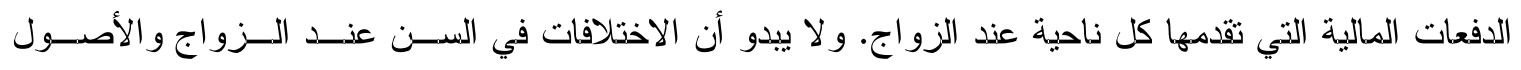
المجلوبة إلى الزيجة قد تغيرت، على الرغم من أن متوسط الاختلافات هذا ليس كبيراً من الأساس. إلا أنه بالنسبة

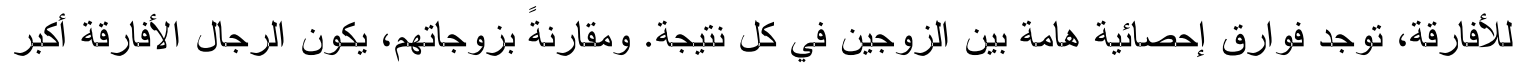

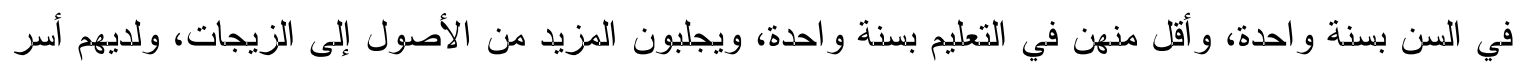
تدفع المزيد من المال عند الزواج.

المكسيك. تم جمع بيانات عن الأصول عند الزواج في ريـف المكسـيك كجـزء مـن تقيـيم نـأثير برنـامج PROGRESA 
دي لا بريار وكويسمبنج de la Brière and Quisumbing ، 2000). فقامت فرق كل من المعهد الدولي لبحـوث سياسات الغذاء (IFPRI) وبرنامج PROGRESA على ندو مشترك بتصميح وحدة لجمع المعلومات عن خلفيـة

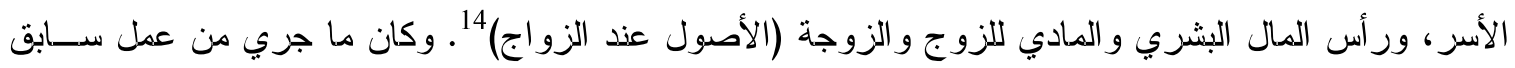
حول أنماط الزواج في ميزوامزيكا Mesoamerica (مثل روبيشو Robicheaux، 1997) له أهميته البالغة في هوني تصميم هذه الوحدة، و التي أديرت في البداية عن طريق مجموعة من الـ بروموتور/س promotoras (مذظمين

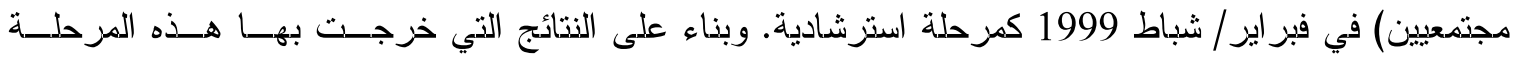
الاسترشادية و المناقثات الإضافية التي جرت مع طاقم موظفي PROGRESA، تم وضع وحدة وحدة حــول خلفيـة الأسرة كجزء من جولة المسوح التقييمية التي جرت في يونيو / حزيران ويوليو/ تموز 199915

طلبت الوحدة الخاصة بخلفية الأسرة و الأصبول عند الزو اج من الزوجات الإفادة بما إذا كنّ وأزو اجهن يمنلكـون

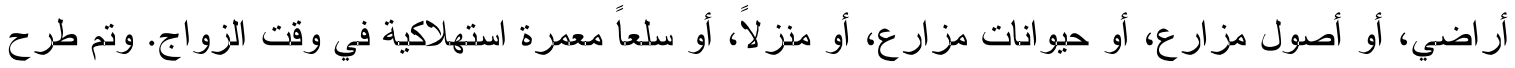

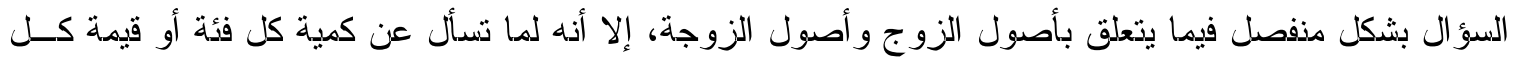
أصل من الأصدول. وقد قمنا بإتباع تعديل لإجز اء استخدمه موريس وآخزون . Morris et al (1999) للوصول إلى

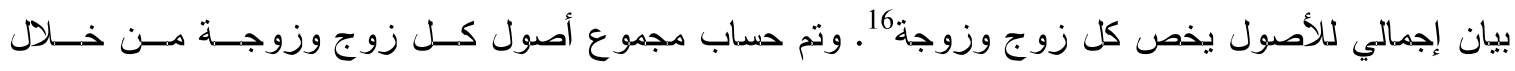

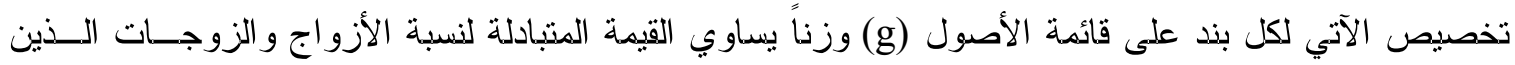
أفادوا بامتلاكهم للبند المذكور في وقت الزواج (Wg)، مع ضرب ذللك الوزن في المؤشر (صـفر أو واحسد) لأن الزوج الآخر امتلك ذلك الأصل المحدد (fg g و ، والخروج بإجمالي للمنتج على جميع الأصول المحتملة

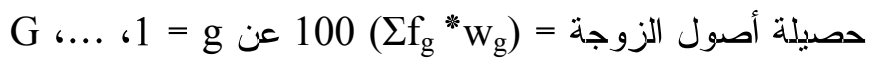

ويقوم اختيار نظام الوزن weighting system على الافتز اض بأن احتمال اقتناء الأسر المعيشية لبند دعين يقـل كلما ارتفعت قيمته الذقدية. ويجد موريس وآخرون . Morris et al (1999) أن السجل الخاص بمجموع الأصــول يرتبط في علاقة مثبادلة وثيقة بسجل قيمة أصول الأسرة المعيشية (و الذي يتم حسابه عن طريق جمع القيمة المبلغ

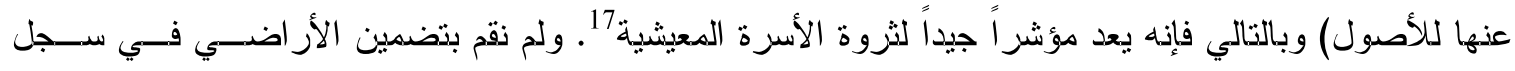

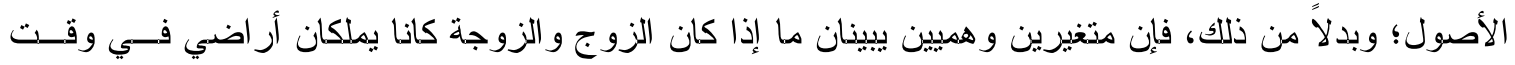
الزو اج.

يدخل الأزواج إلى الزيجات ومعهم رأس مال مادي يفوق رأس مال زوجاتهم: فكان مجموع أصول الأزواج يفوق

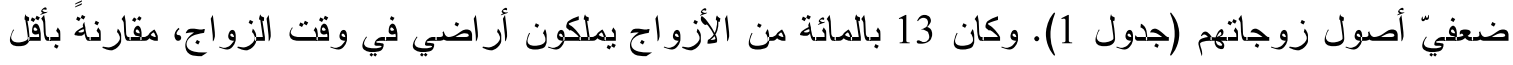

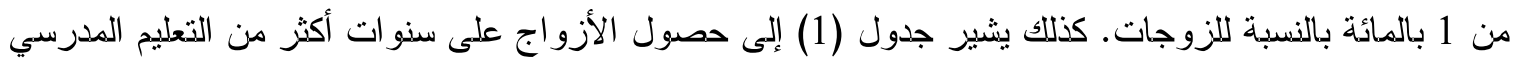

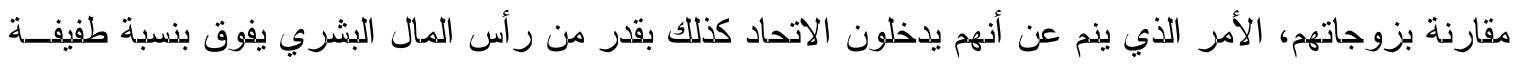

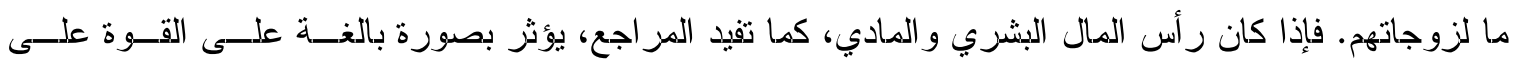


المساومة bargaining power داخل الزواج، فإن الأزواج في ريف المكسيك يمارسون المزيد من القـوة داخـلـ

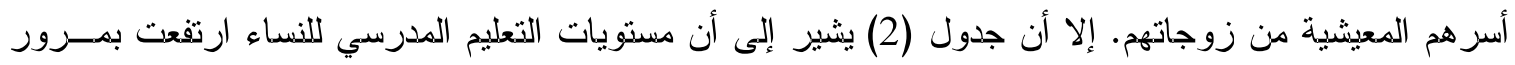

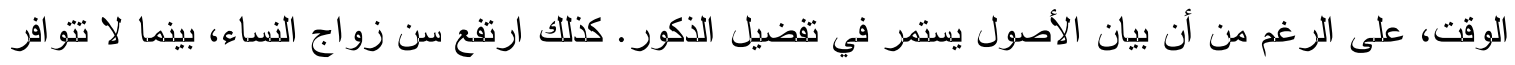

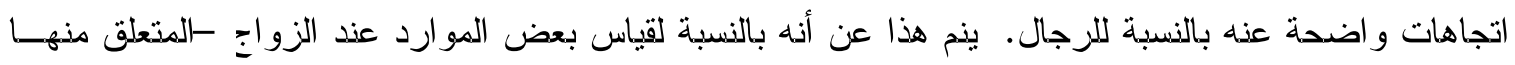

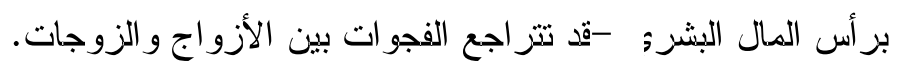

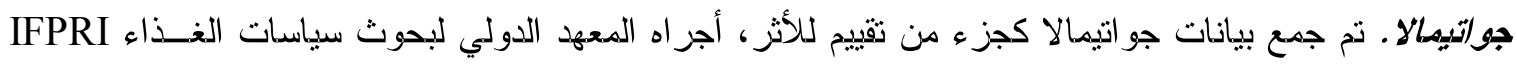

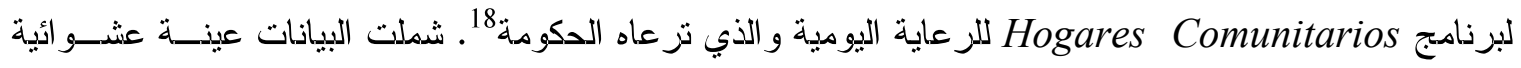

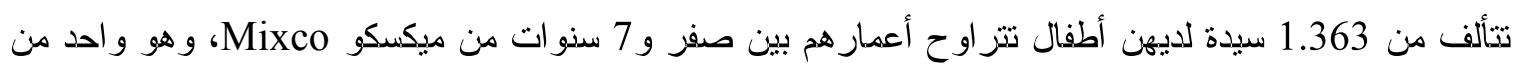

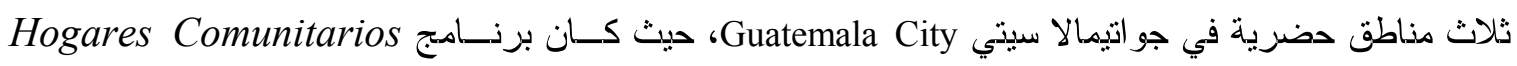
بعمل منذ عام 1999.

قام المسح الخاص بالأسر المعيشية بجمع بيانات حول الذصائص الديموجر الفية و الاقتصادية الاجتماعية للأســر

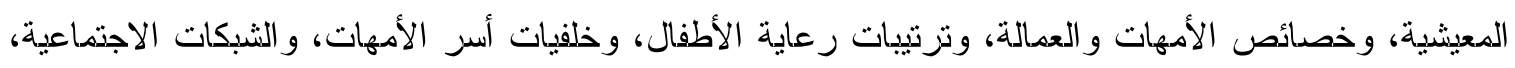

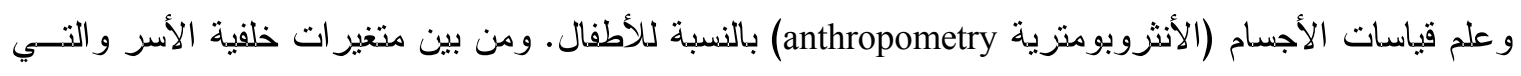

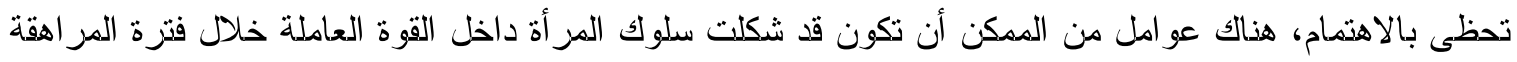

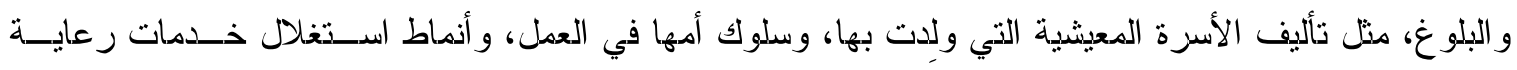

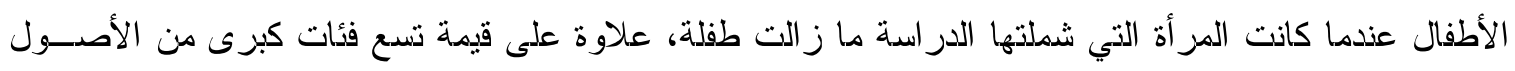

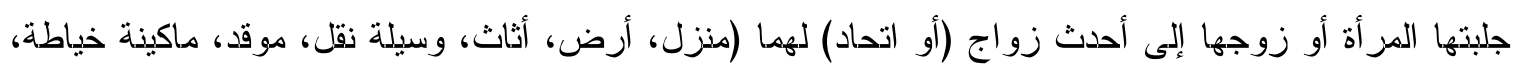
فرش أسرة ومو ائد، مدخرات، وخلافه).

ونظراً لأن الغرض من الدراسة الأصلية كان تثييم المنافع التي حصل عليهـا الأبنـاء و أمهـاتهم مـن برنسامج Hogares Comunitarios

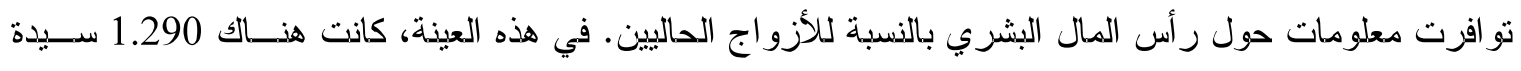

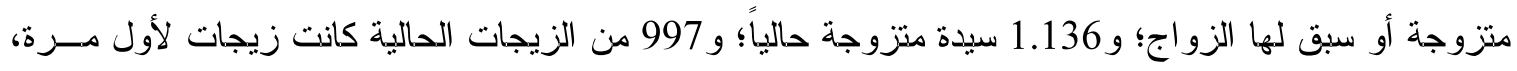
منها 976 زوجة كن قادرات على توفيز معلومات خلفية كاملة عن أنفسين.

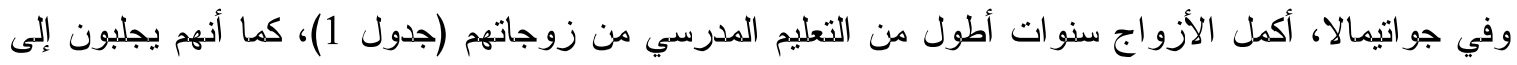

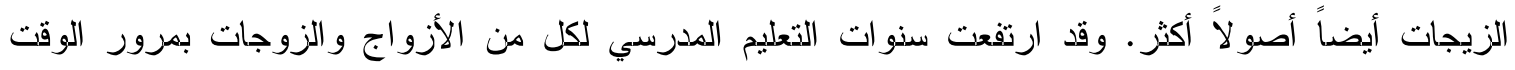

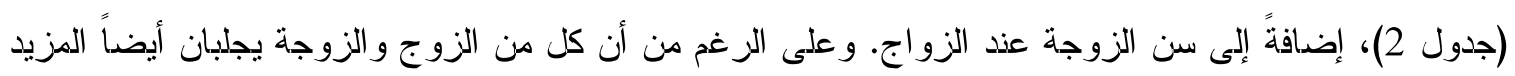

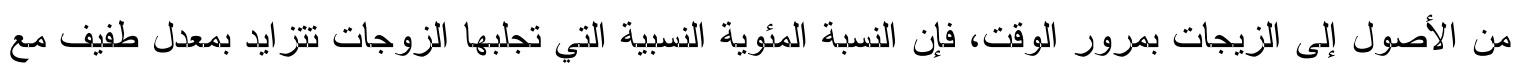


Trends in assortative matching through time تجاهات في المطابقة الاتثقائية عبر الوقت

من بين طرق تشخيص عملية الزواج، يمكن اختبار المعايير التي تتم على أساسها دطابقة الأزواج و الزوجات. هل

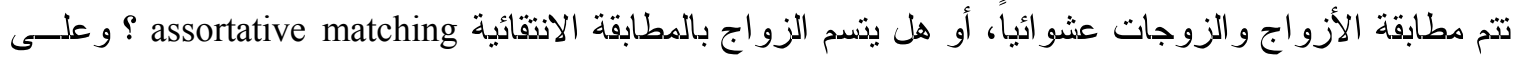

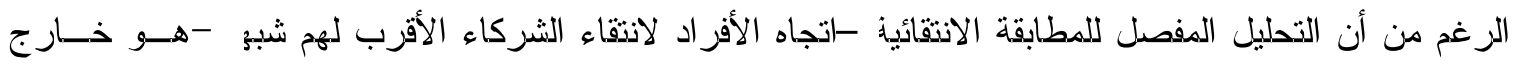
نطاق هذه الورقة (راجع فافثام وكويسمبنج Fafchamps and Quisumbing ، 2003ب)، فإنه بإمكانذـا اختبـار

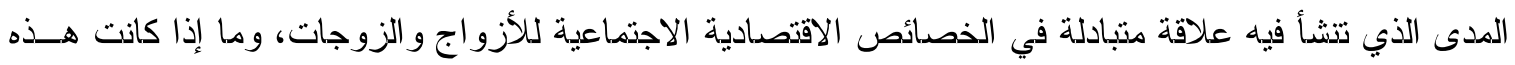
العلاقة المتبادلة تغيرت بمزور الوقت. فنقوم بفحص الأنماط في العلاقة المتبادلة بـين الخصـائص الثخصدسية

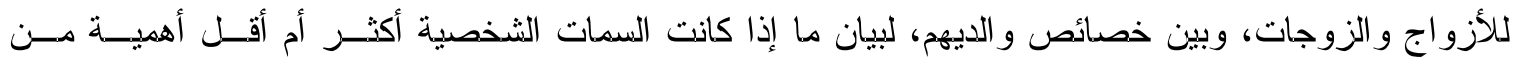
الخصائص العائلية في اختيار الثخص لشريك حياته، وما إذا كانت أهمية الخصائص الثخصية مقابل خصـائص الو الدين قد تغيرت بمزور الوقت.

يعرض جدول (3) معاملات علاقة تر ابطية بسيطة بين الخصائص الثخصية وخصائص و الدي الزوج و الزوجسة على مدار فتزات مدتها خمس سذوات تتماثىى مع سذة الزواج بالنسبة لجميع البلدان التي شملتها الدر اسة. ولتجنب

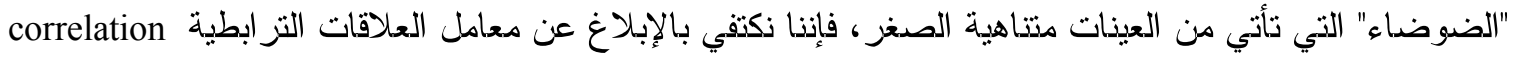

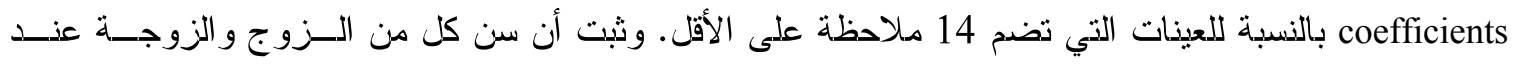

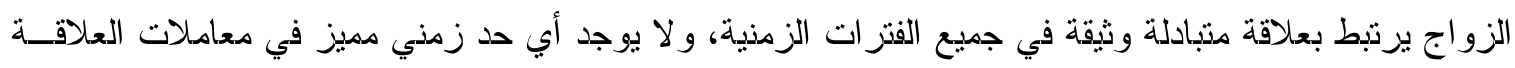

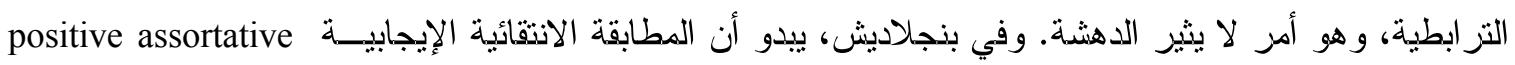

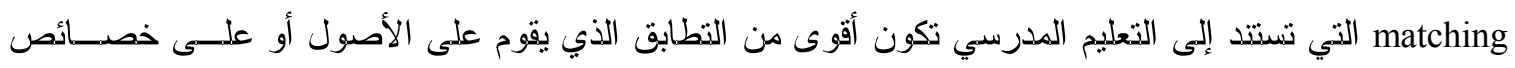
الو الدين. ويكون التطابق الذي يعتمد على المبالغ المالية التي يتم تحويلها عذد الزواج أكبر من التطابق الذي يقوم

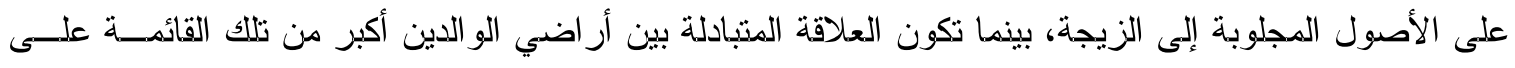

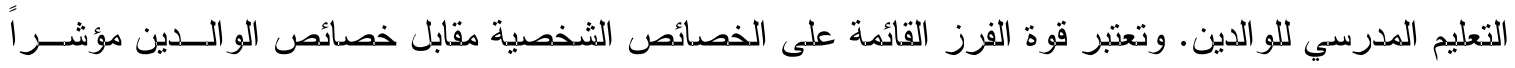

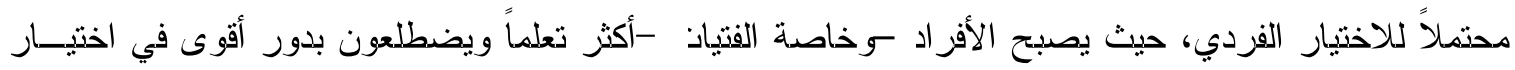

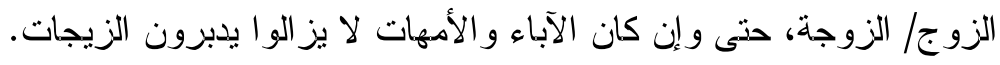

وفي الفلبين، تتجلى المطابقة الانتقائية الإيجابية positive assortative matching في الأصول (بخلاف الأراضي)

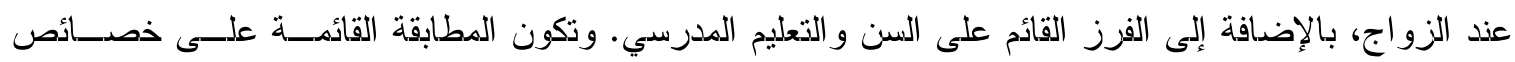

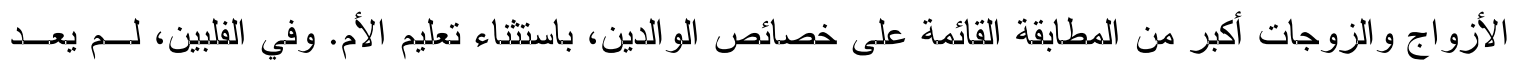

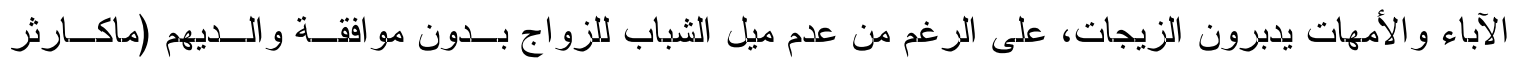

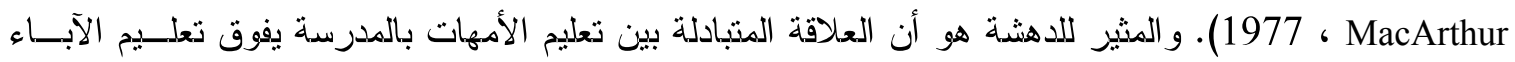
بالمدرسة، وحتى أر اضي الو الدين، الأمر الذي قد يشير إلى أهمية الدور الذي تلعبه الأمهات في اختيـار شـريك 
الحياة في المستقبل أو المو افقة عليه. ومن بين السمات الجديرة بالانتباه، هناك انخفاض العلاقة التزابطية بين مـا

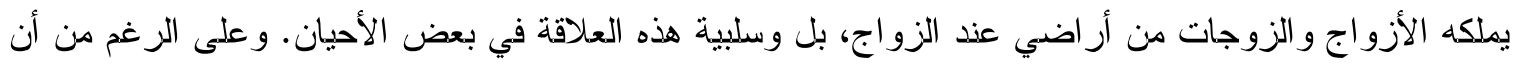

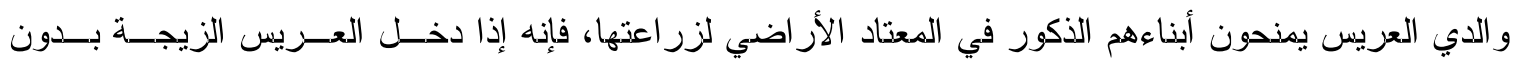

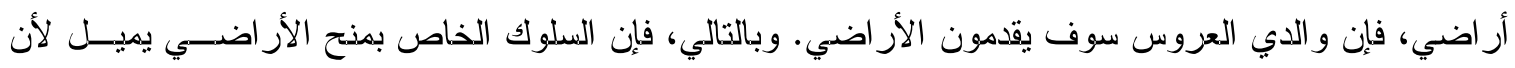

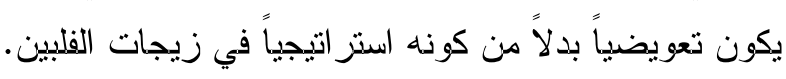

وفي إثيوبيا، تكون أكبر العلاقات التزابطية بين سن الزوجين عند الزواج، تليها سذوات التعليم المدرسي. ويتجلى

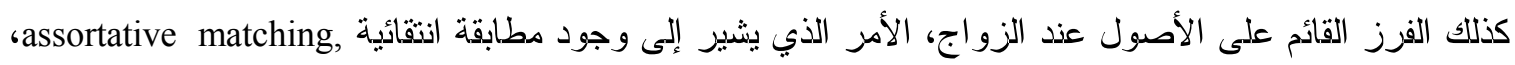

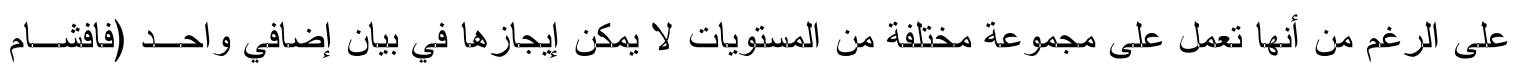
وكويسمبنج Fafchamps and Quisumbing ، 2003ب). وفي جنوب إفريقيا، نتمثل أقوى العلاقات المتبادلة فـي

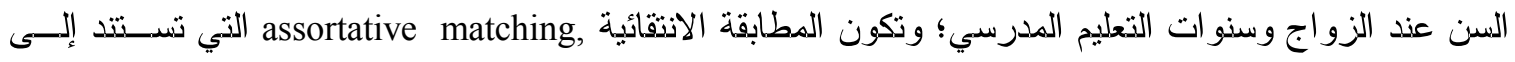

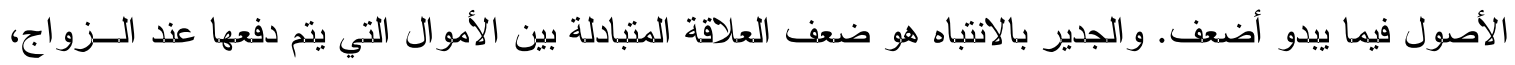

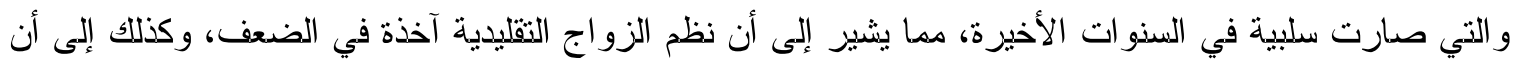

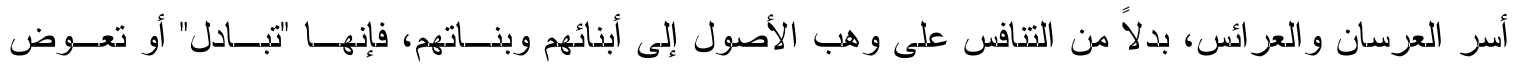
التحويلات من كل جانب. 
جدول (3) اتجاهات في المطابقة الانثقائية , assortative matching عذد الزواج، على أساس فترات زمنية للزواج، طول كل مذها خمس سنوات (معامل العلاقة

التزابطية correlation coefficients بين الزورج و الزورجة

\begin{tabular}{|c|c|c|c|c|c|c|c|c|c|c|}
\hline أراضي & تعليم الأم & تعليم الأب & عند الزويلاج & الأصول عند & الأصول + التحويلات & الأراضي عند & سذوات & الزن الزواج & عدد الزيجات & \\
\hline & & & & & & & & & & بنجلاديش \\
\hline$-\quad .02$ & - & - & - & - & - & - & 0.78 & 0.69 & 16 & $49-945$ \\
\hline 0.71 & $-\quad .06$ & $-\quad .02$ & 0.45 & 0.09 & 0.32 & - & 0.57 & 0.49 & 34 & $54-950$ \\
\hline 0.58 & 0.09 & 0.30 & 0.07 & 0.03 & 0.34 & - & 0.80 & 0.71 & 50 & $59-955$ \\
\hline 0.00 & 0.10 & 0.01 & 0.52 & 0.05 & $-\quad .03$ & - & 0.62 & 0.27 & 62 & $64-960$ \\
\hline 0.33 & 0.18 & 0.14 & 0.22 & $-\quad .08$ & $-\quad .12$ & - & 0.72 & 0.58 & 95 & $69-965$ \\
\hline 0.36 & 0.18 & 0.30 & 0.28 & 0.01 & 0.08 & - & 0.68 & 0.58 & 121 & $74-970$ \\
\hline 0.47 & 0.25 & 0.13 & 0.43 & $-\quad .02$ & 0.00 & - & 0.68 & 0.56 & 122 & $79-975$ \\
\hline 0.35 & $-\quad .03$ & 0.17 & 0.47 & $-\quad .04$ & 0.03 & - & 0.54 & 0.63 & 144 & $84-980$ \\
\hline 0.80 & 0.09 & 0.12 & 0.18 & 0.00 & 0.20 & - & 0.49 & 0.63 & 108 & $89-985$ \\
\hline 0.51 & 0.28 & 0.22 & 0.39 & 0.02 & 0.10 & - & 0.58 & 0.81 & 83 & $94-990$ \\
\hline
\end{tabular}




\begin{tabular}{|c|c|c|c|c|c|c|c|c|}
\hline أل أراضين & تعليم الأم & تعليم الأب & الأصول عند الزواجج & الأراضي عند & سذوات & السن عذداج & عدد الزيجات & \\
\hline & & & & & & & & الفلبين \\
\hline- & - & - & - & - & - & ${ }_{-}$ & 4 & $34-930$ \\
\hline- & - & - & - & - & - & - & 8 & $39-935$ \\
\hline- & - & - & - & - & - & - & 12 & $44-940$ \\
\hline 0.37 & 0.44 & 0.27 & 0.80 & $-\quad .10$ & 0.51 & 0.73 & 14 & $49-945$ \\
\hline-.02 & 0.22 & 0.12 & 0.91 & $-\quad .09$ & 0.37 & 0.86 & 29 & $54-950$ \\
\hline 0.25 & 0.50 & 0.13 & 0.58 & $-\quad .10$ & 0.05 & 0.78 & 28 & $59-955$ \\
\hline 0.15 & 0.11 & 0.07 & 0.57 & -.30 & 0.54 & 0.64 & 27 & $64-960$ \\
\hline 0.24 & 0.65 & 0.38 & 0.79 & 0.48 & 0.53 & 0.75 & 33 & $69-965$ \\
\hline 0.20 & 0.56 & 0.25 & 0.76 & 0.02 & 0.44 & 0.18 & 34 & $74-970$ \\
\hline-.12 & 0.25 & 0.29 & 0.90 & -.03 & 0.63 & 0.70 & 38 & $79-975$ \\
\hline 0.09 & 0.04 & 0.41 & 0.80 & -.20 & 0.13 & 0.59 & 30 & $84-980$ \\
\hline - & - & - & - & - & - & - & 3 & $89-985$ \\
\hline
\end{tabular}




\begin{tabular}{|c|c|c|c|c|c|c|c|c|}
\hline أل أراضي & تعليم الأم & تعليم الأب & الأصول عند الزواجب & الأراضي عند & سذوات & السن عذداج & عدد الزيجات & \\
\hline & & & & & & & & إفريقيا \\
\hline & & & & & & & & إثيوبيا \\
\hline 0.00 & - & $-\quad 1.02$ & 0.20 & - & 0.37 & 0.75 & 144 & $59-955$ \\
\hline 0.29 & $-\quad .03$ & $-\quad .03$ & 0.37 & - & 0.52 & 0.54 & 56 & $64-960$ \\
\hline 0.46 & - & 0.26 & 0.37 & - & 0.44 & 0.63 & 85 & $69-965$ \\
\hline-.06 & - & 0.28 & $-\quad .01$ & - & 0.34 & 0.78 & 62 & $74-970$ \\
\hline 0.41 & 0.70 & 0.27 & 0.25 & - & 0.38 & 0.48 & 72 & $79-975$ \\
\hline.- .01 & 0.29 & 0.06 & 0.45 & - & 0.39 & 0.75 & 99 & $84-980$ \\
\hline 0.32 & 0.43 & $-\quad .07$ & 0.54 & - & 0.34 & 0.60 & 53 & $89-985$ \\
\hline - & - & - & - & - & - & - & 1 & $95-990$ \\
\hline
\end{tabular}




\begin{tabular}{|c|c|c|c|c|c|c|c|}
\hline أمهات تتمتعن & بأب قُاء يتمتعُون من & الأصول عند & مدفوعات كل أسزة عذد & سذوات & الزون عند & عدد الزيجات & \\
\hline & & & & & & & جنوب إفريقيا \\
\hline$-\quad .21$ & 0.15 & 0.37 & 0.87 & 0.85 & 0.51 & 14 & $59-955$ \\
\hline 0.39 & 0.43 & 0.52 & 0.47 & 0.65 & 0.70 & 30 & $64-960$ \\
\hline 0.53 & 0.54 & 0.47 & 0.13 & 0.68 & 0.74 & 66 & $69-965$ \\
\hline 0.36 & 0.65 & 0.41 & 0.35 & 0.84 & 0.66 & 67 & $74-970$ \\
\hline 0.35 & 0.49 & 0.47 & 0.05 & 0.72 & 0.65 & 92 & $79-975$ \\
\hline 0.39 & 0.42 & 0.33 & 0.13 & 0.79 & 0.82 & 83 & $84-980$ \\
\hline 0.39 & 0.55 & 0.39 & 0.07 & 0.61 & 0.60 & 72 & $89-985$ \\
\hline 0.27 & 0.50 & 0.39 & $-\quad .02$ & 0.66 & 0.90 & 47 & $94-990$ \\
\hline$-\quad .03$ & 0.28 & 0.63 & -1.14 & 0.60 & 0.55 & 14 & $99-995$ \\
\hline
\end{tabular}




\begin{tabular}{|c|c|c|c|c|c|c|c|c|}
\hline أراضي & تعليم الأم & تعليم الأب & الأصول عند & الأراضي عذد الزواج & سذوات & السن عذد الزواج & عدد الزيجات & \\
\hline & & & & & & & & ألمريكا \\
\hline 0.14 & - & - & 0.14 & - & $-\quad .01$ & $-\quad 1.28$ & 19 & $34-930$ \\
\hline 0.65 & - & - & 0.44 & - & 0.58 & 0.36 & 53 & $39-935$ \\
\hline 0.16 & - & - & 0.71 & $-\quad .04$ & 0.24 & 0.10 & 134 & $44-940$ \\
\hline 0.43 & 0.71 & 0.50 & 0.29 & - & 0.57 & 0.25 & 220 & $49-945$ \\
\hline 0.55 & 0.58 & 0.40 & 0.19 & 0.09 & 0.30 & 0.25 & 437 & $54-950$ \\
\hline 0.30 & 0.00 & 0.00 & 0.21 & $-\quad .02$ & 0.30 & 0.35 & 679 & $59-955$ \\
\hline 0.24 & 0.77 & 0.39 & 0.25 & 0.04 & 0.39 & 0.33 & 904 & $64-960$ \\
\hline 0.37 & 0.38 & 0.44 & 0.16 & - & 0.38 & 0.37 & 1.233 & $69-965$ \\
\hline 0.29 & 0.23 & 0.36 & 0.23 & 0.00 & 0.44 & 0.42 & 1.484 & $74-970$ \\
\hline 0.31 & 0.23 & 0.23 & 0.19 & 0.01 & 0.45 & 0.39 & 1.899 & $79-975$ \\
\hline 0.27 & 0.23 & 0.31 & 0.18 & 0.03 & 0.45 & 0.47 & 2.038 & $84-980$ \\
\hline 0.27 & 0.16 & 0.30 & 0.19 & -.03 & 0.41 & 0.45 & 2.198 & $89-985$ \\
\hline 0.25 & 0.23 & 0.17 & 0.24 & 0.05 & 0.42 & 0.49 & 2.075 & $94-990$ \\
\hline 0.34 & 0.13 & 0.30 & 0.18 & $-\quad .03$ & 0.44 & 0.49 & 1.086 & $99-995$ \\
\hline
\end{tabular}




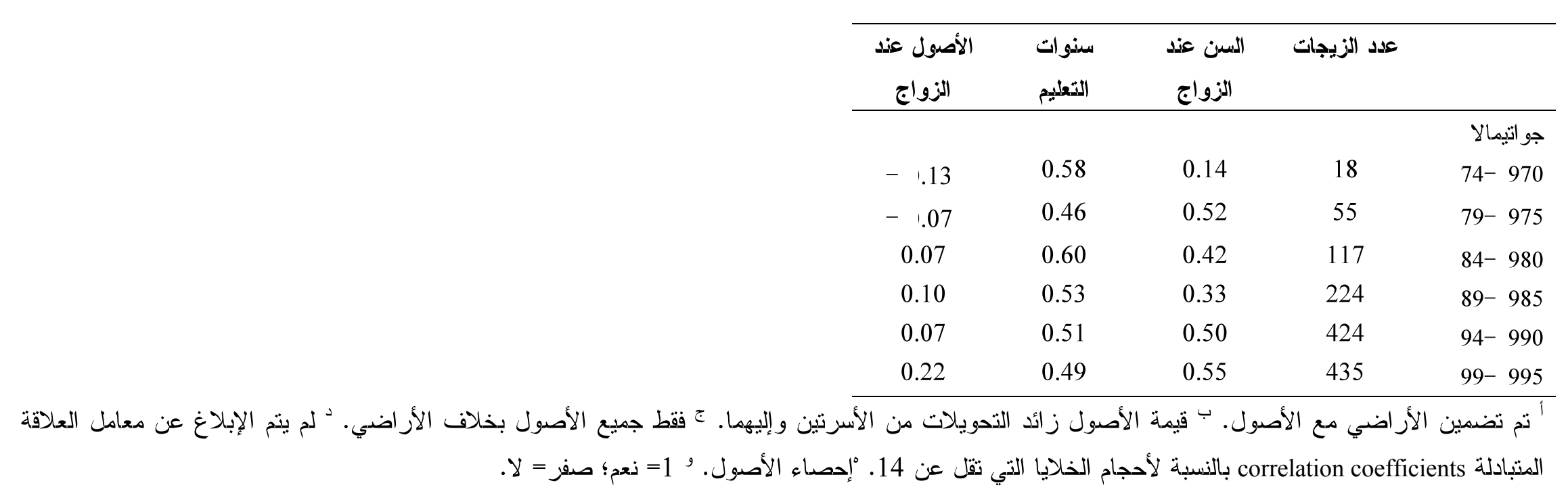


وبيذما نجد أن ما لدينا من معلومات حول خلفية الأسر في مسحج جنوب إفزيقيا محدود، فـإن البيانـات الدنــوفرة

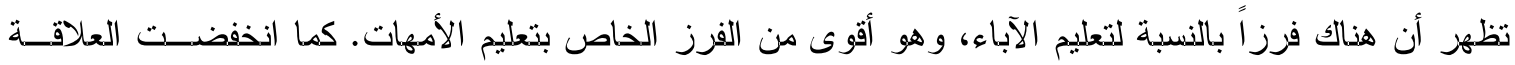
الترابطية بين تعليم أم كلا الزوجين بمزور الوقتا لالت.

وفي كل بلدان أمريكا اللاتينية، نجد أن أقوى العلاقات التزابطية تكون بين سن الأزو اج والزوجات وسنوات التعليم

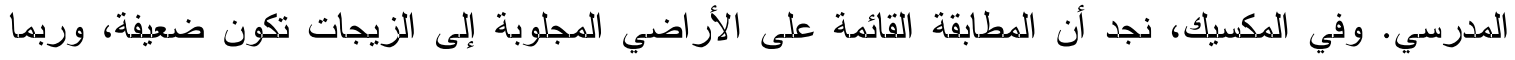

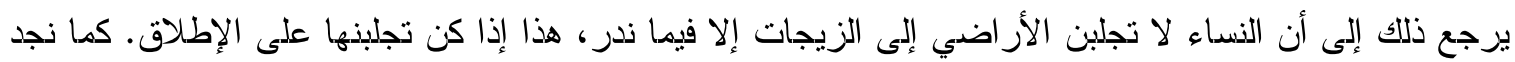

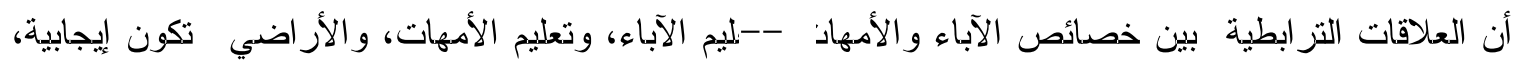

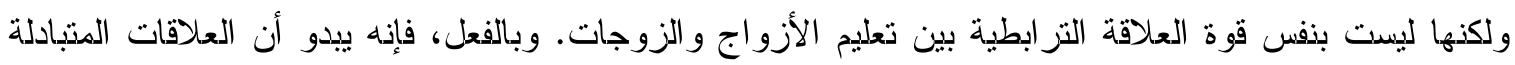

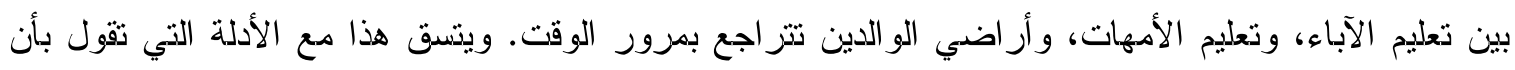

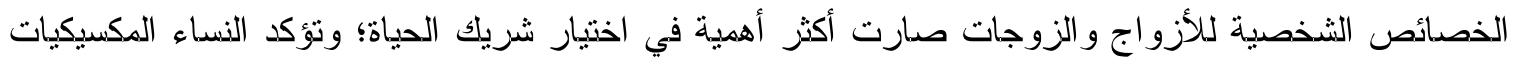
الأصغر سناً على مبادئ الثقة، و الحميمية، و التو اصل، أكثر من النساء من جيل أمهاتهن، و اللاتي تعلقن أهمية أكبر الهير

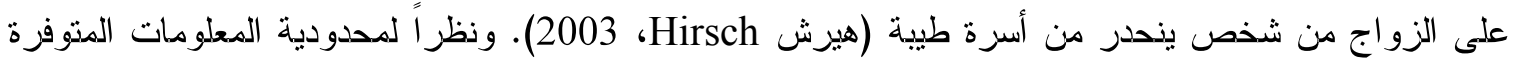

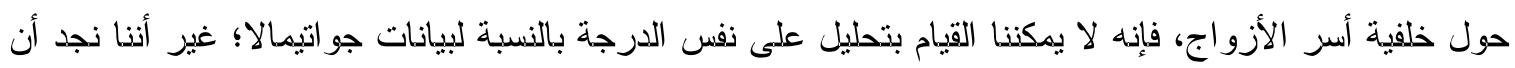
العلاقات التزابطية بين أعمار الأزواج عند الزواج والاجية وسنوات التعليم تكون مرتفعة، أعلى من العلاقات بين الأصول

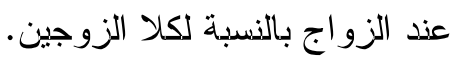

\section{نتائج الإتحدار REGRESSION RESULTS}

بنجلاديش. يعرض جدول (4) انحدارات حول سنوات التعليم المدرسي، و السن عند الزواج، وقيمة الأصول عنسـد

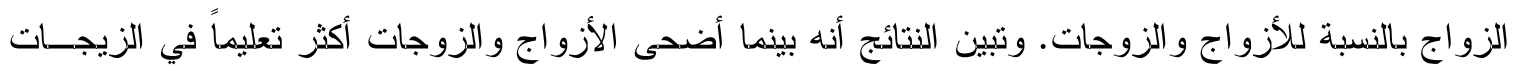

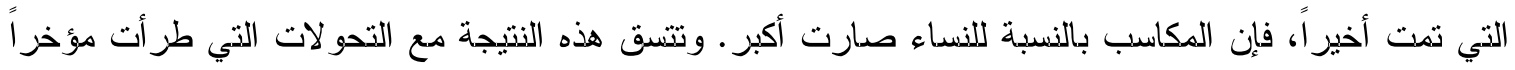

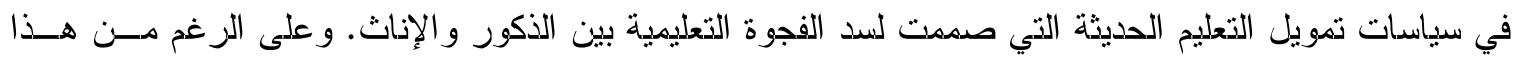

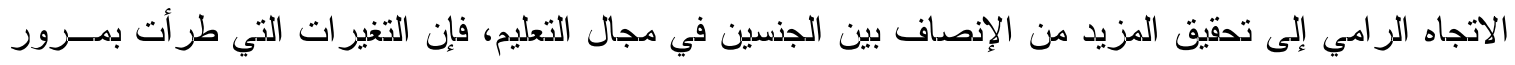

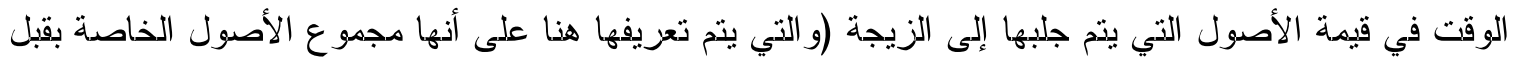

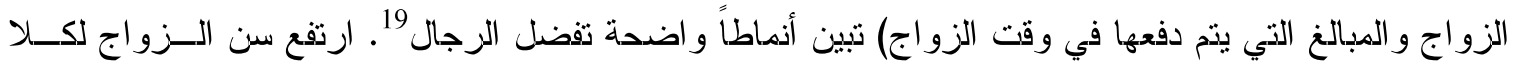

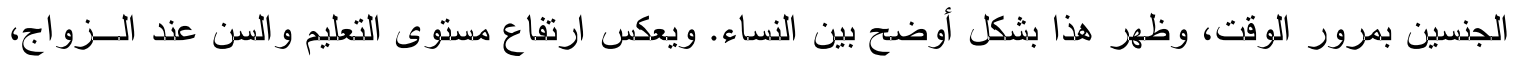

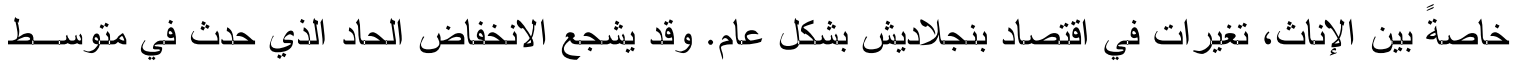

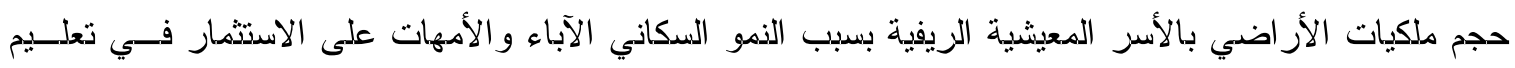

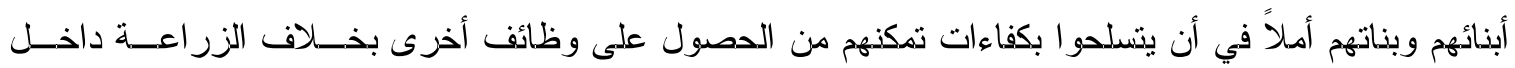

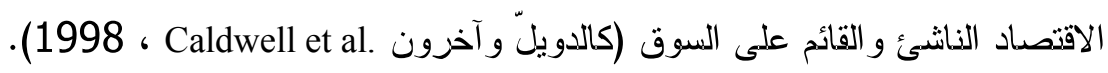


جدول (4) محددات سذو ات التعليم المدرسي، و السن عند الزو اج، و الأصول عند الزو اج (تتضمن الأصول دفعات الزواج)، بنجلاديش

\begin{tabular}{|c|c|c|c|c|c|c|c|c|c|c|c|c|}
\hline \multicolumn{4}{|c|}{ قيمة الأصمل عند الزواج (tobit) } & \multicolumn{4}{|c|}{$\begin{array}{c}\text { السن عند الزواج } \\
\text { (OLS with robust SEs) }\end{array}$} & \multicolumn{4}{|c|}{ سذوات الدر اسة (tobit) } & \\
\hline \multicolumn{2}{|c|}{ الزوجة } & \multicolumn{2}{|r|}{ 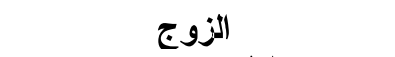 } & \multicolumn{2}{|c|}{ الزوجة } & \multicolumn{2}{|c|}{ الزوج } & \multicolumn{2}{|c|}{ الزوجة } & \multicolumn{2}{|c|}{ 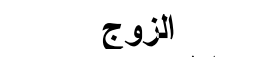 } & \\
\hline $\mathbf{t}$ & معامل & $\mathbf{t}$ & معامل & $\mathbf{t}$ & معامل & $\mathbf{t}$ & معامل & $\mathbf{t}$ & معامل & $\mathbf{t}$ & معامل & \\
\hline-.19 & $-\quad 18.18$ & 2.60 & 827.53 & 10.43 & 0.12 & 4.10 & 0.09 & 4.54 & 0.10 & 1.88 & 0.04 & سذة الزواج \\
\hline 4.27 & 37.851 .37 & 3.08 & 135.290 .20 & -.96 & -.12 & -.61 & -.94 & -.98 & -.78 & 1.17 & 3.89 & نسبة كل جنس \\
\hline 2.16 & 771.82 & 4.98 & 9.456 .12 & -.30 & $-\quad .08$ & $-\quad .87$ & -.20 & -.17 & $-\quad .15$ & -1.27 & $-\quad 1.04$ & ترثيب المولد \\
\hline$-\quad 1.45$ & -97.34 & -.18 & -.17 .54 & $-\quad .47$ & -1.03 & $-\quad .22$ & $-\quad .03$ & 1.05 & 0.16 & -1.17 & $-\quad .03$ & عدد الأشقاء \\
\hline$-\quad .81$ & -43.39 & -.44 & $-\quad .606 .05$ & 1.40 & 0.12 & -1.56 & $-\quad .08$ & 1.71 & 0.25 & 0.39 & 0.07 & عدد الثقيقات \\
\hline 4.79 & 4.69 & 3.66 & 34.00 & -.31 & 0.00 & 0.60 & 0.00 & 3.89 & 0.00 & 6.78 & 0.00 & قيمة أُر اضي \\
\hline 2.79 & 1.630 .56 & $-\quad .57$ & $-\quad .699 .95$ & 1.70 & 0.18 & -.58 & -.24 & 5.95 & 1.19 & 5.98 & 1.31 & تعليم الأب \\
\hline 2.05 & 1.826 .25 & 0.69 & 4.379 .91 & -.69 & $-\quad .41$ & $-\quad .45$ & -.15 & 5.97 & 1.60 & 4.14 & 1.77 & تعليم الأم \\
\hline-.27 & $-\quad .672 .38$ & 1.97 & 17.002 .77 & 2.16 & 0.67 & 2.66 & 1.37 & 5.22 & 3.36 & 4.52 & 2.98 & الموقع 2 \\
\hline-.26 & $-\quad .470 .40$ & -.49 & - 2.291.70 & -1.35 & $-\quad .11$ & 0.65 & 0.32 & 2.33 & 1.49 & 1.59 & 1.04 & الموقع 3 \\
\hline \multirow[t]{5}{*}{4.83} & 593.495 .00 & -.80 & $-\quad .788 .906 .00$ & $-\quad .57$ & -.17 .81 & -.41 & $\begin{array}{c}- \\
142.94\end{array}$ & -.49 & 201.37 & -.10 & -8.47 & الثابت \\
\hline & & & & & 786 & & 779 & & & & & عدد الملاحظات \\
\hline & & & & & 14.54 & & 3.09 & & & & & F-statistic \\
\hline & & & & & 0.00 & & 0.00 & & & & & Prob $>F$ \\
\hline & & & & & 0.17 & & 0.05 & & & & & $\mathrm{R}^{2}$ \\
\hline 766 & 766 & & 755 & & & & & & 778 & & 775 & $\mathrm{Chi}^{2}$ \\
\hline 103.63 & 103.63 & & 67.27 & & & & & & 240.44 & & 171.82 & LR chi ${ }^{2}$ \\
\hline 0.00 & 0.00 & & 0.00 & & & & & & 0.00 & & 0.00 & Prob>chi ${ }^{2}$ \\
\hline 0.01 & 0.01 & & 0.00 & & & & & & 0.11 & & 0.06 & Pseudo $\mathrm{R}^{2}$ \\
\hline & & & & & & & & & & & 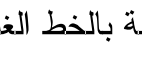 & إحصائيات t \\
\hline
\end{tabular}


ويكون من بين تأثيرات نسية الإناث إلى الذكور من السكان ممن هم في سن الزواج في وقت الزواج أنها تحد من

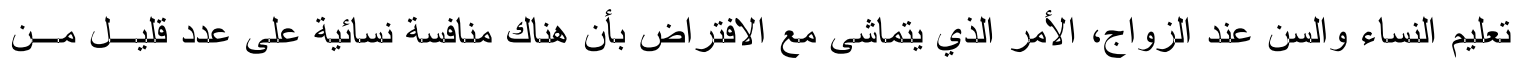

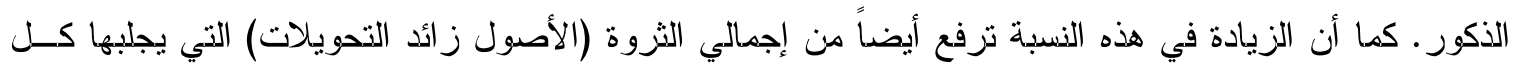

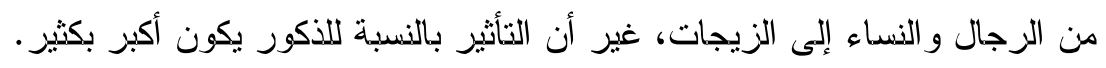

وتعد خصائص الو الدين محددات هامة للتعليم، والسن، و الأصول عند الزواج. كما ترفع قيمـة الأراضـي التــي

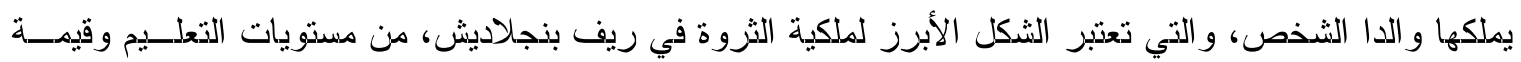

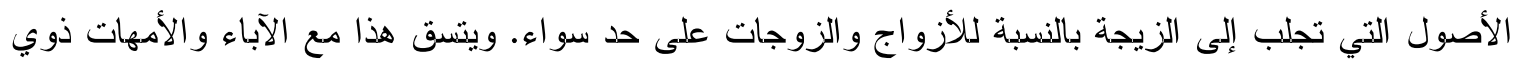

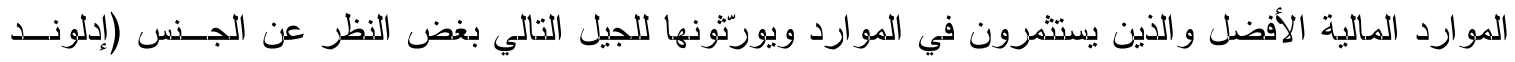
Edlund

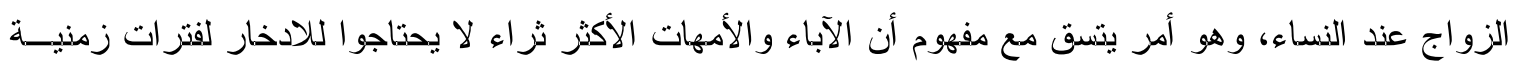

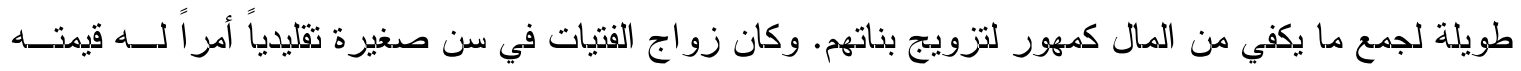

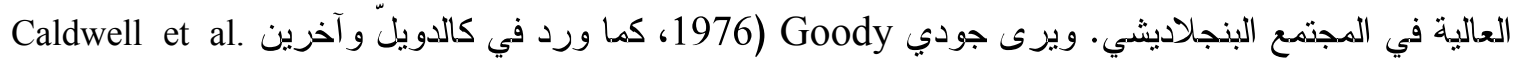

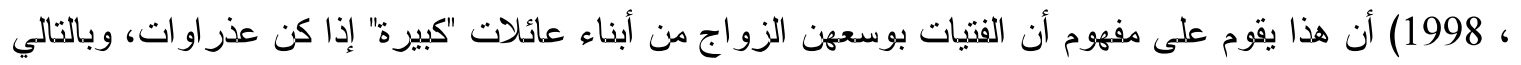

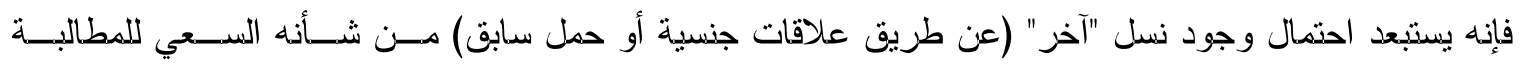

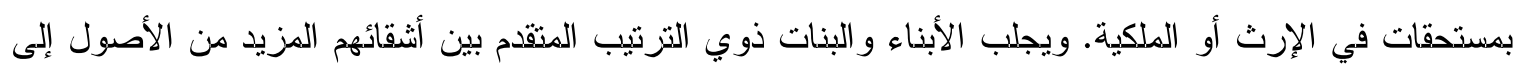

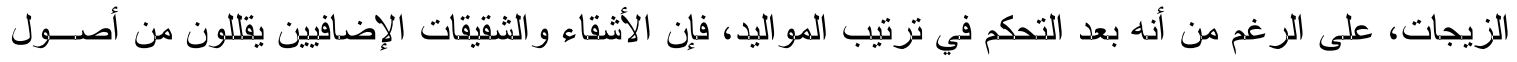

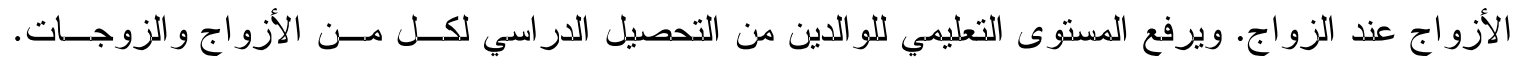

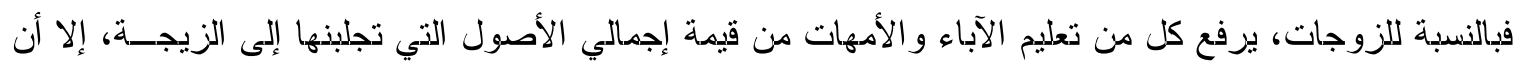

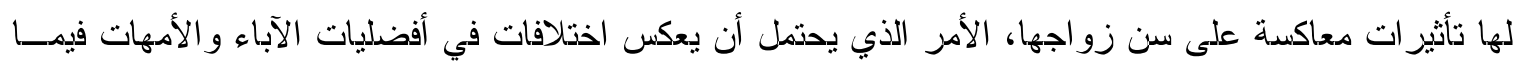
يتعلق بسن زو اج البنات.

جدول (5)محددات الاختلافات (بين الزوج والزوجة) في سنوات التعليم المدرسي، والسن عذد الزواج، والأصول عند الزواج، بنجلاديش (OLS with robust standard errors)

\begin{tabular}{|c|c|c|c|c|c|c|}
\hline \multicolumn{2}{|c|}{ قيمة الأصول عذد الزواج } & \multicolumn{2}{|c|}{ السن عند الزواج } & \multicolumn{2}{|c|}{ سذوات التعليم } & \\
\hline $\mathbf{t}$ & معامل & t & معامل & t & معامل & \\
\hline 1.80 & 386.16 & -.98 & $\begin{array}{l}-\quad .04 \\
-04\end{array}$ & -.20 & $-\quad .03$ & سنة الزواج \\
\hline 1.04 & 48.648 .66 & -.23 & -1.51 & 1.72 & 2.31 & نسبة كل جنس \\
\hline & & & & & & اختلافات في: \\
\hline 1.60 & 3.278 .32 & 0.44 & 0.03 & -1.52 & $-\quad .03$ & عدد الأثشقاء \\
\hline 0.87 & 1.304 .91 & 0.06 & 0.00 & -1.30 & $-\quad .02$ & عدد الثقيقات \\
\hline 2.17 & 11.04 & 2.09 & 0.00 & -.25 & 0.00 & قيمة أر اضي \\
\hline
\end{tabular}




\begin{tabular}{|c|c|c|c|c|c|c|}
\hline & & & & & & الو الدين \\
\hline-1.19 & $-\quad 72.77$ & -.95 & -.10 & 0.25 & 0.02 & تعليم الأب \\
\hline-1.07 & $-\quad 15.00$ & -.14 & -.16 & 0.88 & 0.12 & ت تعليم الأم \\
\hline \multirow[t]{5}{*}{-.86} & -94.488 .00 & 3.26 & 96.34 & 3.13 & 57.43 & الثنابت \\
\hline & 710 & & 729 & & 724 & عدد الملاحظات \\
\hline & 2.34 & & 2.50 & & 2.67 & F-statistic \\
\hline & 0.02 & & 0.02 & & 0.01 & Prob $>F$ \\
\hline & 0.02 & & 0.02 & & 0.03 & $\mathrm{R}^{2}$ \\
\hline
\end{tabular}


و إذا اتجهنا إلى التغيرات فى الاختلاف بين الأزواج و الزوجات، فإننا نلاحظ في جدول (5) نراجع سن الزوج

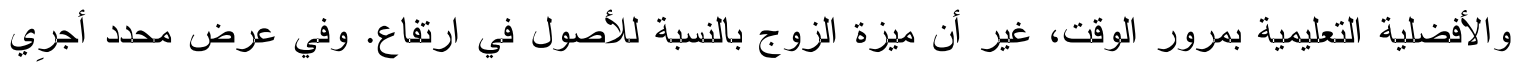

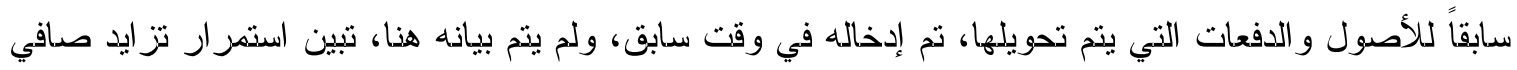

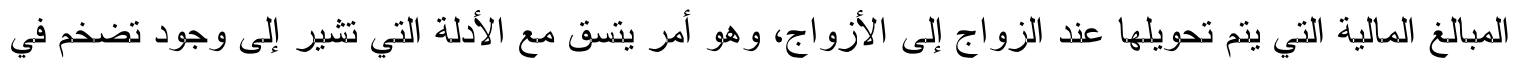

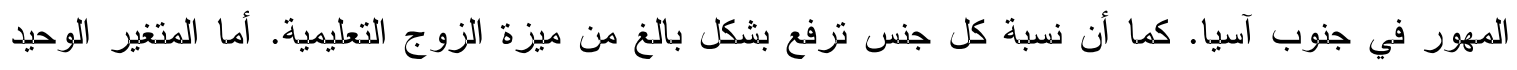

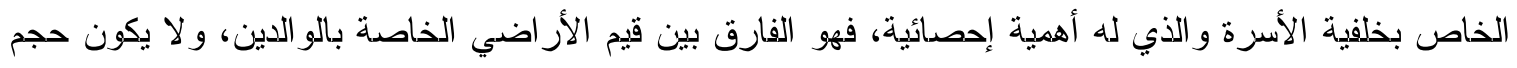

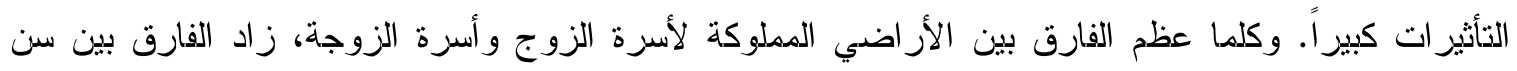
الزوج و الزوجة و الأصول المجلوبة للزيجة.

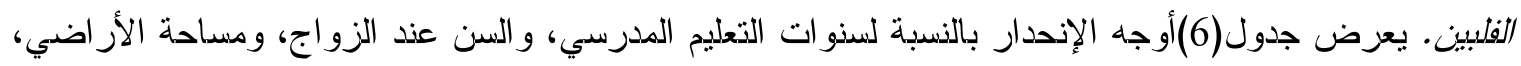

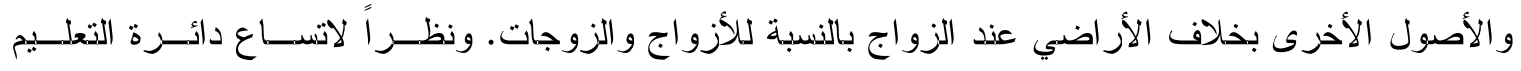

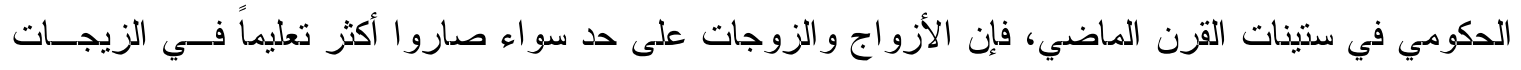

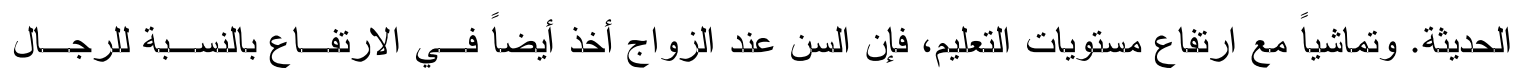

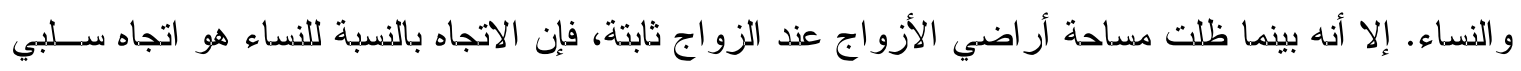

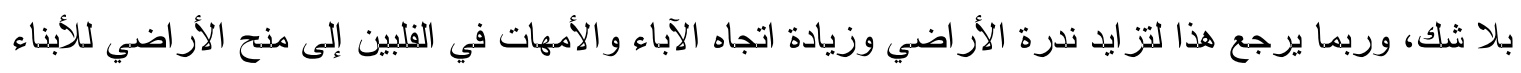

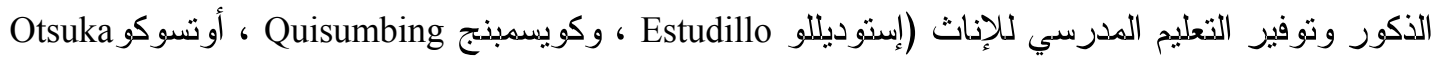
،2001ب). و لا توجد اتجاهات زمنية واضدة بالنسبة للأصول الأخرى بخلاف الأراضي. 
جدول (6)محددات سنوات التعليم المدرسي، و السن عند الزواج، ومساحة الأراضي، و الأصول عند الزواج، الفلبين

\begin{tabular}{|c|c|c|c|c|c|c|c|c|c|c|c|c|c|c|c|}
\hline \multicolumn{3}{|c|}{ t) الأصول بخلاف الأراضي عند الزواج } & \multicolumn{4}{|c|}{ مساحة الأراضي عند الزواج } & \multicolumn{4}{|c|}{$\begin{array}{c}\text { السن عند الزواج } \\
\text { (OLS with robust SEs) }\end{array}$} & \multicolumn{4}{|c|}{$\begin{array}{c}\text { سذوات الدراسدة } \\
\text { (OLS with robust SEs) }\end{array}$} & \\
\hline الزوج & \multicolumn{2}{|c|}{ الزوج } & \multicolumn{2}{|c|}{ الزوجة } & \multicolumn{2}{|c|}{ الزوج } & \multicolumn{2}{|c|}{ الزوجة } & \multicolumn{2}{|c|}{ الزوج } & \multicolumn{2}{|c|}{ الزوجة } & \multicolumn{2}{|c|}{ الزوج } & \\
\hline معامل & $\mathbf{t}$ & معامل & $\mathbf{t}$ & معامل & $\mathbf{t}$ & معامل & $\mathbf{t}$ & معامل & $\mathbf{t}$ & معامل & $\mathbf{t}$ & معامل & $\mathbf{t}$ & معامل & \\
\hline-.24 & 0.85 & 2.79 & -.20 & $-\quad .04$ & 1.55 & 0.02 & 2.51 & 0.08 & 3.79 & 0.12 & 5.28 & 0.07 & 5.55 & 0.08 & سذة الزواج \\
\hline 655.98 & 1.86 & 1.391 .35 & -1.03 & -1.09 & -.23 & $-\quad .61$ & 1.24 & 8.40 & 0.76 & 5.32 & -1.28 & $-\quad .99$ & 0.21 & 0.71 & نسبة كل جنس \\
\hline 26.45 & 0.62 & 9.44 & -1.09 & $-\quad .01$ & -.72 & -.10 & -.12 & -.13 & -.72 & $-\quad 1.09$ & -1.09 & -.01 & 1.42 & 0.09 & تعليم الأب \\
\hline-2.92 & -.87 & -4.48 & -1.20 & $-\quad .01$ & 0.63 & 0.04 & -.32 & -.20 & -.03 & $-\quad 1.49$ & 3.13 & 0.27 & 1.22 & 0.10 & تعليم الأم \\
\hline 8.72 & 1.08 & 12.87 & 3.76 & 0.20 & 2.17 & 0.09 & 2.02 & 0.35 & 2.29 & 0.17 & 1.29 & 0.09 & 0.96 & 0.06 & أر اضدى الأب \\
\hline 3.68 & 3.11 & 51.98 & 2.21 & 0.19 & -.23 & $-\quad .01$ & 0.15 & 0.03 & 0.44 & 0.05 & 0.83 & 0.09 & 1.12 & 0.13 & أر اضي الأم \\
\hline 368.56 & 5.28 & 699.73 & $-\quad 1.65$ & -1.33 & 0.63 & 0.31 & 0.63 & 0.70 & 0.00 & 0.00 & 1.12 & 0.71 & 1.22 & 0.82 & نموذج P2 \\
\hline 136.21 & 1.32 & 166.05 & 1.50 & 0.64 & 2.43 & 1.09 & 1.57 & 1.80 & 0.34 & 0.38 & -.80 & -.25 & -.02 & -1.97 & نموذجP3 \\
\hline 927.27 & 11.80 & 1.404 .18 & 1.87 & 0.75 & 2.59 & 1.14 & -.43 & -.40 & -.10 & -.97 & -.54 & -.77 & 0.80 & 0.44 & نموذج CL1 \\
\hline 515.60 & 2.94 & 353.81 & $-\quad .68$ & -1.84 & 1.54 & 0.68 & -.27 & -.21 & -.68 & -.69 & -.04 & -.02 & -.75 & -1.35 & لموذج CL2 \\
\hline 3.544 .47 & -.09 & -.948 .45 & 3.15 & 72.14 & -.58 & $\begin{array}{c}37.08 \\
-\end{array}$ & -.26 & -39.10 & -.49 & -14.95 & -.13 & -34.16 & -.39 & -43.77 & الثابت \\
\hline \multirow[t]{4}{*}{259} & & 259 & & 259 & & 259 & & 259 & & 259 & & 259 & & 259 & المداحظات \\
\hline & & & & & & & & 2.88 & & 4.50 & & 10.43 & & 9.27 & F-statistic \\
\hline & & & & & & & & 0.00 & & 0.00 & & 0.00 & & 0.00 & Prob $\gg F$ \\
\hline & & & & & & & & 0.11 & & 0.18 & & 0.28 & & 0.24 & $\mathrm{R}^{2}$ \\
\hline 148.14 & & 164.52 & & 57.82 & & 16.71 & & & & & & & & & $\mathrm{Chi}^{2}$ \\
\hline 0.00 & & 0.00 & & 0.00 & & 0.08 & & & & & & & & & Prob>chi ${ }^{2}$ \\
\hline 0.04 & & 0.04 & & 0.15 & & 0.03 & & & & & & & & & Pseudo $\mathrm{R}^{2}$ \\
\hline
\end{tabular}


وتعتبر خصائص الو الدين محددات هامة لكل من السن عند الزواج ورأس المال البشري و المادي الذي يتم جلبـهـ الزبه

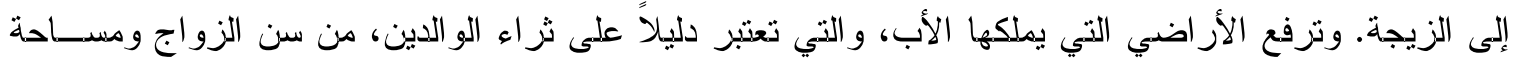

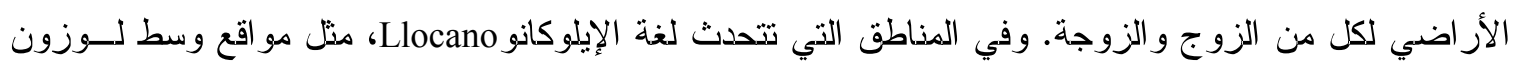
Central Luzon

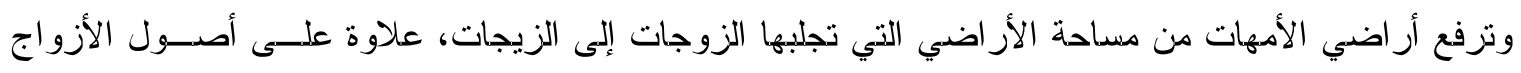

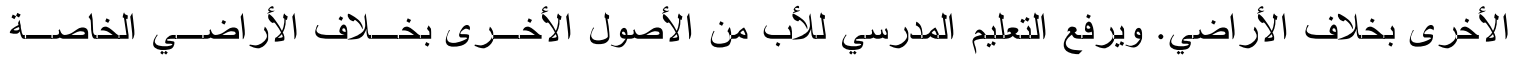

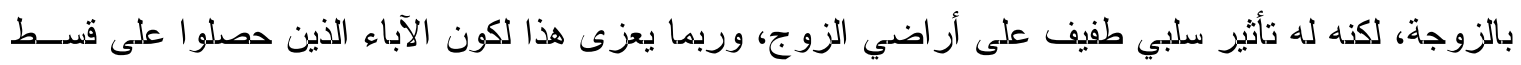

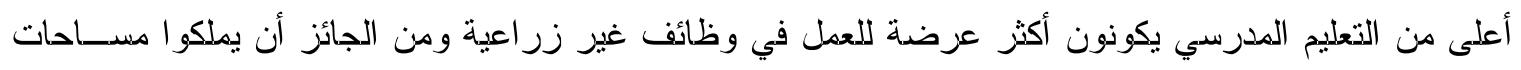

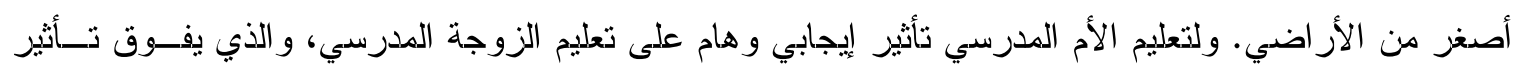

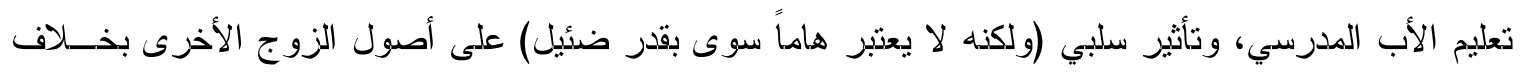

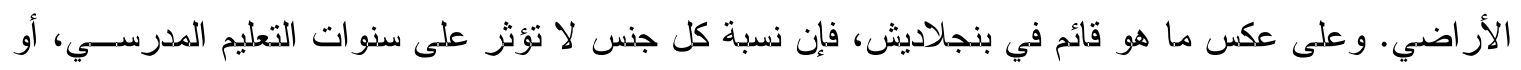

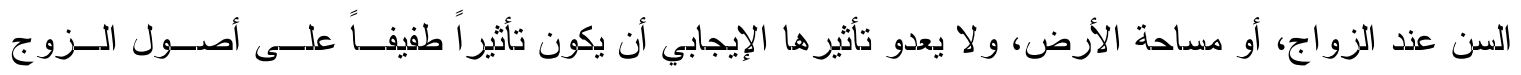
الأخرى بخلاف الأراضي.

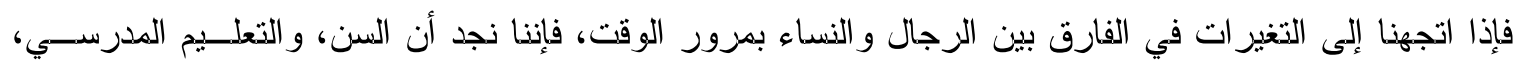

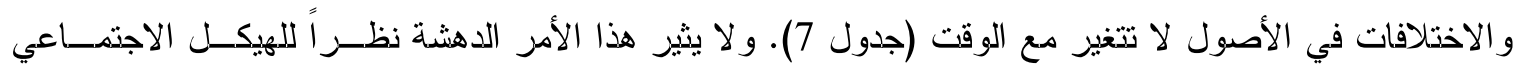

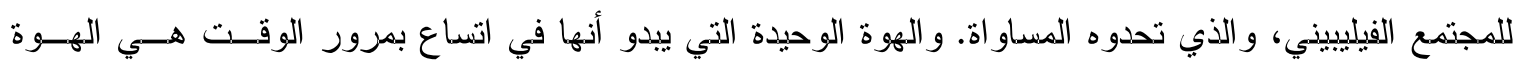

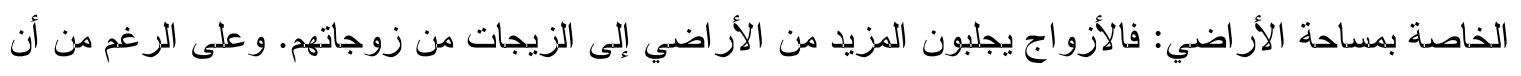

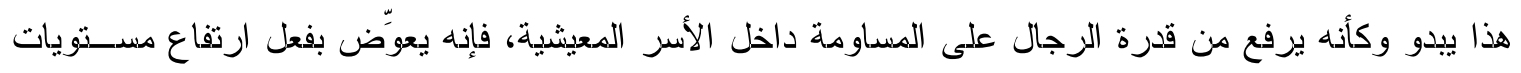

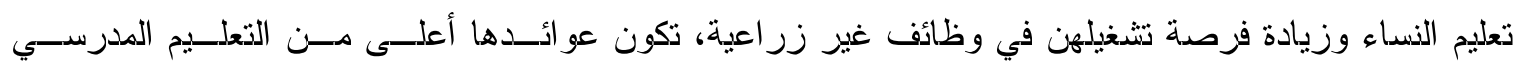

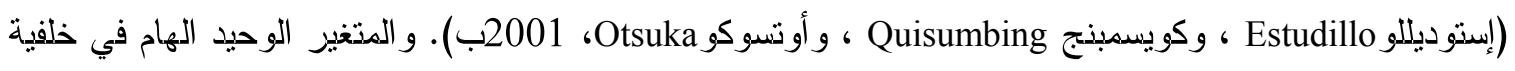

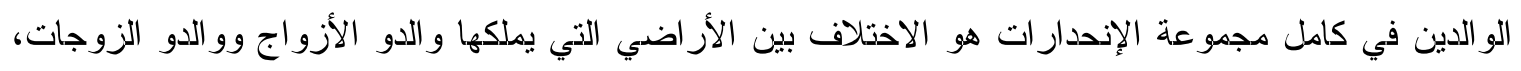

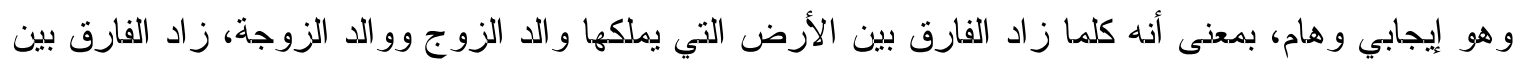

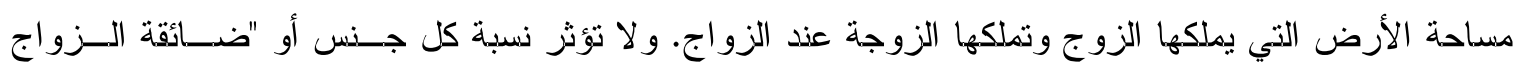
marriage squeeze 
جدول (7) محددات الاختلافات (بين الزوج و الزوجة) في سنوات التعليم المدرسي، و السن عند الزواج، ومساحة الأراضي

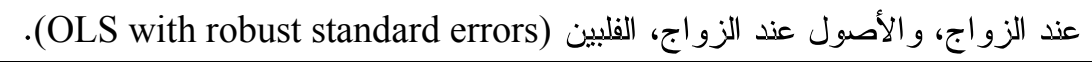

\begin{tabular}{|c|c|c|c|c|c|c|c|c|}
\hline \multicolumn{2}{|c|}{ الأصول الأخزى بخلاف } & \multicolumn{2}{|c|}{ مساحة الأراضي } & \multicolumn{2}{|c|}{ السن عند الزواج } & \multicolumn{2}{|c|}{ سذوات التعليم } & \multirow[b]{3}{*}{ نذة الزواج } \\
\hline $\mathbf{t}$ & معامل & $\mathbf{t}$ & معامل & $\mathbf{t}$ & معامل & $\mathbf{t}$ & معامل & \\
\hline 0.81 & 1.97 & 3.83 & 0.02 & 0.79 & 0.02 & 0.22 & 0.00 & \\
\hline 1.15 & 755.26 & 0.00 & 0.00 & -.12 & $-\quad .71$ & 0.31 & 1.28 & نسبة \\
\hline & & & & & & & & اختلافات في: \\
\hline-.37 & -6.17 & 0.30 & 0.01 & $-\quad .80$ & $-\quad .06$ & 0.42 & 0.02 & تعليم الأب \\
\hline$-\quad .91$ & -3.36 & 0.20 & 0.01 & $-\quad .92$ & -1.10 & -1.20 & $-\quad .01$ & تعليم الأم \\
\hline 0.13 & 0.99 & 2.54 & 0.05 & 1.05 & 0.06 & 0.47 & 0.02 & أر اضي الأب \\
\hline 1.66 & 24.11 & 1.11 & 0.03 & -.03 & 0.00 & 1.62 & 0.22 & أر اضي الأم \\
\hline \multirow[t]{6}{*}{-1.95} & -.459 .98 & -.87 & -3.61 & -.71 & -6.43 & -1.29 & -.05 & الثابت \\
\hline & 259 & & 259 & & 259 & & 259 & عدد \\
\hline & & & & & & & & الملاحظات \\
\hline & 1.31 & & 4.49 & & 0.88 & & 0.70 & F-statistic \\
\hline & 0.25 & & 0.00 & & 0.51 & & 0.65 & Prob $>F$ \\
\hline & 0.04 & & 0.08 & & 0.01 & & 0.04 & $\mathrm{R}^{2}$ \\
\hline
\end{tabular}

إثييوبيا. تشابهاً مع النتائج التي تم التوصل إليها في كل من بنجلاديش و الفلبين، فإن الزيجات الحديثة تتسم بارتفاع

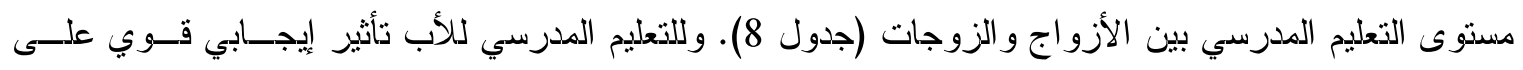

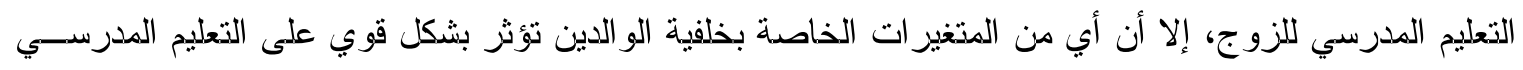

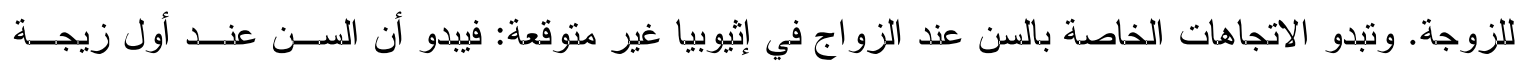

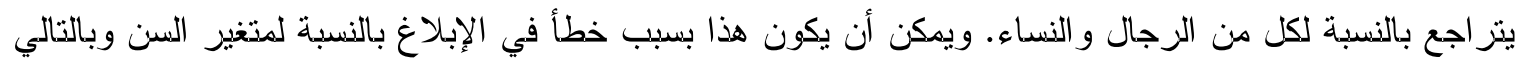

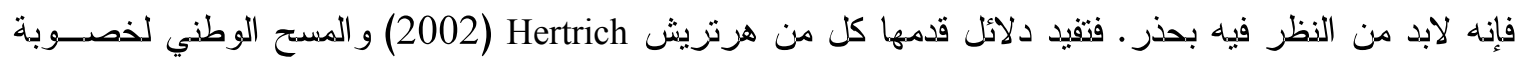

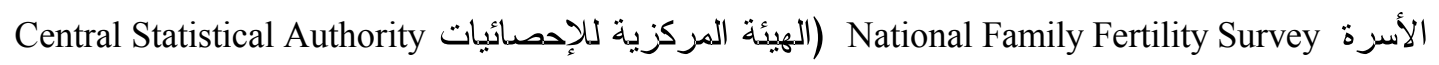

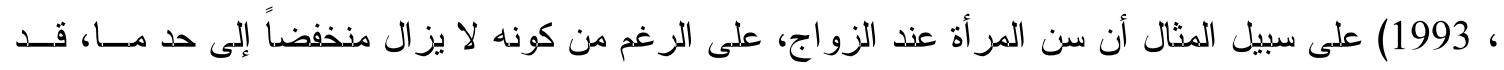

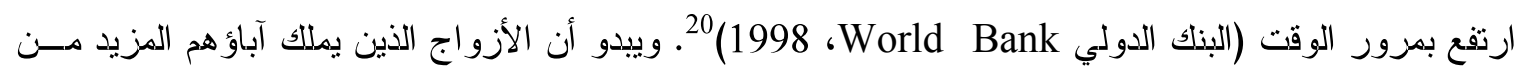

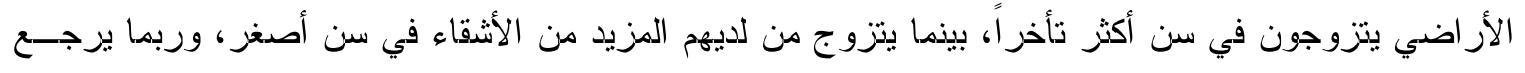

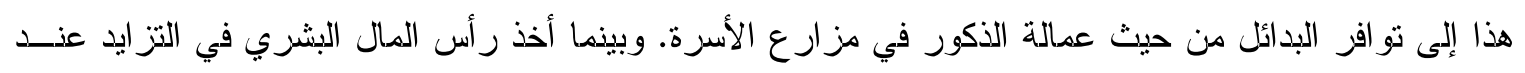
الزواج، فإن القيمة الحقيقية لر أس المال المادي الذي يتم جلبه إلى الزيجة لم يتغيز على نحو يمكن تقديزه بمــرور

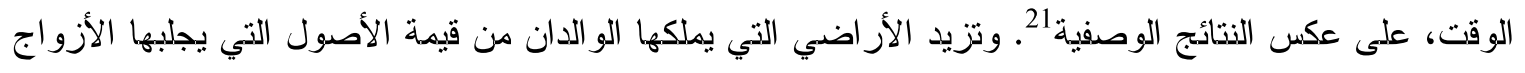
إلى الزيجات، بينما يرفع تعليم الأمهات المدرسي من قيمة الأصول التي تجلبها الزوجات. وتجلب الزوجات اللاثي لديهن شقيقات أكثر حجماً أقل من الأصول، وربما يرجما لأنع هذا إلى تأثيرات المنافسة بين الأشقاء. 
جدول (8) محددات سنو ات التعليم المدرسي، و السن عند الزواج، والأصول عند الزواج، إثيوبيا، الزيجات الأولى فقط

\begin{tabular}{|c|c|c|c|c|c|c|c|c|c|c|c|c|}
\hline \multicolumn{4}{|c|}{ قيمة الأصول عند الزواج (tobit) } & \multicolumn{4}{|c|}{$\begin{array}{c}\text { السن عند الزواج (OLS with robust SEs) } \\
\text { (OLS }\end{array}$} & \multicolumn{4}{|c|}{ سذوات الدر اسة (tobit) } & \\
\hline \multicolumn{2}{|r|}{ الزوجة } & \multicolumn{2}{|r|}{ الزوج } & \multicolumn{2}{|c|}{ الزوجة } & \multicolumn{2}{|c|}{ الززوج } & \multicolumn{2}{|c|}{ الزوجة } & \multicolumn{2}{|c|}{ الزوج } & \\
\hline $\mathbf{t}$ & معامل & $\mathbf{t}$ & معامل & $\mathbf{t}$ & معامل & t & معامل & $\mathbf{t}$ & معامل & $\mathbf{t}$ & معامل & \\
\hline 0.10 & 4.23 & -.59 & $-\quad 32.24$ & -.74 & $-\quad .18$ & -.42 & -.34 & 3.36 & 0.31 & 3.74 & 0.19 & سنة الزواج \\
\hline-.27 & -4.842 .62 & $-\quad .15$ & -.458 .13 & 3.42 & 51.40 & 2.89 & 53.05 & -.44 & -1.65 & $-\quad 1.07$ & $-\quad .92$ & نسبة كل جنس \\
\hline-.13 & -42.93 & 0.52 & 757.76 & 0.11 & 0.08 & 0.72 & 1.13 & 1.43 & 1.81 & 2.77 & 2.27 & تعليم الأب \\
\hline 1.95 & 2.278 .18 & 1.61 & 5.649 .13 & $-\quad .01$ & $-\quad 1.01$ & 0.42 & 1.12 & $-\quad .08$ & $-\quad 1.18$ & 0.38 & 0.80 & تعليم الأم \\
\hline-1.54 & -.78 & 4.90 & 17.23 & 0.13 & 0.01 & 4.74 & 0.01 & -1.53 & -1.04 & 0.65 & 0.00 & أر اضي الو الدين \\
\hline 1.08 & 102.06 & -.32 & -48.52 & 0.10 & 0.01 & -.63 & -.51 & 0.98 & 0.17 & 1.22 & 0.14 & عدد الأثشقاء " \\
\hline$-\quad .98$ & $-\quad 04.45$ & $-\quad .08$ & -6.75 & -.99 & $-\quad .14$ & -.00 & -18 & 1.32 & 0.25 & 0.64 & 0.08 & $\begin{array}{r}\text { المذطقة الثقيقات } \\
\text { (باستثناء }\end{array}$ \\
\hline-.73 & -.017 .56 & -1.54 & - 01.44 & -.19 & -.23 & -.13 & -.55 & 1.48 & 2.64 & $-\quad 1.61$ & -.51 & 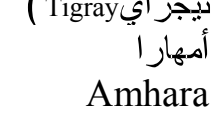 \\
\hline$-\quad .58$ & -.682 .03 & -.31 & -76.69 & -.75 & -.64 & -.01 & -.48 & 2.39 & 4.16 & 1.29 & 1.02 & $\begin{array}{l}\text { أورومو } \\
\text { Oromo }\end{array}$ \\
\hline-.99 & -.045 .30 & -.77 & - 04.75 & -.20 & $-\quad .18$ & -.84 & -.05 & 2.39 & 4.03 & 1.84 & 1.37 & جنوب وسط $\begin{array}{r}\text { South- } \\
\text { central }\end{array}$ \\
\hline 0.27 & $\begin{array}{c}17.929 .32 \\
555\end{array}$ & 2.02 & $\begin{array}{c}270.900 .40 \\
558\end{array}$ & 2.73 & $\begin{array}{c}305.47 \\
554 \\
\mathbf{2 . 3 7}\end{array}$ & 4.88 & $\begin{array}{c}626.59 \\
554 \\
\mathbf{2 2 . 7}\end{array}$ & $-\quad .89$ & $\begin{array}{l}-\quad 03.02 \\
532\end{array}$ & -.52 & $\begin{array}{l}-74.06 \\
546\end{array}$ & $\begin{array}{r}\text { الثابت } \text { عدد الملاحظات } \\
\text { F-statistic }\end{array}$ \\
\hline & & & & & $\begin{array}{l}0.01 \\
0.03\end{array}$ & & $\begin{array}{l}0.00 \\
0.16\end{array}$ & & & & & $\begin{array}{r}\text { Prob }>F \\
\mathrm{R}^{2}\end{array}$ \\
\hline & 85.51 & & 65.94 & & & & & & 92.75 & & 122.83 & $\mathrm{Chi}^{2}$ \\
\hline & 0.00 & & 0.00 & & & & & & 0.00 & & 0.00 & Prob> $\mathrm{chi}^{2}$ \\
\hline & 0.01 & & 0.01 & & & & & & 0.10 & & 0.07 & Pseudo $\mathrm{R}^{2}$ \\
\hline
\end{tabular}




\begin{tabular}{|c|c|c|c|c|c|c|}
\hline \multicolumn{7}{|c|}{ إثيوبيا، الزيجات الأولى فقط (OLS with robust standard errors). } \\
\hline \multicolumn{2}{|c|}{ الأصول الأخزى بذلاف } & \multicolumn{2}{|c|}{ السن عند الزواج } & \multicolumn{2}{|c|}{ سذوات التعليم } & \\
\hline $\mathbf{t}$ & مelol & $\mathbf{t}$ & معامل & $\mathbf{t}$ & معامل & \\
\hline-.52 & -24.89 & -.45 & -1.18 & 1.72 & 0.04 & سنة الزواج \\
\hline 0.47 & 8.407 .69 & -.27 & -.59 & -1.08 & -.55 & 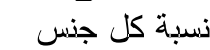 \\
\hline & & & & & & 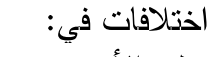 \\
\hline-.53 & -50.54 & -1.45 & -1.31 & 3.82 & 1.26 & ت تعليم الأب \\
\hline 1.57 & 2.982 .81 & -.90 & -.48 & -1.01 & $-\mathbf{0} 1$ & تعليم الأم \\
\hline 13.11 & 19.17 & 1.31 & 0.00 & -.62 & 0.00 & أر اضي الو الدين \\
\hline$-\quad .40$ & -55.96 & 0.38 & 0.03 & -.29 & $-\quad .05$ & عدد الأشقاء \\
\hline-.57 & - 52.99 & -.10 & -1.10 & 0.04 & 0.00 & عدد الثقيقات \\
\hline 1.69 & 236.732 .10 & 4.27 & 368.26 & -.10 & -6.84 & الثابت \\
\hline & 552 & & 548 & & 525 & عدد الملاحظات \\
\hline & 43.47 & & 12.52 & & 11.81 & F-statistic \\
\hline & 0.00 & & 0.00 & & 0.00 & Prob $\gg F$ \\
\hline & 0.09 & & 0.139 & & 0.07 & $\mathrm{R}^{2}$ \\
\hline
\end{tabular}


و لا تؤثر نسبة النساء إلى الرجال ممن هم في سن الزواج على التعليم المدرسي ولا على الأصول التي يتم جلبها

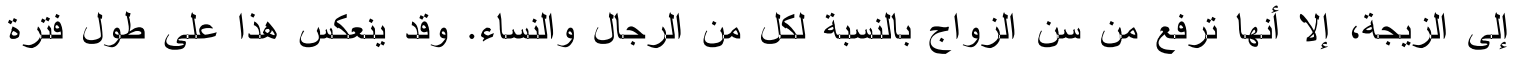

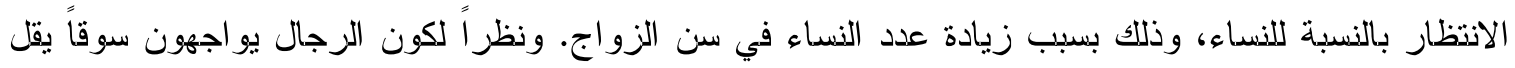
فيها عدد الذكور مقارنة بعدد النساء في سن الزواج، فإنهم قد لا يشعروا بالضغط كي يتزوجوا التبكرين.

كيف تغيرت الاختلافات بين الأزواج والزوجات بمزور الوقت؟ اندسرت الفوارق العمرية بين الأزواج

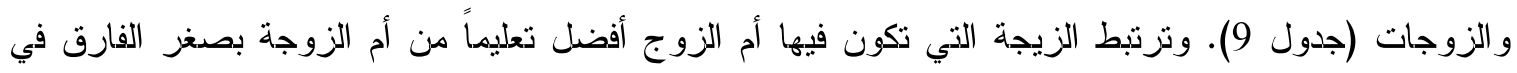

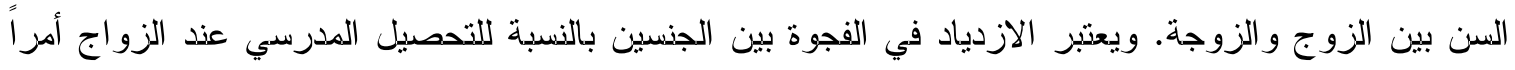

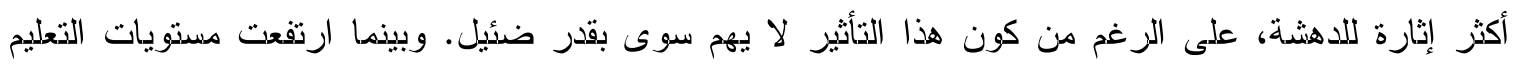

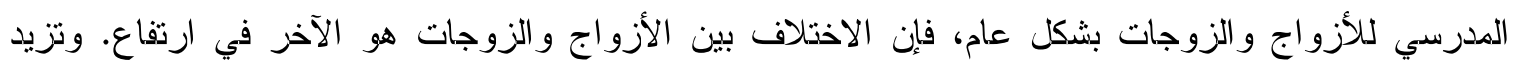

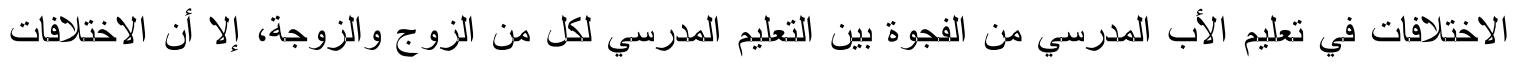

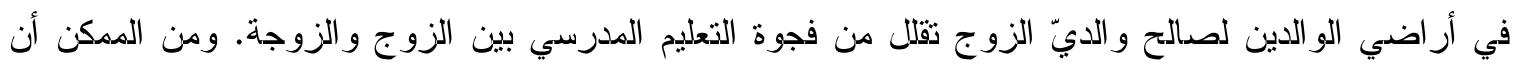

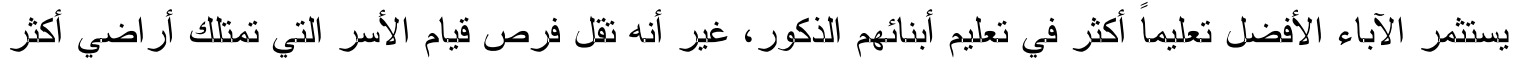

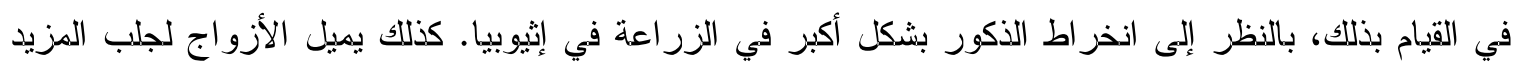

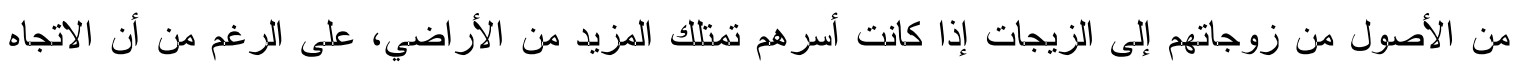

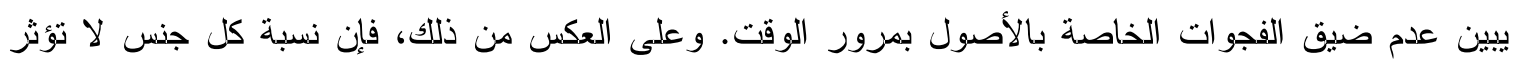

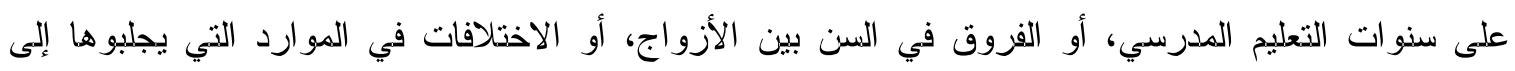
الزيجات.

جنوب إفريقيا. يقدم جدول (10)إنحدارات على سنوات التعليم المدرسي، و السن عذد الزواج، وإحصاء الأصدـول،

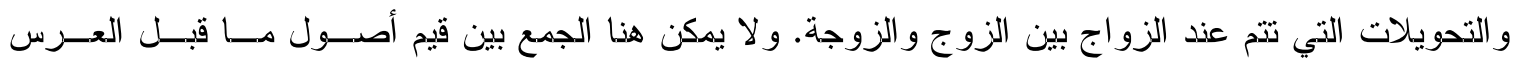

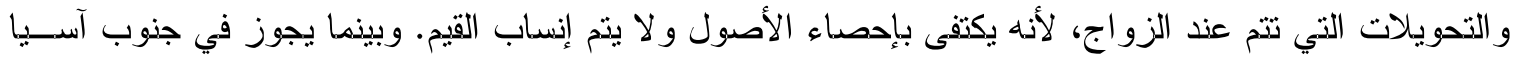

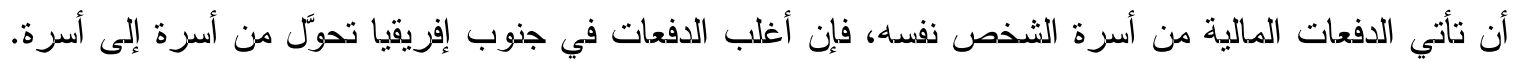

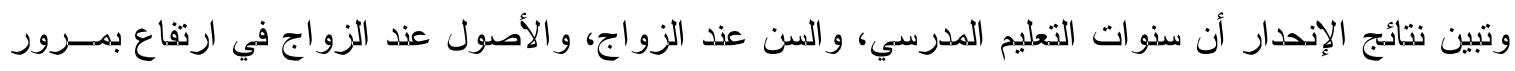

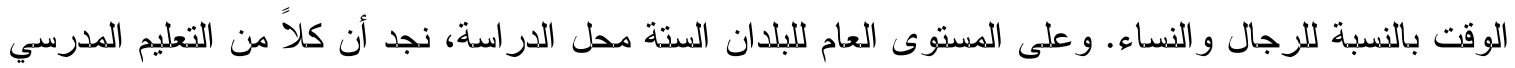

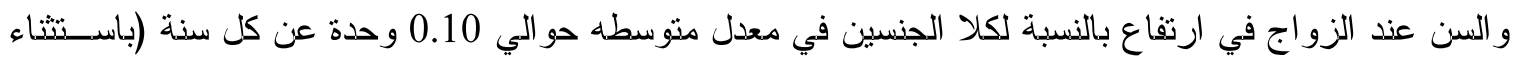

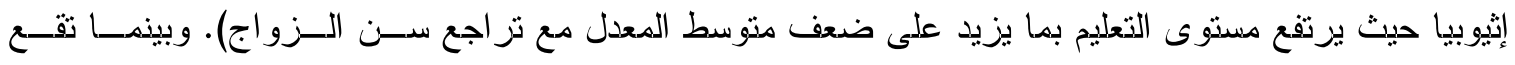

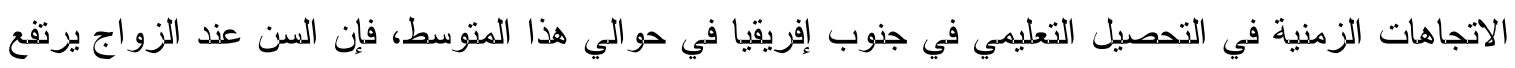

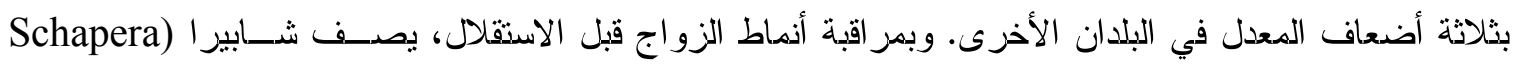

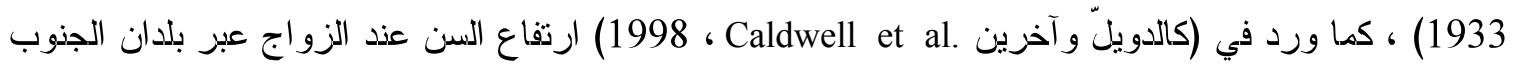

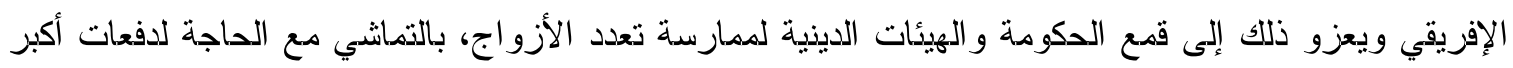

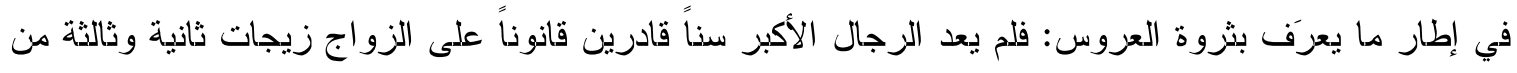




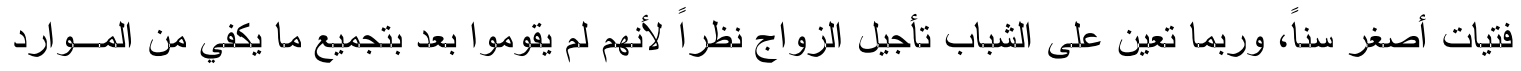

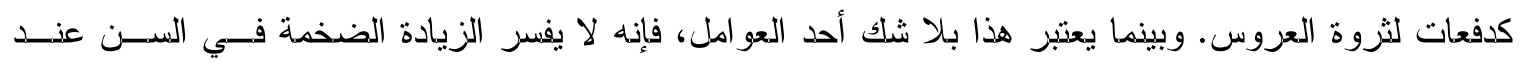

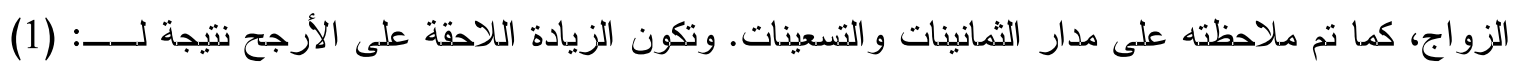

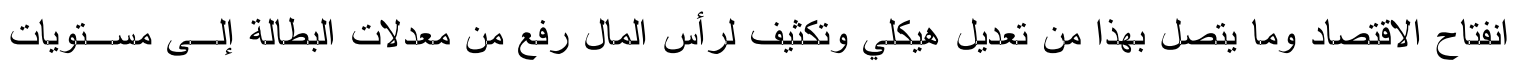

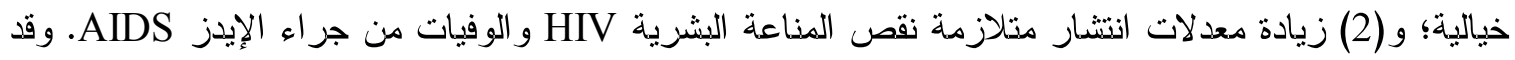

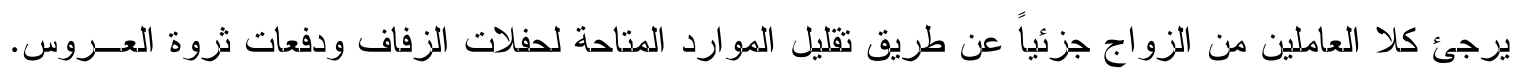

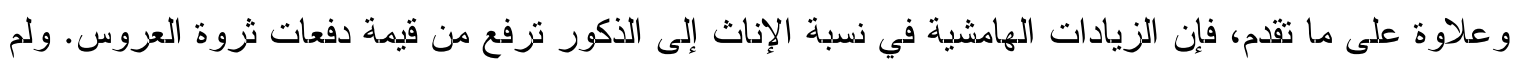

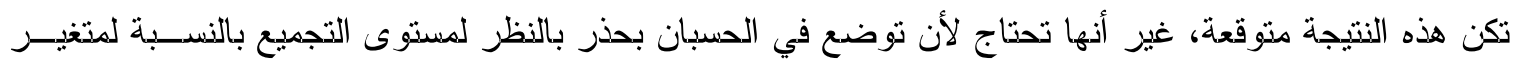
"ضائقة الزواج marriage squeeze ".

ويقلل بقاء الآباء والأمهات على قيد الدياة لدين زواج الأبناء، وهو دليل يشير إلى الوصول إلى موارد الو الدين

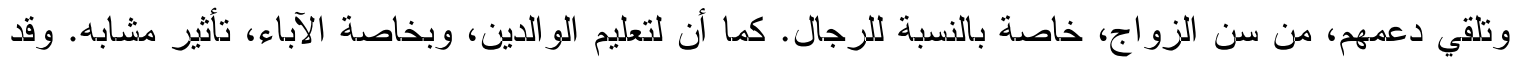

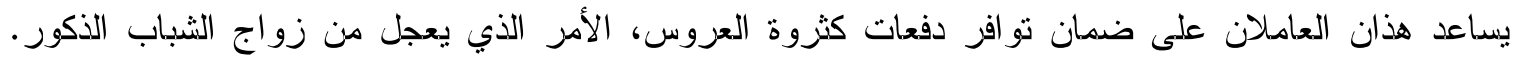

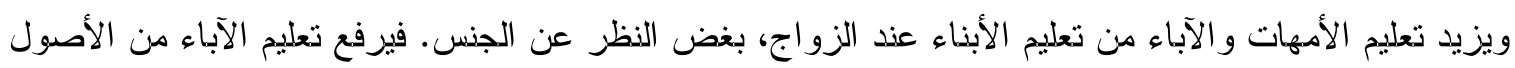

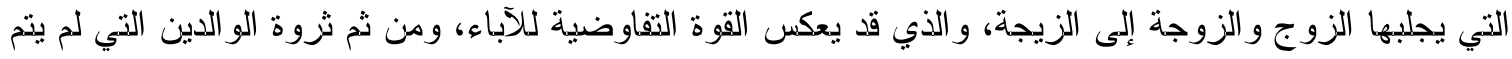

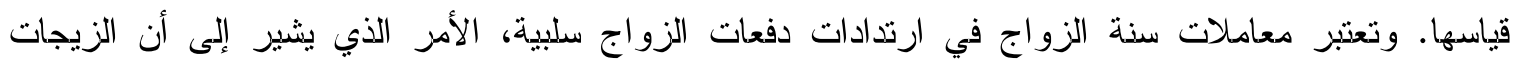
الأحدث يتم فيها دفع مبالغ أصغر . وتتسق هذه النتائج مع الاتجاهات الزمنية الدقدمة في الجدول (2).

ويعرض الجدول (11)محددات للاختلافات بين الأزواج و الزوجات. فتتسم الزيجات الأحسدث بانذفـاض أوجهـه

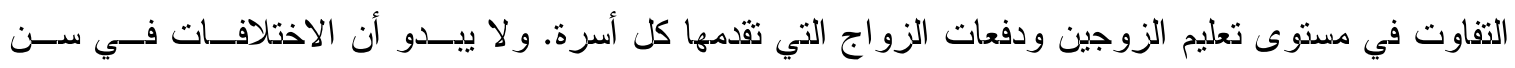

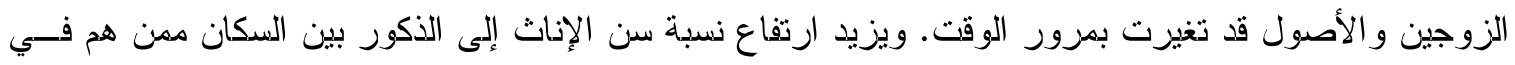

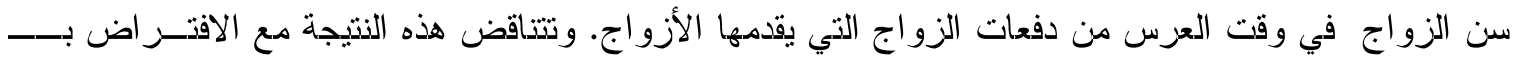

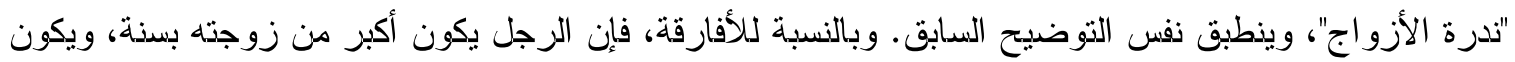

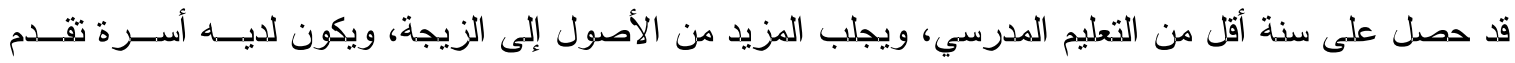

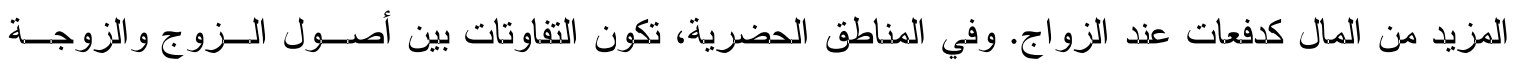

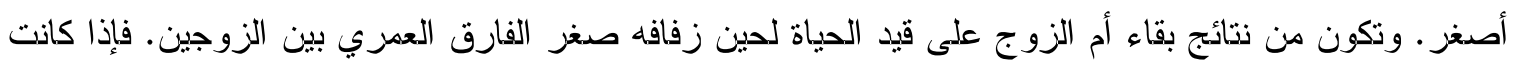

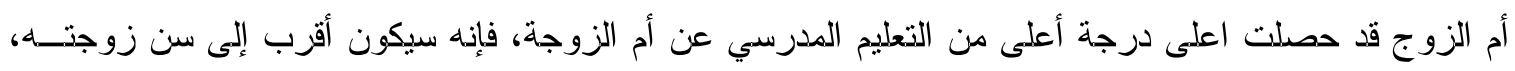
وسيكون الفارق في عدد الأصول التي يجلبها وزوجته إلى الزيجة أقل. ومن ناحية أخرى، فإذإ كان أبــوه أكثــر

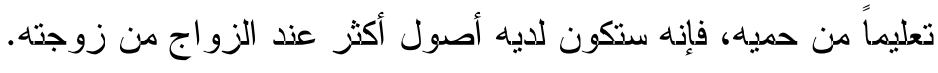


المكسيك. بالذسبة لكل من الزوج و الزوجة، ترتفع سذوات التعليم المدرسي مع تقدم سذوات الزواج جدول (12).

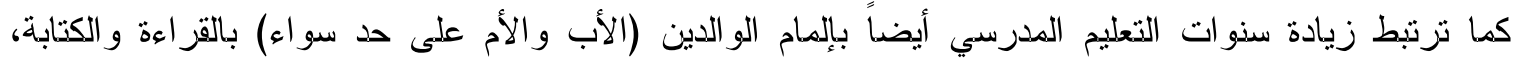
و التحاق كليهما بالتعليم الابتدائي و إتمامهما له. 
جدول(10) محددات سنوات التعليم المدرسي، و السن عند الزواج، والأصول عند الزواج، ودفعات الزواج، جنوب إفريقيا

\begin{tabular}{|c|c|c|c|c|c|c|c|c|c|c|c|c|c|c|c|}
\hline \multicolumn{3}{|c|}{ قيمة دفعات الزواج التي تقدمها الأسرة } & \multicolumn{4}{|c|}{$\begin{array}{c}\text { إحصاء الأصول عند الزواج } \\
\text { (tobit) }\end{array}$} & \multicolumn{4}{|c|}{$\begin{array}{c}\text { السن عذد الزواج (OLS with robust SEs) } \\
\text { (OS }\end{array}$} & \multicolumn{4}{|c|}{$\begin{array}{c}\text { سنوات الدراسة } \\
\text { (OLS with robust SEs) }\end{array}$} & \\
\hline الز & \multicolumn{2}{|r|}{ الزوج } & \multicolumn{2}{|c|}{ 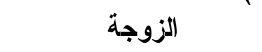 } & \multicolumn{2}{|c|}{ الزوج } & \multicolumn{2}{|c|}{ الزوجة } & \multicolumn{2}{|c|}{ الزوج } & \multicolumn{2}{|c|}{ الزوجة } & \multicolumn{2}{|c|}{ الزوج } & \\
\hline معامل & $\mathbf{t}$ & معامل & $\mathbf{t}$ & معامل & $\mathbf{t}$ & معامل & $\mathbf{t}$ & معامل & $\mathbf{t}$ & معامل & $\mathbf{t}$ & معامل & $\mathbf{t}$ & معامل & \\
\hline 00.31 & -.08 & -.545 .46 & 4.71 & 0.04 & 2.44 & 0.02 & 11.73 & 0.35 & 10.28 & 0.33 & 8.85 & 0.13 & 6.15 & 0.10 & سنة الزواج \\
\hline 8.834 .74 & 2.52 & 182.234 .20 & 0.01 & 0.02 & 0.96 & 2.29 & 0.98 & 8.07 & 0.07 & 0.61 & -.08 & -.64 & -.194 & -.27 & نسبة كل جنس \\
\hline 0.263 .96 & 6.27 & 52.227 .22 & 0.72 & 0.20 & 5.84 & 1.55 & 0.35 & 0.28 & 1.66 & 1.42 & -.14 & $-\quad .99$ & -.20 & -.06 & عرق إفريقي \\
\hline 6.362 .25 & -.40 & $\begin{array}{l}-\quad 1.897 .23 \\
\end{array}$ & 1.55 & 0.39 & -.50 & -1.35 & -1.25 & -1.20 & -.97 & -1.85 & 4.87 & 2.02 & 6.32 & 2.79 & مقيم حضزي \\
\hline 9.310 .94 & 0.25 & 1.655 .72 & -.92 & -47 & 0.81 & 0.18 & -.15 & -.85 & -.23 & -.50 & 0.29 & 0.12 & 1.19 & 0.49 & الالحياة على قليد \\
\hline .962 .29 & 0.31 & 1.674 .52 & 0.29 & 0.06 & -1.26 & $-\quad .05$ & -.13 & -1.66 & -.56 & -.63 & -1.07 & -.02 & 0.64 & 0.22 & الألياة على قديد \\
\hline 2.130 .33 & 0.34 & 2.139 .56 & -.36 & -.30 & -.20 & -1.24 & -.35 & -1.99 & -.08 & -.47 & 4.30 & 1.55 & 4.24 & 1.59 & على ألي قسط الأملة \\
\hline 1.378 .11 & 1.89 & 12.145 .61 & 2.60 & 0.61 & 2.12 & 0.44 & -.45 & -1.69 & -.89 & -.34 & 3.63 & 1.39 & 3.09 & 1.20 & على أي قالب قاصل \\
\hline 73.536 .40 & 5.69 & 2.831 .604 .00 & -.69 & -5.02 & -.57 & -1.86 & -1.61 & $\begin{array}{l}-\quad 79.01 \\
492\end{array}$ & -.86 & $\begin{array}{l}-\quad 24.85 \\
\\
492\end{array}$ & -.58 & -47.80 & -89 & - 82.99 & المدابت \\
\hline & & & & & & & & 19.48 & & 20.42 & & & & & F-statistic \\
\hline & & & & & & & & $\begin{array}{l}0.00 \\
0.30\end{array}$ & & $\begin{array}{l}0.00 \\
0.30\end{array}$ & & & & & $\begin{array}{r}\text { Prob }>F \\
R^{2}\end{array}$ \\
\hline 492 & & 492 & & 492 & & 492 & & & & & & 492 & & 492 & $\mathrm{Chi}^{2}$ \\
\hline 35.36 & & 110.35 & & 41.02 & & 92.64 & & & & & & 242.77 & & 275.98 & LR Chi ${ }^{2}$ \\
\hline 0.00 & & 0.00 & & 0.00 & & 0.00 & & & & & & 0.00 & & 0.00 & Prob> chi ${ }^{2}$ \\
\hline 0.01 & & 0.01 & & 0.03 & & 0.05 & & & & & & 0.10 & $\ldots$ & 0.11 & Pseudo $R^{2}$ \\
\hline
\end{tabular}


جدول (11) محددات الاختلافات (بين الزوج والزوجة) في سنوات التعليم المدرسي، والسن عند الزواج،

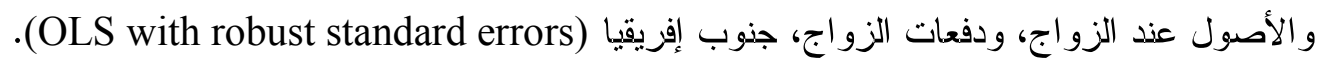

\begin{tabular}{|c|c|c|c|c|c|c|c|c|}
\hline \multicolumn{2}{|c|}{ قيمة دفعات الزواج } & \multicolumn{2}{|c|}{ إحصاء الأصول عذد } & \multicolumn{2}{|c|}{ السن عند الزواج } & \multicolumn{2}{|c|}{ سذوات التعليم } & \\
\hline $\mathbf{t}$ & معامل & $\mathbf{t}$ & معامل & $\mathbf{t}$ & معامل & $\mathbf{t}$ & معامل & \\
\hline-.85 & $-\quad .015 .39$ & $-\quad .66$ & 0.00 & $-\quad 1.99$ & $-\quad 1.02$ & $-\quad .59$ & $-\quad .03$ & سنة الزواج \\
\hline 2.37 & 155.126 .70 & 1.37 & 2.36 & $-\quad 1.71$ & -.67 & 0.26 & 0.94 & 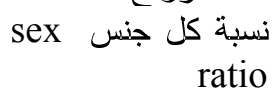 \\
\hline 3.02 & 23.929 .24 & 5.19 & 0.92 & 1.81 & 1.08 & $-\quad .49$ & $-\quad .98$ & عزق إفريقي \\
\hline-.39 & $-\quad 0.446 .60$ & -.13 & -1.55 & -.29 & $-\quad .76$ & 1.46 & 0.50 & دقيم حضري \\
\hline-1.38 & -.248 .93 & 1.26 & 0.20 & -1.13 & $-\quad .09$ & 0.79 & 0.30 & الحياة الزوجدة على فلى قيد \\
\hline 1.86 & 9.275 .94 & 0.53 & 0.08 & 1.65 & 0.84 & 0.62 & 0.18 & الحياة عذد الزة عافى قيد \\
\hline 0.60 & 3.613 .20 & 1.02 & 0.17 & $-\quad .82$ & -.65 & 0.55 & 0.18 & الحياة عذد الزفألى قيد \\
\hline-1.21 & -.001 .00 & -.03 & -1.14 & -.85 & $-\quad .85$ & - 1.19 & $-\quad .05$ & البياة عند الزئ على قيد \\
\hline & & -.65 & & - .77 & & & & اختلافات فى: \\
\hline 1.03 & 845.10 & 2.30 & -1.08 & 0.25 & -1.26 & 0.72 & 0.04 & تعلديم الأبت المدر سـى المدر \\
\hline-.03 & -69.80 & 0.49 & 0.05 & 1.30 & 0.02 & 0.77 & 0.04 & \\
\hline 4.50 & 1.837 .739 .00 & & 5.95 & & 57.10 & 2.61 & 60.61 & الثابت \\
\hline & 492 & & 492 & & 492 & & 492 & عدد الملاحظات \\
\hline & 7.04 & & 15.18 & & 5.47 & & 3.87 & F-statistic \\
\hline & 0.00 & & 0.00 & & 0.00 & & 0.00 & Prob $>F$ \\
\hline & 0.12 & & 0.19 & & 0.14 & & 0.08 & $\mathrm{R}^{2}$ \\
\hline
\end{tabular}

إحصائيات t المبيذة بالذط الغليظ تبين الأهمية عند 10 بالمائة أو أفضل.

وبينما يكون لمتغيز الوضع الاجتماعي للأب -الذي يدلل عليه ارتداء الأب للأحذي - أثر إيجابي وهام على تعليم

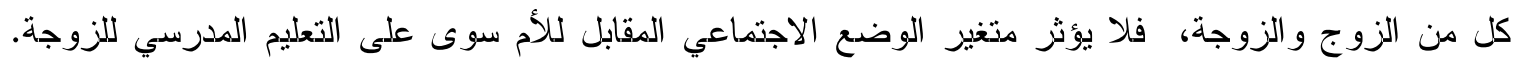

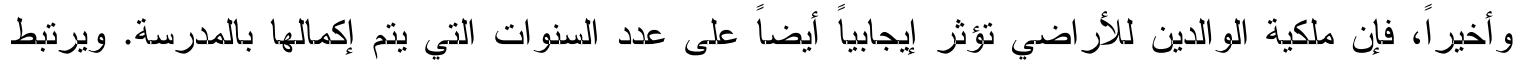

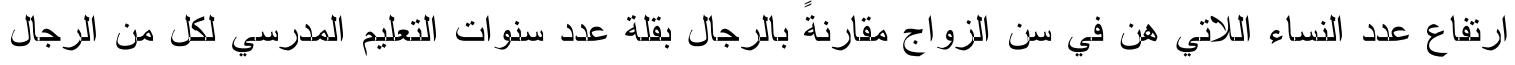

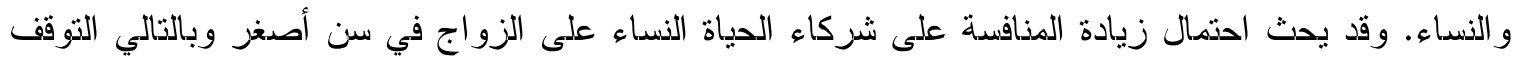
عن الدر اسة بالمدرسة.

وتثابهاً مع البلدان الأخرى التي شملتها الدراسة، فإن كلا الزوجين يكونان أكبر سناً في الزيجات الأحدث. فـإذا

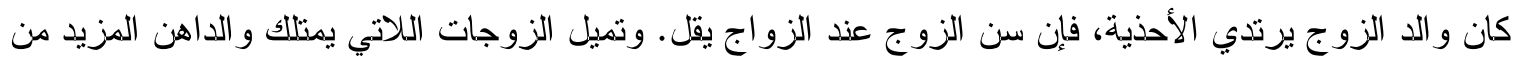

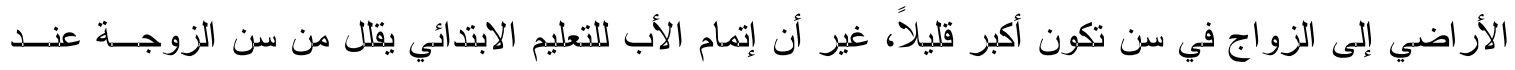

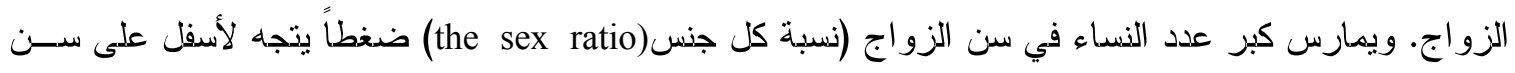

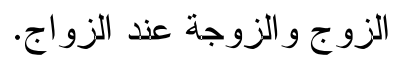


جدول(12) محددات سذوات التعليم المدرسي، والسن عند الزواج، وملكية الأراضي، و الأصول عند الزواج، المكسيك.

\begin{tabular}{|c|c|c|c|c|c|c|c|c|c|c|c|c|c|c|c|}
\hline \multicolumn{3}{|c|}{ محصلة الأصول } & \multicolumn{4}{|c|}{ (بروبيت مي الأراضي متينة) } & \multicolumn{4}{|c|}{$\begin{array}{c}\text { السن عذد الزواج (OLS with robust SEs) } \\
\text { (OLS }\end{array}$} & \multicolumn{4}{|c|}{$\begin{array}{l}\text { سنوات الدراسة } \\
\text { (tobit) }\end{array}$} & \\
\hline الز ل ل & \multicolumn{2}{|c|}{ الزوج } & \multicolumn{2}{|c|}{ الزوجة } & \multicolumn{2}{|c|}{ الزوج } & \multicolumn{2}{|c|}{ الزوجة } & \multicolumn{2}{|c|}{ الزوج } & \multicolumn{2}{|c|}{ الزوجة } & \multicolumn{2}{|c|}{ الزوج } & \\
\hline معامل & $t$ & معامل & $\mathbf{z}$ & $\mathbf{d F} / \mathbf{d} \mathbf{X}$ & $\mathbf{z}$ & $\mathbf{d F} / \mathbf{d} X$ & $\mathbf{t}$ & معامل & $\mathbf{t}$ & معامل & $\mathbf{t}$ & معامل & $\mathbf{t}$ & معامل & \\
\hline 0.00 & 4.44 & 0.00 & 1.06 & 0.00 & -.55 & 0.00 & 14.10 & 0.04 & 4.70 & 0.02 & 54.19 & 0.13 & 46.48 & 0.12 & سنة الزواج \\
\hline-1.21 & -.98 & -1.14 & 0.67 & 0.00 & -.30 & -1.08 & -.37 & -.94 & -.58 & -.09 & -.27 & -.29 & -.05 & -.21 & نسبة كل جنس \\
\hline-1.01 & 0.45 & 0.01 & -.13 & 0.00 & -.44 & -1.01 & 0.71 & 0.11 & -.30 & -.32 & 5.89 & 0.76 & 5.64 & 0.76 & والأب \\
\hline 0.03 & 1.21 & 0.01 & -.76 & 0.00 & -.74 & -1.01 & -.21 & -1.16 & $-\quad .02$ & 0.00 & 3.79 & 0.49 & 3.72 & 0.54 & وتكتب \\
\hline 0.00 & 0.49 & 0.01 & -.45 & 0.00 & -.52 & -1.01 & -.10 & $-\quad .02$ & -.25 & -.31 & 2.52 & 0.33 & 1.72 & 0.23 & التلى الأب بعض \\
\hline-1.01 & -.92 &.- .01 & 0.91 & 0.00 & 0.71 & 0.01 & 0.14 & 0.02 & -.14 & -.29 & 3.38 & 0.43 & 1.18 & 0.17 & 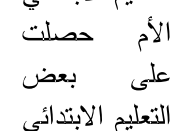 \\
\hline 0.00 & 2.86 & 0.07 & & انسدب & -.09 & 0.00 & -.73 & -1.50 & 1.00 & 0.71 & 2.95 & 0.80 & 3.06 & 0.98 & الأبتليم الابتدائي \\
\hline 0.09 & 1.66 & 0.05 & 0.84 & 0.00 & -1.84 & -1.03 & 0.63 & 0.23 & -.48 & -.89 & 1.99 & 0.65 & 2.13 & 0.83 & التُليم الابتدائي \\
\hline 0.01 & 1.69 & 0.02 & 0.06 & 0.00 & 0.97 & 0.01 & -1.61 & -1.08 & -.24 & -.70 & 2.06 & 0.23 & 1.79 & 0.21 & أحذية الأب يزتدي \\
\hline 0.05 & 2.06 & 0.02 & 0.86 & 0.00 & 1.79 & 0.02 & 1.30 & 0.16 & 0.96 & 0.20 & 3.57 & 0.39 & 0.36 & 0.04 & أحذية الأم" ترتدي \\
\hline 0.00 & 2.32 & 0.00 & 2.76 & 0.00 & 4.74 & 0.00 & 3.44 & 0.03 & 0.91 & 0.01 & 4.14 & 0.03 & 3.07 & 0.02 & 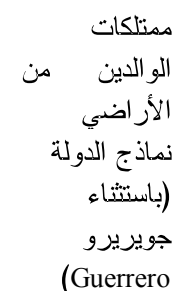 \\
\hline 0.15 & 2.12 & 0.03 & 0.54 & 0.63 & 7.37 & 0.15 & 3.69 & 0.55 & 5.14 & 1.46 & 9.06 & 1.43 & 4.66 & 0.73 & $\begin{array}{r}\text { هيدالجو } \\
\text { Hidalgo }\end{array}$ \\
\hline 0.30 & 8.03 & 0.12 & 0.57 & 0.76 & 1.73 & 0.03 & 4.10 & 0.65 & 3.54 & 1.04 & 9.67 & 1.61 & 0.53 & 0.09 & ميشّو اكان \\
\hline
\end{tabular}




\begin{tabular}{|c|c|c|c|c|c|c|c|c|c|c|c|c|c|c|c|}
\hline & & & & & & & & & & & & & & & Michoacan \\
\hline 0.09 & 3.57 & 0.05 & 0.48 & 0.54 & -1.58 & -1.01 & 0.83 & 0.13 & 4.33 & 1.25 & 7.02 & 1.12 & 3.70 & 0.58 & Pويبلا Puebla \\
\hline 0.05 & 2.28 & 0.04 & & انسدب & -1.03 & 0.00 & 4.21 & 0.80 & 2.03 & 0.67 & 8.04 & 1.56 & 4.90 & 0.96 & $\begin{array}{l}\text { كويريتارو } \\
\text { Queretaro }\end{array}$ \\
\hline 0.16 & 1.25 & 0.02 & 0.52 & 0.60 & 2.20 & 0.04 & 5.02 & 0.80 & 7.05 & 2.08 & 12.37 & 1.98 & 4.68 & 0.74 & 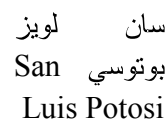 \\
\hline 0.18 & 3.77 & 0.05 & 0.54 & 0.49 & 3.00 & 0.05 & 0.57 & 0.08 & 2.75 & 0.74 & 9.91 & 1.49 & 6.98 & 1.04 & $\begin{array}{c}\text { فير اكروز } \\
\text { Veracruz }\end{array}$ \\
\hline-.82 & -.60 & -.82 & & & & & -0.10 & -0.46 & -.81 & -5.80 & -3.41 & -65.20 & -5.77 & $-\quad 25.59$ & التابت \\
\hline 0.30 & & 0.20 & & & & & & & & & & 3.06 & & 3.09 & $\begin{array}{r}\text { شرط الانثقاء } \\
\text { Selection } \\
\text { term }\end{array}$ \\
\hline 12.279 & & 11.675 & & 11.556 & & 11.675 & & 12.279 & & 11.506 & & 12.218 & & 11.488 & المداحظات \\
\hline & & & & & & & & 18.96 & & 7 & & & & & F-statistic \\
\hline & & & & & & & & 0.00 & & 0.00 & & & & & Prob $\gg F$ \\
\hline & & & & & & & & 0.03 & & 0.01 & & & & & $\mathrm{R}^{2}$ \\
\hline 331.63 & & 349.43 & & غير & & 275.38 & & & & & & 4.765.59 & & 3.275 .26 & $\mathrm{Chi}^{2}$ \\
\hline 0.00 & & 0.00 & & غديرب & & 0.00 & & & & & & 0.00 & & 0.00 & Prob $>\mathrm{chi}^{2}$ \\
\hline 0.07 & & 0.06 & & ـ محسوب 0.05 & & 0.03 & 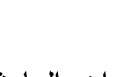 & & 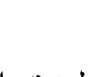 & & . & 0.09 & & 0.06 & Pseudo $R^{2}$ \\
\hline
\end{tabular}




\begin{tabular}{|c|c|c|c|c|c|c|c|c|}
\hline \multirow{2}{*}{\multicolumn{2}{|c|}{$\begin{array}{c}\text { قيمة دفعات الزواج } \\
\text { (OLS with robust } \\
\text { SEs) }\end{array}$}} & \multicolumn{2}{|c|}{$\begin{array}{l}\text { إحصاء الأصول عند الزواج } \\
\text { (ordered probit with } \\
\text { robust SEs }\end{array}$} & \multicolumn{2}{|c|}{$\begin{array}{l}\text { (السن عند الزواج } \\
\text { (OLS with robust } \\
\text { SEs) }\end{array}$} & \multicolumn{2}{|c|}{$\begin{array}{l}\text { سذوات التعليم } \\
\text { (OLS with robust } \\
\text { SEs) }\end{array}$} & \multirow[b]{3}{*}{ سنة الزو اج } \\
\hline & & $\mathbf{z}$ & معامل & $\mathbf{t}$ & معامل & $\mathbf{t}$ & معامل & \\
\hline 5.63 & 0.00 & -.96 & -1.01 & $-\quad .88$ & -.03 & -.57 & -.01 & \\
\hline-.02 & -1.06 & -1.69 & -1.20 & 1.55 & 1.39 & 2.34 & 1.28 & 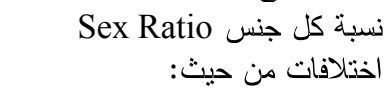 \\
\hline$-\quad .60$ & 0.00 & 0.11 & 0.01 & -1.76 & -.12 & 2.76 & 0.25 & الأب يقرأ ويكثب \\
\hline 0.77 & 0.00 & -.00 & $-\quad 1.05$ & 0.58 & 0.10 & 3.20 & 0.31 & الأم تقرأ وتكتب \\
\hline 0.83 & 0.00 & 0.10 & 0.01 & 0.56 & 0.09 & 1.05 & 0.10 & الابتدائى حصل على بعض التعليم \\
\hline-.22 & 0.00 & 1.09 & 0.06 & $-\quad .97$ & -.16 & $-\quad .63$ & $-\quad .06$ & الابتدائى حصلت على بعض التعليم \\
\hline 1.29 & 0.01 & -1.25 & -1.03 & 0.56 & 0.21 & 1.95 & 0.42 & الأب أكمل التعليم الابتدائي \\
\hline 0.03 & 0.00 & -.62 & -1.21 & -1.63 & -.26 & 0.18 & 0.05 & الأم أكملت التعليم الابتدائي \\
\hline-.18 & 0.00 & -.25 & -1.06 & -.33 & -.22 & 0.91 & 0.08 & الأب يرتدي أحذية \\
\hline-1.54 & 0.00 & 0.99 & 0.06 & -.39 & -.26 & 1.70 & 0.16 & الأم ترتدي أحذية \\
\hline 0.75 & 0.00 & 0.78 & 0.00 & 2.31 & 0.02 & 1.43 & 0.01 & ممتلكات ألو الدين من الأراضي \\
\hline-.44 & -1.56 & & & 9.25 & 65.91 & 4.39 & 15.06 & الثابت \\
\hline & 11.177 & & 11.177 & & 11.177 & & 11.072 & عدد الملاحظات \\
\hline & 3.34 & & & & 8.19 & & 11.28 & F-statistic \\
\hline & 0.00 & & & & 0.00 & & 0.00 & Prob $\gg F$ \\
\hline & 0.00 & & & & 0.01 & & 0.01 & $\mathrm{R}^{2}$ \\
\hline & & & 36.93 & & & & & $\mathrm{Chi}^{2}$ \\
\hline & & & 0.00 & & & & & Prob>chi ${ }^{2}$ \\
\hline & & & 0.00 & & & & & Pseudo $\mathrm{R}^{2}$ \\
\hline
\end{tabular}


كيف تؤثر الاتجاهات الخاصة بالزمن وخلفية الو الدين على الأصول التي يجلبها كل زوج وزوجة إلى الزيجـة؟؟

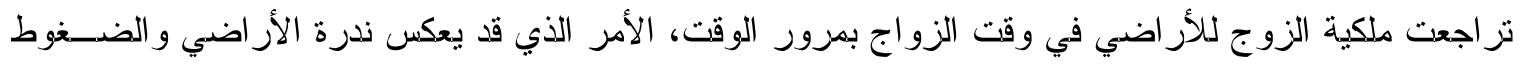
السكانية. أما ملكية الزوجات للأر اضي، وهي نسبة لا تذكر، فلم تتأثر بالاتجاهـات العلمـاني (secular trends).

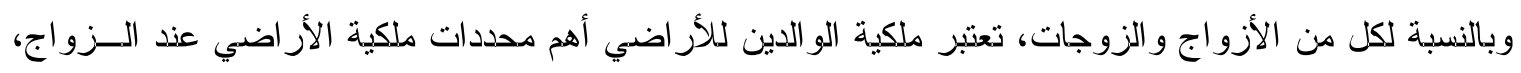

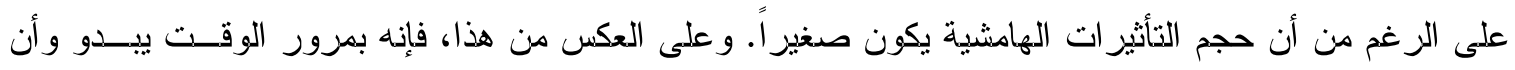

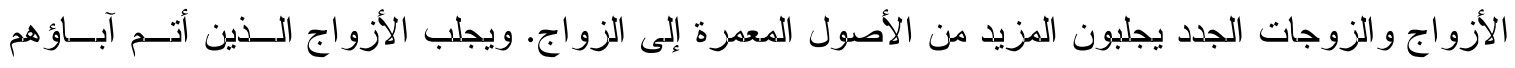
التعليم الابتدائي و الذين كان و الداهم يرتديان أحذية خلال طفولة الزوج المزيد من الأصول إلـى الزيجــة. أمسا

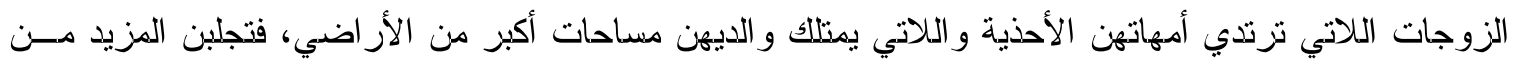
الأصول إلى زيجاتهن. ويبدو أن زيادة عدد النساء في سن الزواج تقلل من الأصول المعمزة التي يجلبهـا كــلا

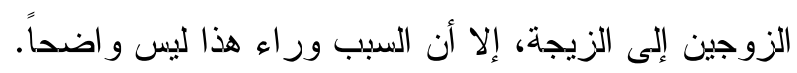

فإذا اتجهنا الآن إلى الفوارق التي تحدث بمزور الوقت، فإننا نجد أن الاختلافات في التعليم المدرسي، و السن عند

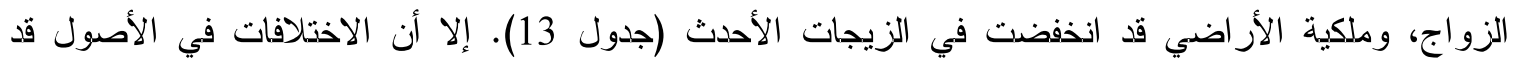
ارتفعت. وبالتالي، فإنه يبدو أنه بينما تضيق الفجوات في رأس المال البشري عند الزواج، فإن الاختلافات بين الجنسين من حيث ملكية الأصول المعمزة في ارتفاع. وتتعكس الاختلافات في مسنوى إلمام الو الدين بالقزاءة

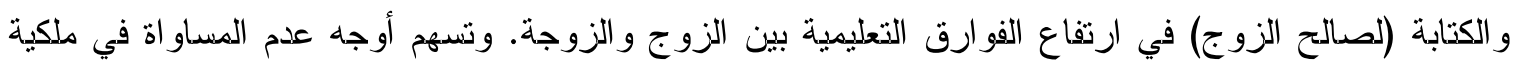

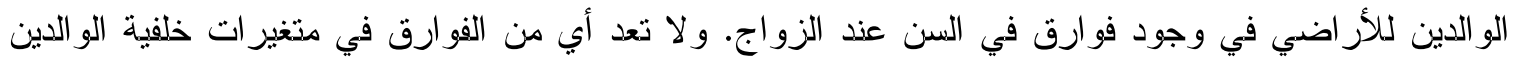
محددات هامة للاختلافات بين الجنسين من حيث محصلة الأصول. غيز أذه تجدر ملاحظة أذه نظر أ لكون المقياس الذي نحدد على أساسه ملكية الأراضي لا يعدو كونه متغيز اصطناعي لما إذا كان الزوج أو كانت الزوجة تمتلك هلك

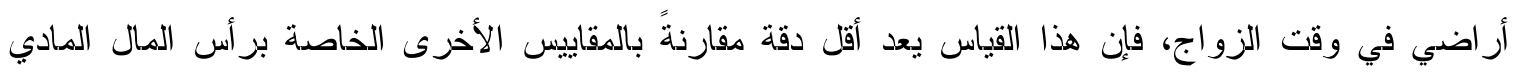
و البشري. وتؤثر نسبة كل جنس Sex ratio على سذوات التعليم المدرسي والاختلافات في محصلة الأصول بطرق معاكسة: فترفع زيادة عدد الإناث في سن الزواج من فجوة التعليم المدرسي بين الأزواج و الزوجات، بيذما تقلل الفجوة بين مجموع أصول الزوج و الزوجة. ومن المدكن، بسبب المنافسة من نساء أخريات، أن نترك النساء المدرسة مبكراً بغية أن نتزوجن. وبسبب أن المكسيك ليست مجتمعاً تسود فيه تقاليد سعر العزوس أو المهور، فإذإ

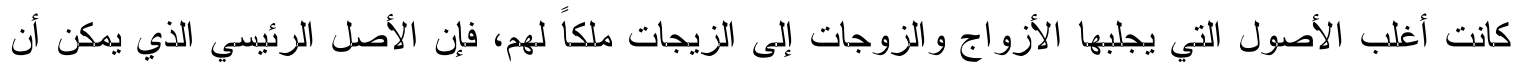

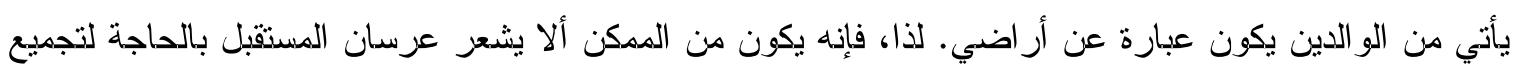
المزيد من الأصول حتى يكونوا مثقدمين جديرين بالزواج في سوق الزواج، وذلك بسبب كثرة الإناث في سن الزواج. 
جدول (14) محددات سنوات التعليم المدرسي، و السن عند الزواج، والأصول عند الزواج، جو اتيمالا، الزيجات الأولى لي

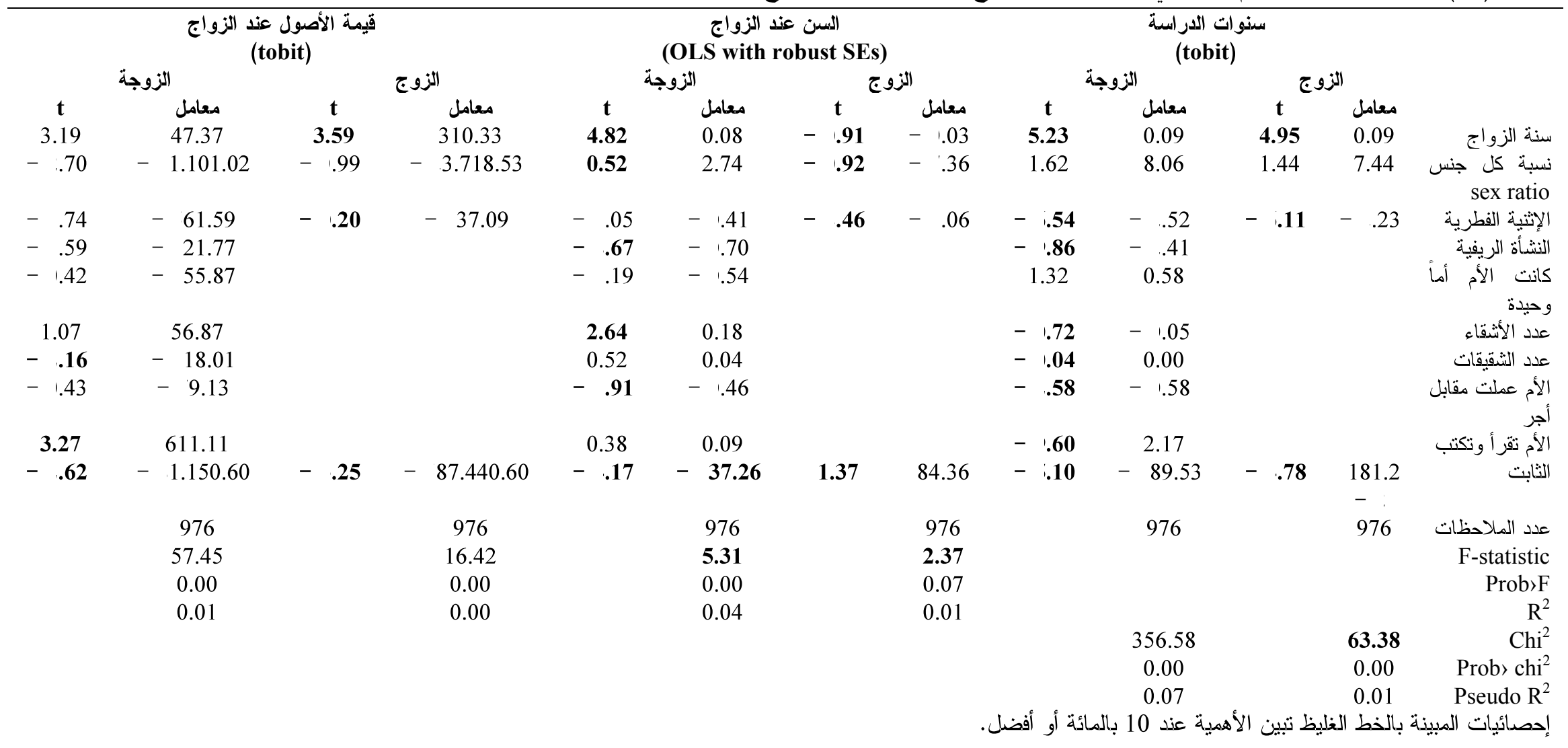


جواتيمالا. يبين الجدول 14 مستويات الإنددار. ويرتفع هنا السن عند الزواج (أو، بعبارة أدق، السن عند أول

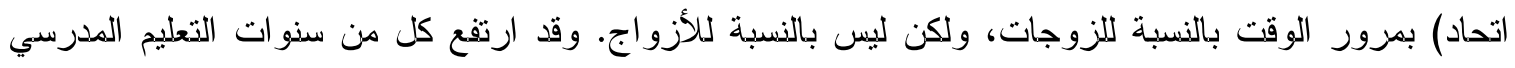

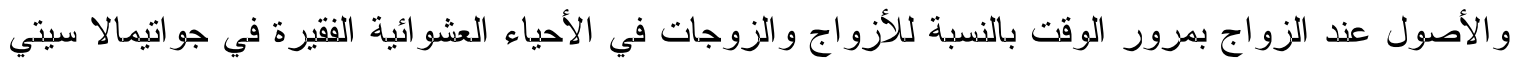
Guatemala City

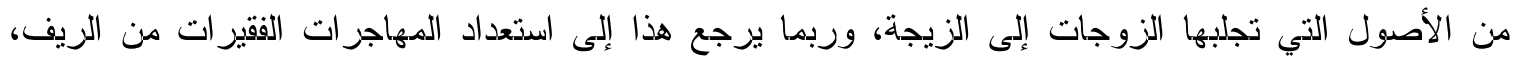

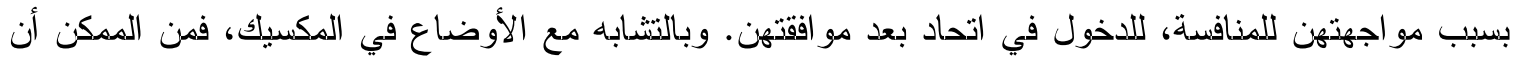

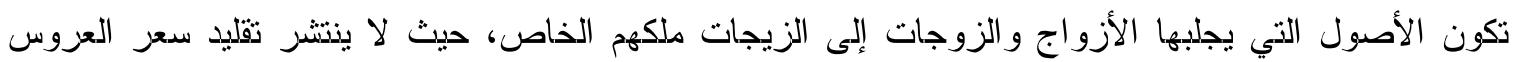

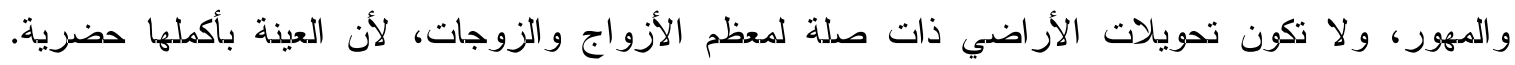

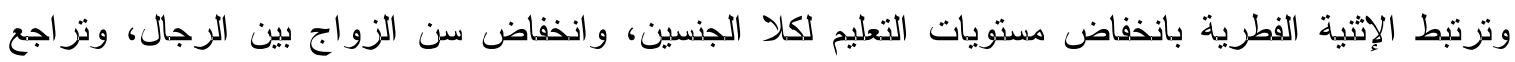
الأصول التي تجلبها النساء إلى الزيجات.

تؤثر الذصائص المرتبطة بخلفية الأسر على التوقيت وعلى رأس المال البشري والمادي الذي تجلبه النساء إلى

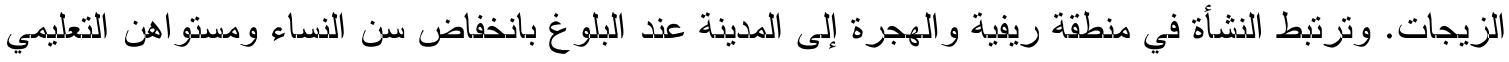

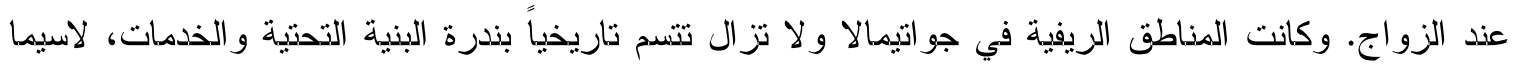

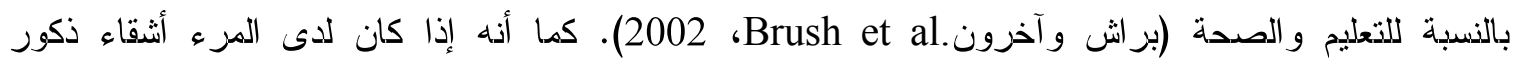

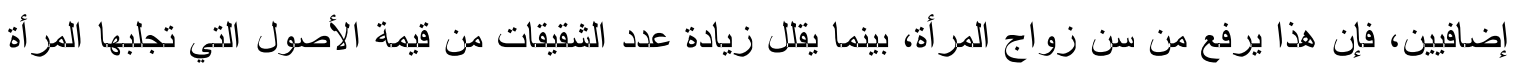

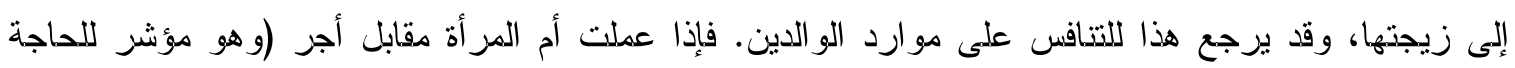

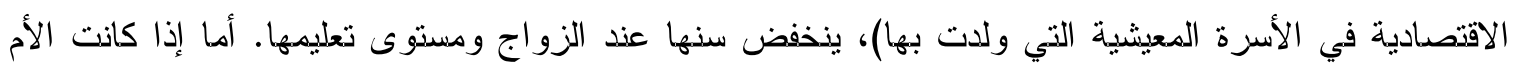

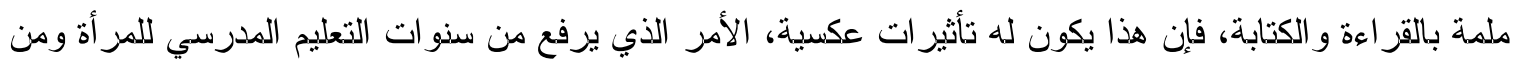
قيمة الأصول التي تجلبها إلى الزيجة.

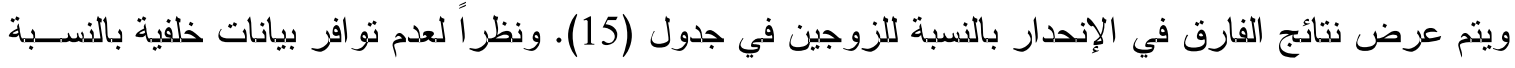

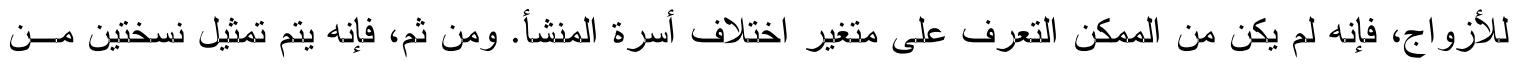

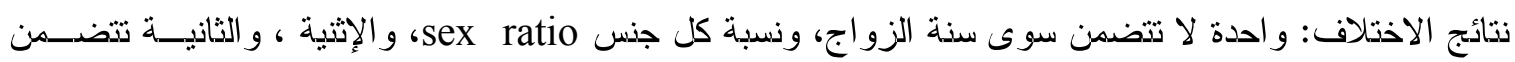

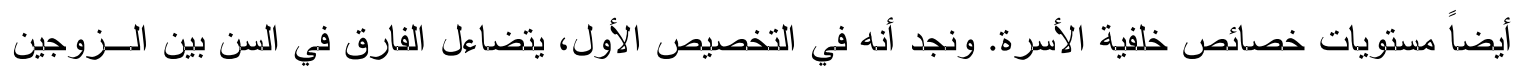

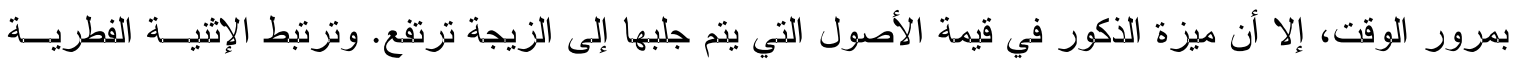

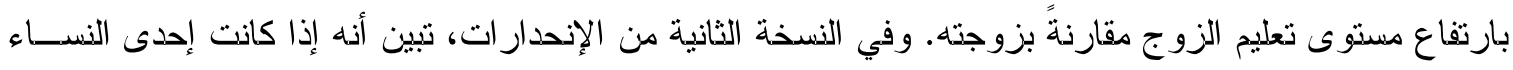

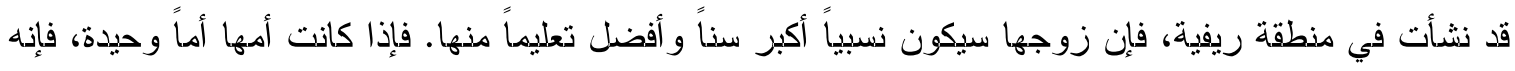

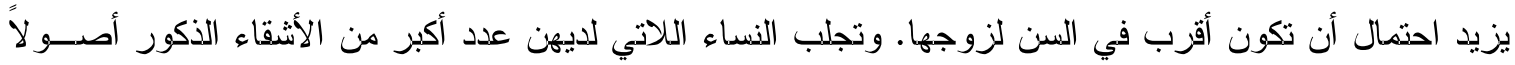

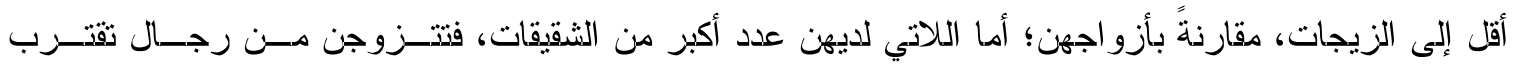

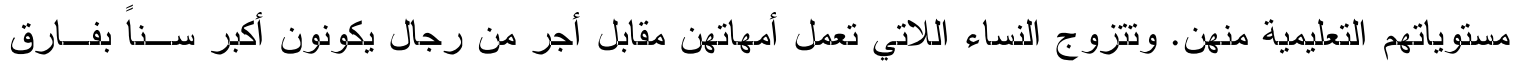

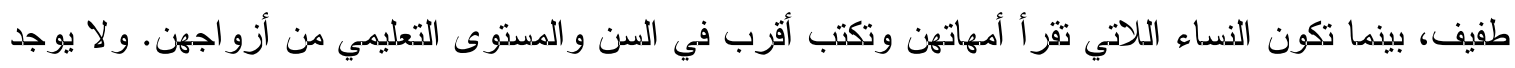

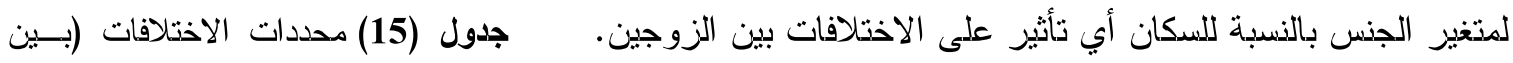




$$
\text { الزوج و الزوجة) في سنوات التعليم المدرسي، و السن عند الزواج، و الأصول عند الزواج، جواتيمـالا، الزيجـات الأولــى }
$$
(OLS with robust standard errors)

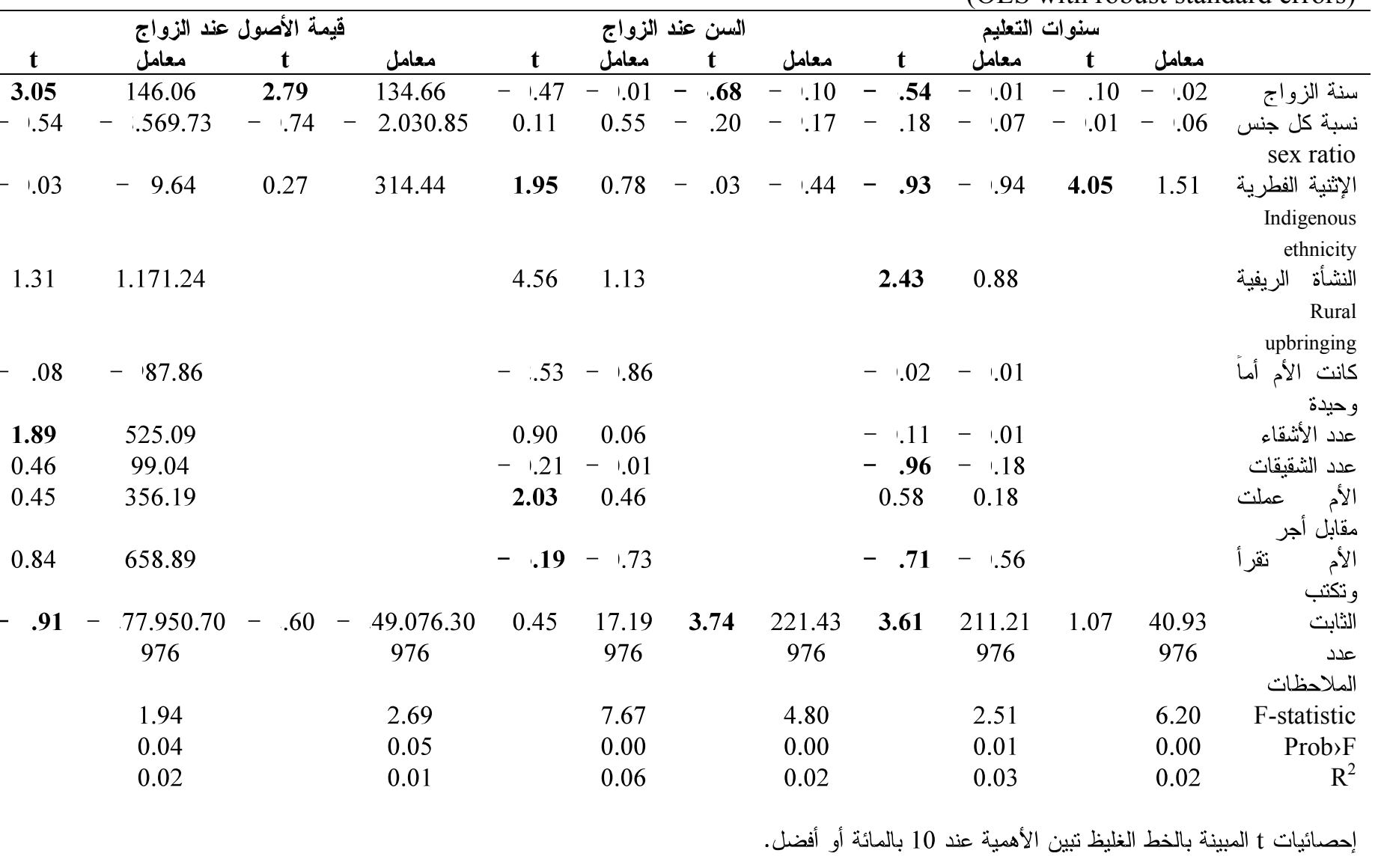




\section{ملخص و استتناجات}

يعرض جدول (16) ملخصاً للاتجاهات الخاصة بالتعليم المدرسي، و السن، والأصول عند الزواج، وذلك بذاء على معاملات الإنحدار على سنة الزواج. وقد ارتفع رأس المال البشري عند الزواج بالذسبة لكل من الزجال و النساء في أغليية البلدان التي شملتها دراستنا. وفي جميع البلدان الستة، ارتفعت سذوات التعليم المدرسي عند الزواج بالنسبة للأزو اج و الزوجات.

وتماثثياً مع ارتفاع دعدلات التحصيل الدر اسي، فإن السن عند الزواج يرتفع بالنسبة للأزواج و الزوجات في غالبية البلدان؛ بمعنى أن الرجال و النساء يتزوجون في أعمار أكثر تقدماً في الزيجات الحديثة الزئة. ويمكن ملاحظة هذاج

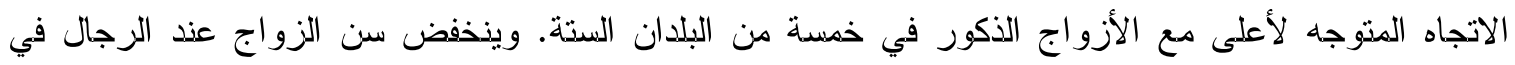
إثيوبيا، بالرغم دن أن هذا قد يعكس خطأ في القياس في متغير السن. كذلك تنتوج الإوج النساء في أعمار أكثر تأخراً في خمسة من البلدان الستة. وفي إثيوبيا، ينذفض السن عذد الزواج، الأمر الذي قد يعكس خطأ في القياس وعزلة فئلة

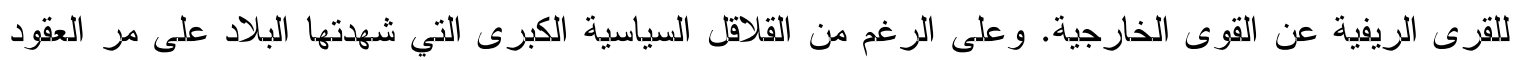

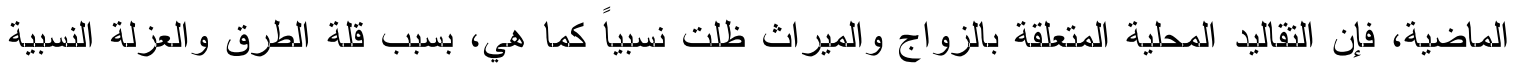

و لا يوجد اتجاه واحد بالنسبة لملكية الأراضي عند الزواج، على الرغم من أن الأزواج الذكور يجلبون في المعتاد المزيد من الأصول المادية للزيجات في أربعة من بين كل ستة بلدان. وفي البلدين اللذين لم يتم فيها جمع الته

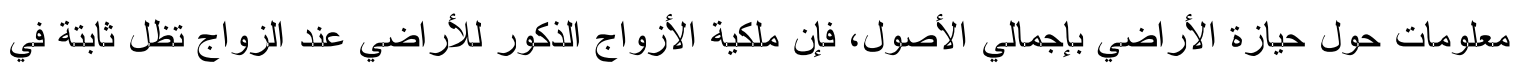

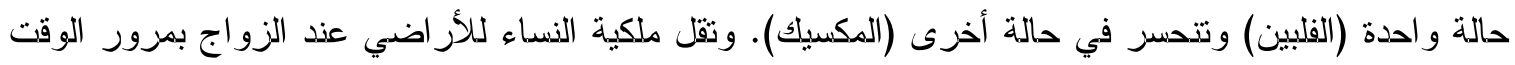
في الفلبين، وتظل ثابتة، وإن كانت شديدة الانذفاض (أقل من 1 بالمائة من الزوجات بالعينة) في المكسيك. وترتفع فيم أصول الأزواج مع الوقت في أربعة بلدان وتظل ثابتة في كل من إثُيوبيا و الفلبين. وترتفع قيم أصول الزورجات في ثلاثة بلدان (جو اتيمالا، و المكسيك، وجنوب إفريقيا)، وتظل ثابتة في إثيوبيا و الفلبين، وتتر اجع في بنجلاديش.

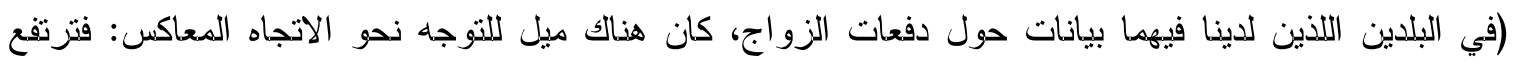
الدفعات عند الأزو اج وتتخفض عند الزوجات في بنجلاديش، وتتخفض بالنسبة لكليهما في جنوب إفريقيا).

و الآن لنتجه إلى الكيفية التي تغيرت بها الاختلافات في رأس المال البشري، و السن، و الأصول عند الزواج بـين الأزواج و الزوجات بمزور الوقت. ففي ثلاثة من البلدان الستة، انذفضت الفجوات بين الزورج والزئ الزوجة من حيث

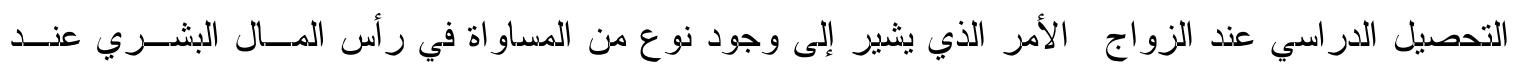

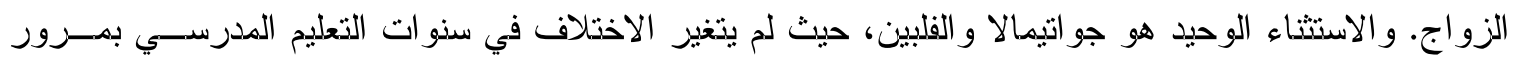

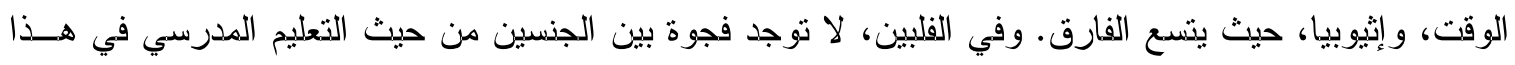

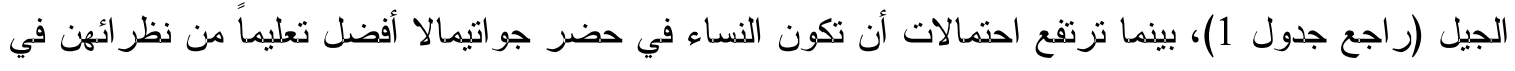

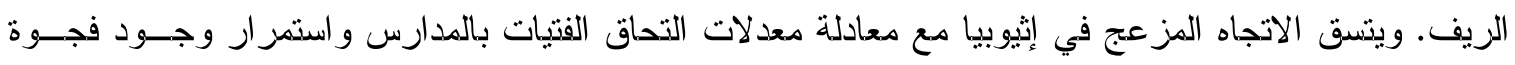


تعليمية بين الجنسين في منطقة جنوب الصحر اء الإفريقية sub-Saharan Africa ، وهو نتيجة لعدم تحسن المر افق التعليمية العامة وارتفاع تكاليف فرص تعليم الفتيات 23.

\begin{tabular}{|c|c|c|c|}
\hline الفارق (الزو & الزوجة & الزوج & \\
\hline & & & 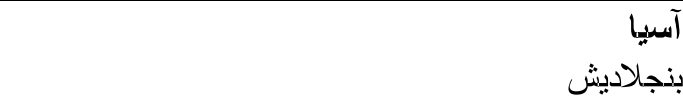 \\
\hline في انخفاض & في ارتفاع & في ارتفاع & سنوات التعليم \\
\hline في انخفاض & في ارتفاع & في ارتفاع & السن عند الزواج \\
\hline في ارتفاع & في انخفاض & في ارتفاع & 1996) قالصمة + التحويلات عند الزواج (تاكا Taka \\
\hline & & & الفلبين \\
\hline ثابت & في ارتفاع & في ارتفاع & 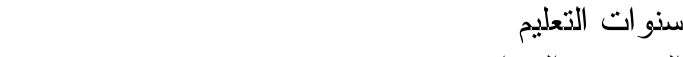 \\
\hline 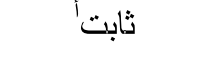 & في ارتفاع & في ارتفاع & السن عند الزواج \\
\hline في ارتفاع & في انخفاض & ثابت & مساحة الأر اضي عند الزواج \\
\hline 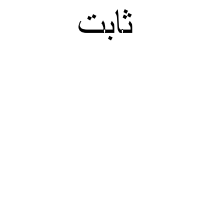 & ثابت & 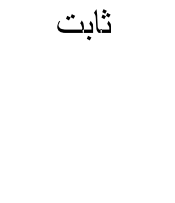 & 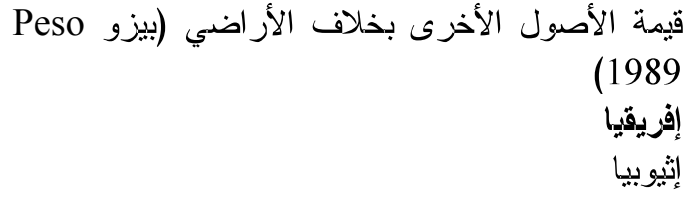 \\
\hline في ارتفاع & في ارتفاع & في ارتفاع & 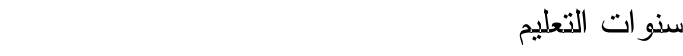 \\
\hline في انخفاض & 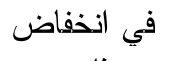 & في انخفاض & 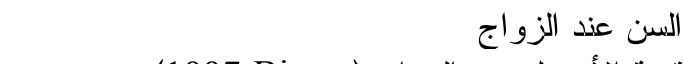 \\
\hline ثابت & ثابت & 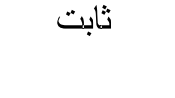 & جنوب إفريقيا عند الزواج (بير 1997 Birr) \\
\hline في انذفاض & في ارتفاع & في ارتفاع & سذوات التعليم \\
\hline 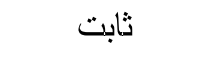 & في ارتفاع & في ارتفاع & السن عند الزواج \\
\hline ثابت & في ارتفاع & في ارتفاع & إحصداء الأصول عند الزواج \\
\hline في انخفاض & في انذفاض & في انذفاض & 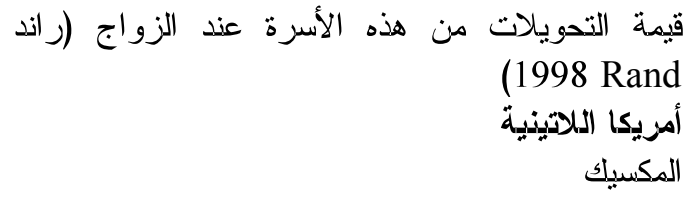 \\
\hline 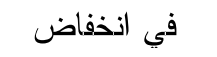 & في ارتفاع & في ارتفاع & 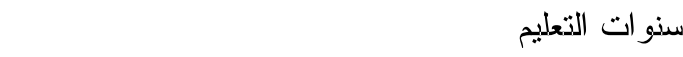 \\
\hline 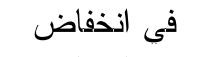 & فى ارتفاع & في ارتفاع & السن عند الزواج \\
\hline في انخفاض & 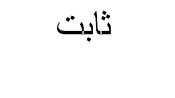 & في انخفاض & الأرماضي المملوكة عند الزواج (1 إذا كانت الإجابة \\
\hline في ارتفاع & في ارتفاع & في ارتفاع & جو اتيمالاب الأصول \\
\hline 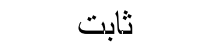 & في ارتفاع & في ارتفاع & سنوات التعليم \\
\hline في انذفاض & في ارتفاع & ثابت & السن عند الزواج \\
\hline في ارتفاع & في ارتفاع & في ارتفاع & قيمة الأصول عند الزواج (كويتسيل (1999) Quetzal) \\
\hline
\end{tabular}


وتماثشياً مع سد الفجوة التعليمية، انذفضت في أربعة من البلدان الستة الاختلافات العمرية بين الأزواج و الزوجات

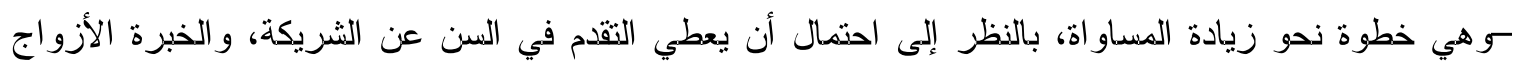
ميزة تفاوضية على زوجاتهم. و البلدان اللذان لم يقل فيهما الفارق العمزي عند الزواج هما لفا الفلبين وجنوب إفريقيا، و هما البلدان اللذان يكون فيهما سن المزأة عند الزواج هو الأعلى بين النساء في البلدان التي شملتها دراستتا.

ويستمز توزيع الأصول عند الزواج في تفضيل الأزواج. ففي ثلاثة من ستة بلدان، لم يتغيز الاختلاف في

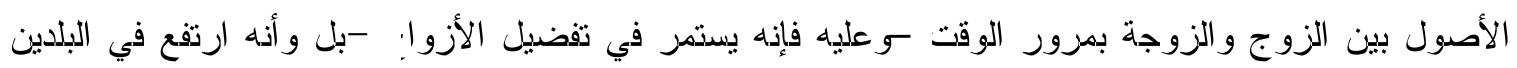

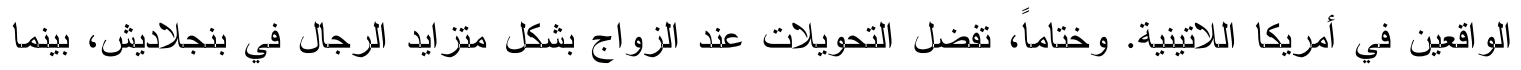
تأخذ الفجوة في التحويلات عند الزواج في الضيق في جنوب إفريقيا.

علامَ تدلل هذه الاتجاهات بالنسبة لتوزيع الأصول داخل الزيجة؟ يشير انذفاض الفجـوات فـي الســن و التعلـيم المدرسي بين الأزواج و الزوجات إلى احتمال حدوث تحسن في ميزان القوى داخل الأسرة، بيد أن ملكية الأصول

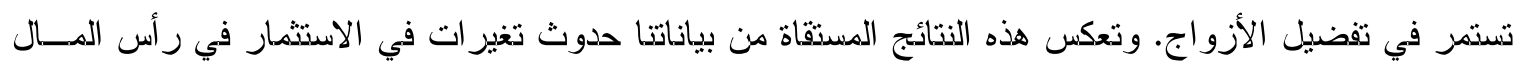

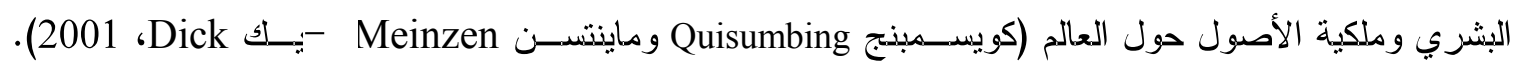

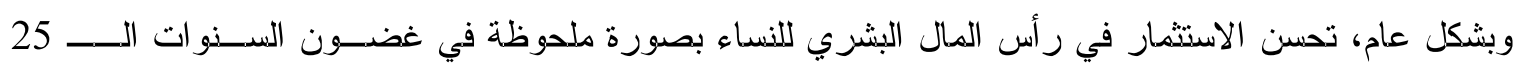

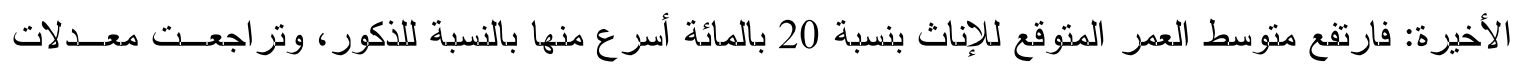
الخصوبة، وبدأت الفجوات في التحصيل التعليمي في الضيق. غير أن الفجوات بين الجنسين من حيث الأصــول

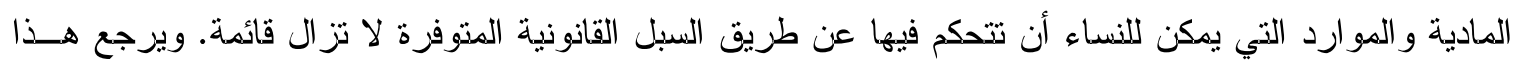
في المقام الأول إلى الآليات الاجتماعية و القانونية التي لا تمنح النساء الدقوق المتساوية فــي امـتنالك العقـارات

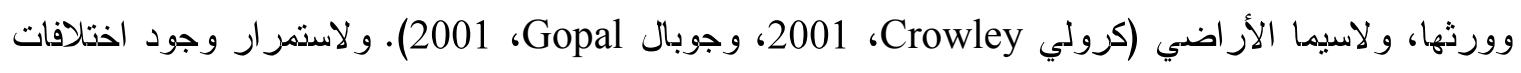

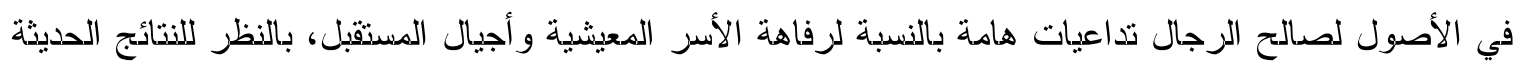
التي رفعت من وضع المز أة وجعلت لها السلطة في التحكم في الأصول، وهو أمر له تأثيرات مو اتية على تغذيـة

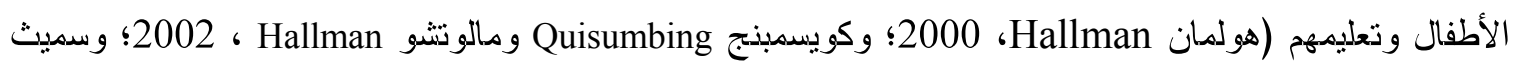

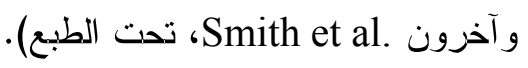

ولا تؤثر هذه الاتجاهات على توزيع السلطة داخل الزيجات فحسب، و إنما أيضاً على الدور الذي يلعبه الزواج في

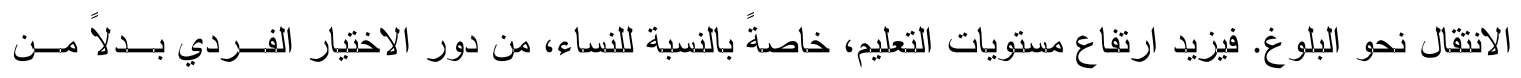

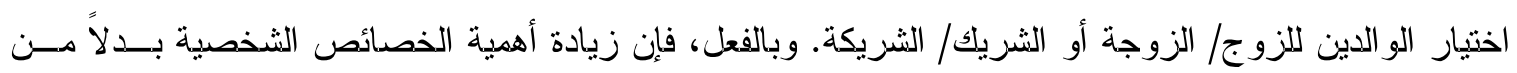
خصائص الو الدين في تشخيص المطابقات في سوق الزواج تشير إلى زيادة الاختيار الفردي. وفي نفس الوقــــات،

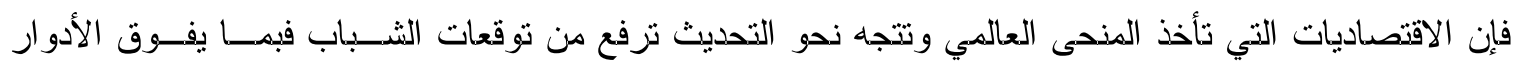
التقليدية. فيؤجل الثباب الزواج على أمل أن يتم تعويضهم عذه من خلال استثمار هم في التعليم على هيئة وظائف دأف

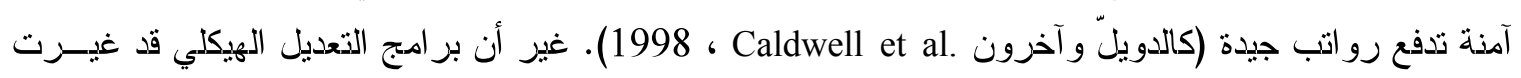


هن هيكل العمالة بالكثير من الاقتصاديات النامية؛ ومع انكماش القطاع العام، توجد الآن أنواع أقل من الوظـائف

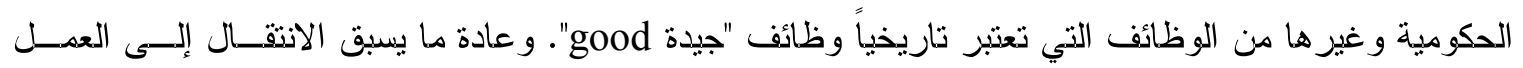

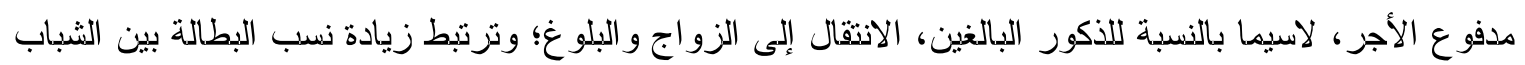

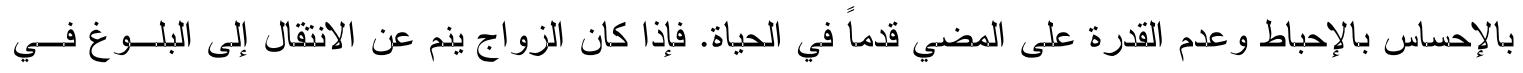

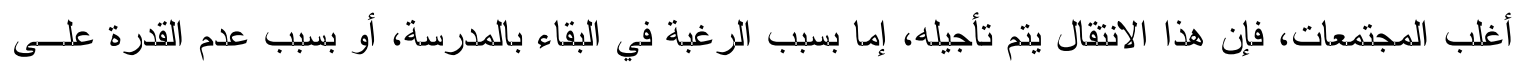

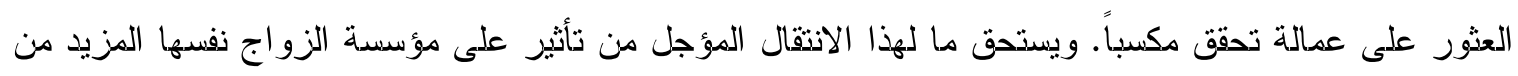
البحث. 
جدول ملدق 1 وصف مجموعات البيانات

\begin{tabular}{|c|c|c|c|}
\hline \multicolumn{2}{|c|}{ الأدوات الوصفية على البلد } & وصف البياتات & البلد \\
\hline 23.9 & 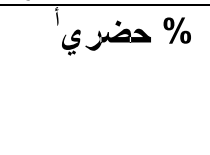 & 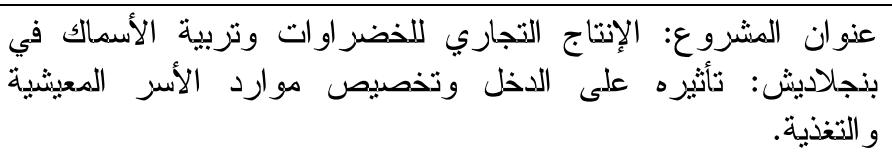 & بنجلاديش \\
\hline & 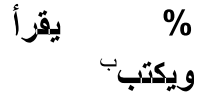 & 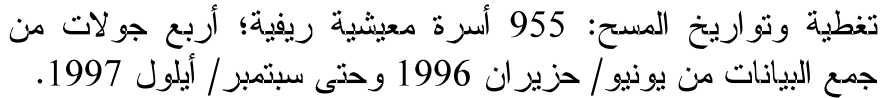 & \\
\hline 23.9 & 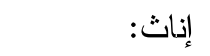 & & \\
\hline 51.7 & $\begin{aligned} \text { ذالكور } \\
\text { المكسوب }\end{aligned}$ & 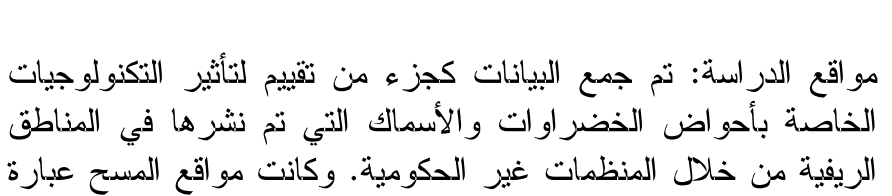 & \\
\hline$\stackrel{د}{1} 1.076$ & 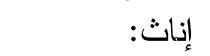 & عن مناطق نم فيها إدخال التكنولوجيات الخاصة بالمجموعة الاستثارية & \\
\hline${ }^{2} 1.866$ & 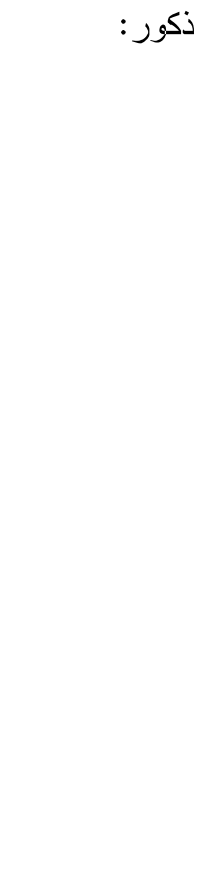 & 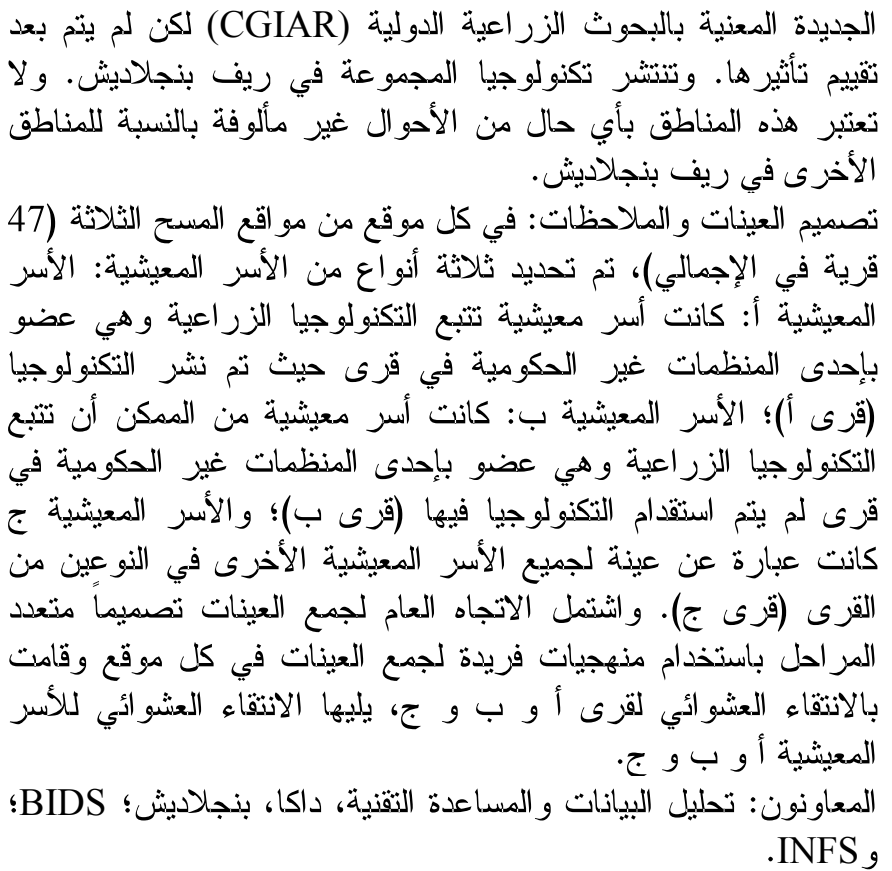 & \\
\hline 57.7 & \% حضزي' & 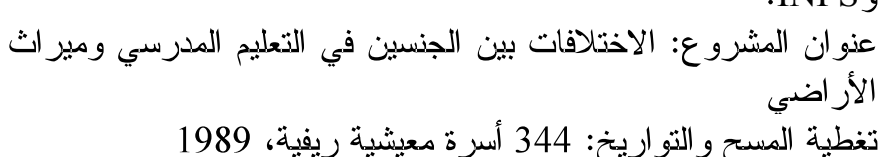 & 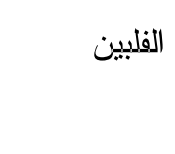 \\
\hline & و & 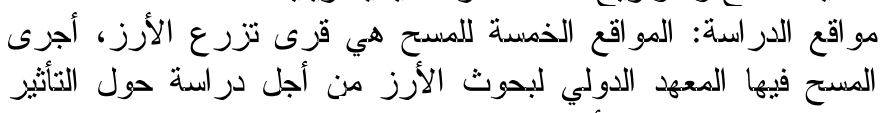 & \\
\hline 94.9 & 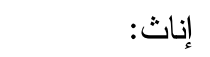 & التفاضلي لتكنولوجيا الأرزّ الحديثة (985 -86). وهي في المعتاد قرى & \\
\hline 95.3 & 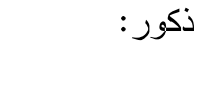 & تزرع الأرز نتراوح فيها الظروف البيئية من الري الكامل إلى التغذية & \\
\hline & 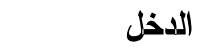 & تصميم العينات و الملاحظات: تأني البيانات من مسح أجزي بأثر رجعي & \\
\hline & المقدرج المبرب & في عام 1989، ويغطي 344 أسرة دعيشية ريفية. & \\
\hline 2.684 & 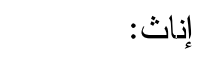 & & \\
\hline 4.910 & 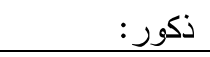 & & \\
\hline
\end{tabular}




\begin{tabular}{|c|c|c|c|}
\hline \multirow[t]{2}{*}{17.2} & \% حضري' & 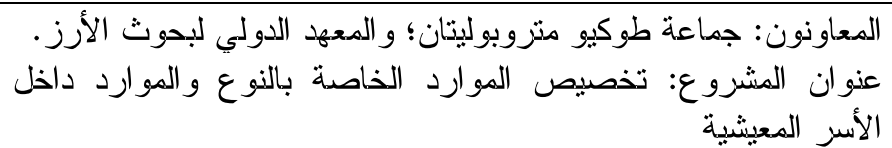 & إثيوبيا \\
\hline & و & 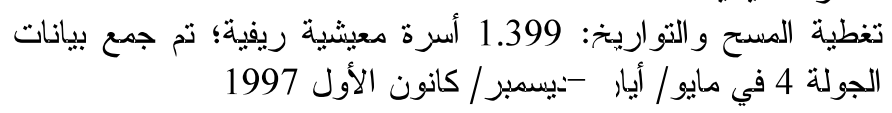 & \\
\hline 31.8 & 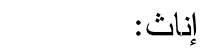 & & \\
\hline \multirow[t]{4}{*}{42.8} & 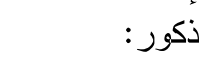 & & \\
\hline & 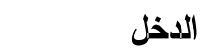 & مواقع المسح: أضاف هذا المسح، المسح الإثثيوبي للأسر المعيشية & \\
\hline & 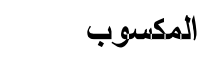 & الريفية لعام 1997 (ERHS)، جولة رابعة إلى فزيق جمعه المعهد & \\
\hline & 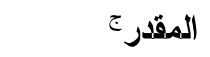 & الدولي لبحوث سياسات الغذاء (IFPRI)، و مركز در اسات الاقتصاديات & \\
\hline 2414 & 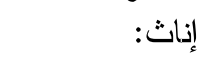 & الإفريقية، وجامعة أديس أبابا في عام 994 -95. أجري المزكز المسح & \\
\hline \multirow[t]{4}{*}{ د 844} & 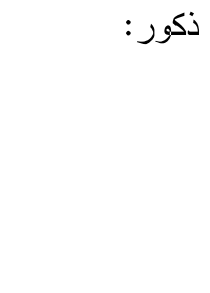 & 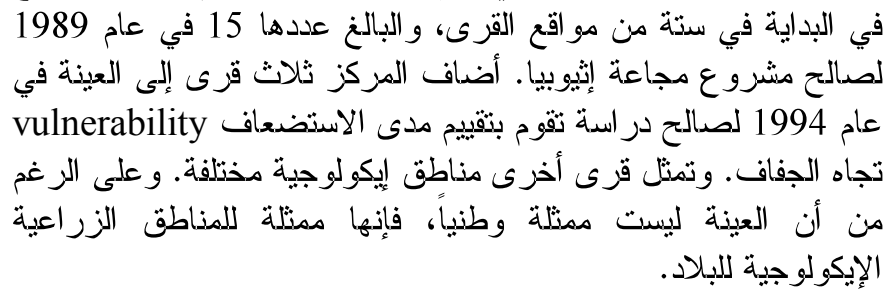 & \\
\hline & & 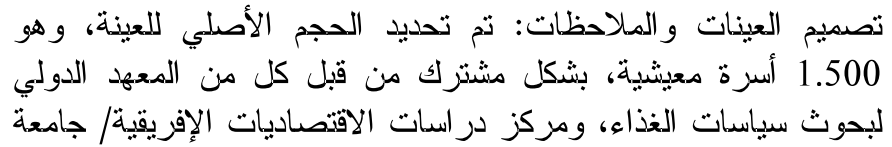 & \\
\hline & & 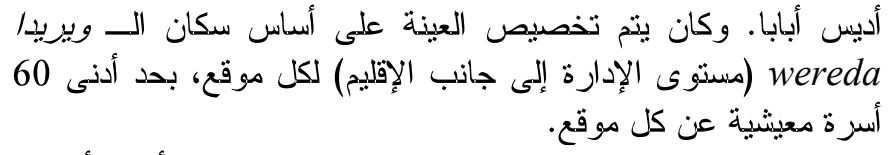 & \\
\hline & & المعاونون: مركز دراسات الاقتصاديات الإفريقية؛ وجامعة أديس أبابا. & \\
\hline \multirow[t]{3}{*}{50.1} & \% حضزي' & عنوان المشروع: دراسة ديناميكيات الدخل في إقليم كوازول -اتال & جذوب إفريقيا \\
\hline & يقزأ & تغطية وتواريخ المسح: 1.200 أسرة دعيشية ريفية وحضرية؛ الجولة & \\
\hline & 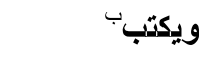 & 1، أغسطس/ آد --فمبر/ تشرين الثاني، 1993؛ الجولة 2، مارس/ & \\
\hline 84.2 & 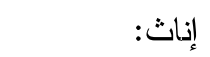 & آذار يونيو / حزيران، 1998. & \\
\hline \multirow[t]{5}{*}{85.7} & 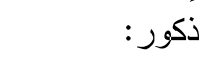 & & \\
\hline & & 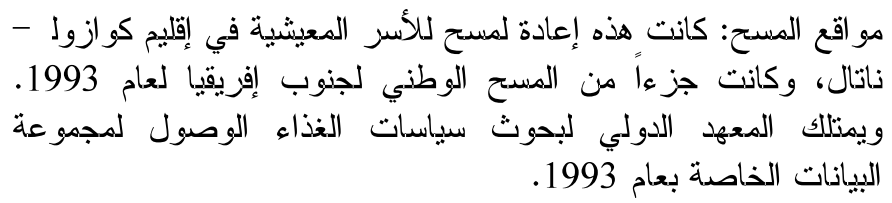 & \\
\hline & 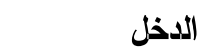 & كوازول -تال هو إقليم حضري بنسبة 43 بالمائة وبه نسبة من السكان & \\
\hline & 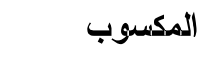 & من ذوي الأصول الهندية تزيد ازدياداً طفيفاً عن باقي المناطق. وتعتبر & \\
\hline & المقدرج & مؤشرات الفقر ، و التعليم، و البطالة، و البنية التحتية فيهاً أسوا بقدر بسيط & \\
\hline${ }^{2} 5.473$ & 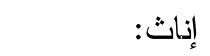 & من المتوسط العام للبلاد، غير أن غالبية هذه الاختلافات لا تعتبر هامة & \\
\hline \multirow[t]{2}{*}{ د 12.452} & 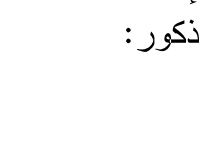 & 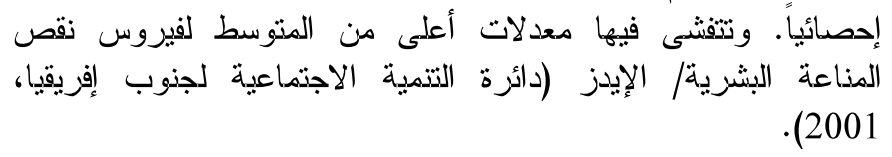 & \\
\hline & & 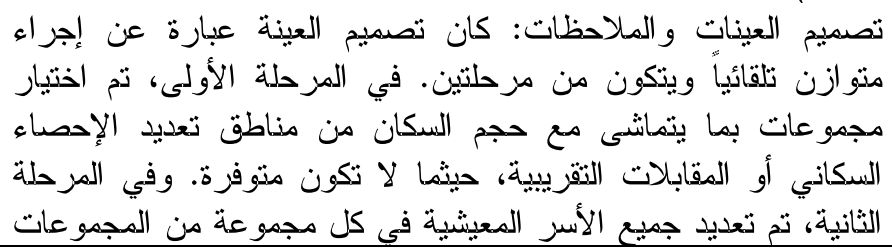 & \\
\hline
\end{tabular}




\begin{tabular}{|c|c|c|c|}
\hline & & 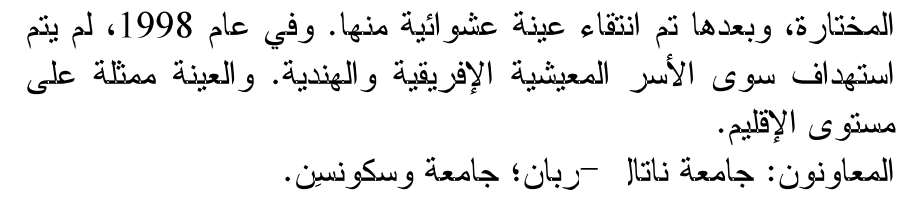 & \\
\hline 74.2 & \% حضري' & 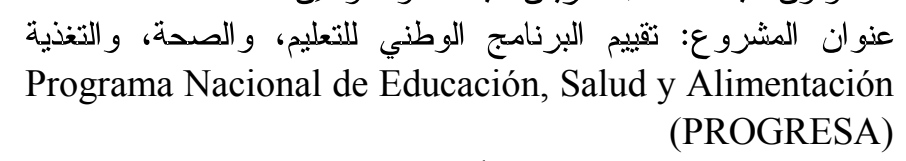 & المكسيك \\
\hline & 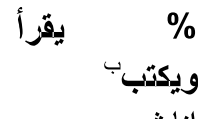 & 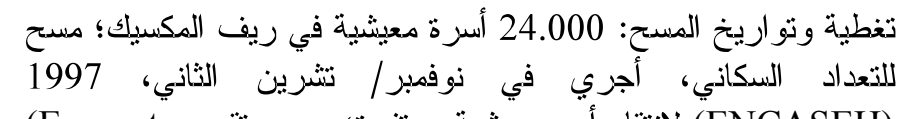 & \\
\hline $\begin{array}{l}89.1 \\
93.1\end{array}$ & 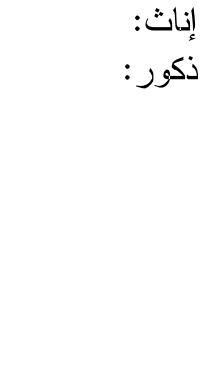 & 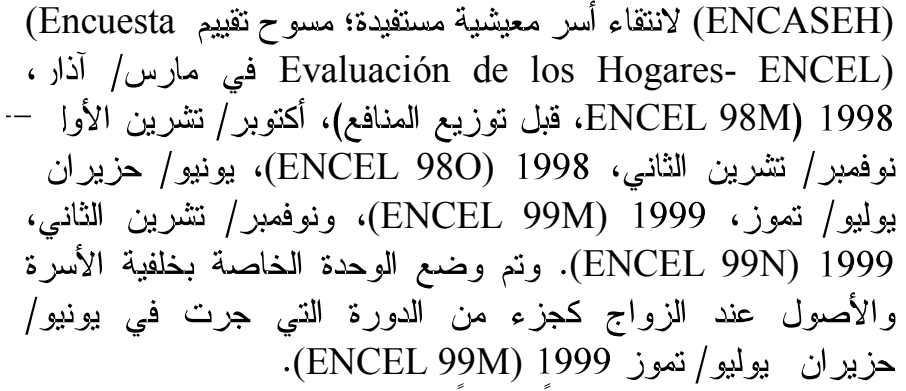 & \\
\hline & |الدكل المقدب & 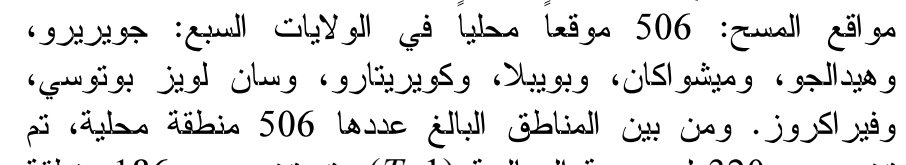 & \\
\hline $\begin{array}{c}4.486 \\
12.184\end{array}$ & 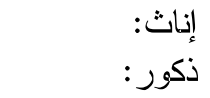 & كمناطق رقابة (320 لمجموعة المعالجة (T=1) & \\
\hline & & 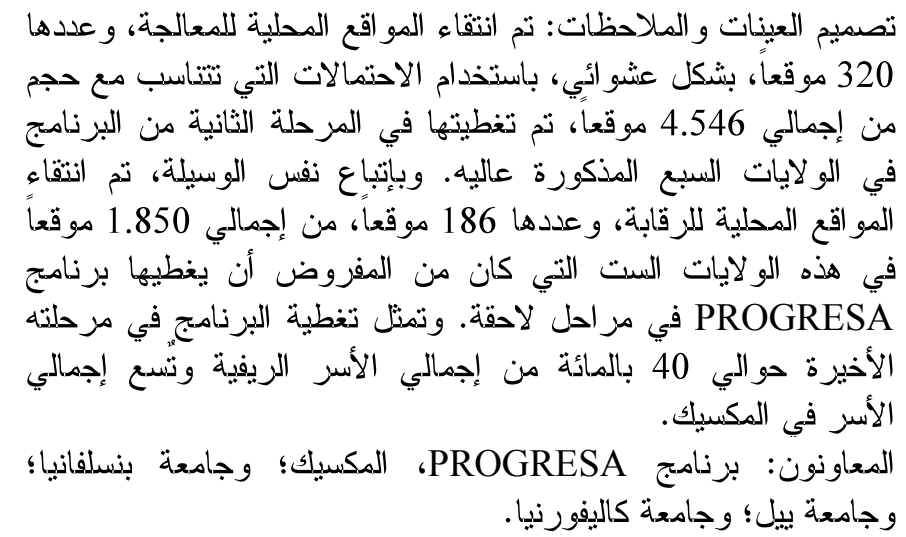 & \\
\hline \multirow[t]{2}{*}{39.4} & 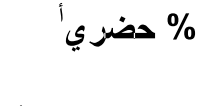 & عو اتيمالا سيتي. المشرو: تقوية وتقييم برنامج Hogares Comunitarios في & جو اتيمالا \\
\hline & و & تغطية ونت اريخ المسح: 1.363 أسرة معيشية حضرية في جو اتيمالا & \\
\hline \multirow[t]{2}{*}{75.6} & 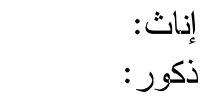 & & \\
\hline & الدذل & 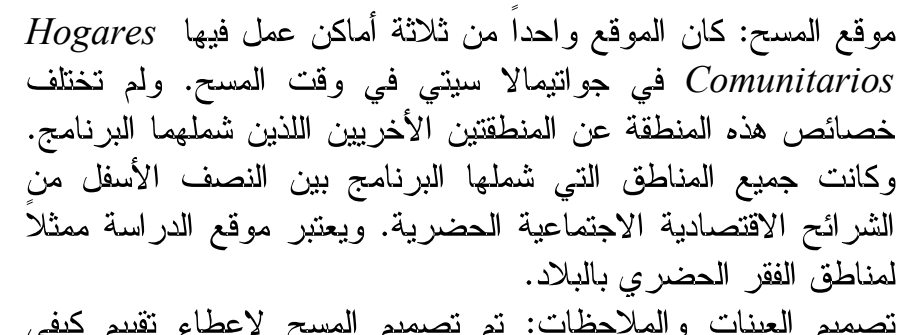 & \\
\hline
\end{tabular}




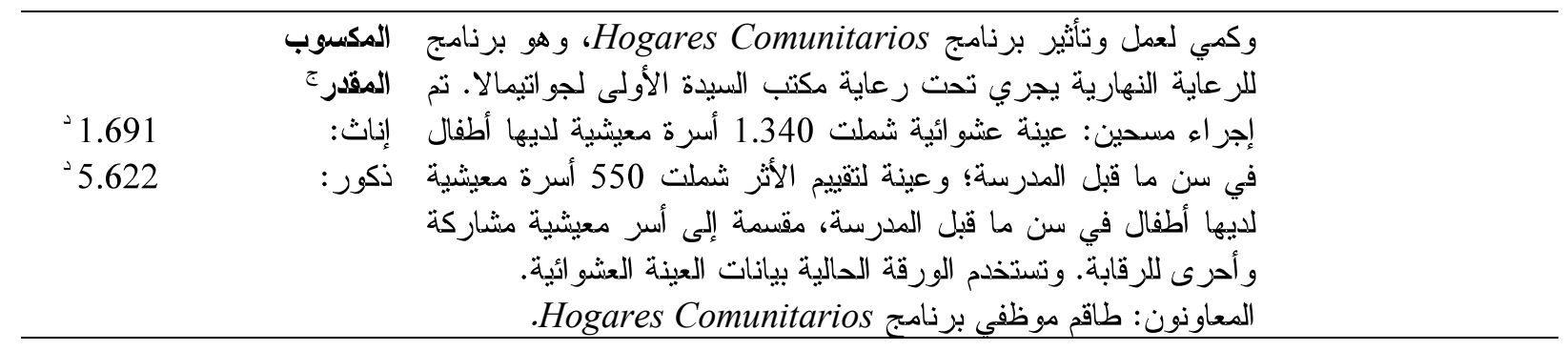

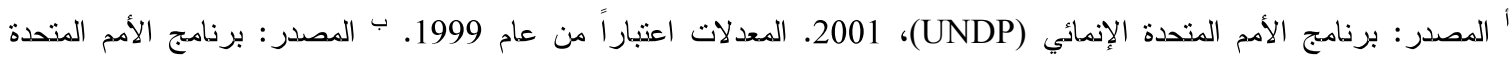

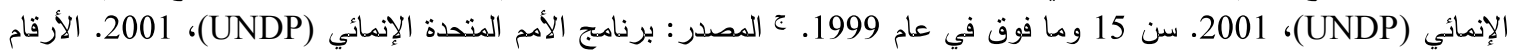

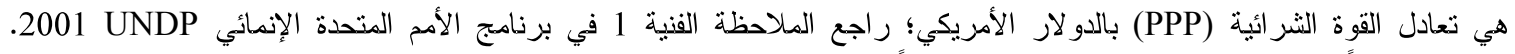

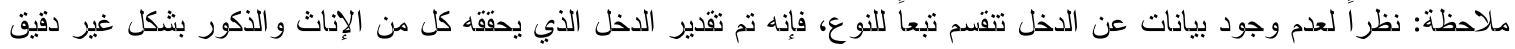

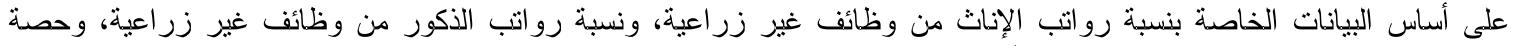

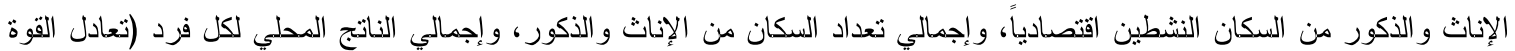

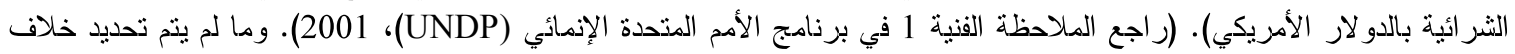

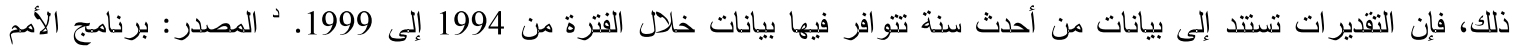

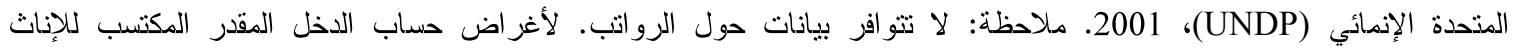

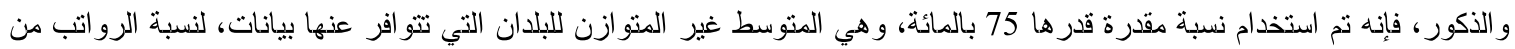

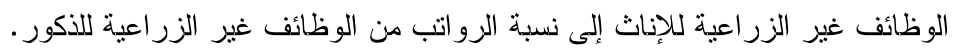


جدول ملدق(2) محددات السن عند الزواج، مخصصات بديلة نشمل سنة الميلاد وسنة الزواج (OLS with robust) standard errors)

\begin{tabular}{|c|c|c|c|c|c|c|c|c|}
\hline \multirow[b]{2}{*}{$\mathbf{t}$} & \multicolumn{3}{|c|}{ سن الزوجة عند الزواج } & \multicolumn{4}{|c|}{ سن الزوج عند الزواج } & \multirow[b]{3}{*}{ بنجلاديش } \\
\hline & معامل & $\mathbf{t}$ & معامل & $\mathbf{t}$ & معامل & $\mathbf{t}$ & معامل & \\
\hline & & & & & & & & \\
\hline \multirow{2}{*}{1.05} & 0.01 & & & -.98 & -1.16 & & & سنة الميلاد \\
\hline & & 10.43 & 0.12 & & & 4.10 & 0.09 & سنة الزواج \\
\hline-.20 & -.55 & -.96 & -.12 & -.46 & -.24 & -.61 & -.94 & نسبة كل جنس \\
\hline-.01 & 0.00 & -.30 & $-\quad .08$ & -.31 & -1.03 & -.87 & -.20 & ترنيب \\
\hline-.31 & -1.11 & $\begin{array}{l}-\quad .47 \\
\end{array}$ & -.03 & 1.36 & 0.19 & -.22 & -.03 & عدد الأشقاء \\
\hline 1.80 & 0.16 & 1.40 & 0.12 & 0.91 & 0.12 & $-\quad .56$ & $-\quad .08$ & عدد الثقيقات \\
\hline \multirow{2}{*}{-.07} & 0.00 & -.31 & 0.00 & -.23 & 0.00 & 0.60 & 0.00 & أر اضي \\
\hline & & & & & & & & الو الدين \\
\hline 2.20 & 0.25 & 1.70 & 0.18 & -.20 & $-\quad 1.18$ & -.58 & -.24 & ت تعليم الأب \\
\hline-.48 & -1.23 & -.69 & -.41 & 0.66 & 0.18 & $-\quad .45$ & -.15 & تعليم الأم \\
\hline 1.15 & 0.37 & 2.16 & 0.67 & 1.72 & 0.85 & 2.66 & 1.37 & موقع 2 \\
\hline-.33 & -1.12 & -1.35 & -.11 & 0.79 & 0.38 & 0.65 & 0.32 & موقع 3 \\
\hline \multirow{6}{*}{-.19} & -.80 & $-\quad .57$ & -17.81 & 8.58 & 347.72 & -.41 & -42.94 & الثابت \\
\hline & 786 & & 786 & & 779 & & 779 & عدد الملاحظات \\
\hline & 3.87 & & 14.54 & & 7.59 & & 3.09 & F-statistic \\
\hline & 0.00 & & 0.00 & & 0.00 & & 0.00 & Prob $\gg F$ \\
\hline & 0.04 & & 0.17 & & 0.13 & & 0.05 & $\mathrm{R}^{2}$ \\
\hline & & & & & & & & القلبين \\
\hline \multirow{2}{*}{-.51} & -1.10 & & & $-\quad .86$ & -1.10 & & & سنة الميلاد \\
\hline & & 2.51 & 0.08 & & & 3.79 & 0.12 & سنة الزواج \\
\hline 1.55 & 10.25 & 1.24 & 8.40 & 1.35 & 9.45 & 0.76 & 5.32 & نسبة كل جنس \\
\hline-.54 & -1.06 & -.12 & -.13 & 0.37 & 0.04 & $-\quad .72$ & -.09 & تعليم الأب \\
\hline 0.76 & 0.11 & -.32 & -.20 & -.76 & $-\quad 1.10$ & -.03 & $-\quad .49$ & تعليم الأم \\
\hline 0.78 & 0.12 & 2.02 & 0.35 & 1.37 & 0.12 & 2.29 & 0.17 & أر اضي الأب \\
\hline$-\quad .59$ & -1.13 & 0.15 & 0.03 & -.46 & -1.08 & 0.44 & 0.05 & أر اضي الأم \\
\hline & & & & & & & & نماذج القرية \\
\hline 0.03 & 0.04 & 0.63 & 0.70 & -.34 & $-\quad 1.45$ & 0.00 & 0.00 & ندوذج Pو \\
\hline 1.27 & 1.37 & 1.57 & 1.80 & 0.23 & 0.25 & 0.34 & 0.38 & نموذجP3 \\
\hline-.22 & -.18 & -.43 & -.40 & -.41 & -.32 & -.10 & -.97 & نموذج CL1 \\
\hline-.22 & -.18 & -.27 & -.21 & -.19 & -.18 & -.68 & -.69 & نL2 نموذج \\
\hline \multirow[t]{6}{*}{3.73} & 208.16 & -.26 & -39.10 & 4.09 & 210.90 & -.49 & -.14 .95 & الثابت \\
\hline & 259 & & 259 & & 259 & & 259 & عدد الملاحظات \\
\hline & 2.87 & & 2.88 & & 4.50 & & 4.50 & F-statistic \\
\hline & 0.00 & & 0.00 & & 0.00 & & 0.00 & Prob $\gg F$ \\
\hline & 0.13 & & 0.11 & & 0.18 & & 0.18 & $\mathrm{R}^{2}$ \\
\hline & & & & & & & & إثيوبيا \\
\hline \multirow[t]{2}{*}{-9.23} & -1.66 & & & $-\quad 2.49$ & -1.71 & & & سنة الميلاد \\
\hline & & -.74 & -.18 & & & -.42 & -.34 & سنة الزواج \\
\hline 23.28 & 170.51 & 3.42 & 51.40 & 26.35 & 173.44 & 2.89 & 53.05 & نسبة كل جنس \\
\hline
\end{tabular}




\begin{tabular}{|c|c|c|c|c|c|c|c|c|}
\hline 1.44 & 0.79 & 0.11 & 0.08 & 0.79 & 0.55 & 0.72 & 1.13 & تعليم الأب \\
\hline$-\quad .69$ & -1.48 & -1.01 & -.01 & 0.90 & 1.40 & 0.42 & 1.12 & تعليم الأم \\
\hline 0.10 & 0.00 & 0.13 & 0.01 & 0.31 & 0.00 & 4.74 & 0.01 & أر اضي الو الدين \\
\hline 1.78 & 0.13 & 0.10 & 0.01 & -.52 & -1.04 & -.63 & -.51 & عدد الأشقاء \\
\hline \multirow[t]{2}{*}{0.74} & 0.06 & -1.99 & -.14 & -.11 & -1.01 & -.00 & -.18 & عدد الثققيقات \\
\hline & & & & & & & & تيمر اي المنطقة (باستثناء \\
\hline 0.73 & 0.36 & -.19 & -.23 & 0.42 & 0.20 & -.13 & -.55 & أمهار ا Amhara Amhara \\
\hline-.07 & $-\quad 1.47$ & -.75 & -.64 & -.48 & -.07 & -.01 & -.48 & أورومو Oromo \\
\hline 1.10 & 0.49 & -1.20 & -.18 & 0.26 & 0.11 & -.84 & -.05 & جنود. -سط $\begin{array}{r}\text { جنth-Central } \\
\text { South- }\end{array}$ \\
\hline \multirow[t]{6}{*}{30.12} & 1.064 .71 & 2.73 & 305.47 & 46.70 & 1.163 .44 & 4.88 & 626.59 & الثابت \\
\hline & 554 & & 554 & & 554 & & 554 & عدد الملاحظات \\
\hline & 90.77 & & 2.37 & & 321.1 & & 22.7 & F-statistic \\
\hline & 0.00 & & 0.01 & & 0.00 & & 0.00 & Prob $>F$ \\
\hline & 0.72 & & 0.03 & & 0.82 & & 0.16 & $\mathrm{R}^{2}$ \\
\hline & & & & & & & & جذوب إفريقيا \\
\hline \multirow[t]{2}{*}{-.35} & -1.18 & & & -.12 & -1.31 & & & سنة الميلاد \\
\hline & & 11.73 & 0.35 & & & 10.28 & 0.33 & سذة الزواج \\
\hline 2.45 & 26.51 & 0.98 & 8.07 & 1.99 & 21.16 & 0.07 & 0.61 & نسبة كل جنس \\
\hline 0.85 & 0.78 & 0.35 & 0.28 & 1.75 & 1.66 & 1.66 & 1.42 & عرق إفريقي \\
\hline-.29 & -.21 & -1.25 & -.20 & -.70 & -.66 & -.97 & -.85 & مقيم حضري \\
\hline-.91 & -.95 & -.15 & -.85 & -.57 & -.32 & -.23 & -.50 & عند الزفاف قبد الحياة \\
\hline-.65 & -.14 & -.13 & -.66 & -.14 & -.81 & -.56 & -.63 & الأب على قيد \\
\hline 0.89 & 0.68 & -.35 & -.99 & 1.22 & 0.95 & -.08 & -.47 & أي قسط ماصلة على التعليم \\
\hline-.02 & $-\quad .75$ & -.45 & $-\quad .69$ & 0.35 & 0.26 & $-\quad .89$ & -.34 & الي قسط من التعليم على \\
\hline \multirow[t]{6}{*}{4.25} & 352.95 & -1.61 & -79.10 & 7.17 & 616.97 & $-\quad .86$ & $-\quad 24.85$ & الثابت \\
\hline & 492 & & 492 & & 492 & & 492 & عدد الملاحظات \\
\hline & 5.82 & & 19.48 & & 13.72 & & 20.42 & F-statistic \\
\hline & 0.00 & & 0.00 & & 0.00 & & 0.00 & Prob $>F$ \\
\hline & 0.12 & & 0.30 & & 0.28 & & 0.30 & $\mathrm{R}^{2}$ \\
\hline & & & & & & & & المكسيك \\
\hline \multirow[t]{2}{*}{16.52} & $-\quad .05$ & & & -7.40 & -1.18 & & & سنة الميلاد \\
\hline & & 14.10 & 0.04 & & & 4.70 & 0.02 & سنة الزواج \\
\hline-.30 & -.73 & $-\quad .37$ & -.94 & 2.36 & 2.83 & -.58 & -.09 & نسبة كل جنس \\
\hline 1.75 & 0.26 & 0.71 & 0.11 & 1.51 & 0.33 & -.30 & -.32 & الأب يقرأ ويكتب \\
\hline 0.02 & 0.00 & -.21 & -.16 & 2.00 & 0.46 & $-\quad .02$ & 0.00 & الأم تقرأ وتكتب \\
\hline 1.05 & 0.16 & -1.10 & -.02 & -.16 & -1.04 & -.25 & -.31 & بعض الأب حصل على التعليم \\
\hline 1.50 & 0.20 & 0.14 & 0.02 & 0.32 & 0.07 & -.14 & -.29 & بعض الأم حصلت على التعليم \\
\hline
\end{tabular}




\begin{tabular}{|c|c|c|c|c|c|c|c|c|}
\hline-.67 & -1.19 & -.73 & -.50 & 1.51 & 0.97 & 1.00 & 0.71 & الأب أكمل التعليم \\
\hline 1.26 & 0.46 & 0.63 & 0.23 & -.50 & $-\quad 1.82$ & -.48 & $-\quad .89$ & الأم أكملت التعليم \\
\hline 0.46 & 0.06 & -1.61 & -.08 & -.90 & -1.38 & -.24 & -.70 & الأب يرتدي أحذية \\
\hline 2.85 & 0.36 & 1.30 & 0.16 & 3.55 & 0.69 & 0.96 & 0.20 & الأم تزتدي أحذية \\
\hline 2.40 & 0.02 & 3.44 & 0.03 & -.26 & 0.00 & 0.91 & 0.01 & 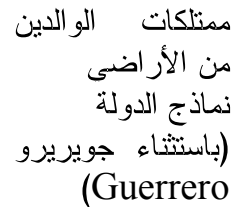 \\
\hline 2.61 & 0.38 & 3.69 & 0.55 & 3.77 & 0.95 & 5.14 & 1.46 & هيدالجو Hidalgo \\
\hline 1.44 & 0.22 & 4.10 & 0.65 & 0.26 & 0.07 & 3.54 & 1.04 & ميشو اكان \\
\hline-.13 & $-\quad .02$ & 0.83 & 0.13 & 3.02 & 0.78 & 4.33 & 1.25 & بويلا Puebla \\
\hline 2.86 & 0.54 & 4.21 & 0.80 & 0.40 & 0.12 & 2.03 & 0.67 & كويريتارو \\
\hline 1.52 & 0.23 & 5.02 & 0.80 & 2.21 & 0.58 & 7.05 & 2.08 & $\begin{array}{lr}\text { سان لويز بوتوسي } & \text { Luis } \\
& \text { Potos }\end{array}$ \\
\hline-.32 & $-\quad .04$ & 0.57 & 0.08 & 1.64 & 0.39 & 2.75 & 0.74 & $\begin{array}{r}\text { فير اكروز } \\
\text { Veracruz }\end{array}$ \\
\hline 20.22 & 119.71 & -0.10 & -0.46 & 39.60 & 372.75 & -.81 & -5.80 & الثابت \\
\hline & 12.279 & & 12.279 & & 11.506 & & 11.506 & عدد الملاحظات \\
\hline & 25.45 & & 18.96 & & 88.16 & & 7 & F-statistic \\
\hline & 0.00 & & 0.00 & & 0.00 & & 0.00 & Prob $\gg F$ \\
\hline & 0.04 & & 0.03 & & 0.17 & & 0.01 & $\begin{array}{r}R^{2} \\
\text { جو اتيمالا }\end{array}$ \\
\hline$-\quad .58$ & $-\quad .24$ & & & -3.13 & $-\quad .41$ & & & سذة الميلاد \\
\hline & & 4.82 & 0.08 & & & -.91 & -.03 & سنة الزواج \\
\hline-.83 & -2.24 & 0.52 & 2.74 & -.99 & -4.05 & $-\quad .92$ & -.36 & نسبة كل جنس \\
\hline-.08 & $-\quad 1.40$ & -.05 & -41 & -.74 & -.04 & -.46 & -.06 & الإثثية الفطرية \\
\hline-.86 & $-\quad .69$ & -.67 & -.70 & & & & & النشأة الريفية \\
\hline-.72 & -1.67 & -.19 & -.54 & & & & & وحيدة $\quad$ الأم أما \\
\hline 1.06 & 0.07 & 2.64 & 0.18 & & & & & عدد الأتقاء \\
\hline-.27 & $-\quad .02$ & 0.52 & 0.04 & & & & & عدد الثقيقات \\
\hline-.22 & -.49 & -.91 & -.46 & & & & & ألأم عملت مقابل \\
\hline 1.96 & 0.44 & 0.38 & 0.09 & & & & & الأم تقرأ وتكتب \\
\hline 9.35 & 498.22 & -.17 & 137.26 & 12.83 & 853.23 & 1.37 & 84.36 & الثابت \\
\hline & 976 & & 976 & & 976 & & 976 & عدد الملاحظات \\
\hline & 13.86 & & 5.31 & & 63.40 & & 2.37 & F-statistic \\
\hline & 0.00 & & 0.00 & & 0.00 & & 0.07 & Prob $>F$ \\
\hline & 0.20 & & 0.04 & & 0.43 & & 0.01 & $\mathrm{R}^{2}$ \\
\hline
\end{tabular}




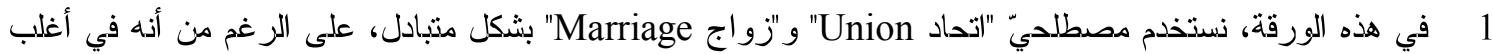

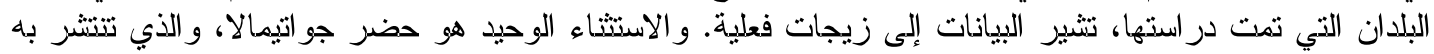

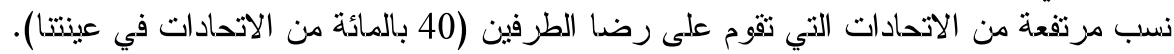

أدارت كويسمبنج Quisumbing البرنامج البحثي بشكل عام في المعهد الدولي لبحوث سياسات الغذاء IFPRI ، بينما

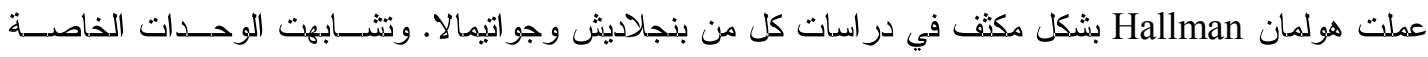

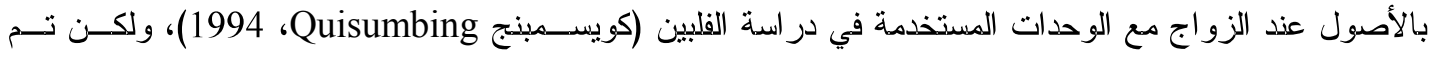
تطويعها تبعاً للظروف الخاصة بكل بلد.

للاطلاع على مناقثة للنصوص الخاصة بالنموذج الجماعي مقابل الذموذج الأحادي للأسر المعيشية، راجسع حسداد،

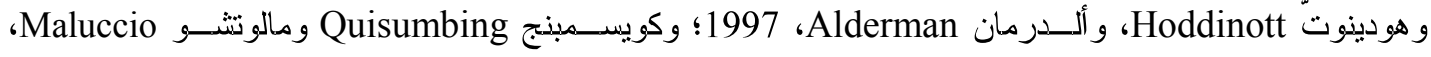
2002؛ وتوماس Thomas وتشين Chen، 1994.

يقدم الجدول الملحق 2 تقديرات للارتدادات الخاصة بالسن عند الزواج، باستخدام تخصيصين بديلين: (1) سنة الميلاد

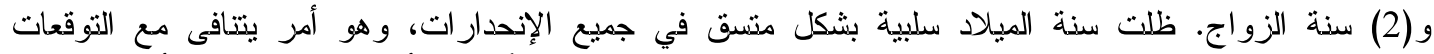

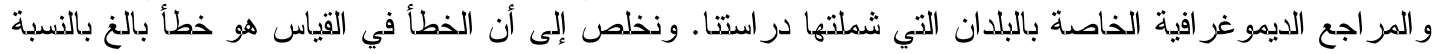
لمتغير سنة الميلاد، وبالتالي فإنه يتم استخدام سنة الزواج في النيان إنحدار اتتا.

كما نوقش سابقاً، تم اختيار البلدان التي شملتها در اسة المعهد الدولي لبحوث سياسات الغـذاء IFPRI أيضــاً لييـان

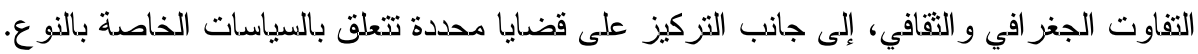
هذا الجزء مستقى من كويسمبنج Quisumbing ودي لا بريار de la Brière (2000).

تم الإبلاغ عن حدوث هذه الظاهزة على نطاق واسع أيضاً في الهند. راجع راو Rao (1997) وبلوش Bloch ور او Rao (2002).

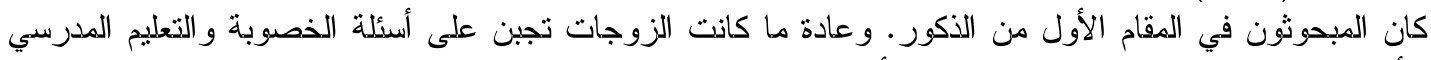

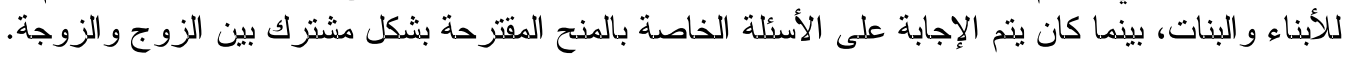
8

تم تقدير الأصول الأخرى بخلاف الأر اضي بعملة البيزو pesos وقيمتها في عام 1989. وتم استخدام القيم الحاليــة 9

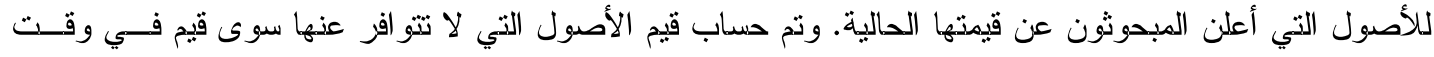

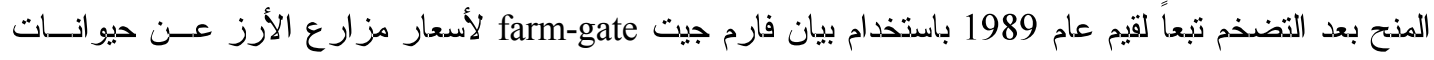

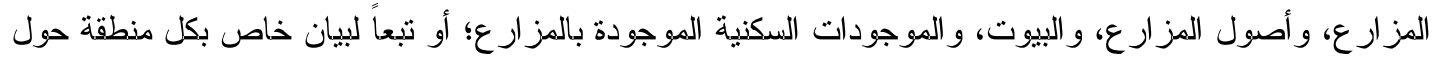

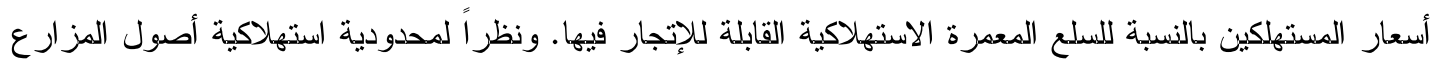

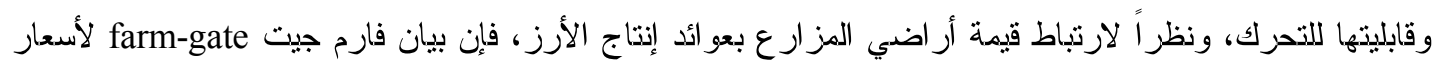

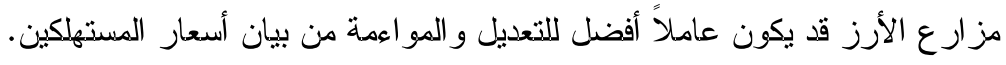

10 تم إجراء المسح الإثيوبي للأسر المعيشية الريفية (ERHS) من جانب دائرة الاقتصاديات بجامعة أديس أبابا ، Department of Economics, Addis Ababa University (AAU),

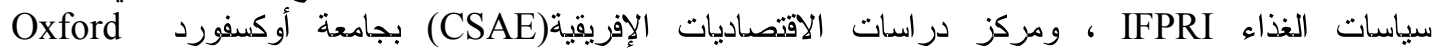
University 
الاقتصاديات الإفريقية CSAE في عام 95/1994، غير أنه لم يتم استخدام المعلومات التي تم جمعها في هذه الجو لات السابقة في التحليل الحالي.

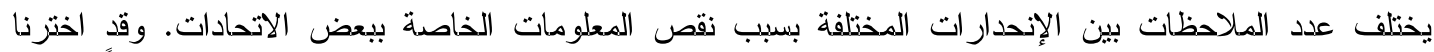

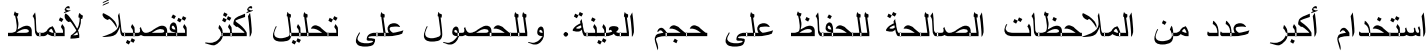

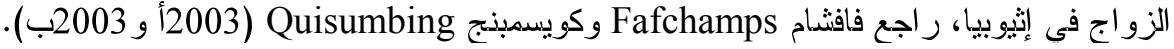

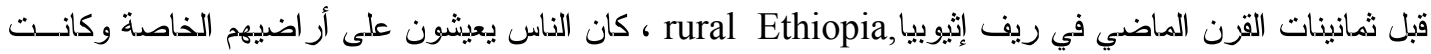
الأسر المعيشية في أغلب الأحيان متفرقة. وفي ظل مثل هذه الظروف، كانت الدكومة تثعر بأنه من الصعب للغايـة

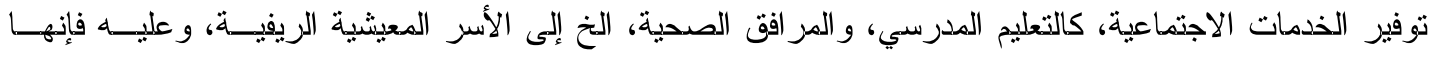

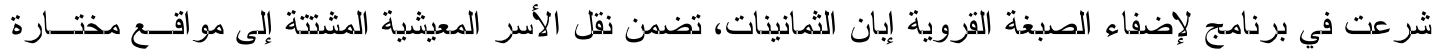

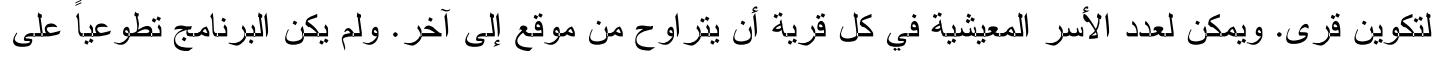

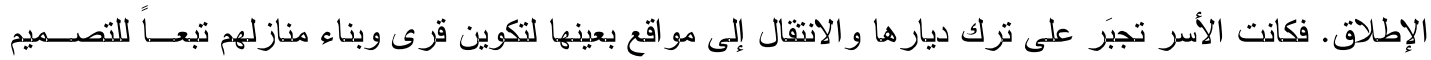

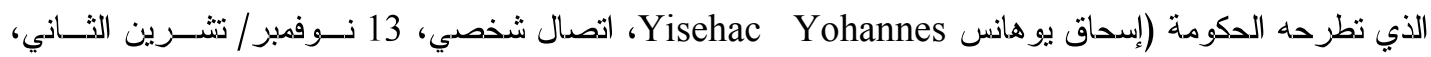

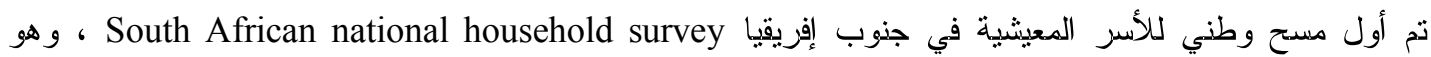
مشروع الإحصائيات الخاصة بمعايير المعيشة والتنمية (PSLSD) في النصف الثاني من عام 1993 (PSLSD)،

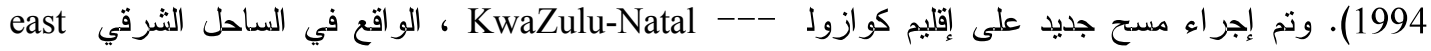

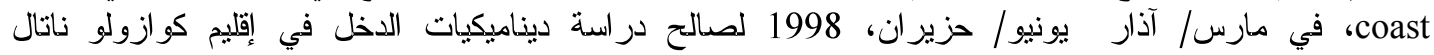

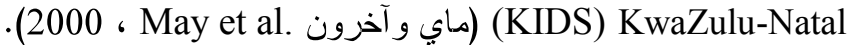

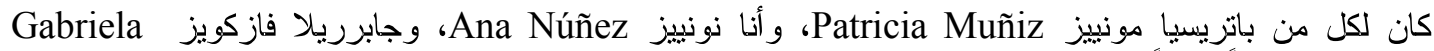

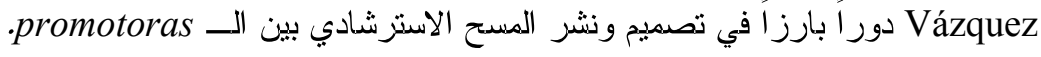

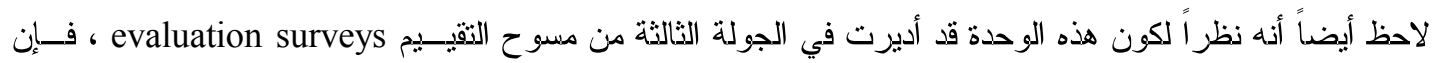

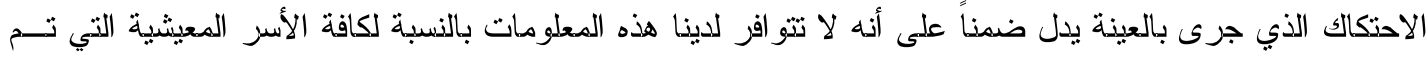

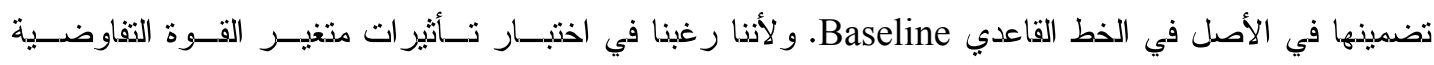
bargaining power الذي تم في هذه الورقة مقصور على الأزواج و الزوجات الذين تم إجز اء مقابلات معهم سوياً في جميع جو لات المسح

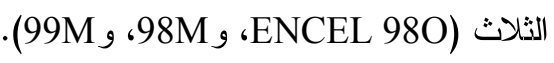

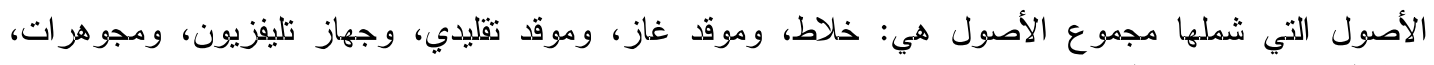

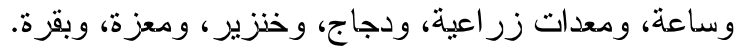

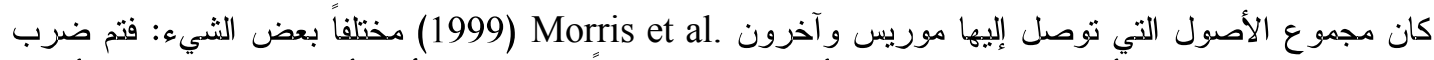

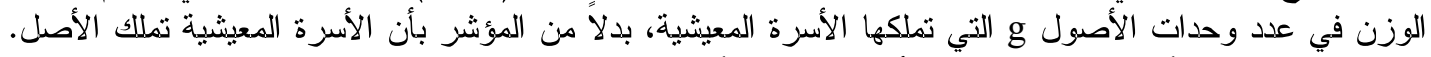

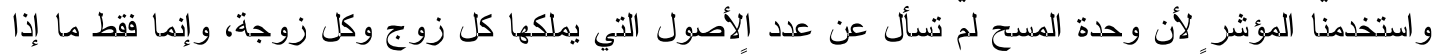

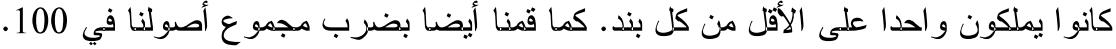

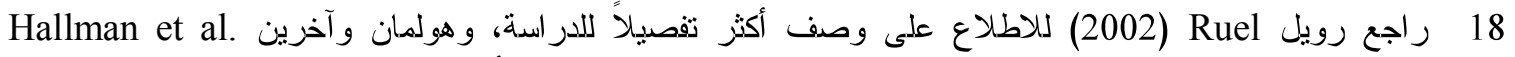
(2002) للاطلاع على ورقة ذات صلة حول عمل النساء وترتييات رعاية الأطفال.

تم جمع قيمة أصول ما قبل الزواج و التحويلات التي تم تلقيها في وقت الزواج بصورة إجمالية هنا لأنها قد تشكل في التي 19

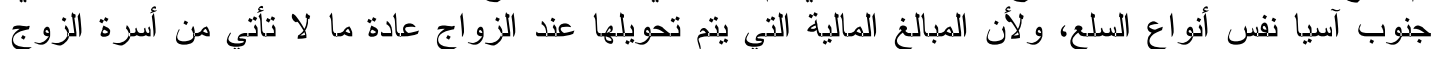




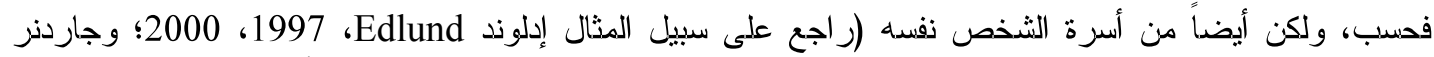
Gardner

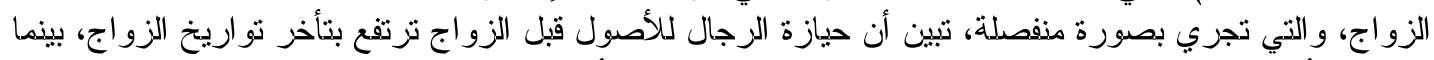

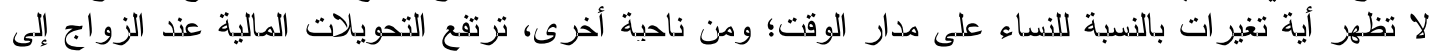

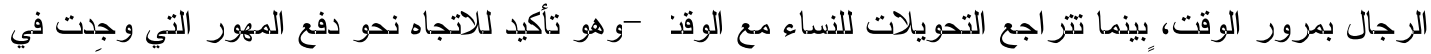
المز اجع المذكورة سابقاً.

20 وفقاً للمسح الوطني لخصوبة الأسرة National Family Fertility Survey ، فإن المتوسطة العمـري mean age

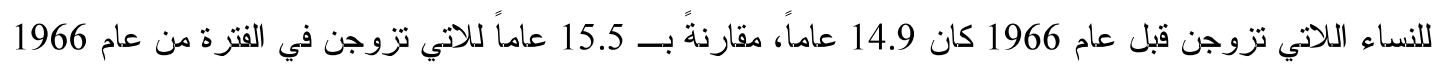

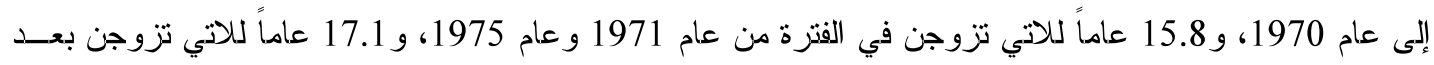
عام 1976.

وجد كل من فافشام وكويسمبنج Fafchamps and Quisumbing (2003ب)، باستخدام تخصيص مختلف، أن قيمـة

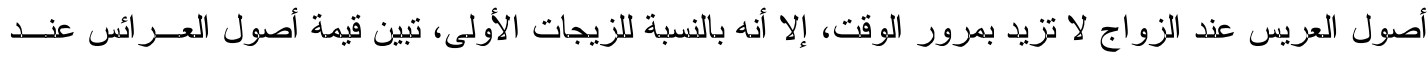

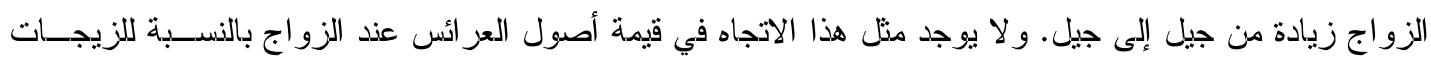

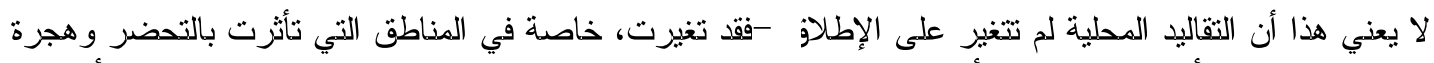

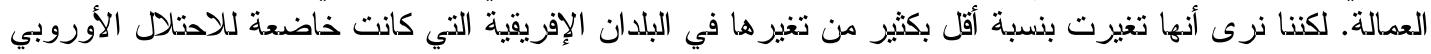
.Europeans على الرغم من أن الفجوة بين الجنسين في التعليم المدرسي حول العالم قد اندسرت بمرور الوقت، فإن معدلات

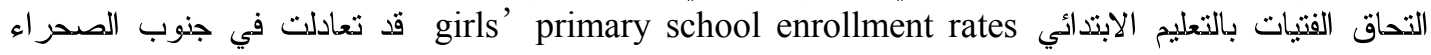

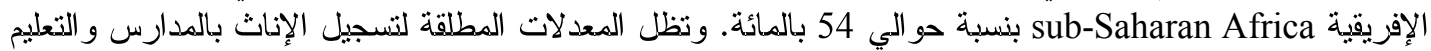

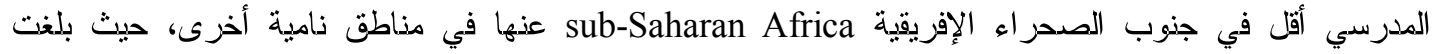

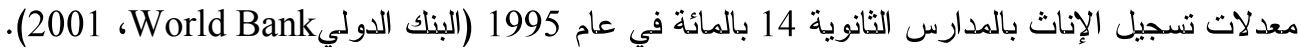

\section{References}

Adato, M., B. de la Brière, D. Mindek, and A. Quisumbing. 2000. "Final report: The impact of PROGRESA on women' s status and intrahousehold relations." Washington, DC: International Food Policy Research Institute.

Ahmed, A. and C. del Ninno. 2002. "The Food for Education program in Bangladesh: An evaluation of its impact on educational attainment and food security," Food Consumption and Nutrition Division Discussion Paper no. 138. Washington, DC: International Food Policy Research Institute.

Anderson, J.N. 1962. "Some aspects of land and society in a Pangasinan community," Philippine Sociological Review 19: 41-58.

Bloch, F. and V. Rao. 2002. "Terror as a bargaining instrument: A case study of dowry violence in rural India," American Economic Review 92(4): 1029-1043.

Bouis, H.E., M. Palabrica-Costello, O. Solon, D. Westbrook, and A.B. Limbo. 1998. "Gender equality and investments in adolescents in the rural Philippines," Research Report 108. Washington, DC: International Food Policy Research Institute. 
Brush, Lorelei, Cory Heyman, Stephen Provasnik, Marina Fanning, Drew Lent, and Johan De Wilde. 2002. "Description and analysis of the USAID girls' education activity in Guatemala, Morocco, and Peru," report produced for the Bureau for Economic Growth, Agriculture and Trade, Office of Women in Development, U.S. Agency for International Development.

Cain, Mead T. 1984. “Women' s status and fertility in developing countries: Son preference and economic security," World Bank Staff Working Paper no. 682. Washington, DC: World Bank.

Caldwell, J.C., P. Caldwell, B.K. Caldwell, and I. Pieris. 1998. "The construction of adolescence in a changing world: Implications for sexuality, reproduction, and marriage," Studies in Family Planning 29(2): 137-153.

Caldwell, J.C., P.H. Reddy, and P. Caldwell. 1983. "The causes of marriage change in South India, " Population Studies 37(3): 343-361.

Carter, M.R. and J. May. 1998. "Poverty, livelihood and class in rural South Africa," World Development 27: 1-20.

Casterline, John, Lindy Williams, and Peter McDonald. 1986. "The age difference between spouses: Variations among developing countries,” Population Studies 40(3):353-374.

Central Statistical Authority. 1993. "Report on the national rural nutrition survey, core module," Statistical Bulletin 113. Addis Ababa, Ethiopia: Central Statistical Authority.

Crowley, E. 2001. "Land rights," in A.R. Quisumbing and R.S. Meinzen-Dick (eds.), Empowering Women to Achieve Food Security. 2020 FOCUS 6, A 2020 Vision for Food, Agriculture, and the Environment. Washington, DC: International Food Policy Research Institute.

de la Brière, B. and A.R. Quisumbing. 2000. "The impact of PROGRESA on intrahousehold decisionmaking and relative schooling achievements of boys and girls," in M. Adato, B. de la Brière, D. Mindek, and A. Quisumbing, "The impact of PROGRESA on women's status and intrahousehold relations: A final report," mimeo submitted to PROGRESA. Washington, DC: International Food Policy Research Institute.

Dixon, R.B. 1971. "Explaining cross-cultural variations in age at marriage and proportions never marrying," Population Studies 25(2): 215-234.

Doss, C.R. 1999. "Intrahousehold resource allocation in Ghana: The impact of the distribution of asset ownership within the household," in G.H. Peters and J. von Braun (eds.), Food Security, Diversification and Resource Management: Refocusing the Role of Agriculture? Aldershot, UK: Dartmouth Publishing.

Edlund, Lena. 1997. "Dowry to daughters: Theory and evidence," manuscript. New York: Columbia University.

- 2000. "The marriage squeeze interpretation of dowry inflation: A critique," Journal of Political Economy 108: 1327-1333. 
Estudillo, Jonna, Agnes R. Quisumbing, and Keijiro Otsuka. 2001a. "Gender differences in land inheritance, schooling, and lifetime income: Evidence from the rural Philippines," Journal of Development Studies 37(4): 23-48.

- 2001b. "Gender differences in schooling and land inheritance in the rural Philippines," Land Economics 77(1): 130-143.

Fafchamps, M. and A.R. Quisumbing. 2003a. “Assets at marriage in rural Ethiopia," manuscript. Centre for the Study of African Economies, University of Oxford and International Food Policy Research Institute.

- 2003b. "Marriage and assortative matching in rural Ethiopia," manuscript. Centre for the Study of African Economies, University of Oxford and International Food Policy Research Institute.

—. 2002. "Control and ownership of assets within rural Ethiopian households," Journal of Development Studies 38: 47-82.

Gardner, Katy. 1995. Global Migrants, Local Lives: Travel and Transformation in Rural Bangladesh. New York: Oxford University Press.

Gavian, S. and S. Ehui. 1999. "Measuring the production efficiency of alternative land tenure contracts in a mixed crop-livestock system in Ethiopia," Agricultural Economics 20(1): 37-49.

Gavian, S. and A. Teklu. 1996. "Land tenure and farming practices: The case of Tiyo Woreda, Arsi, Ethiopia," paper presented at the Annual Conference, Agricultural Economics Society of Ethiopia. International Livestock Research Institute, Addis Ababa, July.

Goody, Jack R. 1976. Production and Reproduction: A Comparative Study of the Domestic Domain. Cambridge: Cambridge University Press.

Gopal, G. 2001. "Law and legal reform," in A.R. Quisumbing and R.S. Meinzen-Dick (eds.), Empowering Women to Achieve Food Security. 2020 FOCUS 6, A 2020 Vision for Food, Agriculture, and the Environment. Washington, DC: International Food Policy Research Institute.

Gregson, Simon, Constance A. Nyamukapa, Geoffrey P. Garnett, Peter R. Mason, Tom Zhuwau, Michael Carael, Stephen K. Chandiwana, and Roy M. Anderson. 2002. "Sexual mixing patterns and sex-differentials in teenage exposure to HIV infection in rural Zimbabwe," Lancet 359(9321): 18961903.

Haddad, L., J. Hoddinott, and H. Alderman. 1997. Intrahousehold Resource Allocation in Developing Countries: Methods, Models, and Policy. Baltimore: Johns Hopkins University Press.

Hallman, Kelly. 2000. "Mother-father resources, marriage payments, and girl-boy health in rural Bangladesh," Food Consumption and Nutrition Division Discussion Paper no. 93. Washington, DC: International Food Policy Research Institute.

Hallman, Kelly, Agnes R. Quisumbing, Marie Ruel, and Bénédicte de la Brière. 2002. "Childcare, mothers' work, and earnings: Findings from the urban slums of Guatemala City," Policy Research Division Working Paper no. 165. New York: Population Council. 
Hertrich, Véronique. 2002. "Nuptiality and gender relationships in Africa: An overview of first marriage trends over the past 50 years," session on Family Change in Africa and Latin America, Population Association of America Annual Meeting, Atlanta, 9-11 May.

Hirsch, J.S. 2003. A Courtship After Marriage: Sexuality and Love in Mexican Transnational Families. Los Angeles: University of California Press.

Hoddinott, J. and L. Haddad. 1995. "Does female income share influence household expenditures? Evidence from Côte d' Ivoire," Oxford Bulletin of Economics and Statistics 57: 77-95.

IFPRI-BIDS-INFS. 1998. "Commercial vegetable and polyculture fish production in Bangladesh: Their impacts on income, household resource allocation, and nutrition," donor report. Washington, DC: International Food Policy Research Institute.

Jejeebhoy, S.J. 1995. Women's Education, Autonomy, and Reproductive Behavior: Experience from Developing Countries. Oxford: Clarendon Press.

Kelly, Robert J., Ronald H. Gray, Nelson K. Sewankambo, David Serwadda, Fred Wabwire-Mangen, Tom Lutalo, and Maria J. Wawer. 2001. "Age differences in sexual partners and risk of HIV-1 infection in rural Uganda," mimeo. Baltimore: Johns Hopkins University School of Hygiene and Public Health.

Kishor, Sunita. 1995. "Autonomy and Egyptian women: Findings from the 1988 Egypt Demographic and Health Survey,” DHS Occasional Papers no. 2. Calverton, MD: Macro International Inc.

Kishor, Sunita and Katherine Neitzel. 1996. "The status of women: Indicators for twentyfive countries," DHS Surveys Comparative Studies no. 21. Calverton, MD: Macro International Inc.

Luke, Nancy and Kathleen M. Kurz. 2002. "Cross-generational and transactional sexual relationships in sub-Saharan Africa: Prevalence of behavior and implications for negotiating safer sexual practices.

" Washington, DC: International Center for Research on Women and Population Services International.

Lundberg, S., R. Pollak, and T.J. Wales. 1997. "Do husbands and wives pool their resources? Evidence from the United Kingdom Child Benefit," Journal of Human Resources 32: 463-480.

MacArthur, H.J. 1977. "Adolescent peer groups and socialization in the rural Philippines: A socioecological perspective,” Ph.D. dissertation, University of Hawaii.

Malhotra, A. 1997. "Gender and the timing of marriage: Rural-urban differences in Java," Journal of Marriage and the Family 59(2): 434-450.

Maluccio, J., L. Haddad, and J. May. 2000. "Social capital and income generation in South Africa, 1993-98,” Journal of Development Studies 36(6): 54-81.

May, J., M.R. Carter, L. Haddad, and J.A. Maluccio. 2000. "KwaZulu-Natal Income Dynamics Study (KIDS) 1993-1998: A longitudinal household database for South African policy analysis," Development Southern Africa 17: 567-581. 
Medina, B.T.G. 1991. The Filipino Family: A Text with Selected Readings. Diliman, Quezon City: University of the Philippines Press.

Mensch, Barbara S., Judith Bruce, and Margaret E. Greene. 1998. The Uncharted Passage:

Girls'Adolescence in the Developing World. New York: Population Council.

Miller, B.D. 1981. The Endangered Sex: Neglect of Female Children in Rural North India. Ithaca: Cornell University Press.

Morris, S., C. Carletto, J. Hoddinott, and L.J.M. Christiaensen. 1999. "Validity of rapid estimates of household wealth and income for health surveys in rural Africa," Food Consumption and Nutrition Division Discussion Paper no. 72. Washington, DC: International Food Policy Research Institute.

Naved, R.T. 2000. " Intrahousehold impact of the transfer of modern agricultural technology:

A gender perspective," Food Consumption and Nutrition Division Discussion Paper no. 85. Washington, DC: International Food Policy Research Institute.

Pankhurst, H. 1992. Gender, Development, and Identity: An Ethiopian Study. London: Zed Books.

PSLSD. 1994. "Project for Statistics on Living Standards and Development: South Africans rich and poor: Baseline household statistics." Cape Town, South Africa: South African Labour and Development Research Unit, University of Cape Town.

Quisumbing, A.R. 1994. "Intergenerational transfers in Philippine rice villages: Gender differences in traditional inheritance customs," Journal of Development Economics 43: 167-195.

Quisumbing, A.R. and B. de la Brière. 2000. “Women' s assets and intrahousehold allocation in rural Bangladesh: Testing measures of bargaining power," Food Consumption and Nutrition Division Discussion Paper no. 86. Washington, DC: International Food Policy Research Institute.

Quisumbing, A.R. and J.A. Maluccio. 2002. "Resources at marriage and intrahousehold allocation: Empirical evidence from Bangladesh, Ethiopia, Indonesia, and South Africa." Washington, DC: International Food Policy Research Institute.

Quisumbing, A.R., and R.S. Meinzen-Dick. 2001. "Overview," in A.R. Quisumbing and R.S. Meinzen-Dick (eds.), Empowering Women to Achieve Food Security. 2020 FOCUS 6, A 2020 Vision for Food, Agriculture, and the Environment. Washington, DC: International Food Policy Research Institute.

Rao, Vijayendra. 1993a. "Dowry 'inflation' in rural India: A statistical investigation," Population Studies 47: 283-293.

—. 1993b. "The rising price of husbands: A hedonic analysis of dowry increases in rural India," Journal of Political Economy 101(4): 666-677.

-. 1997. "Wife-beating in rural South India: A qualitative and econometric analysis," Social Science and Medicine 44: 1169-1180.

Robicheaux, D.L. 1997. "Residence rules and ultimogeniture in Tlaxcala and Mesoamerica," Ethnology 36(2): 149-171. 
Rubaclava, L. and D. Thomas. 2002. "Family bargaining and welfare," mimeo. Santa Monica: RAND.

Ruel, M.T., B. de la Brière, K. Hallman, A. Quisumbing, and N. Coj. 2002. "Does subsidized childcare help poor working women in urban areas? Evaluation of a government-sponsored program in Guatemala City," Food Consumption and Nutrition Division Discussion Paper no. 131. Washington, DC: International Food Policy Research Institute.

Schapera, Isaac. 1933. "Premarital pregnancy and native opinion: A note on social change," Africa 6(1): 59-89.

Schultz, T.P. 1990. "Testing the neoclassical model of family labor supply and fertility," Journal of Human Resources 25: 599-634.

Sen, Amartya K. 1989. "Cooperation, inequality, and the family," Population and Development Review 15(supplement): 61-76.

Singh, S. and R. Samara. 1996. "Early marriage among women in developing countries," International Family Planning Perspectives 22(4): 148-157, 175.

Skoufias, Emmanuel. 2001. "PROGRESA and its impacts on the welfare and human capital of adults and children in rural Mexico: A synthesis of the results of an evaluation by the International Food Policy Research Institute.” Washington, DC: International Food Policy Research Institute.

Smith, L.C., U. Ramakrishnan, A. Ndiaye, L. Haddad, and R. Martorell. Forthcoming. "The importance of women's status for child nutrition in developing countries," research report. Washington, DC: International Food Policy Research Institute.

Smith, P.C. 1980. “Asian marriage patterns in transition," Journal of Family History 5(1): 58-96.

South Africa Department of Social Development. 2001. The State of South Africa's Population Report: Population, Poverty, and Vulnerability. Pretoria: National Population Unit.

Statistics South Africa. 2001. "South Africa in transition: Selected findings from the October household survey of 1999 and changes that have occurred between 1995 and 1999." Pretoria: Statistics South Africa.

Strauss, J. and D. Thomas. 1995. "Human resources: Empirical modeling of household and family decisions," in T.N. Srinivasan and J. Behrman (eds.), Handbook of Development Economics, vol. 3A. Amsterdam: North Holland/Elsevier.

Subramanian, J. 1998. "Rural women' s rights to property: A Bangladesh case study," mimeo. Madison: Land Tenure Center, University of Wisconsin-Madison.

Thomas, D. 1990. "Intrahousehold resource allocation: An inferential approach," Journal of Human Resources 25: 635-664. 
- 1993. "The distribution of income and expenditure within the household," Annales $d$ ' äonomie et de Statistiques 29: 109-136.

Thomas, D. and C. Chen. 1994. "Income shares and shares of income," Labor and Population Working Paper 94-08. Santa Monica: RAND.

Thomas, D., D. Contreras, and E. Frankenberg. 1997. "Child health and the distribution of household resources at marriage,” mimeo. Santa Monica: RAND.

- 2002. "Distribution of power within the household and child health," mimeo. Santa Monica: RAND.

United Nations. 1990. Patterns of First Marriage: Timing and Prevalence. New York: United Nations, Department of International Economic and Social Affairs.

United Nations Development Programme (UNDP). 2000. Human Development Report 2000. New York: UNDP.

—. 2001. Human Development Report 2001. New York: UNDP.

Webb, P. and J. von Braun. 1994. Famine and Food Security in Ethiopia: Lessons for Africa. Chichester, UK: John Wiley and Sons.

World Bank. 2001. "Engendering development through gender equality in rights, resources, and voice," World Bank Policy Research Report. Washington, DC: World Bank.

—. 1998. "Ethiopia: Social sector note," Report no. 16860-ET. Washington, DC: World Bank.

Zhang, J. and W. Chan. 1999. "Dowry and wife' s welfare: A theoretical and empirical analysis," Journal of Political Economy 107(4): 786-808. 


\section{POLICY RESEARCH DIVISION WORKING PAPERS}

Recent back issues available at www.popcouncil.org/publications/wp/prd/rdwplist.html.

2001

144 John Bongaarts, "Household size and composition in the developing world."

145 John B. Casterline, Zeba A. Sathar, and Minhaj ul Haque, "Obstacles to contraceptive use in Pakistan: A study in Punjab."

\section{Zachary Zimmer, Albert I.} Hermalin, and Hui-Sheng Lin, "Whose education counts? The impact of grown children' $s$ education on the physical functioning of their parents in Taiwan."

147 Philomena Nyarko, Brian Pence, and Cornelius Debpuur, "Immunization status and child survival in rural Ghana. "

148 John Bongaarts and Zachary Zimmer, "Living arrangements of older adults in the developing world: An analysis of DHS household surveys."

149 Markos Ezra, "Ecological degradation, rural poverty, and migration in Ethiopia: A contextual analysis."
150 Cynthia B. Lloyd, Sahar El Tawila, Wesley H. Clark, and Barbara S. Mensch, "Determinants of educational attainment among adolescents in Egypt: Does school quality make a difference? "

151 Barbara S. Mensch, Paul C. Hewett, and Annabel Erulkar, "The reporting of sensitive behavior among adolescents: A methodological experiment in Kenya."

152 John Bongaarts, "The end of the fertility transition in the developed world."

153 Mark R. Montgomery, GebreEgziabher Kiros, Dominic Agyeman, John B. Casterline, Peter Aglobitse, and Paul Hewett, "Social networks and contraceptive dynamics in southern Ghana.”

154 Paul C. Hewett and Mark R. Montgomery, "Poverty and public services in developing-country cities."

* No longer available as a printed publication. Download electronic file from Web site only. 
155 Zachary Zimmer, Linda G. Martin, and Ming-Cheng Chang, "Changes in functional limitations and survival among the elderly in Taiwan: 1993, 1996, and 1999."

156 John Bongaarts and Griffith Feeney, "How long do we live?"

157 Zachary Zimmer and Sovan Kiry Kim, "Living arrangements and sociodemographic conditions of older adults in Cambodia."

158 Geoffrey McNicoll, "Demographic factors in East Asian regional integration."

159 Carol E. Kaufman, Shelley Clark, Ntsiki Manzini, and Julian May, "How community structures of time and opportunity shape adolescent sexual behavior in South Africa."

*160 Julia Dayton and Martha Ainsworth, "The elderly and AIDS: Coping strategies and health consequences in rural Tanzania."

161 John Bongaarts, "The end of the fertility transition in the developing world."
162 Naomi Rutenberg, Carol E. Kaufman, Kate Macintyre, Lisanne Brown, and Ali Karim, "Pregnant or positive: Adolescent childbearing and HIV risk in South Africa."

163 Barbara S. Mensch, Wesley $\mathrm{H}$. Clark, and Dang Nguyen Anh, "Premarital sex in vietnam: Is the current concern with adolescent reproductive health warranted?"

164 Cynthia B. Lloyd, Cem Mete, and Zeba A. Sathar, "The effect of gender differences in primary school access, type, and quality on the decision to enroll in rural Pakistan."

165 Kelly Hallman, Agnes R. Quisumbing, Marie Ruel, and Bénédicte de la Brière, Childcare, mothers' work, and earnings: Findings from the urban slums of Guatemala City."

166 Carol E. Kaufman and Stavros E. Stavrou, “"Bus fare, please': The economics of sex and gifts among adolescents in urban South Africa."

167 Dominic K. Agyeman and John B. Casterline, "Social organization and reproductive behavior in southern Ghana."

No longer available as a printed publication. Download electronic file from Web site only. 
168 Paul C. Hewett, Annabel S. Erulkar, and Barbara S. Mensch, "The feasibility of computer-assisted survey interviewing in Africa: Experience from two rural districts in Kenya."

169 Zachary Zimmer and Julia Dayton, "The living arrangements of older adults in sub-Saharan Africa in a time of HIV/AIDS."

170 Ravai Marindo, Steve Pearson, and John B. Casterline, "Condom use and abstinence among unmarried young people in Zimbabwe: Which strategy, whose agenda?"

171 Sajeda Amin and Nagah H. AlBassusi, "Wage work and marriage: Perspectives of Egyptian working women."

172 Zachary Zimmer, Napaporn Chayovan, Hui-Sheng Lin, and Josefina Natividad, "How indicators of socioeconomic status relate to physical functioning of older adults in three Asian societies."

173 Paul Demeny, "Population policy: A concise summary."

174 Geoffrey McNicoll, "Population and development: An introductory view."

175 James F. Phillips, Tanya C. Jones, Frank K. Nyonator, and Shruti Ravikumar, "Evidence-based development of health and family planning programs in Bangladesh and Ghana."
176 Cynthia B. Lloyd and Paul C. Hewett, "Primary schooling in subSaharan Africa: Recent trends and current challenges."

177 John Bongaarts, "Completing the fertility transition in the developing world: The role of educational differences and fertility preferences."

178 Elizabeth F. Jackson, Patricia Akweongo, Evelyn Sakeah, Abraham Hodgson, Rofina Asuru, and James F. Phillips, "Women's denial of having experienced female genital cutting in northern Ghana: Explanatory factors and consequences for analysis of survey data."

179 John Bongaarts and Griffith Feeney, "Estimating mean lifetime."

180 Frank K. Nyonator, J. Koku Awoonor-Williams, James F. Phillips, Tanya C. Jones, and Robert A. Miller, "The Ghana Community-based Health Planning and Services Initiative: Fostering evidence-based organizational change and development in a resourceconstrained setting."

181 Zachary Zimmer, Linda G. Martin, and Hui-Sheng Lin, "Determinants of old-age mortality in Taiwan."

182 Paul C. Hewett, Barbara S. Mensch, and Annabel S. Erulkar, "Consistency in the reporting of sexual behavior among adolescent girls in Kenya: A comparison of interviewing methods."

183 Agnes R. Quisumbing and Kelly Hallman. "Marriage in transition: 
Evidence on age, education, and assets

from six developing countries." 